JUL 161965

COO-119-232

\title{
Research in Radiobiology
}

\author{
Annual Report of Progress \\ in the Internal Irradiation Program \\ of the
}

RADIOBIOLOGY DIVISION OF THE DEPARTMENT OF ANATOMY

UNIVERSITY OF UTAH COLLEGE OF MEDICINE

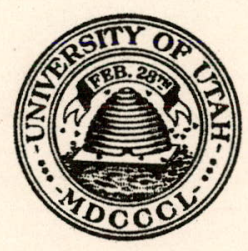

Respectfully Submitted by

THOMAS F. DOUGHERTY, Director

MARCH 31, 1965

CONTRACT NO. AT $(11-1)-119$ 


\section{DISCLAIMER}

This report was prepared as an account of work sponsored by an agency of the United States Government. Neither the United States Government nor any agency Thereof, nor any of their employees, makes any warranty, express or implied, or assumes any legal liability or responsibility for the accuracy, completeness, or usefulness of any information, apparatus, product, or process disclosed, or represents that its use would not infringe privately owned rights. Reference herein to any specific commercial product, process, or service by trade name, trademark, manufacturer, or otherwise does not necessarily constitute or imply its endorsement, recommendation, or favoring by the United States Government or any agency thereof. The views and opinions of authors expressed herein do not necessarily state or reflect those of the United States Government or any agency thereof. 


\section{DISCLAIMER}

Portions of this document may be illegible in electronic image products. Images are produced from the best available original document. 
RESEARCH IN RADIOBIOLOGY $\cdot r^{-}$

Annual Report of Work in Progress

on the Chronic Toxicity. Program

Radiobiology Division of the Department of Anatomy, University of Utah College of Medicine

Respectfully Submitted by:

Thomas F. Dougherty, Director

March 31, 1965

Contract No. AT $(11-1)-119$ 
Availability of Previous Reports

Group Leaders and Sections

Preface to Injection Tables

Injection Tables

I. Toxicity Animals

A. Radium-226

10

B. Plutonium-239

16

C. Radium-228 (Mesothorium)

24

D. Thorium-228 (Radiothorium)

30

E. Strontium-90

II. Test Animals

42

A . Radium-226 42

B. Plutonium-239 48

C. Radium-228 (Mesothorium) 52

D. Thorium-228 (Radiothorium) 54

E. Strontium-90 56

F. Radium-224 (Quickradium) 60

G. Ancillary 62

Current Census of the Beagle Colony

The Use of Therapy in Experimental Animals 65

Dental Eruption Pattern of the Beagle 68

Thorium-228 Induced Fractures in Beagles 74

$\begin{aligned} \text { The Correlation of Bone Strength with Radiation Dose From } & \\ \text { Internal Emitters and Bone Resorption } & 88\end{aligned}$

Studies of Trabecular Bone in Beagles and Humans 99 
Bioassay of the Influence of Contisol in Bones of Growing Rabbits

The Effects of Irradiation on Endocrine Cells V. A Comparison Between the Effects of Inanition and Irradiation on Androgen Production by Murine Testicular Tissue

A Comparison of Two Methods of Analyzing the Hematological Data From Strontium-90 Injected Beagles

Pilor Study of the Effect of Cortisol on $\mathrm{Na}_{3} \mathrm{CaDTPA}$ Enhanced Excretion of $\mathrm{Pu}^{239}$ in the Beagle

Effect of EDTA on the Excretion of $\mathrm{Sr}^{90}$ and $\mathrm{Y}^{\circ}$

The Determination of Half-Periods of Dog Serum Proteins Using $\mathrm{S}^{35}$-L-Methionine 


\section{AVA ILABILITY OF PREVIOUS REPORTS}

Copies of our reports may be obtained from the Office of Technical Services, U. S. Department of Commerce, Washington 25, D. C.

\begin{tabular}{|c|c|c|c|c|}
\hline Report & Da.te & Title & Photocopy & Microfilm \\
\hline $\operatorname{co0}-119-232^{*}$ & Mar 1965 & Research in Radiobiology & $\$ 22.20$ & $\$ 11.10$ \\
\hline $\operatorname{coo}-119-231^{*}$ & Sep 1964 & Research in Radiobiology & 17.20 & 8.60 \\
\hline c00-119-230* & Jul 1964 & Safety Manual & 3.10 & 1.55 \\
\hline $\operatorname{co0}-119-229^{*}$ & Mar 1964 & Research in Radiobiology & 13.00 & 5.84 \\
\hline $\operatorname{coo}-228^{*}$ & Sep 1963 & Research in Radiobiology & 13.00 & 5.84 \\
\hline $\operatorname{co0}-227^{*}$ & Mar 1963 & Research in Radiobiology & 15.50 & 7.22 \\
\hline $\operatorname{coo}-226^{*}$ & Sep 1962 & Research in Radiobiology & 10.50 & 4.31 \\
\hline $\mathrm{c} 00-225$ & Mar 1962 & Research in Radiobiology & 10.50 & 4.28 \\
\hline $\operatorname{coo}-224^{*}$ & Sep 1961 & Research in Radiobiology & 9.10 & 3.32 \\
\hline $\operatorname{coo}-223^{*}$ & Mar 1961 & Research in Radiobiology & 6.30 & 3.00 \\
\hline $\mathrm{co0}-222^{*}$ & Sep 1960 & Research in Radiobiology & 22.80 & 7.20 \\
\hline $\operatorname{co0}-221^{*}$ & Aug 1960 & Interim Report of $\mathrm{Sr}^{\circ \circ}$ & 3.30 & 2.40 \\
\hline $\operatorname{coo}-220^{*}$ & Mar 1960 & Research in Radiobiology & 34.80 & 9.90 \\
\hline $\operatorname{co0}-219^{*}$ & Sep 1959 & Semi-Annual Report & 10.80 & 3.90 \\
\hline $\operatorname{coo}-218^{*}$ & Mar 1959 & Annual Report & 34.80 & $\dot{9} .90$ \\
\hline AECU- 4112 & Feb 1959 & Radioactive Fallout & 3.30 & 2.40 \\
\hline $\operatorname{coo}-217^{*}$ & Sep 1958 & Semi-Annual Report & 28.80 & 8.40 \\
\hline $\operatorname{co0}-216^{*}$ & Mar 1958 & Escape of Radon \& Thoron & 9.30 & 6.30 \\
\hline $\operatorname{co0}-215^{*}$ & Mar 1958 & Annual Report & 28.80 & 8.40 \\
\hline AECU-3583 & Sep 1957 & Semi-Annual Report & 19.80 & 6.30 \\
\hline AECU-3522 & Mar 1957 & Annual Report & 27.30 & 8.10 \\
\hline TID -16459 & Sep 1956 & Semi-Annual Report & 5.60 & 2.05 \\
\hline TID-16458 & Mar 1956 & Annual Report & 10.50 & 4.40 \\
\hline AECU-3109 & Sep 19.55 & Semi-Annual Report & 12.30 & 4.50 \\
\hline AECU-3418 & Mar 1955 & Annual Report & 9.30 & 3.60 \\
\hline TID -7639 & Consultan & ts Meeting & 19.75 & 9.40 \\
\hline
\end{tabular}

*

Also available on request from this laboratory. 


\section{GROUP LEADERS AND SECTIONS}

Division of Radiobiology, Department of Anatomy, University, of Utah College of Medicine

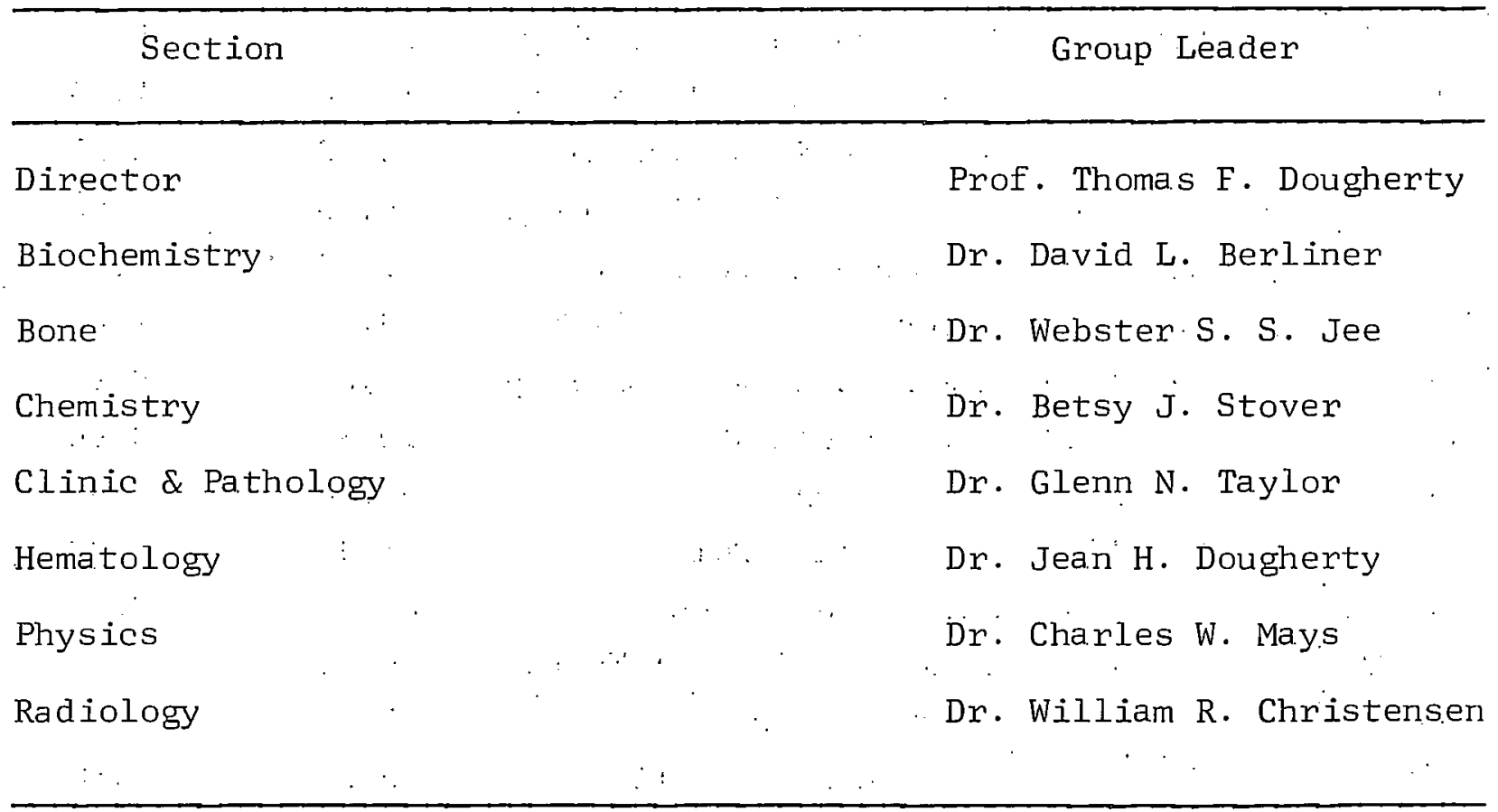




\section{INJECTION TABLES}

Tables I and II list the toxicity and test animals, respectively. Toxicity animals are those animals which will be maintained until sacrifice becomes a clinical necessity; test animals may be sacrificed as needed for special studies.

Dogs are put into the toxicity study groups of six or seven of the same sex. (five or six dose levels plus one control). Litter mates are used whenever possible. Each animal receives the designated dose of one radionuclide in a single $\mathrm{I} . \mathrm{V}$. injection. The animals are injected at approximately 17 months of age. At this age the skeleton is mature with all epiphyses fused except those of the ribs. Twelve such groups have been injected for each of the five radionuclides, $\mathrm{Ra}^{226}$, $\mathrm{Pu}^{239}, \mathrm{Ra}^{228}$, $\mathrm{Th}^{228}$, and $\mathrm{Sr}^{90}$. The current injection program is limited to $\mathrm{Ra}^{226}$ and $\mathrm{Pu}^{239}$ at lower dose levels.

The five dose levels designated by integers are those specified at the early meetings of the consultants, and those designated by nonintegers have been added by the laboratory staff. Since those dose levels were originally specified as "retained" doses, the actual injected doses are four times the desired "retained" doses of $\mathrm{Ra}^{226}$, $\mathrm{Ra}^{228}$ (Mesothorium), and $\mathrm{Sr}^{90}$, and 1.11 times the desired "retained" doses of $\mathrm{Pu}^{239}$ and $\mathrm{Th}^{228}$ (Radiothorium). " The desired "retained" activities are the same for all

* Since radioactive decay and excretion occur continously, the term "retained" dose is obviously meaningless unless the time after injection is specified. Our present measurements indicate that

average $\mathrm{Ra}^{226}$ retention $=0.25$ after 271 days
average $\mathrm{Pu}^{239}$ retention $=0.90$ after 6 days
average $\mathrm{Ra}^{28}$ retention $=0.25$ after 214 days
average $\mathrm{Th}^{238}$ retention $=0.90$ after 6 days
average $\mathrm{Sr}^{90}$ retention $=0.25$ after 135 days


the radionuclides except $\mathrm{Sr}^{90}$, in which case they are greater by a factor of 10. Dose level 1 is the basis of the scheme, and is 10 times the maximum permissible $\mathrm{Ra}^{226}$ in man. Level $l=10 \times \frac{0.1 \mu \mathrm{C} \mathrm{Ra}^{226}}{70 \mathrm{~kg} \operatorname{man}}=$ 0.0143 "retained" $\mu \mathrm{c} / \mathrm{kg}$. All other dose levels are simple multiples of level 1 as shown below.

$\begin{array}{lrlrl}\text { Level } 0.1 & \text { is } 1 / 27 & \text { of level } 1 \\ \text { Level } & 0.2 & \text { is } 1 / 9 & \text { of level } 1 \\ \text { Level } 0.5 & \text { is } 1 / 3 & \text { of level } 1 \\ \text { Level } 1.5 & \text { is } & 2 \text { times level } 1 \\ \text { Level } 1.7 & \text { is } & 3 \text { times level } 1 \\ \text { Level } 2 & \text { is } & 6 \text { times level } 1 \\ \text { Level } 3 & \text { is } & 18 \text { times level } 1 \\ \text { Level } 4 & \text { is } & 54 \text { times level } 1 \\ \text { Level } 5 & \text { is } & 162 \text { times level } 1\end{array}$

The numbering system for the dogs has been built around the injection program and serves as a code to describe each dog's place in the experiment. The first letter tells the sex of toxicity animals (M= male, $F=$ female). When the first letter is $\mathrm{T}$, the dog is a test animal. $M, F$, or $T$ is followed by a number which denotes chronological order of groups in the case of toxicity dogs and of individual test dogs.

Next comes a code letter for the radionuclide: $\mathrm{R}=\mathrm{Ra}^{226}, \mathrm{P}=\mathrm{Pu}^{239}$ $M=R a^{228}, T=T^{228}, S=S r^{90}, Q=R^{224}, J=S r^{85}$, and $A=$ Aging Control.

"A" following the regular dog number means that the dog is a replacement. "H" following the regular dog number means that the dog received. its dose in more than one injection. "B", "C", or "D". denotes assignment to serial sacrifice schedule. Any of the above letters denoting a radionuclide may follow the final number, in which case the letter indicates that two radionuclides were given. The dose level refers to the radionuclide appearing first in the identifying code.

Example: MlR5 is a male animal in the first radium group at the highest dose level. 


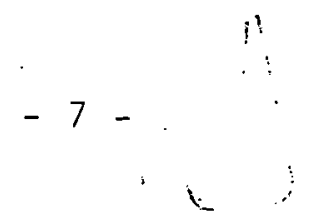

Although MlR5; MlR4, MlR3, MlR2, MlRI, and MlR0 constitute a. . group and were injected at the same time, the tables are arranged according to dose level to facilitate comparison of all the R5 animals., a.11 the $\mathrm{R} 4$ animals, etc:

The conditions listed in the injection tables under "Comments on Dead Dogs" present the lesions or factors that had the most prominent effect on the clinical status of the animal. For example, multiple rib fractures, which seldom produced symptoms, are not listed, even though their incidence was usually much higher than the crippling fractures involving the limb bones or mandible. The hematological changes have been omitted unless they were extreme. Increased rate of tooth losis, hepatic changes, eye lesions, and many other factors in the various. syndromes have not been included because of space limitations. Over the years many soft tissue tumors have been removed surgically; these tumors were the subject of a separate report, Research in Radiobiology, September 30, 1963 (C00-228), pp. 95-108. In many instances, the conditions that have been listed were the reasons for sacrifice of the animal but they were not the immediate cause of death. Most of the animals were euthanized when death appeared eminent or when life could no longer be humanely prolonged.

\section{DOS IMETRY REVIS IONS}

A number of new values appear for the dose in rads to the skeleton at death. $\mathrm{Ra}^{226}, \mathrm{Ra}^{228}$, and $\mathrm{Sr}^{90}$ doses are calculated for each dog using his individually observed retention values: $\mathrm{Pu}^{239}$ and $\mathrm{Th}^{228}$ doses are from our average skeletal retention equations. 
For our standard: beagle, the following equations were used for the effective* skeletal retention at $(t)$ days after injection:

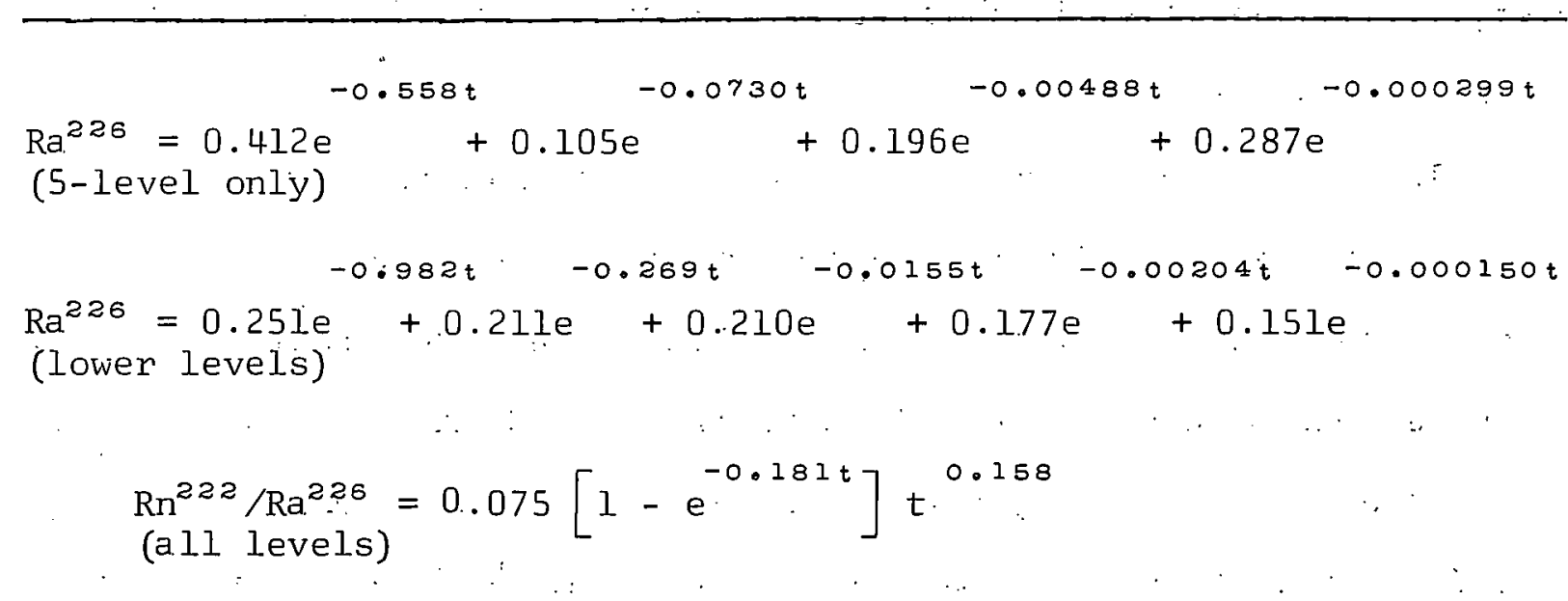

$\mathrm{Pu}^{239}=0.72 \mathrm{t}^{-0.040}$

$-0.982 \mathrm{t} \cdot-0.269 \mathrm{t}-0.0158 \mathrm{t}-0.00237 \mathrm{t}-0.000479 \mathrm{t}$
$\operatorname{Ra}^{228}=0.251 \mathrm{e}+.0 .211 \mathrm{e}+0.210 \mathrm{e}+0.177 \mathrm{e}+0.151 \mathrm{e}$
$($ pure at $\mathrm{t}=0) \cdots$

84. $4 \%$ retention of $\underline{\text { in }}$ vivo produced $\mathrm{Th}^{228}$ and daughters..

$$
\begin{aligned}
\mathrm{Th}^{228} & =0.69 \mathrm{e}^{-0.00113 \mathrm{t}} \\
\mathrm{Ra}^{224} / \mathrm{Th}^{228} & =0.895 \\
\mathrm{~Pb}^{212} / \mathrm{Th}^{228} & =0.866
\end{aligned}
$$

$\operatorname{Sr}^{90}=0.402 \mathrm{e}^{-0.748 \mathrm{t}}+0.259 \mathrm{e}^{-0.102 \mathrm{t}}+0.181 \mathrm{e}^{-0.00469 t}+0.158 \mathrm{e}^{-0.000302 \mathrm{t}}$

Effective retention is decreased by both radioactive decay and biological elimination. 
We hope to present our detailed retention data and dosimetric analysis in a future report.

Razas doses deserve special comment. The dose from "pure" $\mathrm{Ra}^{228}$ and its in vivo produced daughters is based on our best evaluation of $5.77 \pm 0.02 \mathrm{yr}$ for the $\mathrm{Ra}^{238}$ half-period. The tabulated total doses include the contributions from $\mathrm{Th}^{228}$ contamination in the injection solutions. For example, $\mathrm{Th}^{228}$ contaminations of $0.6 \%, 3 \%$, and $15 \%$, respectively, account for $2.8 \%, 13 \%$ and $42 \%$ of the total dose in rads at 1000 days. If injected $\mathrm{Th}^{228}$ is 4 times more toxic rad-for-rad than is in vivo produced $\mathrm{Th}^{228}$, these injected $\mathrm{Th}^{228}$ contaminations would. account for $10 \%, 37 \%$ and $.74 \%$ of the total biological damage at 1000 days. Therefore, it may be desirable to use only results from the slightly contaminated $\left(0.6 \% \mathrm{Th}^{228}\right)$ dogs in evaluation of $\mathrm{Ra}^{228}$ toxicity. 
TABLE I.TOXICITY ANIMALS (MARCH 31; 1965)

\section{A. RADIUN-226}

Dอง

NUYBER

$M 0180.0$

MO2R0:0

F03R 0.0

$M O 4 R 0.0$

Y YO5R 0.:0

FO6R 0.0 0

YOTRO.O

FOBR 0.0

FO9R 0.0

M IOR O.O

FIIR0.0

FI2R 0.0

M 13R 0.0

F14R 0.0

M 15R 0.0

F $31 R 0.0 \mathrm{C}$

F $31 R 0.03$
AT INJECTION AGE WEIGHT (DAYS) : (KG)

$\begin{array}{ll}558 & 8.03\end{array}$

487

$461 \quad 11.0$

$460 \quad 6.57$

$483 \cdot 8.43$

$511 \quad 11.0$

638 - 8.21

$700-11: 7$

$522 \quad 10.9$

$544 \quad 10.2$

$501 \quad 8.68$

$515 \quad 12.3$

$536 \quad 10.8$

$564 \quad 12.8$

536.9 .88

$536 \quad 10.6$

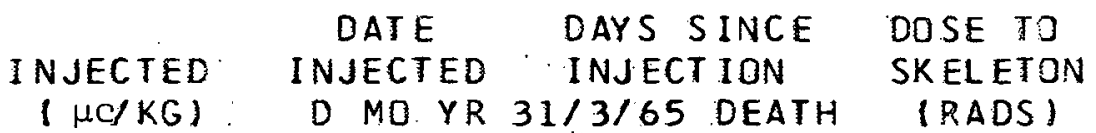

$20 \cdot 04: 53$

1611.53

10.03 .54

.704 .54

$\begin{array}{lll}22 & 06 \quad 54\end{array}$

27.754

$24 \quad 8 \quad 54$

$21 \quad 12 \quad 54$

$11: 4: 55$

270755

$20 \quad 1255$

17. 0156

4. 364

$23 \quad 10.64$

4265

2310.64

$23 \quad 10.64$.
3116

3675

2139

4011

3935

3182

3360

3361

1550
3535

3389

3361

392

159

.55

159

159

$\begin{array}{rlccrrrr}M 13 R 0.2 & 529 & 9.77 & .00577 & 4 & 3 & 64 & 392 \\ F 14 R 0.2 & 460 & 8.10 & .00836 & 23 & 10 & 64 & 159 \\ M 15 R 0.2 & 504 & 10.8 & .00873 & 4 & 2 & 65 & 55\end{array}$

$\begin{array}{rrcrrrrr}M 13 R 0.5 & 529 & 11.0 & .0171 & 4 & 3 & 64 & 392 \\ \text { F14R0.5 } & 510 & 9.75 & .0220 & 23.10 & 64 & 159 \\ \text { M15R0.5 } & 490 & 10.4 & .0263 & 4 & 2.65 & 55\end{array}$

MOIR 1. 0

47

MO2R 1.0

62

8.48

.0618

20.04 .53

16. 11.53

$10: 0354$

7. $04: 54$

MOLR 1.0

706

.0876

$2206 \quad 54$.

$490: 11.7$

.0642

$\begin{array}{lll}27 & 07 & 54\end{array}$

$24.8 \cdot 54$

$21 \quad 12 \quad 54$

11:.04:55

$\begin{array}{lll}27 & 07 & 55\end{array}$

4363

$483 \quad 7.23$

.0584

.0651

861

8.98

.0559

9.88

.0521

$20: 12.55$

.0573
.0522

$511 \quad 11.2$

3535

3389

3850

237

2038

151

3.780

108

3900

3544

112

FIIR 1.0

11

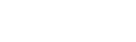


DOG

MOLRO. 0 MOZRO. O: FO3ROOO MOLRO. 0 MOSR 0.0 FO6RO. 0 MOTROOO FOBR O.: 0 "FO9R O.. 0 M IOR 0.0 FIIR 0.0 FIIR 0.0 M $13 R 0.0$ F 14R O. 0 MISR 0.0 F $31 R 0.0 C$ F 31 IR $0_{0}: O B$

$M 13 R 0.2$ F 14R 0.2 M15R 0.2

M13R.0. 5 F.14R0. 5 M15R0. 5

MOLR 1.0 MO2R 1.0 FO3R 1.0 MOAR 1.0 MOSR 1.0 FO6R 1.0 MOTR 1.O FOBR1.0 FO9R 1:O M1ORLO FIIR I:0
SEMINOMA, LYMPHOS ARCOMA

TRANSITIONAL CELL CARCI NOMA

STATUS EPI LEPTICUS

STATUS EPILEPTICUS

STATUS EPILEPTICUS; NEPHRITIS

PANCREATIC ADENOC ARCI NOMA

AORTIC BODY TUMOR
SEMI NOMA.

MAMMARY GLAND CARCI NOMA

TRA UMA

TRANSI TI ONAL CELL CARCI NOMA, HYDRONEPHROS IS

STATUS EPI LEPTICUS

LYMPHOSARCOMA 


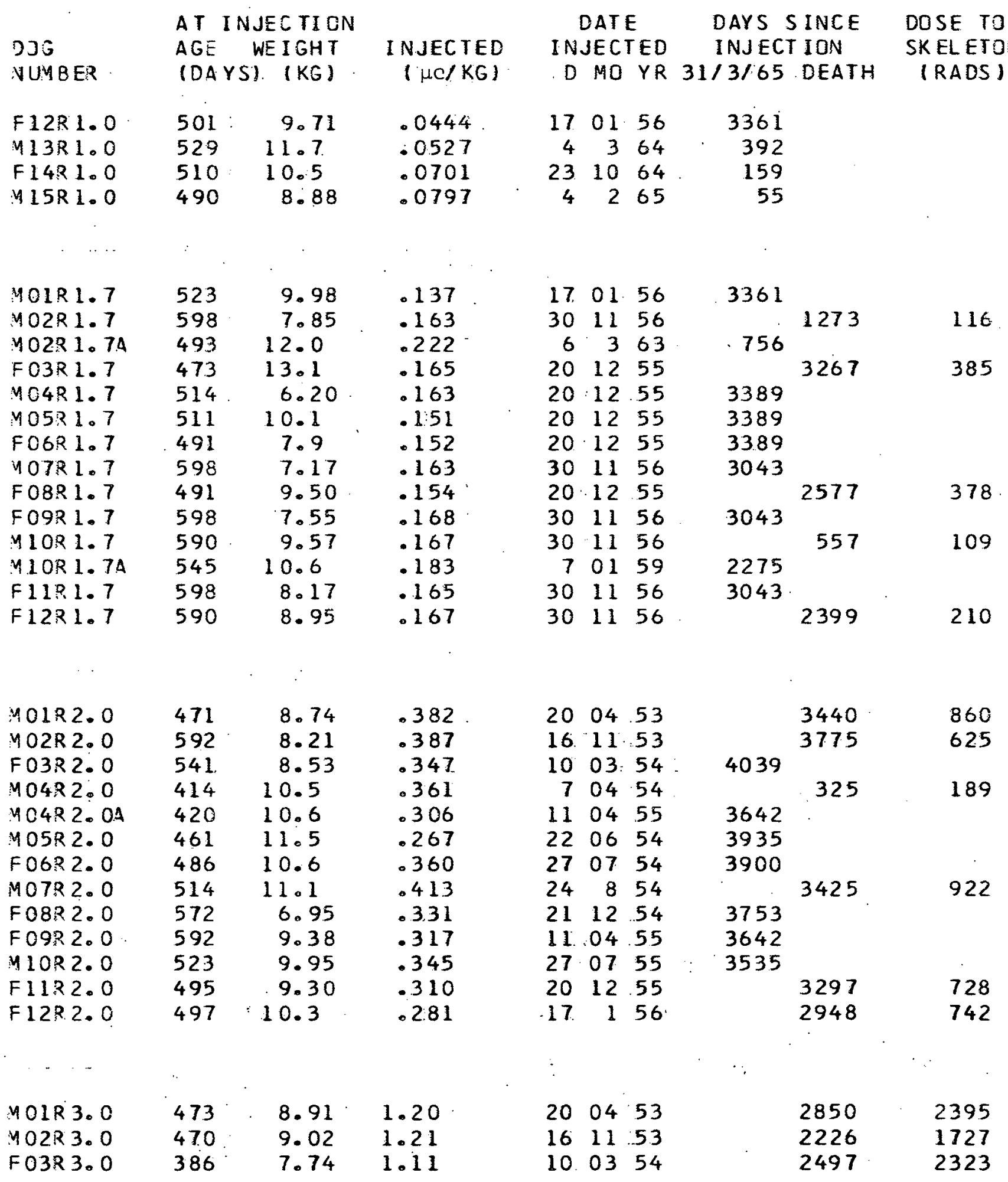


DOG:

NUMBER

F12R 1.0

MI $13 R 1.0$

F I 4R 1.0

M15R 1.0

MOLR 1.7

MO2R 1. 7

MO2R 1. TA

F03R 1.7

MO4R 1. 7

MOSR 1.7

FO6R 1.7

MOTR 1. 7

FOBR 1.7

FO9R 1. 7

MIOR 1. 7

MIOR I. TA

F11R 1.7

F12R:1. 7

MOIR 2.0

MO2R 2. 0

FO3R 2.0

MO4R 2.O.

MOLR 2.OA

MOSR 2:O

FO6R 2.0

MOTR 2: 0

F 08R 2.0

F O9R 2.0

M IOR 2.0

FIIR2.0

F12R 2.0

MOLR 3.0

MO2R 3: 0

FO3R 3. 0
LYMPHOSARCOMA

MAMMARY GLAND CARCINOMA

DRUG ALLERGY

TRA UMA

COMMENTS ON DEAD DOGS 


\begin{tabular}{|c|c|c|c|c|c|c|c|c|c|}
\hline $\begin{array}{l}\text { DOQ } \\
\text { NUMBER }\end{array}$ & $\begin{array}{l}\text { AT IN } \\
\text { AGE } \\
\text { DAYS }\end{array}$ & $\begin{array}{l}\text { JECTION } \\
\text { WE IGHT } \\
\quad(K G)\end{array}$ & $\begin{array}{l}\text { INJECTEO } \\
(\mu C / K E)\end{array}$ & & $\begin{array}{l}\text { ATE } \\
\text { MOC }\end{array}$ & $\begin{array}{l}E D \\
Y R R\end{array}$ & $\begin{array}{r}\text { DAYS } \\
\text { INJEC } \\
31 / 3 / 65\end{array}$ & $\begin{array}{l}\text { SINCE } \\
\text { ION } \\
\text { DEATH }\end{array}$ & $\begin{array}{c}\text { DOSE TO } \\
\text { SKELETON } \\
\text { (RADS) }\end{array}$ \\
\hline $\begin{array}{l}\text { MO4R3.0 } \\
\text { MOSR3.0 } \\
F 06 R 3.0 \\
\text { MOTR3.0 } \\
F 08 R 3.0 \\
\text { MOR3.0 } \\
M 10 R 3.0 \\
F 11 R 3.0 \\
F 12 R 3.0\end{array}$ & $\begin{array}{l}412 \\
461 \\
486 \\
514 \\
542 \\
551 \\
525 \\
495 \\
497\end{array}$ & $\begin{array}{l}11.7 \\
13.0 \\
9.75 \\
12.3 \\
7.76 \\
8.02 \\
10.1 \\
12.9 \\
11.4\end{array}$ & $\begin{array}{r}1.16 \\
.846 \\
1.14 \\
1.29 \\
1.03 \\
.987 \\
1.06 \\
.938 \\
.883\end{array}$ & $\begin{array}{l}7 \\
22 \\
27 \\
24 \\
21 \\
11 \\
27 \\
20 \\
17\end{array}$ & $\begin{array}{l}04 \\
06 \\
07 \\
08 \\
12 \\
04 \\
07 \\
12 \\
1\end{array}$ & $\begin{array}{l}54 \\
54 \\
54 \\
54 \\
54 \\
55 \\
55 \\
55 \\
56\end{array}$ & & $\begin{array}{l}1917 \\
2955 \\
1932 \\
2099 \\
2612 \\
2487 \\
1737 \\
1610 \\
1897\end{array}$ & $\begin{array}{l}2361 \\
2317 \\
2246 \\
3029 \\
1916 \\
1839 \\
2336 \\
1333 \\
1639\end{array}$ \\
\hline . & & & & & . & & & . & . \\
\hline $\begin{array}{l}M O 1 R 4.0 \\
M O 2 R 4.0 \\
F O 3 R 4.0 \\
F 03 R 4.0 A \\
M O 4 R 4.0 \\
M O 5 R 4.0 \\
F 06 R 4.0 \\
M O R R 4.0 \\
F O 8 R 4.0 \\
F O 9 R 4.0 \\
Y 1 O R 4.0 \\
F 11 R 4.0 \\
F 12 R 4.0\end{array}$ & $\begin{array}{l}471 \\
470 \\
384 \\
598 \\
408 \\
461 \\
486 \\
453 \\
474 \\
542 \\
527 \\
491 \\
496\end{array}$ & $\begin{array}{c}9.08 \\
9.53 \\
8.55 \\
7.20 \\
8.83 \\
13.2 \\
8.55 \\
9.55 \\
8.94 \\
8.53 \\
10.8 \\
10.4 \\
9.61\end{array}$ & $\begin{array}{l}3.58 \\
3.55 \\
3.33 \\
3.10 \\
3.47 \\
2.42 \\
3.44 \\
3.88 \\
3.14 \\
3.02 \\
3.28 \\
2.84 \\
2.81\end{array}$ & $\begin{array}{l}20 \\
16 \\
10 \\
30 \\
7 \\
22 \\
27 \\
24 \\
21 \\
11 \\
27 \\
20 \\
17\end{array}$ & $\begin{array}{l}04 \\
11 \\
03 \\
11 \\
04 \\
06 \\
07 \\
.8 \\
12 \\
04 \\
07 \\
12 \\
01\end{array}$ & $\begin{array}{l}53 \\
53 \\
54 \\
56 \\
54 \\
54 \\
54 \\
54 \\
54 \\
55 \\
55 \\
55 \\
56\end{array}$ & & $\begin{array}{r}1606 \\
1884 \\
490 \\
1614 \\
1518 \\
1659 \\
1939 \\
1647 \\
1324 \\
1471 \\
1553 \\
1469 \\
1435\end{array}$ & $\begin{array}{l}6575 \\
6150 \\
2208 \\
3855 \\
6063 \\
4505 \\
7133 \\
5844 \\
4615 \\
4095 \\
7582 \\
5273 \\
3877\end{array}$ \\
\hline . & $\cdots$ & & & & & & & & $\therefore \cdots$ \\
\hline 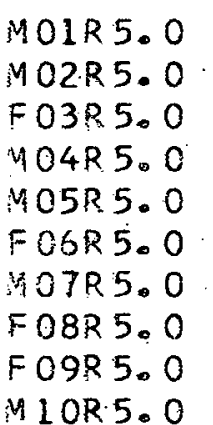 & $\begin{array}{l}473 \\
470 \\
380 \\
408 \\
458 \\
480 \\
453 \\
474 \\
420 \\
527\end{array}$ & $\begin{array}{c}9.87 \\
8.85 \\
7.82 \\
8.90 \\
10.9 \\
9.66 \\
8.85 \\
7.76 \\
9.16 \\
10.7\end{array}$ & $\begin{array}{l}10.5 \\
10.8 \\
10.1 \\
10.6 \\
10.1 \\
10.2 \\
11.9 \\
9.68 \\
9.48 \\
10.2\end{array}$ & $\begin{array}{r}20 \\
16 \\
10 \\
7 \\
22 \\
27 \\
24 \\
21 \\
11 \\
27\end{array}$ & $\begin{array}{l}04 \\
11 \\
03 \\
04 \\
6 \\
07 \\
08 \\
12 \\
04 \\
07\end{array}$ & $\begin{array}{l}53 \\
53 \\
54 \\
54 \\
54 \\
54 \\
54 \\
54 \\
55 \\
55\end{array}$ & & $\begin{array}{r}908 \\
1380 \\
481 \\
1091 \\
1220 \\
1015 \\
1288 \\
968 \\
1288 \\
825\end{array}$ & $\begin{array}{r}14943 \\
18071 \\
7147 \\
16417 \\
15433 \\
15414 \\
16708 \\
11564 \\
15941 \\
11179\end{array}$ \\
\hline
\end{tabular}


DOG

NUMBER

COMMENTS ON DEAD DOGS

MO4R 3.0

OSTEOSARCOMA

MOSR 3.0

OSTEOSARCOMA

FO6R 3.0 = O OSTEOSARCOMA

MOTR 3.0 OOSTEOSARCOMA

FOBR 3.0 : OSTEOSARCOMA

FO9R3.0 : OSTEOSARCOMA

MIOR 3.0 : OSTEOSARCOMA

F 1 IR 3:0

PYOMETRITIS + SECONDARY PERITONITIS

FI2R 3.0 -

OSTEOSARCOMA

MOIR 4.0
OSTEOSARCOMA OSTEOSARCOMA
CANINE DISTEMPER
OSTEOSARCOMA
OSTEOSARCOMA
OSTEOSARCOMA
OSTEOSARCOMA
OSTEOSARCOMA
OSTEOSARCOMA.
OSTE OSARCOMA
OSTE OSARC OMA
DSTEOSARCOMA
O STEOSARCOMA

MO2R 4. 0 =

F03R 4. 0

FO3R 4. OA:

MO4R 4. O =

M05R 4. $0=$

F 06R 4. 0

MOTR 4. 0

FO 8R 4:0.

FO9R 4. 0 :

$M 10 R 400=$

FIIR 4.0

FI2R 4. 0
MOLR 5.0
OSTE OSA RCOMA
MO2R 5.0
OSTEOSARCOMA
FO3R5.
CANINE DI STEMPER
MOLR5:O
O STE OSARCOMA
MOSR 5. 0
OSTEOSARCOMA
FO6R.5. 0 :
MOTR 5.O =
OSTE OSARCOMA
FOQR.5०
OSTEOSARCOMA
FO9R 5.0 =
OSTEOSARCOMA
M 1OR 5.0
OSTEOSARCOMA: - ANEMIA
OSTEOSARCOMA + FRACTURED MANDIBLE 
B. PLUTONIUM-239

DOG

NUMBER

VOPO. 0

F 02P 0.0

MOSPO.O

$M 04 P 0.0$

FO5P0.0

FO6PO. 0

FOTP0.0

MOSPO.O

F O9P 0.C

F1OP 0.0

$M 11 P 0.0$

$M 12 P 0.0$

F13P0.0

F14P 0.0

M $15 P 0.0$

M31PO.OB

$431 P 0.05$

132PO. OB
AT INJECTION AGE WEIGHT (DAYS) (KG)

443

424

515

426

620

410

515

585

658

658

602

630

517

452

527

452

452

452
9.70

6.36

10.8

10.7

9.75

5.59

6.90

10.9

11.0

11.0

10.3

10.9

9.47

9.89

12.1

11.8

12.6

11.2
DATE

INJECTEC

( $\mu C / K G)$

INJECTED

$D M O Y R$

11252

20353 .

10653

16.09.53

$14 \cdot 10 \cdot 53$

$\begin{array}{lll}12 & 05 & 54\end{array}$

$\begin{array}{lll}25 & 10 & 54\end{array}$

15. 03.55

221155

221155

$\begin{array}{lll}24 & 04 \quad 56\end{array}$

$2905 \quad 56$

$4: 364$

12.5 .64

$2310 \quad 64$

12564

12. 564

12.564
DAYS SINCE

INJECTION

$31 / 3 / 65$ DEATH
DOSE TO

SKELETON

(RADS)

$\begin{array}{lcccrrrr}\text { F13P0.1 } & 515 & 9.46 & .00068 & 4 & 364 & 392 \\ \text { F14P.0.1 } & 452 & 10.3 & .00055 & 12 & 564 & 323 \\ M 15 P 0.1 & 536 & 9.67 & .00071 & 23 & 1064 & 159 \\ M 1 P 0.13 & 517 & 12.2 & .00068 & 4 & 364 & 392\end{array}$

F13P0.2

F14P0.2

$M 15 P 0.2$

$M 31 P 0.28$

F $31 P 0.25$

F $31 P 0.20$

F $32 P 0.2 C$

F $32 P 0.20$
517

516

505

515

452

429

494

490
9.44

7.44

10.9

10.7

11.9

9.35

10.1

8.04
.00206

.00173

.00201

.00185

.00169

.00186

.0 .0183

.00193
4364

$12 \quad 5 \quad 64$

2310.64 :

4364

12 . 564

12564

4. 265

4265
4003

2755

4321

4214

3976

3810

3669

3417

3263

3228

392

14

159

323

323

323

.3032

4088

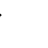

2


DOG

NUMBER COMMENTS ON DEAD DOGS

MOPO. 0 SPLENIC RUPTURE, METASTATIC SEMINOMA

F O2P O. 0 ANE STHETIC ACCIDENT

M03P 0. 0

MO4P 0.0

FOSP O. 0

ADRENAL CORTICAL CARCINOMA

F06P 0.0

F07P 0.0

MOSPO.O

FO9P.0.0

PULMONARY EMBOLISM, NEPHRITIS

F $10 P 0.0$

$M 11 P 0.0$

$M 12 P 0.0$

F13P0.0

$F 14 P 0.0$

$M 15 P 0.0$

$M 31 P 0.03$

$431 P 0.0 C$

M 32P0.03

F 13P0.1 F $14 P 0.1$ M15P0.1 M31P0.18.

F13P0.2 F14P0.2 M $1.5 P 0.2$ F $31 P 0.26$ M3IPO. 28

F $31 P 0.20$

F $32 P 0.25$

F 32P.0. 20

F13P0.5

F14P0. 5

M15P0.5

M $31 P 0.53$ 


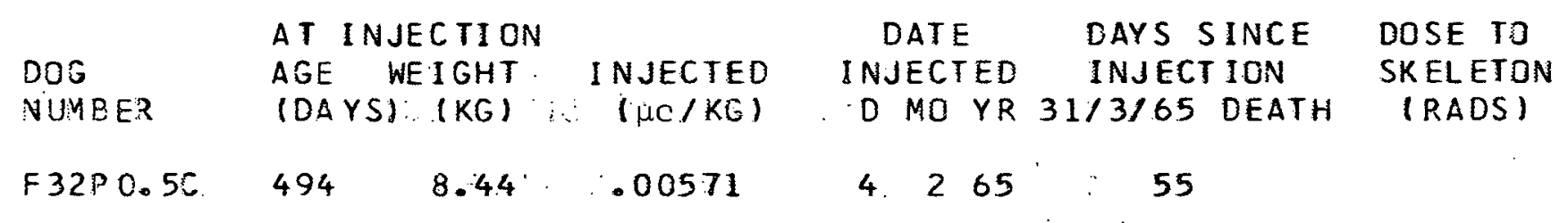

$\begin{array}{lccc}\text { MO1P1.0 } & 442 & 9.41 & .0150 \\ \text { FO2P1.0 } & 422 & 6.85 & .0163 \\ \text { MO3P1.0 } & 515 & 8.00 & .0165 \\ \text { MO4P1.0 } & 608 & 9.97 & .0139 \\ \text { FO5P1.0 } & 620 & 8.80 & .0142 \\ \text { FO5P1.0A } & 472 & 11.0 & .0168 \\ \text { FO6P1.0 } & 410 & 7.38 & .0140 \\ \text { FO7P1.0 } & 510 & 6.36 & .0167 \\ \text { MO8P1.0 } & 453 & 10.6 & .0172 \\ \text { FO9P1.0 } & 556 & 7.87 & .0168 \\ \text { F1OP1.0 } & 641 & 12.00 & .0152 \\ \text { M11P1.0 } & 602 & 8.90 & .0157 \\ \text { M12P1.0 } & 629 & 9.67 & .0167 \\ \text { M13P1.0 } & 504 & 12.7 & .0153\end{array}$

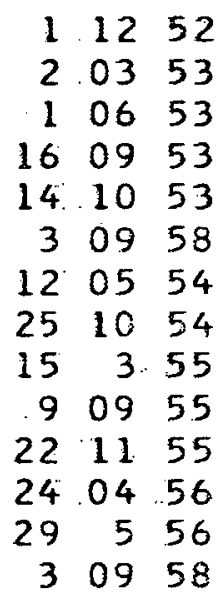

$26 \quad 06 \quad 56$

22.1155

$2606 \quad 56$

$10: 10 \cdot 56$

$\begin{array}{lll}26 & 6 & 56\end{array}$

$\begin{array}{lll}26 & 06 \quad 56\end{array}$

10. 10.56

10. 10.56

10. 1056

101056

30958

$24: 4: 56$

10. 10.56

30958
4503

4412

$4292 \quad 102$

4214

1539

30

2401

3976

3810

3367

83

60

3417

3263

2401

2374

60
FIOP 1.7
F1OP 1.7

MIP1.7

M12P1.7

M13P1.7
673

504
11.6

9.41

10.60
.0491

.0473
MO1P 2.0

F02P 2.0

MO3P2.0

M $04 \mathrm{P} 2.0$

F 05P 2.0

$\begin{array}{ccc}442 & 7.61 & .0853 \\ 422 & 7.73 & .112 \\ 485 & 10.5 & .0940 \\ 608 & 9.84 & .0862 \\ 594 & 8.12 & .0846\end{array}$

11252

20353

10653

1609.53

$14: 10.53$

3025

210

3417

3200

3094

2659
2221

3094

$\begin{array}{rr}2500 & 180 \\ 467 & 40 \\ 2401 & 200 \\ 2777 & 200 \\ 2973 & 213\end{array}$

2401 
DOS

NUYBER

F 32 P 0. $5 C$

MOIPI.O

FO2P1:0

MO3P 1. 0 .

MO4P 1.0

FOSP 1.0

FO5P 1.0A

F06P1.0

FO7P 1.0

MO8P 1.0

F09P 1.0

F1OP1:0

M11P1.0

$M 12 P 1.0$

M1.3P L.O

MOIP 1.7

F.02P 1.7

$M 03 P 1.7$

M04P1.7

F05P 1.7

F06P1.7

F07P 1.7

F.08P.1.7

FO9P 1.7

F1OP 1.7

F 1OP 1.7A

MIIP 1. 7

M12P1.7

M13P1.7
OSTEOSARCOMA

COLITIS, ENTERITIS + SECONDARY HEPATIC NECROS IS

OSTEOSARCOMA

OSTEOSARCOMA

CHRONIC PANCREATITIS

\section{OSTEOSARCOMA}

OSTEOSARCOMA

OSTE OSARCOMA

OSTE OSA RCOMA

ACUTE ENTERITIS

BILE DUCT CARCINOMA

LEUKEMI A 
DOG

NUMBER

F06P 2.0

F07P 2.0

$M 08 P 2.0$

FO9P 2.0

ᄃ $10 . P 2.0$

$M 11 P 2.0$

$M 12 P 2.0$
AT INJECTION AGE WEIGHT (DAYS) (KG)
DATE INJECTED INJECTED $(\mu C / K G)$
D MO YR 31/3/65 DEATH

12. $05 \quad 54$

$\begin{array}{llll}25 & 10 & 54\end{array}$

$\begin{array}{lll}15 & 03 & 55\end{array}$

90955

221155

24.04 .56

290556
2947.

2093

1761

2014

2912

1617

2284
DOSE TO

SKELETON

(RADS)

370

310

250

300

410

230

370
MO1P 3.0

F02P 3.0

M $03 P 3.0$

MO4P. 3.0

F O5P 3.0

FO6P 3.0

F07P 3.0

MO8P.3.0

FO9P 3.0

F1OP 3.0

MIIP3.0

M12P3.0

$\begin{array}{lll}417 & 8.00 & .261 \\ 422 & 6.85 & .312 \\ 485 & 8.74 & .291 \\ 608 & 8.51 & .292 \\ 650 & 8.22 & .288 \\ 415 & 8.38 & .282 \\ 485 & 9.00 & .314 \\ 406 & 9.73 & .300 \\ 552 & 7.67 & .300 \\ 533 & 8.94 & .298 \\ 599 & 10.5 & .309 \\ 622 & 10.2 & .308\end{array}$

\section{2}

567

485

566

650

420

485

651

552

527

596

598

$\begin{array}{cc}7.61 & .823 \\ 8.65 & 1.03 \\ 9.36 & .929 \\ 8.74 & .974 \\ 7.05 & .872 \\ 9.26 & .811 \\ 8.45 & .963 \\ 9.22 & .887 \\ 8.58 & .960 \\ 6.48 & .868 \\ 9.56 & .927 \\ 11.4 & .838\end{array}$

$\begin{array}{lll}1 & 12 & 52 \\ 2 & 03 & 53\end{array}$

$\begin{array}{lll}2 & 0353\end{array}$

10653

$\begin{array}{lll}16 & 09 & 53\end{array}$

$14 \quad 10.53$

12. 0554

$25 \quad 10: 54$

15. 03.55

90955

221155

$2404 \quad 56$

29. 05,56
1476

1947

1604

1950

1504

1617

1627

1771

1894

1547

1198

1659
580

900

700

840

630

670

750

780

840

700

550

760

M 12 P 4.0

$401 P 5.0$

417

$8.86 \quad 2.67$

11252

1324

5370

F02P5. 0

1150

8.75

$\begin{array}{llll}2 & 03 & 53\end{array}$

1576

7830

M03P 5.0

515

$8.10: 3.00$

10653

499

2100

2380

1680

1560

1650

1660

1730

1560

1920

1660

$\begin{array}{ll}1288 & 1790 \\ 1463 & 1840\end{array}$

$\begin{array}{ll}17246 & 2380 \\ 1198 & 1680 \\ 1066 & 1560 \\ 1245 & 1650 \\ 1357 & 1660 \\ 1198 & 1730 \\ 1157 & 1560 \\ 1343 & 1920 \\ 1241 & 1660 \\ 1288 & 1790 \\ 1463 & 1840\end{array}$

2340 
DOS

NUMBER

COMMENTS ON DEAD DOGS

FO6P 2:0

OSTEOSARCOMA

F07P 2.0

SQUAMOUS CELL CARCINOMA

M08P. 2.0

A SP IRATI ON PNEUMONI A

F O9P 2.0

OSTEOSARCOMA

F1OP 2.0

OSTEOSARCOMA

$M 11 P 2.0$

OSTEOSARCOMA

M12P 2.0

OSTEOSARCOMA

MO1P 3.0

OSTEDSARCOMA

F02P 3.0

OSTEOSARCOMA

$M 03 P 3.0$

OSTEOSARCOMA

MO4P 3.0

DSTEOSARCOMA

FO5P 3.0

OSTEOSARCOMA

FO6P 3.0

OSTEOSA RCOMA

FO 07 P 3.0

O STEOSARCOMA

MO8P 3.0

OSTEUSARCOMA

FO9P 3.0

OSTEOSARCOMA

F $10 . P 3.0$

OSTEOSARCOMA

M11P 3.0

M12P. 3.0

OSTEOSARCOMA

OSTEOSARCOMA

MO1P4.0

OSTEOSARCOMA

F 02P 4.0

OSTEOSARCOMA

$M 03 P 4.0$ :

OSTEOSARCOMA

$M 04 P 4.0$

OSTEOSARCOMA

F05P 4.0

OSTEOSARCOMA

F 06P.4. 0 .

OSTEOSARCOMA

FO7P 4. $0=$

OSTEOSARCOMA

$M 08 P 4.0$

OSTE OSARCOMA

FO9P 4.0

OSTEOSARCOMA

F1 OP 4.0

OSTEOSARCOMA

$M 11 P 4.0$

OSTEOSARCOMA

$M 12 P 4.0$

OSTEOSARCOMA

MO1P 5.0 OSTEOSARCOMA

F02.P 5.0 OSTEOSARCOMA + FRACTURED MANDIBLE

MO3P 5.0

LIVER DEGENERATION + ASCITES 


\begin{tabular}{|c|c|c|c|c|c|c|c|c|c|}
\hline $\begin{array}{l}\text { DOG } \\
\text { NUY BER }\end{array}$ & $\begin{array}{l}\text { AT INJE } \\
A G E \text { WE } \\
\text { (DAYS) }\end{array}$ & $\begin{array}{l}\text { CTION } \\
\text { (GHT } \\
(K G)\end{array}$ & $\begin{array}{c}\text { INJEC TED } \\
(\mu C / K G)\end{array}$ & $\begin{array}{l}\text { IN } \\
\mathrm{D}\end{array}$ & $\begin{array}{l}\text { ATE } \\
\text { JECT } \\
\text { MO }\end{array}$ & $\begin{array}{l}\text { E } \\
\text { YED } \\
\text { YR }\end{array}$ & $\begin{array}{r}\text { DAYS } \\
\text { INJEC } \\
31 / 3 / 65\end{array}$ & $\begin{array}{l}\text { S INCE } \\
\text { I ION } \\
\text { DEATH }\end{array}$ & $\begin{array}{l}\text { DOSE TO } \\
\text { SKELETON } \\
\text { (RADS) }\end{array}$ \\
\hline $\begin{array}{l}\text { YO4P } 5.0 \\
\text { FOSP } 5.0 \\
\text { FO6P } 5.0 \\
\text { FOTP } 5.0 \\
\text { MOSP } 5.0 \\
\text { FO9P } 5.0\end{array}$ & $\begin{array}{l}566 \\
691 \\
407 \\
482 \\
497 \\
552\end{array}$ & $\begin{array}{l}9.1 .8 \\
8.77 \\
7.90 \\
8.33 \\
9.55 \\
9.45\end{array}$ & $\begin{array}{l}3.17 \\
2.77 \\
2.57 \\
2.99 \\
2.69 \\
2.73\end{array}$ & $\begin{array}{r}16 \\
14 \\
12 \\
25 \\
15 \\
9\end{array}$ & $\begin{array}{l}09 \\
10 \\
05 \\
10 \\
03 \\
09\end{array}$ & $\begin{array}{l}53 \\
53 \\
54 \\
54 \\
55 \\
55\end{array}$ & $\cdot$ & $\begin{array}{l}1562 \\
2059 \\
1194 \\
1491 \\
1192 \\
1145\end{array}$ & $\begin{array}{l}7380 \\
8690 \\
4620 \\
6630 \\
4840 \\
4750\end{array}$ \\
\hline
\end{tabular}


$-23-$

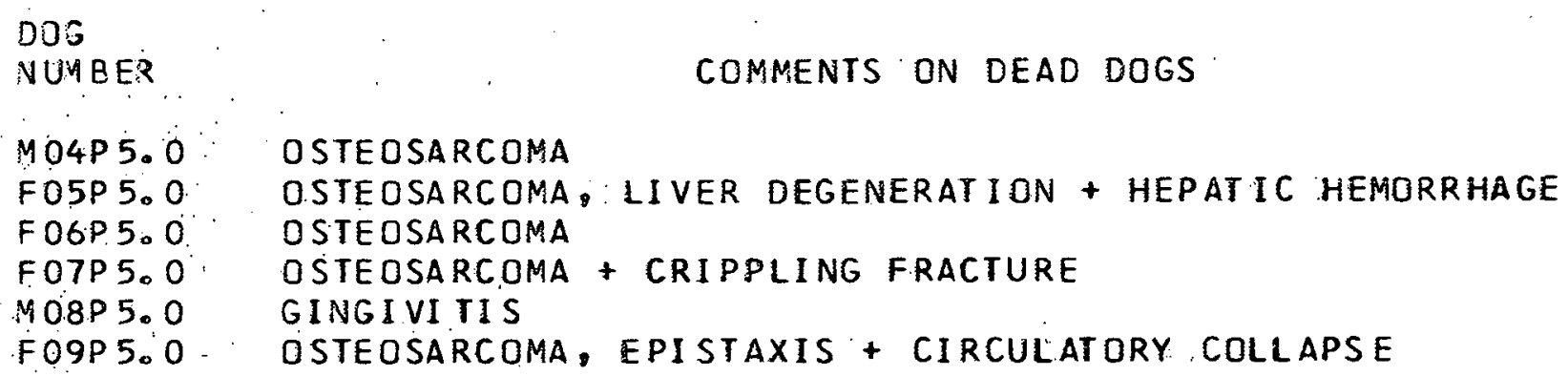


C. RADIUM-228 (MESOTHORIUM) *

\begin{tabular}{|c|c|c|c|c|c|c|c|c|}
\hline \multirow{3}{*}{$\begin{array}{l}\text { DOS } \\
\text { NUYBER }\end{array}$} & \multicolumn{2}{|c|}{ AT INJECTION } & \multirow{3}{*}{$\begin{array}{l}\text { INJECTED } \\
(\mu C / K G)\end{array}$} & \multicolumn{3}{|c|}{ DATE } & AYS & SINCE \\
\hline & $A G E: W$ & WE I GHT & & IN & JECT & TED & INJEC] & IION \\
\hline & (DAYS) & $(K G)$ & & D & MO & $Y R$ & $31 / 3 / 65$ & DEATH \\
\hline F01MO.O & 732 & 7.33 & & 4 & 1 & 54 & & 3451 \\
\hline$F 02 M O .0$ & 545 & 6.94 & & 29 & 11 & 54 & 3775 & \\
\hline MO3MO.O & 579 & 13.0 & & 1.3 & 03 & 56 & 3305 & \\
\hline MO4MO.O & 601 & 10.3 & & 15 & 01 & .57 & 2997 & \\
\hline F05M 0.0 & 671 & 11.2 & & 5 & 03 & 57 & 2948 & \\
\hline MOSMO.O & 492 & 7.56 & & 23 & $.04^{\circ}$ & 57 & 2899 & \\
\hline FO7MO. 0 & 395 & 8.71 & & 4 & 6 & 57 & & 1414 \\
\hline FO7MO.04 & 594 & 10.9 & & 15 & 1 & 63 & 806 & \\
\hline FOBMO. 0 & 654 & 11.6 & & 9 & 03 & 60 & 1848 & \\
\hline MO9MO.:O & 575 & $12: 4$ & & 13 & 04 & 60 & 1813 & \\
\hline M1OMO.O & 581 & $13: 3$ & . & 17 & 7 & 62 & 988 & \\
\hline F 11 & 475 & 9.31 & & 18 & 9 & 62 & 925 & \\
\hline$M 12 M O .0$ & 695 & 10.0 & & 22 & 12 & 60 & 1560 & \\
\hline
\end{tabular}

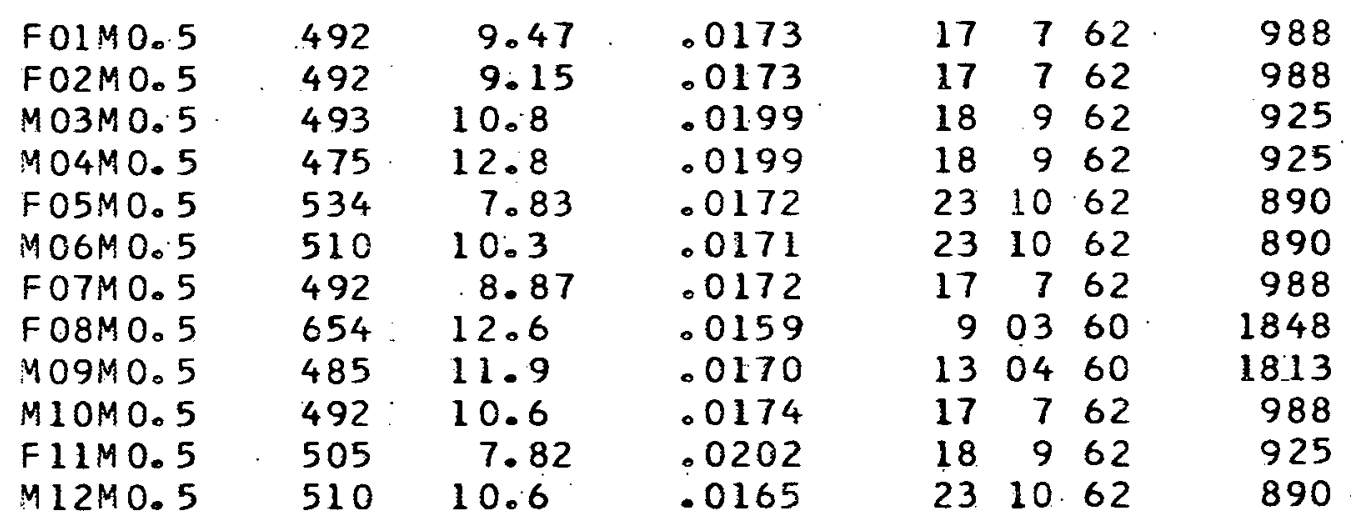

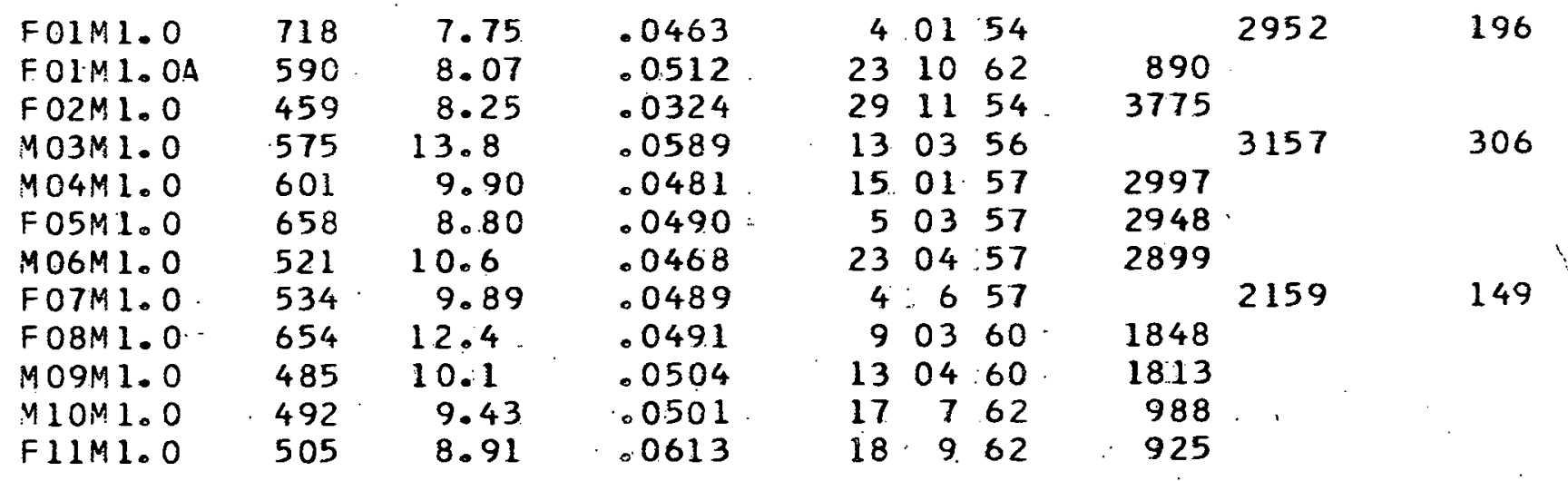


DOG :

NUMBER -

COMMENIS ON DEAD DOGS

FOI:MO. 0

PUR ULENT MENI NGOENCEPHALITIS

FO2MO.O

MO3M0. 0

M04MO.O

F05MO. 0

MOSMO.O

FOTM 0. 0

FOTMO. OA

$F O 8 M 0.0$

MO9MO.O

M $10 M 0.0$

FIIMO.0

M $12 M 0.0$

F01M0.5

F $02 \mathrm{MO}_{0} .5$

$M 03 M 0.5$

$M O 4 M 0.5$

FO5M 0.5

MOSMO. 5

FO7M0. 5

FO $O M 0.5$

MO9M 0.5

M1OM 0.5

F11M0.5

M12M0.5

FO1M 1.0

HEMANGI OSARCOMA

FO1M1. OA

STA TUS EPILEPTICUS

F O2M1.0

MO3M1.O

MO4M1.0

FO5M 1. O :

MO6M L.O

FOTM1.0.

FO8M1.0

MOSM1.0

M1OM1.0

FIIMLOO

OSTEOSARCOMA

HEMANG I OSARCOMA 


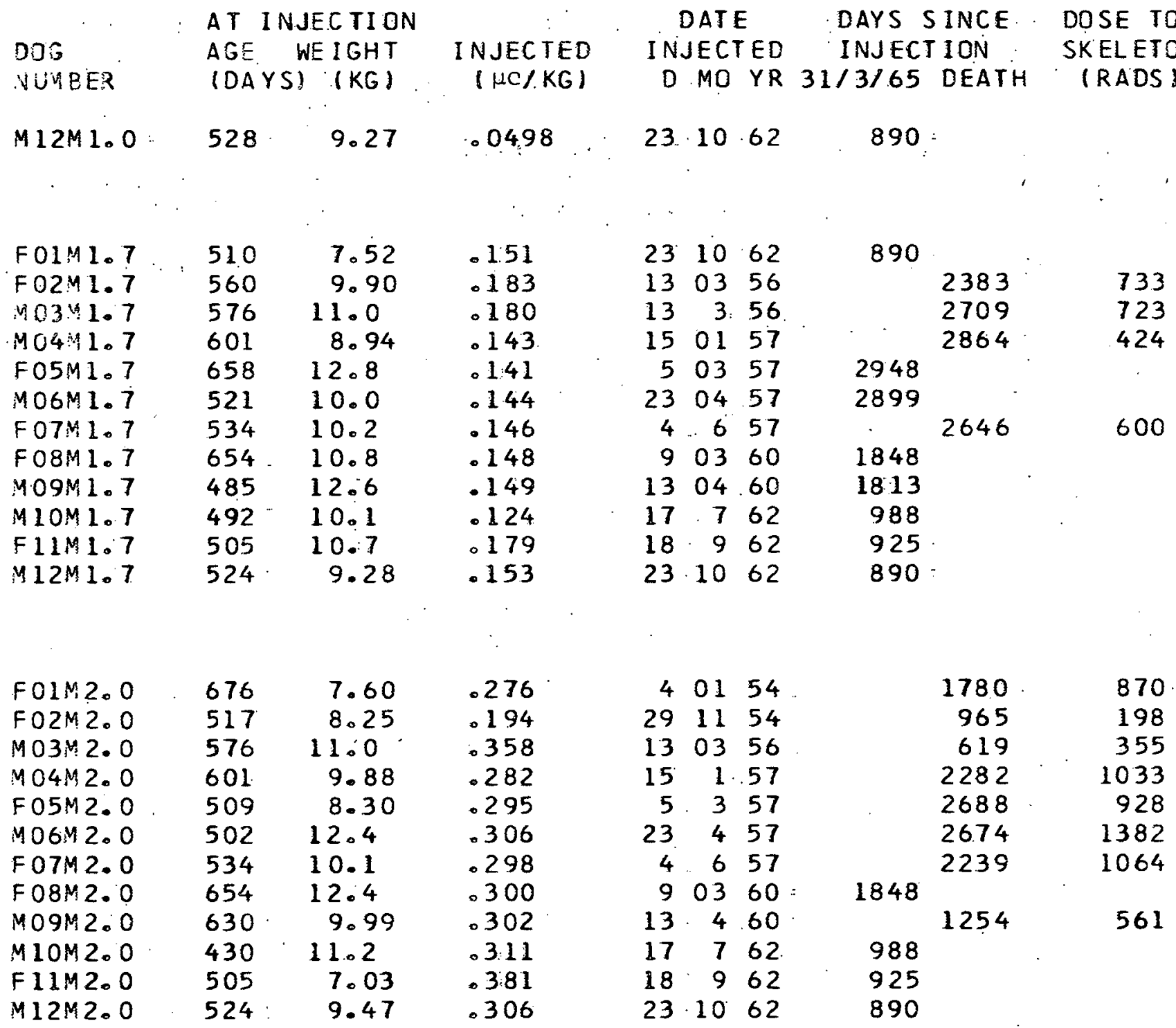

$\begin{array}{lcccrrrrr}\text { FOIM 3.0 } & 519 & 10.4 & .858 & 40154 & 918 & 1833 \\ \text { FO2M3.0 } & 460 & 6.70 & .612 & 29 & 1154 & 1856 & 2075 \\ \text { MOSM3.0 } & 579 & 10.4 & .965 & 13 & 3.56 & 1185 & 2464 \\ \text { MO4M3.0 } & 601 & 10.2 & .916 & 1501 & 57 & 1176 & 1592 \\ \text { FOSM3.0 } & 531 & 8.51 & .940 & 503 & 57 & 1869 & 2148 \\ \text { MOSM3.0 } & 502 & 9.09 & .953 & 2304.57 & 1421 & 1906 \\ \text { FOTM3.0 } & 534 & 9.94 & .907 & 4 & 6 & 57 & 1463 & 3145 \\ \text { FOBM3.0 } & 633 & 11.8 & .950 & 9 & 360 & 1447 & 2158 \\ \text { MO9M3.0 } & 630 & 9.83 & .918 & 13 & 460 & 1570 & 2277\end{array}$


DOS

NUMBER

COMMENTS ON DEAD DOGS

$M 12 M 1.0$

FOIM1.7

FO2M1.7

MO3M1.7

MO4M1.7

FO5M1.7

MO6M1.7

F.07M1.7

FOOM 1.?

MOSM 1.7

M1OM1.7

F. $11 M 1 \div ?$

M.12M1:7

OSTEOSARCOMA

OSTEOSARCOMA

CARCINOMA SMALL INTESTINE

DSTEOSARCOMA

FOIM2:0

OSTEOSARCOMA

FO2M2.O

$M 03 M 2.0$

M $04 M 2.0$

FO5M.2:0

MOSM2.O

FOTM2.0

FOBM 2.0

$M O 9 M 2.0$

$M 1 O M 2.0$

F11M2:0

M12M2:0
INTE STINAL HE MORRHAGE

PNE UMONI A

OSTEOSARCOMA

OSTEOSARCOMA

OSTEOSARCOMA

CHRONIC PANCREATITIS

RETICUL UM CELL SARCOMA. OF VERTEBRA

FOIM3.O : OSTEOSARCOMA

FO2M3.0 : OSTEOSARCOMA

MO3M3.0 - OSTEOSARCOMA

MO4M3.0 OSTEOSARCOMA

FOSM3.0 OSTEOSARCOMA

MOGM 3.0 . OSTEOSARCOMA

FOTM3.0 : OSTEOSARCOMA

FO 8M3.0 OSTEOSARCOMA

MOOM 3.0 : OSTEOSARCOMA 
D0G

NUM $8 E R$

$M 10 M 3 . C$

F11M3.0

M $12 M 3.0$
AT. INJECTI ON AGE WEIGHT (DAYS) : (KG) :
I NJECTED

$(\mu C / K G)$

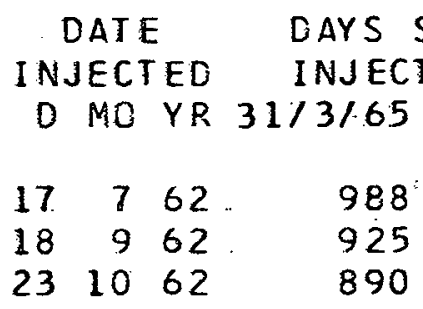

$\begin{array}{rrr}4 & 01 & 54 \\ 29 & 11 & 54 \\ 13 & 03 & 56 \\ 4 & 06 & 57 \\ 15 & 1 & 57 \\ 5 & 03 & 57 \\ 23 & 04 & .57 \\ 4 & 06 & 57\end{array}$

4.0154

FOIM4.O

$\mathrm{FO}_{2} \mathrm{M}_{4} \mathrm{O} O$

$M O 3 M 4.0$

MO3M 4.0A

MO4M4. 0

F $05 M_{3} 4.0$

$M 06 M 4.0$

F07M4. 0
510

460

579

494

609

509

502

544
7.56

6.95

9.65

7.34

7.84

9.63

9.49

$8.40 \quad 2.67$
2.60

1.86

3.37

2.64

2.47

2.67

2.66
841

778

418

1063

896

1064

112.1

1253
DOSE TO

SKELETON

(RADS:

$\begin{array}{llrc}\text { FO1M5.0 } & 494 & 7.77 & 8.11 \\ \text { F02M5.0 } & 460 & 7.35 & 5.46 \\ \text { MO3M5.0 } & 579 & 8.87 & 10.4 \\ \text { MO4M5.0 } & 482 & 7.29 & 7.89 \\ \text { F05M5.0 } & 658 & 11.1 & 8.48 \\ \text { MO6M5.O } & 580 & 7.53 & 8.67 \\ \text { F07M5.O } & 494 & 7.35 & 8.92\end{array}$

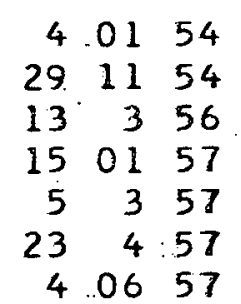

5614

2272

1795

5604

2680

4358

4784

4636

* $\left(\mu \mathrm{c} \mathrm{Th}^{228} / \mu \mathrm{c} \mathrm{Ra}{ }^{228}\right)$ injected $=0.15$ for FlMl.0, 2.0,3.0, 4.0, 5.0.

$$
\begin{array}{r}
=0.03 \text { for F2M1.0, } 1.7,2.0,3.0,4.0,5.0 \\
\text { M3Ml.0, } 1.7,2.0,3.0,4.0,5.0 . \\
=0.006 \text { for groups 4, 5, 6, 7, 8, 9, 10, } \\
\text { II, 12, and dogs FIMO.5, F2M0.5, } \\
\text { M3M0.5, FlMLA, FIMI.7 and M3M4.0A. }
\end{array}
$$


DOG

NUMBER

COMMENTS ON DEAD DOGS

M10M3.0

F11M 3.0

M12M3.O :

FO1M4.0: OSTEOSARCOMA + CRIPPLING FRACTURE

F.02M 4.: : : OSTEOSARCOMA

MO3M4.0 STRANGULATED INGUINAL HERNIA

MO3M4. OA: OSTEOSARCOMA, NEPHRITIS; ULCERATIVE GINGIVITIS + PNEUMONIA

M04M4.0 : FRACTURED MANDIBLE + ULCERATIVE GINGIVITIS

FO5M 4:0 :- OSTEOSARCOMA

MO6M 4.0 : OSTEOSARCOMA

FOTM.4.0 : OSTEOSARCOMA

F01M5.0 NEPHRITIS + SEVERE ANEMIA

FO2M5.0 CRIPPLING FRACTURES

MO3M5.0 ULCERATIVE GINGIVITIS

MO4M5.0. CRIPPLING FRACTURE

F05M5:0: ULCERATIVE GINGIVITIS

MO6M5.0 : OSTEOSARCOMA +CRI PPLING :FRACTURE

FO7M5.0: ULCERATIVE GINGIVITIS, MYOCARDIAL:INFARCTION + GLAUCOMA 
D. THORIUM-228 (RADIOTHORIUM) *

\begin{tabular}{|c|c|c|c|c|c|c|c|c|}
\hline $\begin{array}{l}\text { DOG } \\
\text { VUMBER }\end{array}$ & $\begin{array}{l}\text { AT IN } \\
\text { AGE } \\
\text { IDAYS }\end{array}$ & $\begin{array}{l}\text { JEC TI ON } \\
\text { WEIGHT. } \\
\text { ) (KG) }\end{array}$ & $\begin{array}{l}\text { INJEC TED } \\
(\mu \mathrm{C} / \mathrm{KG})\end{array}$ & & $\begin{array}{l}\text { DATE } \\
\text { JECT } \\
\text { MO }\end{array}$ & & $\begin{array}{l}\text { DAYS S } \\
\text { INJECT } \\
31 / 3 / 65\end{array}$ & $\begin{array}{l}\text { SINCE } \\
\text { TION } \\
\text { DEATI }\end{array}$ \\
\hline MOLTO. 0 & 493 & 8.24 & & 8 & 02 & 54 & 4069 & \\
\hline 02 & 488 & 7.28 & & $\begin{array}{r}28 \\
6\end{array}$ & 09 & $\begin{array}{l}54 \\
55\end{array}$ & & \\
\hline $\begin{array}{l}03 \\
0.4\end{array}$ & $\begin{array}{l}797 \\
591\end{array}$ & $\begin{array}{r}11.6 \\
8.10\end{array}$ & & $\begin{array}{r}6 \\
18\end{array}$ & $\begin{array}{l}06 \\
10\end{array}$ & $\begin{array}{l}55 \\
55\end{array}$ & & $\begin{array}{l}2592 \\
3072\end{array}$ \\
\hline 0 & 458 & 10.4 & & 14 & 10 & 58 & 2360 & \\
\hline $66 \mathrm{T0} 0$ & 489 & 9.64 & & 10 & 1. & 61 & & 171 \\
\hline $56 \mathrm{TO} 0.0 \mathrm{~A}$ & 688 & 8.61 & & 15 & 12 & 60 & 1567 & \\
\hline 0750.0 & 517 & 10.5 & & 7 & 2 & 61 & & 1412 \\
\hline $8 B$ & 533 & 10.8 & & 24 & 5. & 61 & 1407 & \\
\hline 910.0 & $569^{\circ}$ & 8.28 & & 29 & 6. & 61 & 1371 & \\
\hline 0 & 536 & 10.4 & & 28 & 7. & 61 & 1342 & \\
\hline 0 & 530 & 9.45 & & 4 & 6 & 63 & 666 & \\
\hline$=12 \mathrm{~T} 0.0$ & 492 & 9.09 & & 9 & 7 & 63 & 631 & \\
\hline
\end{tabular}

\begin{tabular}{|c|c|c|c|c|c|c|c|c|c|}
\hline M01T0.2 & 682 & 11.4 & .00164 & 27 & 03 & 62. & 1100 & & \\
\hline $402 T 0.2$ & 682 & 10.4 & .00166 & 27 & 03 & 62 & 1100 & & \\
\hline F03T0. 2 & 478 & 9.86 & .00163 & 27 & 03 & 62 & 1100 & & \\
\hline M04T0.2 & 478 & 10.0 & .00166 & 27. & 03. & 62 & 1100 & & \\
\hline $405 T 0.2$ & 625 & 13.8 & .00162 & 9 & 02 & 60 & & 889 & 10 \\
\hline M05T0.2A & 530 & 13.4 & .00173 & 4 & 6 & 63 & 666 & & \\
\hline F06T0.2 & 489 & 8.85 & .00176 & 10 & 1 & 61 & 1541 & & - \\
\hline $907 T 0.2$ & .532 & 10.5 & .00159 & 7 & 2 & 61 & $15: 13$ & & \\
\hline MO8T0.2 & 494 & 13.9 & .00189 & 24. & 5 & 61 & 1407 & & \\
\hline F09 0.2 & 569 & 7.82 & .00171 & 29. & 6 & 61 & 1371 & & \\
\hline F10T0. 2 & 508 & 10.5 & .00170 & 28 & 7 & 61 & 1342 & & \\
\hline F11T0.2 & 530 & 9.76 & .00171 & 4 & 6 & 63 & 666 & & \\
\hline F12T0.2 & 492 & 7.37 & .00190 & 9 & 7 & 63 & 631 & & \\
\hline
\end{tabular}

\begin{tabular}{|c|c|c|c|c|c|c|c|c|c|}
\hline MOLTO. 5 & 699 & 14.3 & .00496 & 7 & 9 & 56 & 3127 & & \\
\hline $402 T 0.5$ & 455 & 10.5 & .00490 & 28 & 09 & 54 & & 1976 & 41 \\
\hline F03T0.5 & 659 & 8.59 & .00485 & 6 & 6 & 55 & & 3032 & 44 \\
\hline M04T0.5 & 516 & 8.58 & .00540 & 18 & 10 & 55 & & 2159 & 46 \\
\hline $1405 T 0.5$ & 513 & 8.46 & .00522 & 14 & 10 & 58 & 2360 & & \\
\hline F06 10.5 & 489 & 9.66 & .00510 & 10 & 1 & 61 & 1541 & & \\
\hline M07T0.5 & 532 & 9.11 & .00491 & 7 & 2 & 61 & 1513 & & \\
\hline 190810.5 & 533 & 9.53 & .00562 & 24 & 5 & 61 & 1407 & & \\
\hline F09T0. 5 & 569 & 8.62 & .00529 & 29 & 06 & 61 & 1371 & & \\
\hline F10T0. 5 & 508 & 10.2 & .00510 & 28 & 7 & 61 & 1342 & & \\
\hline F $11 T 0.5$ & 530 & 7.78 & .00518 & 4 & 6 & 63 & 666 & & \\
\hline
\end{tabular}


DOG

NUM $B E R$

COMMENTS ON DEAD DOGS

MOLTO.O

MO2T0. 0

F03TO. 0

BRA I N HEMORRHAGE

MO4TO.O

LYMPHOSARCOMA

MOSTO.

F.06 T0.0

TRA UMA

F06TO. OA

MOTTO.:

BRA IN HEMORRHAGE

MO8 T0: 0

F09T0.0

F10T0.0

Fil T0:0

F12 TO.0 0

M01T0.2

$M 02 T 0.2$

F 0350.2

$M 04 \mathrm{TO} .2$

M05T0.2

MO5.TO.2A

STRANGULATION ON VOMITUS + GRAND MAL

F06T0.2

MOT.T0.2

MO8T.0.2

FO9.10.2

F10T0.2 2

FIITO.2

F12T0.2

MO1T0.5

MO2TO. 5

F 03 T0. 0

$M 04 T 0.5$

$M 05 T 0.5$

F06T0.5

MOT.T0.5

M08T0.5

F0910.5

F.10.10.5

F11T0.5

STRANGULATION ON VOMITUS + GRAND MAL PYOMETRI TIS + SEC ONDARY PERITONITIS

STA TUS EPILEPTICUS + PNEUMONIA 
DOG

VUMBER

F12 T0.
AT INJECTION AGE WEIGHT (DAYS) (KG)
DATE

I NJECTED

( $\mu \mathrm{C} / \mathrm{KG}$ )
INJECTED

D MG YR

9763

492

.00567

$\begin{array}{cc}9.36 & .0146 \\ 9.27 & .0146 \\ 8.84 & .0145 \\ 8.27 & .0146 \\ 11.9 & .0146 \\ 8.81 & .0150 \\ 9.18 & .0147 \\ 8.69 & .0166 \\ 10.0 & .0160 \\ 10.2 & .0150 \\ 7.55 & .0154 \\ 9.96 & .0167\end{array}$

$\begin{array}{lll}8 & 02.54\end{array}$

70956

7.0956

70956

$\begin{array}{lll}14 & 10 & 58\end{array}$

10161

7261

24: 561

29. 661

28761

4.663

9763
CAYS SINCE INJECTION

631
DOSE TO SKELETON

(RADS)

FIITLO

5.21

F12T1.0: $\quad 472$

533

527

508

9.96

$\begin{array}{lll}699 & 7.95 & .0289 \\ 458 & 10.0 & .0293 \\ 609 & 10.3 & .0303 \\ 591 & 8.59 & .0299 \\ 598 & 9.65 & .0286 \\ 489 & 8.14 & .0292 \\ 517 & 8.83 & .0292 \\ 521 & 9.08 & .0311 \\ 494 & 11.6 & .0324 \\ 527 & 8.80 & .0306 \\ 508 & 11.6 & .0296 \\ 518 & 11.4 & .0305 \\ 465 & 7.56 & .0329\end{array}$

$\begin{array}{rrr}7 & 9 & 56\end{array}$

$\begin{array}{lll}28 & 09 & 54\end{array}$

$606 \quad 55$

$18 \quad 10 \quad 55$

9260

10161

7261

4. $6 \quad 63$

$24 \quad 561$

2961

$28 \quad 761$

4663

9763

1541

2894

2576

1921

2309

1624

3127

3127

3127

2360

1541

1513

1407

1371

1342

666

631

3172

132

$\begin{array}{ll}\text { FO9T1.5 } & 527 \\ \text { F1OT1.5 } & 508 \\ \text { F11T1.5 } & 518 \\ \text { F12T1.5 } & 465\end{array}$

$40152: 0$

प 0272.0

F03T2.0

$M 04 \mathrm{~T} 2.0$

MO4T2. OA

M05T2. 0

F06T2.0

491

10.2

.0976

$8.02 \quad 54$

1282

69.3

483

9.16

$28.09 \quad 54$

1234

1541

611

474

$7.87 \quad .0908$

$\begin{array}{llll}6 & 06 & 55\end{array}$

695

553

13.0

181055

78

70

7.0956

1222

625

598

$9.12: .0848$

90260

1085

556

451

$8.65 \quad .0879$

M07T2.0

517

8.85

.0881

$10 \quad 161$

1108

583

1015

558 
DOG

NUMBER

F $12 T 0.5$

M01T1.0

OSTEOSARCOMA

MO2T1.0

F03T1.0

MO4T1.0

MO5T1.0

F.06T1.0

MOTT1.0

MO8T1:0

F09T1:0

F10T1.0

FIIT1.0

F $12 T 1.0$

$M 01 T 1.5$

OSTE OSARCOMA

OSTEOSARCOMA

$M 02 T 1.5$

COMA OF UNKNOWN ETIOLOGY

F03T1.5

$M 04 \mathrm{~T} 1.5$

OSTEOSARCOMA

$M 05 \mathrm{~T} 1.5$

OSTEOSARCOMA

F06T1.5

M07T1.5

M07. 1.5A

LEP TOSPIROSIS

MO8T1:5

F09T1.5

F10T1.5

F 11 T.1.5

F12Ti.5

MO1T2.0

OSTEOSARCOMA

MO2T2.O OSTEOSARCOMA

F03T2.0 DSTEOSARCOMA

MO4T2.0

TRA UMA

M04T2. OA. OSTEOSARCOMA

MO5T2.0 OSTEOSARCOMA

F06T2.0: OSTEOSARCOMA

MOTT2.0: OSTEOSARCOMA 
DOG :

NUYBER

Y०० T2.0

F09T2. 0

F10T2.0

FIIT2.0

F12T2:0

$401 T 3.0$

$\mathrm{MO} T 3.0$

F03T3.0

MO4T3.0

$M 05 T 3.0$

F06T3:0

M07T3.0

40813.0

F09T3.0

F $10 T 3.0$

FIIT3.0

$F 12 \times 3.0$

M01T4.0

MO2.T4. 0

FO3 14.0

MO 14.0
AT INJECTION AGE WEIGHT

(DAYS) : (KG)

533

527

508

518

464

$$
10.7
$$

8.09

10.7

10.8

8.92
DATE

I NJECTED

( $\mu C / K G)$

INJECTED

D MO YR 31/3/65 DEATH

24. 5.61

29. $6 \quad 61$

$\begin{array}{lll}28 & 7 & 61\end{array}$

4663

9763

.100

$\begin{array}{lll}8 & 02 & 54\end{array}$

$\begin{array}{llll}28 & 09 & 54\end{array}$

$\begin{array}{llll}6 & 06 & 55\end{array}$

$18 \quad 10: 55$

9.0260

$10: 161$

$\begin{array}{lll}7 & 2 & 61\end{array}$

24.561

29661

$28 \cdot 7 \quad 61$

$4: 663$

9763

DAYS SINCE

INJECT ION

$\begin{array}{lll}494 & 10.1 & .313\end{array}$

$\begin{array}{lll}511 & 11.5 & .298\end{array}$

508

518

459
9.26

10.3

11.5
.280

.320
1078

1209

1022

666

988

859

547

801

890

1156

861

685

1062

971

666

631

8.02.54

$\begin{array}{llll}28 & 09 & 54\end{array}$

$\begin{array}{lll}606 & 55\end{array}$

$18 \quad 10.55$

645

4237

833

5185

461

7.25

.800

8.81

.835

606

MO1T5.0

480

483

80254

28.0954
DOSE TO

SKELETON

(RADS)

641

677

584

MO2T5. 0

$\begin{array}{ll}9.48 & 2.76 \\ 8.22 & 2.63\end{array}$

212

97

5457

$793 . \quad 4587$

1736

1164

1575

1584

1909

1536

1566

1933

1732

2535 
DOG

NUMBER

COMMENTS ON DEAD DOGS

MO8T2.0
FO9T2.0 OSTEDSARCOMA
F10T2.0 OSTEOSARCOMA
F11T2.0 OSTEOSARCOMA
F12T2.0

M01T3.0:- OSTEOSARCOMA + SEVERE ANEMIA

M02T3.0 - OSTEOSARCOMA + TRAUMA

FO3T3.0 - OSTEOSARCOMA

M04T3.0: OSTEOSARCOMA

MO5T3.0 : OSTEOSARCOMA

FO6T3.0. OSTEOSARCOMA

MO7T3.0 - OSTEOSARCOMA

M08T3.0: OSTEOSARCOMA

FO9T3.0: OSTEOSARCOMA

F10T3.0 = OSTEOSARCOMA

F11T3.0

F12.T3.0

MO1T4. 0

MO2T4.O

FO3T4.O

$M 04 \mathrm{~T} 4.0$

$1901 T 5.0$

$M 02 T 5.0$
OSTEOSARCOMA + CRIPPLING FRACTURE OSTEOSARCOMA, CRI PPLING FRACTURE + NEPHRITIS ULCERATI VE GINGIVITIS + NEPHRITIS. ULCERATIVE GINGIVITIS

NEPHRITISS

PANC YTOPENIA 
E. STRONIIUM-90

\begin{tabular}{|c|c|c|}
\hline \multirow{3}{*}{$\begin{array}{l}\text { DOG } \\
\text { VUYBER }\end{array}$} & \multicolumn{2}{|c|}{ AT INJECTIO } \\
\hline & & WE I GHT \\
\hline & (DAYS) & ) $(K G)$ \\
\hline $01: 50.0$ & 502 & 8.4 \\
\hline & 600 & 11.1 \\
\hline 03 & 493 & 9. \\
\hline 450.0 & 520 & \\
\hline 05 & 542 & 10.6 \\
\hline 06 & 466 & 9.6 \\
\hline 075 & 462 & \\
\hline 0850.0 & 483 & 9. \\
\hline 0950.0 & 549 & \\
\hline $0950.0 \mathrm{~A}$ & 535 & 11. \\
\hline & 522 & 13.9 \\
\hline 1150.0 & 541 & 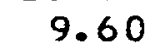 \\
\hline 1250.0 & 605 & \\
\hline
\end{tabular}

\begin{tabular}{|c|c|c|c|c|c|}
\hline \multirow{3}{*}{$\begin{array}{c}\text { INJECTED } \\
(\mu C / K G)\end{array}$} & \multicolumn{3}{|c|}{ DATE } & \multicolumn{2}{|c|}{ DAYS SINCE } \\
\hline & IN & $E C T$ & IED & INJECT & ION \\
\hline & & MO & $Y R$ & $31 / 3 / 65$ & DEAT \\
\hline & 18 & 01 & 55 & 3725 & \\
\hline & 14 & .02 & 56 & 3333 & \\
\hline & 11 & 09 & 57 & 2758 & \\
\hline & 15 & 10 & 57 & 2724 & \\
\hline & 19 & 11 & 57 & 2689 & \\
\hline & 27 & 05 & 58 & 2500 & \\
\hline & 7 & 01 & .59 & 2275 & \\
\hline & 19 & 05 & 59 & 2143 & \\
\hline & 11 & .08 & 59 & & 708 \\
\hline & 4 & 6 & 63 & 666 & \\
\hline & 29 & 09 & 59 & 2010 & \\
\hline & 3 & 11 & 59 & 1975 & \\
\hline & 6 & 01 & 60 & 1911 & \\
\hline
\end{tabular}

$\begin{array}{lrcr}\text { F01S1.0 } & 1524 & 6.84 & .573 \\ \text { FO1S1.0A } & 521 & 9.38 & .588 \\ \text { MO2S1.0 } & 567 & 8.81 & .606 \\ \text { MO3S1.0 } & 493 & 10.9 & .572 \\ \text { FO4S1.0 } & 525 & 8.96 & .560 \\ \text { MOSS1.0 } & 555 & 10.2 & .532 \\ \text { MOSS1.0 } & 466 & 9.56 & .581 \\ \text { FOTS1.0 } & 524 & 9.94 & .517 \\ \text { FOSS1.0 } & 483 & 10.8 & .6997 \\ \text { FO9S1.0 } & 549 & 11.6 & .534 \\ \text { M1OS1.0 } & 522 & 11.5 & .558 \\ \text { F11S1.0 } & 543 & 10.3 & .550 \\ \text { M12S1.0 } & 607 & 13.7 & .559\end{array}$

180155

308

21

14.0 $0256 \quad .3333$

$\begin{array}{llll}14 & 02 & 56\end{array} \quad 3333$

$\begin{array}{llll}11 & 09 & 57 & 2758\end{array}$

15. $10 \quad 57 \quad 27.24$

$\begin{array}{llll}19 & 1157 & 2689\end{array}$

$\begin{array}{llll}27 & 05 & 58 & 2500\end{array}$

$111158 \quad 2332$

$19.05 .59 \quad 2143$

$11.08=59 \quad 2059$

$\begin{array}{lll}29 & 09.59 \quad 2010\end{array}$

$\begin{array}{lllll}3 & 11 & 59 & 1975\end{array}$

60160.1911

$\begin{array}{lccc}\text { FO1S1.7 } & 526 & 7.41 & 1.78 \\ \text { MO2S1.7 } & 567 & 11.6 & 1.84 \\ \text { MOSS1.7 } & 493 & 9.19 & 1.69 \\ \text { FO4S1.7 } & 522 & 9.60 & 1.68 \\ \text { MOSS1.7 } & 560 & 9.85 & 1.60 \\ \text { MOSS1.7A } & 493 & 11.4 & 1.78 \\ \text { MOSS1.7 } & 466 & 10.6 & 1.72 \\ \text { FO SS1.7 } & 488 & 10.2 & 1.60 \\ \text { FOBS1.7 } & 472 & 8.47 & 2.03 \\ \text { FO9S1.7 } & 549 & 10.0 & 1.62 \\ \text { MIOS1.7 } & 519 & 13.6 & 1.66\end{array}$

14.02:56. 3333

$\begin{array}{lll}14 & 02.56 .3333\end{array}$

$\begin{array}{llll}11 & 09 & 57 & 2758\end{array}$

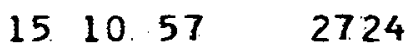

$\begin{array}{lll}19 & 11.57\end{array}$

$\begin{array}{lll}6 & 3 & 63\end{array}$

756

1715

161

$\begin{array}{llll}27 & 05 & 58 & 2500\end{array}$

$1111.58 \quad 2332$

19. 5.59

2059

1973

SKELETON

(RADS)

11. 0859

2010 . 
DOG

NUMBER

COMMENTS ON DEAD DOGS

F01:SO.0

$\mathrm{MO2} \mathrm{SO}_{0}=0$

$M 0350.0$

F04 $\mathrm{SO}_{0}: 0$

$M 0550.0$

$M 0650.0$

F0750.0A

F08 SO. 0

FO9S0:0

FO9S0.0A

M10S0.0

F 1150.0

$M 1250.0$

FOIS1.0

SACRIFICED -IMPROPER INJECTION AGE-

F01:S1.0A

TRA UMA

$M 0251.0$

$M 0351.0$

F04S1.0

MOSS1.0

M06S1.0

F0751.0

F08S1.0

FO9.S1.0

M1OS1.0

F11S1.0

$M 1251.0$

F01S1.7

$M 0251.7$

$M 0351.7$

F04.S1.7

M05S1.7

M05S1.7A

$M 0651.7$

F0751.7

F0851.7

F $09 \$ 1.7$

M1OS1.7

COMA OF UNKNOWN ETI OLQGY

STATUS EPILEPTICUS, CHRONIC PANCREATITIS 
005

VUMBER

F11S1.7

$M 1251.7$
AT I NJECTION AGE WEIGHT (DAYS) (KG)
I NJECTED $(\mu \mathrm{C} / K G)$

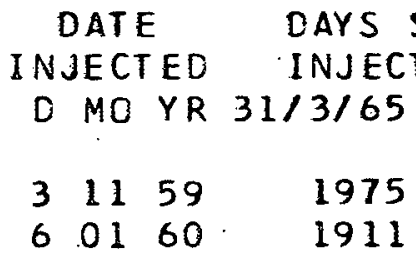

$18 \quad 155$

$\begin{array}{lll}14 & 02 & 56\end{array}$

$\begin{array}{lll}11 & 09 & 57\end{array}$

$\begin{array}{lll}15 & 10 & 57\end{array}$

$\begin{array}{lll}19 & 11 & 57\end{array}$

27. $05 \quad 58$

111158

19. 05.59

11.08 .59

$2909 \quad 59$

31159

60160
3269

480
$M 10 \$ 2.0$

F1IS2.0

412 S2. 0
FO1S3.0

$M 0253.0$

$M 0.353 .0$

$\mathrm{F} 0453.0$

40553.0

M0653.0

F0753.0

F 0853.0

FO9S3.0

41053.0

F11S3.0

M1253.0

$\begin{array}{ccc}468 & 7.36 & 11.6 \\ 565 & 9.62 & 11.6 \\ 494 & 11.4 & 10.8 \\ 527 & 9.17 & 10.6 \\ 557 & 8.90 & 10.1 \\ 466 & 9.44 & 10.9 \\ 486 & 9.80 & 10.1 \\ 465 & 12.5 & 12.9 \\ 468 & 10.0 & 10.1 \\ 519 & 12.5 & 10.3 \\ 541 & 9.00 & 10.8 \\ 605 & 8.43 & 10.2\end{array}$

$16.0 \quad 32.7$

10.930 .9

$10.9 \quad 40.6$
468

567

593

528

562

504

478

465

$8.74 \quad 33.3$

32.6

32.1

$\begin{array}{ll}8.24 . & 32.1 \\ 9.65 & 30.6\end{array}$

$M 0654.0$

$F 07 \$ 4.0$

FO8S4.0

$\begin{array}{llll}18 & 01 & 55 & 3725 \\ 14 & 02 & 56 & 3333 \\ 11 & 09 & 57 & 2758 \\ 15 & 10 & 57 & 2724 \\ 19 & 11 & 57 & 2689 \\ 27 & 05 & 58 & 2500 \\ 11 & 11 & 58 & 2332 \\ 19 & 05 & 59 & 2143 \\ 11 & 08 & 59 & 2059 \\ 29 & 09 & 59 & 2010 \\ 3 & 11 & 59 & 1975 \\ 6 & 01 & 60: & 1911\end{array}$

$\begin{array}{lll}18 & 0155\end{array}$

3682

6832

14. 02.56

2093

$\begin{array}{lll}11 & 09.57\end{array}$

2758

$15.10 .57 \quad 2724$

$\begin{array}{llll}19 & 11 & 57 \quad 2689\end{array}$

$309.58 \cdot 240.1$

$\begin{array}{llll}11 & 1158 & 2332\end{array}$

19. $0559 \quad 2143$
DSE TO

(RADS) 
DOS

NUMBER -

COMMENTS ON DEAD DOGS

F11S1.7

M12S1.7

FOIS2:0

BAC TERI AL PNE UMONI A

$M 0252.0$

M03.52.0

$\mathrm{FO4} \$ 2.0=$

MO5\$2.0

MO6S2.0

F0752:0

F0852.0

F0952.0

MIOS2.0

F11S2.0

M12S2.0

F01:S3.0

$M 0253.0$

$M 0353.0$

$\mathrm{F} 04 \mathrm{S3} .0$

MO5S3.0

MO6S3.0

F.0753.0

F 0853.0

F0953.0

M10S3.0

F 11:S3.0

M1253.0

FOI 54.0 NOT DETERMINED. (NO DSTEOSARCOMA)

MO254. 0 SQUAMOUS CELL CARGI NOMA -GINGIVA-

.$M 0354.0$

F04.\$4:0

M05\$4. 0

M0654.0

F07:54:0

F08S4.0 


\begin{tabular}{|c|c|c|c|}
\hline $\begin{array}{l}\text { DOS } \\
\text { NUMBER }\end{array}$ & $\begin{array}{l}\text { AI IA } \\
\text { AGE } \\
\text { IDAYS }\end{array}$ & $\begin{array}{l}\text { JEC TI O } \\
\text { WEI IGHT } \\
(\mathrm{KG})\end{array}$ & I $N$ \\
\hline $\begin{array}{l}F 09 S 4.0 \\
M 10 S 4.0 \\
F 11 S 4.0 \\
M 12 S 4.0\end{array}$ & $\begin{array}{l}468 \\
517 \\
542 \\
605\end{array}$ & $\begin{array}{l}9.56 \\
8.20 \\
8.86 \\
10.9\end{array}$ & $\begin{array}{l}30.6 \\
31.3 \\
32.7 \\
32.3\end{array}$ \\
\hline .. & & & \\
\hline $\begin{array}{l}F 0155.0 \\
M 0255.0 \\
M 0255.0 A \\
M 0355.0 \\
F 04 \$ 5.0 \\
M 0555.0 \\
M O 655.0 \\
M 0655.0 A \\
F O 755.0 \\
F 0855.0 \\
F O 955.0 \\
M 1 O S 5.0 \\
F 11 S 5.0 \\
M 12 S 5.0\end{array}$ & $\begin{array}{l}434 \\
551 \\
545 \\
507 \\
528 \\
621 \\
504 \\
462 \\
478 \\
535 \\
459 \\
517 \\
542 \\
606\end{array}$ & $\begin{array}{l}9.38 \\
12.2 \\
11.4 \\
10.3 \\
11.4 \\
8.53 \\
9.33 \\
11.2 \\
10.2 \\
11.2 \\
8.82 \\
8.55 \\
8.97 \\
12.5\end{array}$ & $\begin{array}{c}1.03 . \\
102 . \\
96.6 \\
102 . \\
105 . \\
95.2 \\
98.8 \\
94.2 \\
92.7 \\
90.5 \\
93.5 \\
95.09 \\
102 . \\
99.2\end{array}$ \\
\hline
\end{tabular}

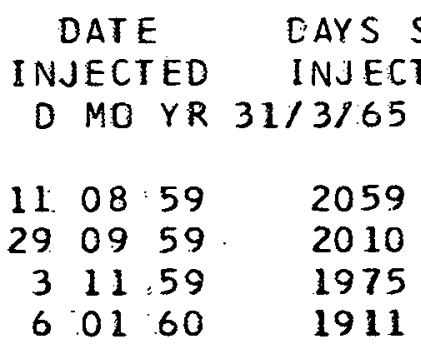

180155

$1402: 56$

7159

$\begin{array}{ll}15 & 10.57\end{array}$

15. 10.57

19. 1157

3958

7.01 .59

1111.58

$\begin{array}{lll}7 & 0159\end{array}$

$1108: 59$

290959

$\begin{array}{lll}3 & 1159\end{array}$

60160 :

$\begin{array}{rr}960 & 8127 \\ 255 & 3202 \\ 1740 & 12007 \\ 2256 & 16297 \\ 1448 & 9281 \\ 1285 & 9930 \\ .35 & 647 \\ 1021 & 11616 \\ 1129 & 10822 \\ 1469 & 10941 \\ 1982 & 13569 \\ 990 & 7744 \\ 1667 & 9956 \\ 1165 & 8327\end{array}$


D0ิ

NUMBER

COMMENTS ON DEAD DOGS

F0954. 0

M10S4.0

F1154.0

$M 1254.0$

F01S5.0

$M O 2 S 5.0$

M0255.0.4

MO355:O

F0455.0

$M 0555.0$

$M 0655.0$

190655.04

F0755.0

F0855.0

F0955.0

MIOS5.0

F1155.0

$M 1255.0$
OSTEOSARCOMA

STRANGULATED INGUINAL HERNIA

OSTEOSARCOMA

CSTEOSARCOMA

OSTEOSARCOMA

SEVERE ANEMIA, AUTOAGGLUTINATICN, INFARCT ION, SPLENOMEGALY INTE STI NAL HEMORRHAGE

OSTEOSARCOMA INFARCTION * THROMBOCYTOPENIA

STATUS EPILEPTICUS

OSTEOSARCOMA

SQUAMOUS CELL CARCINOMA ARISING FROM FRONTAL SINUS

SEVERE ANEMIA + THROMBOCYTOPENIA

HEMANG I OSARCOMA (LEFT MANDIBLE)

HEMANG I OSARCOMA (RIB) 
A. RADIUM-226*

D)

NUY BER

TO1R5.0

TO2R 5.0

TO3R.5.0

TO4P 5.0

TOSR 5.0

TOSR 5.0

TO7? 5.0

TO8R 5.0

TO9R 5.0

TIOR 5.0

$T 11 R 5.0$

T12R 5.0

T13R 5.0
AT INJECTION AGE WEIGHT (DAYS) (KG)

INJECTED

$(\mu \mathrm{C} / K G)$

DATE
INJECTED

D MO YR $31 / 3 / 65$ DEATH

11252

12.01 .53

120153

$\begin{array}{llll}6 & 07.53\end{array}$

$6 \cdot 10: 53$

$6 \cdot 10 \cdot 53$

$6 \quad 10: 53$

$10 \quad 05.55$

$1005 \quad 55$

10.0555

$10.05 \quad 55$

9. 0556

$905 \quad 56$

110756

110756
72
127

2127

DOSE TO. SKELETON

(RADS)

$\begin{array}{rr}1074 & 9469 \\ 1368 & 4724 \\ 428 & 1316 \\ 1 & 24 \\ 1 & 25 \\ 1 & 24 \\ 1 & 25 \\ 58 & 488 \\ 58 & 585 \\ 49 & 293 \\ 49 & 363 \\ 225 & 2707 \\ 188 & 2319\end{array}$

12

183

1147

1226

1219

1330

386

587
380

51.17
13655

12628

11580

12937

3710

5911
$\mathrm{T} 19 \mathrm{R} 5 . \mathrm{OH}$

T2OR 5. OH

T21R5. OH

T22R5.0H

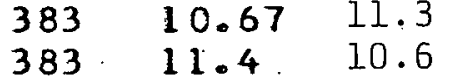

$\begin{array}{lll}381 & 11.8 & 10.1\end{array}$

$381 \cdot 11.9 \quad 10.1$
$28 \cdot 10 \cdot 58$

28.10 .58

$2810 \quad 58$

28.10 .58

$\begin{array}{lll}28 & 10 \quad 58\end{array}$

$28 \cdot 10.58$
1471

1505

1309

1780

1414

$\begin{array}{llll}\text { T23R 4.OH } & 384 & 9.50 & 4.05 \\ \text { T24R 4.OH } & 384 & 11.9 & 3.24 \\ \text { T25R4.OH } & 379 & 11.3 & 3.42 \\ \text { T26R4.OH } & 379 & 11.0 & 3.48 \\ \text { T27R4.OH } & 372 & 11.5 & 3.34\end{array}$

T28R 3. OH
$372 \quad 11.7$

1.11 $\begin{array}{lll}25 & 11 & 58\end{array}$

$\begin{array}{llll}25 & 11 & 58\end{array}$

251158

251158

251158
4340

5593

4672

4719

3382

$\begin{array}{llll}\text { T29R 5.0 } & 474^{\prime} & 13.5 & 10.4\end{array}$

$\begin{array}{lll}3 & 03 & 59\end{array}$

216

3404 
DOG

VUYBER

COMMENTS ON DEAD DOGS

TOLR5.0 TO2R 5.0

TO3R 5.0

TO4R 5.0

TOSR 5.0

TOGR 5.O

TOTR 5.0

TO8R 5.0

TOSR 5.0

TIOR 5.0

TIIR 5.0

$T 12 R 5.0$

TI $13 R 5 . \circ$

T14R 4.0

T15R4.0

T16R5.0

T17R5.0:

T1 $18 R 5.0 \mathrm{OH}$

T19R 5. OH

T2OR 5. OH

$T 21 R 5.0 H$

T22R 5.OH

\begin{abstract}
oSTEOSARCOMA
DSTEOSARCOMA

SPECIAL STUDY SPECIAL STUDY SPECIAL STUDY SPECIAL STUDY. SPECIAL STUDY SPECIAL STUDY SPECIAL STUDY SPECIAL STUDY SPECIAL STUDY SPECIAL STUDY SPECIAL STUDY
\end{abstract}

SPECIAL STUDY OSTEOSARCOMA
T23R 4. OH

T24R 4. OH

$\mathrm{T} 25 \mathrm{R} 4 . \mathrm{OH}$

T26R 4. OH:

T27R 4. OH

SPECIAL STUDY OSTEOSARCOMA * ULCERATIVE GINGIVIT IS OSTEOSARCOMA \& ULCERATIVE. GINGIVITIS DSTEOSARCOMA + ULCERATIVE GINGIVITIS OSTEOSARCOMA + ULCERATIVE GINGIVITIS NEPHRITIS

CRIPPLING FRACTURES
OSTEOSARCOMA

OSTEOSARCOMA

OSTEOSARCOMA

OSTEOSARCOMA

OSTEOSARCOMA

T28R 3. OH SPECIAL STUDY

T29R5.0 NEPHRITIS

T29R5.0 NEPHRIIIS 


\section{Dof}

NUYBER

T30R. 5.0

T3IR 5.0
AT INJECTION AGE WEIGHT (DAYS) (KG)

INJECTEO

474. 11.5

$471 \cdot 10.5$
DATE INJECTED $(\mu \mathrm{C} / K G)$

D MO YR 31/3/65 DEATH

DAYS SINCE

30359

$\begin{array}{lll}3 & 0 & 59\end{array}$

178

303

2851

4758
2220

$$
\begin{array}{ll}
11.4 & 1.13 \\
10.6 & 1.15 \\
15.7 & 1.12 \\
9.44 & .9 .51
\end{array}
$$

T35R 3.0J

670

$\begin{array}{rr}1822 & 1921 \\ 1737 & 1603 \\ 8 & 14\end{array}$

$\begin{array}{lll}3 & 3 & 59\end{array}$

$\begin{array}{lll}3 & 3 & 59\end{array}$

5. 559

22. $12 \cdot 60$

$22 \quad 12 \quad 60$

$22 \quad 12: 60$

1560

1154

1503

3657
T4OR 1.

THIR 1:0
899

899
13.0

12.7

$$
.0483
$$

.0487
T $42 R 1.7$
T43R 1.7

967
963

14.0

13.2

.146
.145

11.1 .

13.6

12.5
.937

. $9: 41$

.928
T 4683.0
3462

3. $4: 62$

4. 4.62

4.462 .
4. $4: 62$

54.62

54.62
7

63

7
64

68

7

69

11. 6.62

27.12 .62
4

49
DOSE TO

SKELETON

(RADS)

99

$5.27 \quad 29.04$

TH8R 6.0: 2842 11.2: 25.1
.352 15.97
T49R 5.0 TSOR 5.0 $T 51 R 5.0$ TS2R 5.0

$\begin{array}{lll}485 & 10.6 & 7.54 \\ 485 & 13.7 & 7.46 \\ 418 & 13.3 & 8.48 \\ 418 & 10.7 & 8.57\end{array}$

$10.6-7.54$

$13.3 \quad 8.48$

10.7

8.57
111 274 1689 258 
DOG

T3OR 5.0

T 31R 5.0

$T 32 R 3.0$

$T 33 R 3.0$

T34R 3.0

T35R 3. OJ

$T 36 R 4.0$

$T 37 R 4.0$

$T 38 R 4.0$

T4OR 1.0

T41R1.0

T42R 1. 7

T43R 1. 7

T 44R 3.0

T45R 3.0

T 46R 3.0

T $47 R 6.0$

$T 48 R 6.0$

T49R 5. 0

TSOR 5. 0

TS1R 5. 0

T S2R 5.0
NEPHRITIS

NEPHRI TIS

OSTEOSARCOMA, NEPHRITIS

OSTEOSARCOMA

SPECIAL STUDY

OSTEOSARCOMA

OSTEOSARCOMA

SPECIAL STUDY

SPECIAL STUDY

SPECIAL STUDY

SPECIAL STUDY

SPECIAL STUDY SPECIAL STUDY SPECIAL STUDY

SPECIAL STUDY LEUKOPENIA, PNEUMONIA +.SPECI AL MELANOMA STUDY

SPECIAL STUDY SPECIAL STUDY SPECIAL STLDY SPECIAL STUDY 


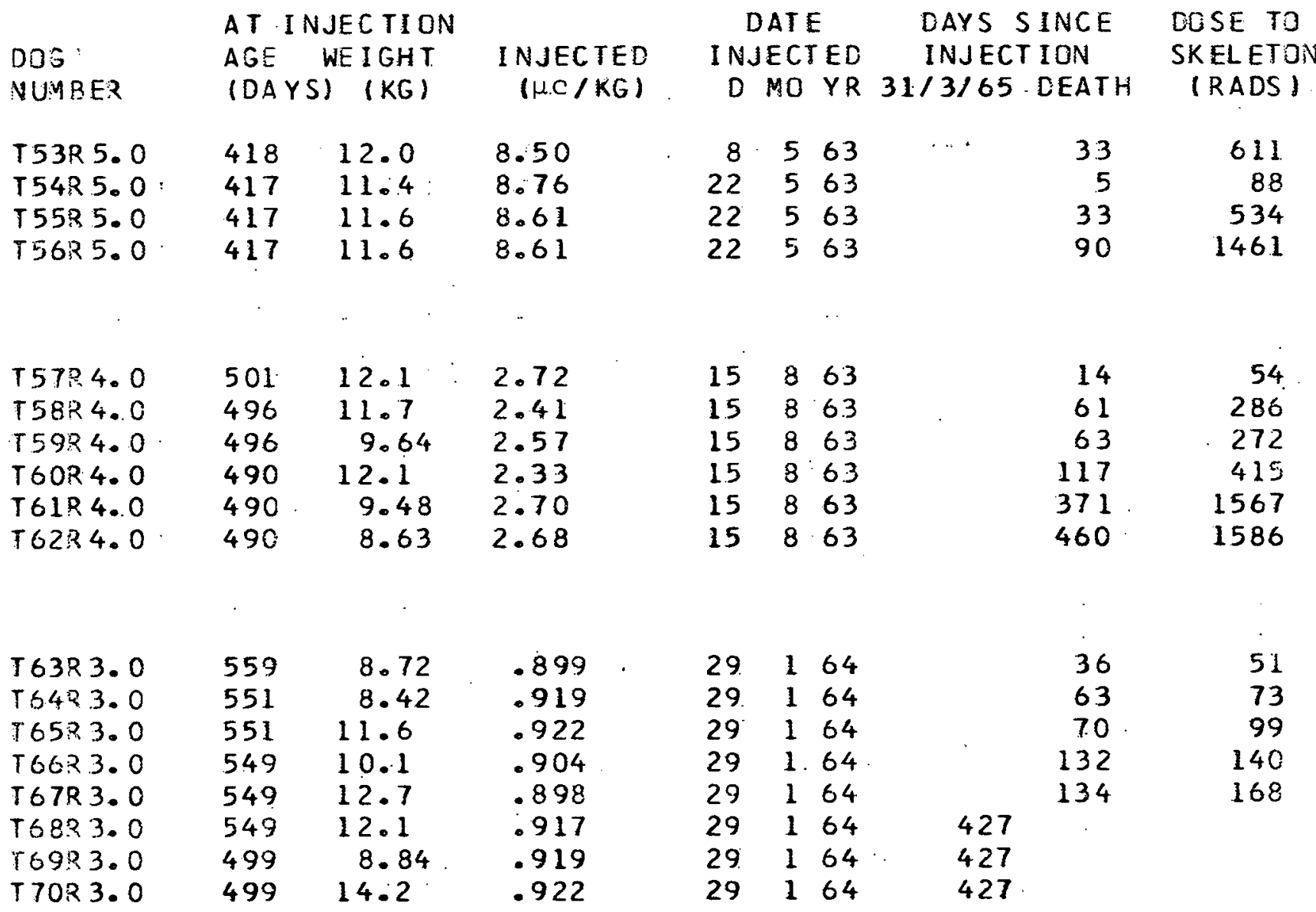

* The multiple injection dogs were male beagles born in Davis, California but injected in our laboratory. Each was injected 6 times over a 280 day period with 56 days between each injection. Each $\operatorname{Ra}^{226}$ injection was $20.0 \mu \mathrm{c}$ for the dogs Tl7R5H - T22R5H; $6.41 \mu \mathrm{C}$ for T23R4H - T27R4H; and $2.16 \mu \mathrm{c}$ for T28R3H. Tabulated for each dog are his age at lst injection, his average weight during the injection period, total $\mu \mathrm{c} /$ average weight, the date of lst injection, the time from lst injection to death, and sum of the skeletal doses computed from each injection to death.

T35R3J also received $99 \mu \mathrm{C} \mathrm{Sr}^{85}$.

T39R0.0 has been reassigned and is now Ml2M0.0. 
D05

NUMBER

T53R 5.0

TS4R 5.0

T S5R 5.0

T S6R 5. O

T57R 4.0

T $58 R 4.0$

TS 5 R. 0

T $60 R 4.0$

T61R4.0

$T 62 R 4.0$

T63R 3.0

T 64R 3.0

T65R 3.0

T66R 3.0

T67R 3.0

T $68 R 3.0$

T69R 3.0

T TOR 3. O.

\section{COMMENTS ON DEAD DOGS}

\begin{abstract}
SPECIAL STUDY SPECIAL STUDY SPECIAL STUDY SPECIAL STUDY
\end{abstract}

SPECIAL STUDY SPECIAL STUDY SPECIAL STUDY SPECIAL STUDY SPECIAL STUDY SPECIAL STUDY

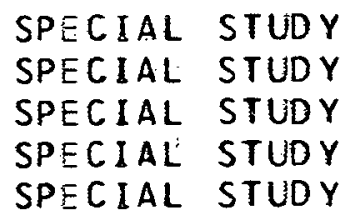

SPECIAL STUDY 
B: PLUTONIUM-239

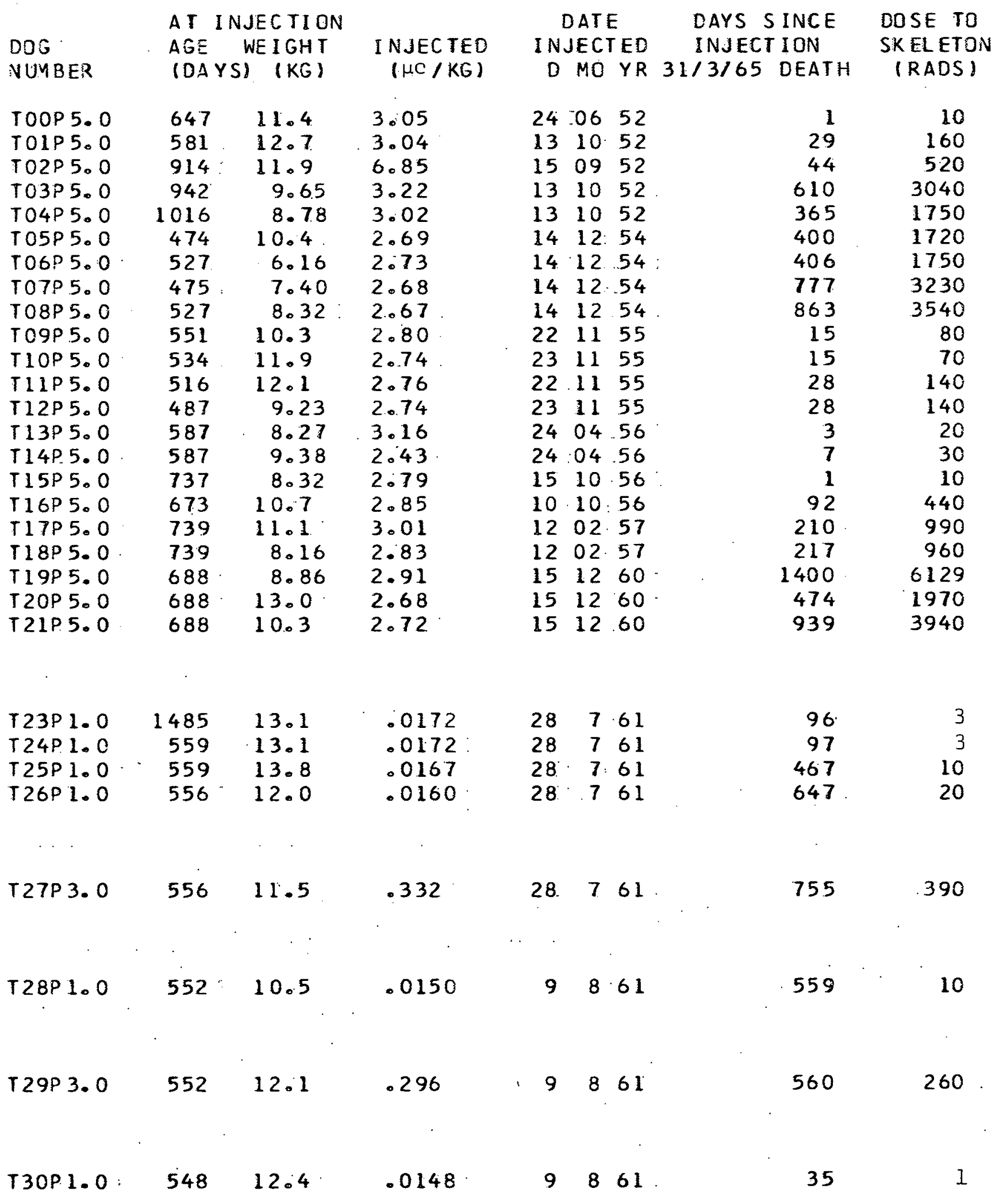


DOS

NUMBER

COMMENTS ON DEAD DOGS

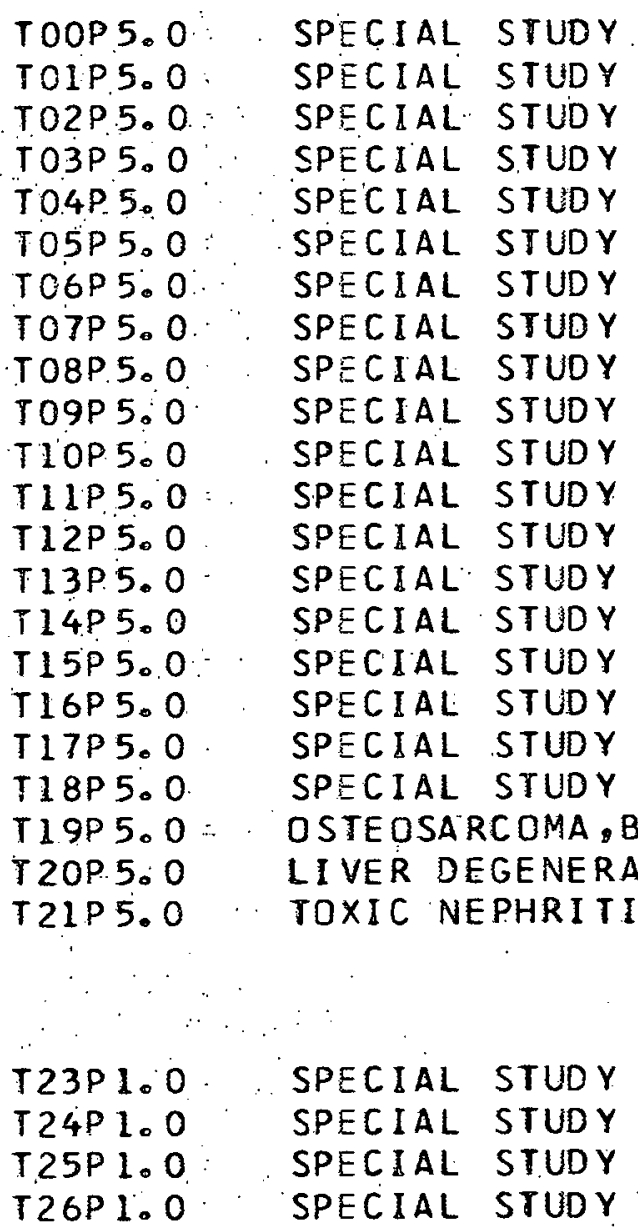

T27P3.0 0 SPECIAL STUDY

T28P1.0 SPECIAL STUDY

T29P3.0 : SPECIAL STUDY.

T3OP 1.0 SPECIAL STUDY 


\begin{tabular}{|c|c|c|c|c|c|c|c|c|c|}
\hline $\begin{array}{l}\text { DOG } \\
\text { NUYBER }\end{array}$ & $\begin{array}{l}\text { A T } \\
A G E \\
\text { IDA }\end{array}$ & $\begin{array}{l}\text { JEC TI ON } \\
\text { WE I GHT } \\
ر .(K G)\end{array}$ & $\begin{array}{c}\text { I NJEC TED } \\
(\mu C / K G)\end{array}$ & & $\begin{array}{l}A T \text { I } \\
\text { ECI } \\
\text { MO }\end{array}$ & $\begin{array}{l}\text { ED } \\
Y R\end{array}$ & $\begin{array}{r}\text { DAYS } \\
\text { INJEC } \\
31 / 3 / 65\end{array}$ & $\begin{array}{l}\text { INCE } \\
\text { ION } \\
\text { DEATH }\end{array}$ & $\begin{array}{l}\text { DOSE TO } \\
\text { SKELETON } \\
\text { (RADS) }\end{array}$ \\
\hline T31P 3.0 & 519 & 13.0 & .305 & 9 . & 8 & 61 & & 40 & 20 \\
\hline $\begin{array}{l}T 32 P 1.0 \\
T 33 P 1.0 \\
T 34 P 1.0\end{array}$ & $\begin{array}{l}520 \\
550 \\
550\end{array}$ & $\begin{array}{c}8.47 \\
10.7 \\
9.68\end{array}$ & $\begin{array}{l}.0162 \\
.0153 \\
.0154\end{array}$ & $\begin{array}{l}9 \\
15 \\
15\end{array}$ & $\begin{array}{l}8 \\
9 \\
9\end{array}$ & $\begin{array}{l}61 \\
61 \\
61\end{array}$ & & $\begin{array}{l}274 \\
375 \\
746\end{array}$ & $\begin{array}{l}10 \\
10 \\
20\end{array}$ \\
\hline T 35P 3.0 & 550 & 11.9 & .303 & 15 & 9 & 61 & & 362 & 180 \\
\hline $\begin{array}{l}T 36 \mathrm{P} 1.0 \\
\text { T } 37 \mathrm{P} 1.0\end{array}$ & $\begin{array}{l}544 \\
542 .\end{array}$ & $\begin{array}{l}10.4 \\
8.59\end{array}$ & $\begin{array}{l}.0158 \\
.0148\end{array}$ & $\begin{array}{l}15 \\
15\end{array}$ & $\begin{array}{l}9 \\
9\end{array}$ & $\begin{array}{l}61 \\
61\end{array}$ & & $\begin{array}{r}5 \\
186\end{array}$ & 4 \\
\hline T38P 3.0 & 489 & 7.96 & .304 & 15 & 9 & 61 & & 187 & 90 \\
\hline $\begin{array}{l}\text { T39P 1.0 } \\
\text { T } 40 P 1.0\end{array}$ & $\begin{array}{l}1534 \\
1534\end{array}$ & $\begin{array}{c}10.7 \\
9.92\end{array}$ & $\begin{array}{l}.0151 \\
.0177\end{array}$ & $\begin{array}{l}15 \\
15\end{array}$ & $\begin{array}{l}9 \\
9\end{array}$ & $\begin{array}{l}61 \\
61\end{array}$ & & $\begin{array}{l}376 \\
769\end{array}$ & $\begin{array}{l}10 \\
20\end{array}$ \\
\hline $\begin{array}{l}\text { T } 41 P 5.0 \\
\text { T } 42 P 5.0\end{array}$ & $\begin{array}{l}543 \\
51.0\end{array}$ & $\begin{array}{r}8.50 \\
11.4\end{array}$ & $\begin{array}{l}3.01 \\
2.40\end{array}$ & $\begin{array}{l}30 \\
10\end{array}$ & $\begin{array}{r}11 \\
2\end{array}$ & $\begin{array}{l}64 \\
65\end{array}$ & 121 & 13 & 57 \\
\hline
\end{tabular}

$\mathrm{T} 22 \mathrm{P0} .0$ has been reassigned and is now F06T0.0A. 
DOG

NUMBER

T31P3.0 SPECIAL STUDY

T32P1.0

T33P 1.0

T34P.1.0

T35P3.0

T36P1.0

T3TP1.0

$T 38 P 3.0$

T39P1.0

THOP.1.0

$T 41 P 5.0$

T42P5.0
SPECIAL STUDY SPECIAL STUDY

SPECIAL STUDY SPECIAL STUDY SPECIAL STUDY

SPECIAL STUDY

SPECIAL STUDY

SPECIAL STUDY

SPECIAL STUDY 
C. RADIUM-228 (MESOTHORIUM) *

\begin{tabular}{|c|c|c|c|c|c|c|c|c|c|}
\hline $\begin{array}{l}\text { DOG } \\
\text { NUYBER }\end{array}$ & $\begin{array}{l}\text { AT INJ } \\
\text { AGE W } \\
\text { (DAYS) }\end{array}$ & $\begin{array}{l}E C T I O N \\
E I G H T \\
(K G)\end{array}$ & $\begin{array}{c}\text { INJECTED } \\
(\mu C / K G)\end{array}$ & IN & $\begin{array}{l}\text { ATE } \\
\text { JECT } \\
\text { MO }\end{array}$ & $\begin{array}{l}\text { TED } \\
\text { YR }\end{array}$ & $\begin{array}{r}\text { DAYS } \\
\text { INJEC } \\
31 / 3 / 65\end{array}$ & $\begin{array}{l}\text { SINCE } \\
\text { TION } \\
\text { DEATH }\end{array}$ & $\begin{array}{l}\text { DOSE TO } \\
\text { SKELETON } \\
\text { (RADS) }\end{array}$ \\
\hline $\begin{array}{l}\text { TO1M4.5 } \\
\text { T02M4.5 }\end{array}$ & $\begin{array}{l}529 \\
463\end{array}$ & $\begin{array}{l}9.13 \\
8.93\end{array}$ & $\begin{array}{l}4.23 \\
4.27\end{array}$ & $\begin{array}{l}8 \\
8\end{array}$ & $\begin{array}{l}09 \\
09\end{array}$ & $\begin{array}{l}54 \\
54\end{array}$ & & $\begin{array}{l}314 \\
755\end{array}$ & $\begin{array}{l}1598 \\
5097\end{array}$ \\
\hline T03M5.0 & 579 & 9.15 & 10.6 & 13 & 03 & 56 & & 700 & 15867 \\
\hline
\end{tabular}


$-53-$

000

NUMBER

$\operatorname{TO} 14_{4} .5$

T.02M4.5

T03M 5. O
COMMENTS ON DEAD DOGS

CANINE DISTEMPER

SPECIAL STUDY

ULCERATIVE GINGIVITIS, SEVERE ANEMIA \& CRIPPS ING FRACTURE 
D. THORIUM-228 (RADIOTHORIUM)

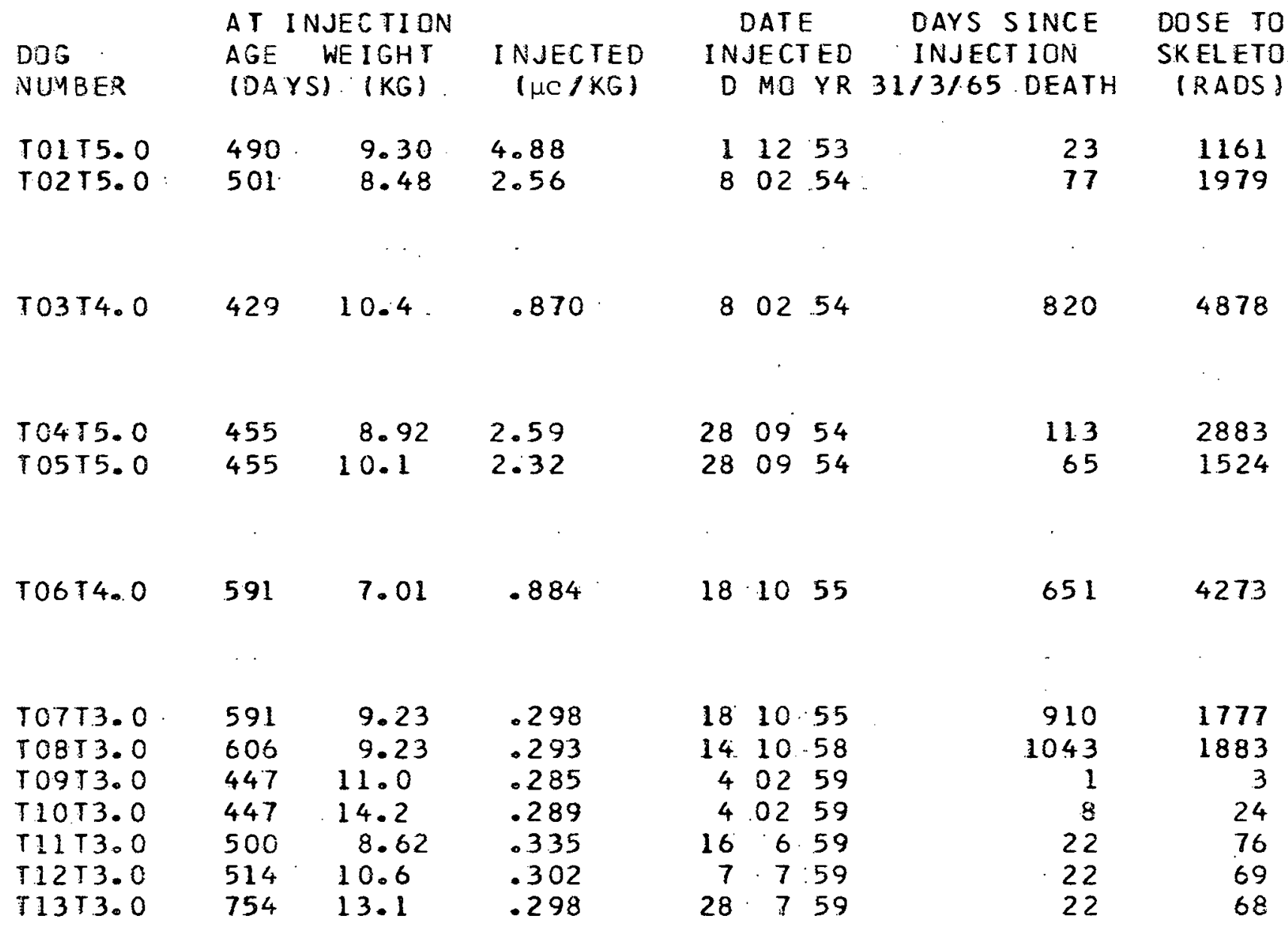

${ }^{*} \mathrm{~T} 1 \mathrm{l}, 12,13 \mathrm{~T} 3$ received 40,4 , and $0.4 \mathrm{mg} \mathrm{Th}^{232}$, respectively. 
DOo

IUMBER

COMMENTS ON DEAO DOES

TO1T5.0

DIED, SPECIAL STUDY

TO2T5.O SPECLAL STUDY

TO3T4.0 CRIPPLING FRACTURES + NEPHRITIS

T04T5.0

THROMBOC YTOPENIA + PURPURA

TO5T5.0

NEPHRITIS, THROMBOCYTOPENIA + PURPURA

TOST4.0

CRIPPLING FRACTURES

T07T3.0

SPECIAL STLOY

$108 \div 3.0$ OSTEOSARCOMA

10973.0 SPECIAL STLDY

12073.0

SPETIAL STLDY

T11T3.0

SPECIAL STUDY

$T 12 T 3.0$

SPECIAL STUDY

T13T3.0

SPECIAL STUOY 
E. STRONTIUM-90

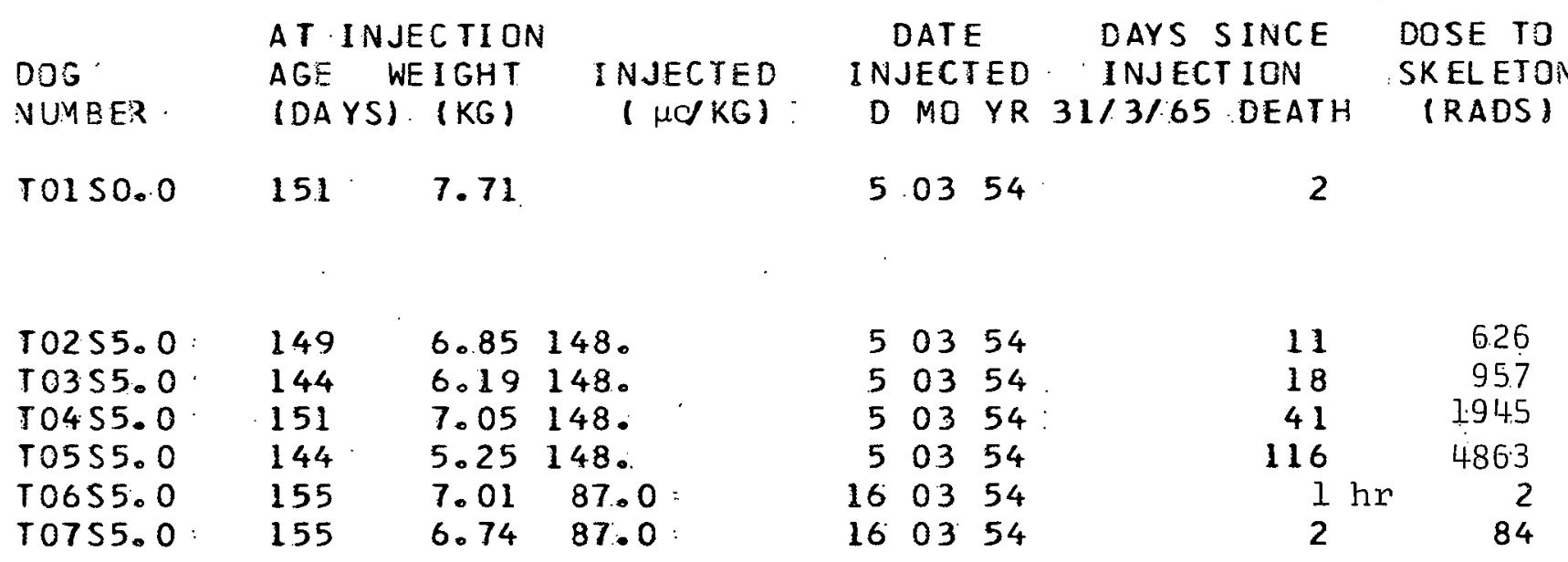

T0850.0 $243 \quad 7.00$

$\begin{array}{llllllll}\text { TO8S2.OH } & 67 & 3.69 & 2.74 & 27.0955 & 66 & 31 \\ \text { TO9S2.OH } & 67 & 2.79 & 3.62 & 27.09 .55 & 66 & 40 \\ \text { T1OS2.OH } & 67 & 3.11 & 3.25 & 27.0955 & 132 & 93 \\ \text { T11S2.OH } & 67 & 3.85 & 2.62 & 27.0955 & 132 & 75\end{array}$

$\begin{array}{llll}T 12 S 3.0 & 593 \quad 10.6 & 10.5\end{array}$

110957

5

15

$\begin{array}{llll}T 1354.0 & 324 & 10.5 & 19.1\end{array}$

80760

8

50

T14S5.0

$542 \quad 10.0 \quad 96.1$

$\begin{array}{llll}T 15 S 5.0 & 595 & 9.43 \quad 98.4\end{array}$

$\begin{array}{lll}7 & 11 & 61\end{array}$

71161

175

9
30

423

T16S2.0 604 $9.71 \ldots .3 .27$

$8 \cdot 11 \cdot 61$

9

6

T17S6.0 $670 \quad 7.18295$.

T18S6.0 $670 \quad 5.94: 302$.

$19 \quad 1 \quad 62$

$19162 \quad 1167$

14

689 
DOG

NUMBER

COMMENTS GN DEAD DOGS

TO1S0.0 SPECIAL STUDY

T0255.0

SPECIAL STUDY

10355.0

10455.0

SPECIAL STUDY

SPECIAL STUDY

TO555.0

10655.0

SPECIAL STUDY

T0755.0

SPECIAL STUDY

SPECIAL STUDY

TOBS 0 SPECIAL STUDY

TO8S2.04. SPECIAL STUDY TO9S2.0H SPECIAL STUDY

TIOS2.OH SPECIAL STUDY

TIIS2.OH SPECIAL STUDY

T1253.0 BREMSSTRAHLUNG PHANTOM

T1354.0 BREMSSTRAHLUNG PHANTOM SAM MCGEE

T14S5.0 SPECIAL STUDY

T15S5.0 SPECIAL STUDY

T16S2.0 SPECIAL STUDY

T1756.0

LEUKOPENIA, THROMBOCYTOPENIA + PURPURA

11856.0 


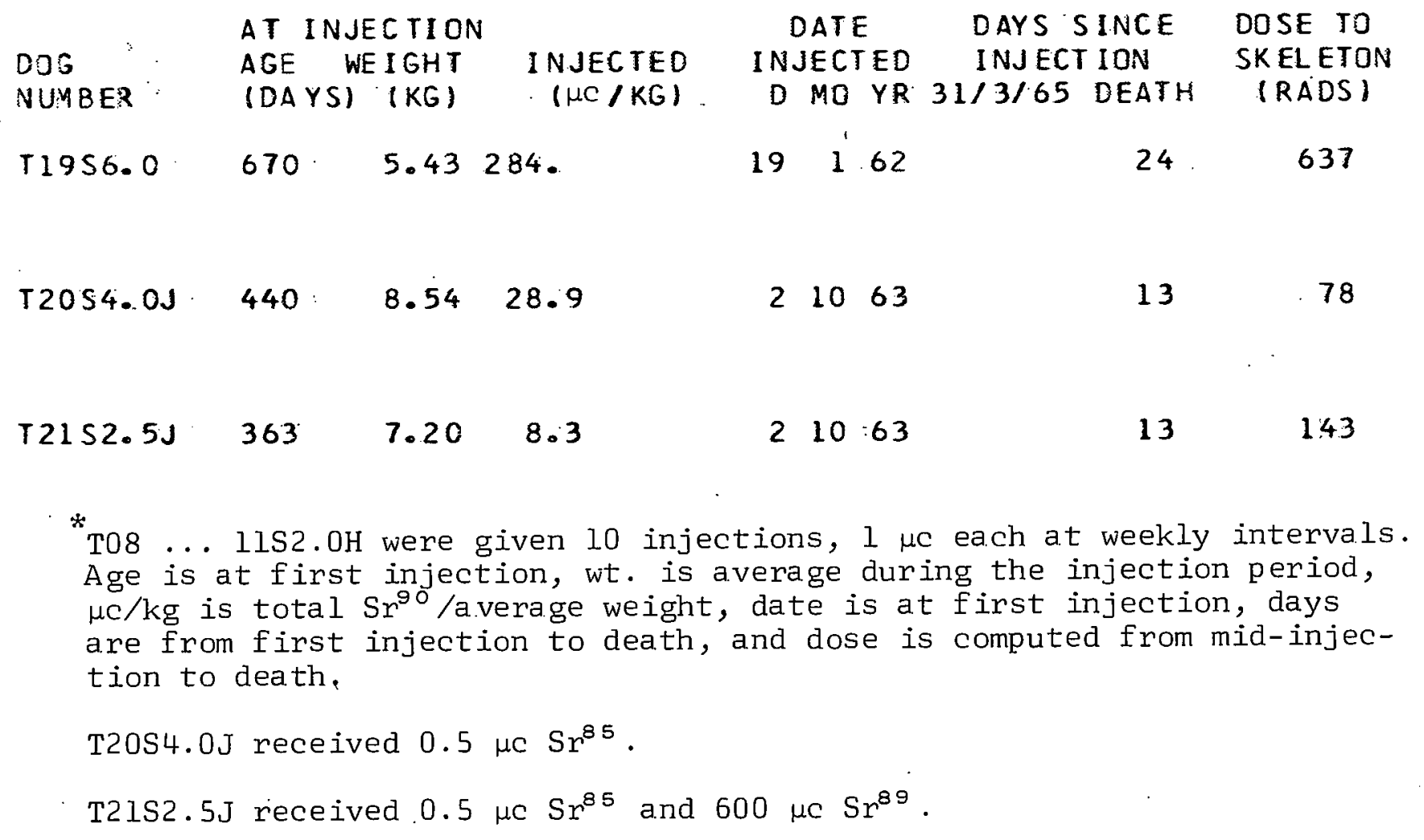


$-59-$

DOS.

NUMBER

COMMENTS ON DEAD DOGS

T19S6.0

LEUKOPENIA. THROMBOCYTOPENIA + PURPURA

T20S4. OJ SPECIAL STUDY

T21S2.5J SPECIAL STUDY: 
F. RADIUA-224

\begin{tabular}{|c|c|c|c|c|c|c|c|c|c|}
\hline $\begin{array}{l}\text { DOG } \\
\text { NUMBER }\end{array}$ & $\begin{array}{l}\text { AT INJ } \\
\text { AGE } \\
\text { (DAYS) }\end{array}$ & $\begin{array}{l}\text { JECTION } \\
\text { WEIGHT } \\
(K G)\end{array}$ & $\begin{array}{l}\text { INJEC TED } \\
(\mu C / K G)\end{array}$ & $\begin{array}{l}\text { IN } \\
\therefore \quad \text { D }\end{array}$ & $\begin{array}{l}\text { DAT } \\
\text { JEC } \\
\text { MO }\end{array}$ & $\begin{array}{l}E \text { TED } \\
Y R\end{array}$ & $\begin{array}{r}\text { DAYS S } \\
\text { : INJECT } \\
31 / 3 / 65\end{array}$ & $\begin{array}{l}\text { SINCE } \\
\text { ION } \\
\text { DEATH }\end{array}$ & $\begin{array}{l}\text { OOSE TO } \\
\text { SKELETON } \\
\text { IRADS I }\end{array}$ \\
\hline TO1Q3.0J & 460 & .9 .55 & .875 & 26 & 3 & 63 & & $.4 \mathrm{hr}$ & \\
\hline $\begin{array}{l}\text { TO2Q4.0 } \\
\text { T03Q4.0 }\end{array}$ & $\begin{array}{l}466 \\
466\end{array}$ & $\begin{array}{l}12.0 \\
13.1\end{array}$ & $\begin{array}{l}2: 91 \\
2.91\end{array}$ & $\begin{array}{l}27 \\
27\end{array}$ & $\begin{array}{l}3 \\
3\end{array}$ & $\begin{array}{l}63 \\
63\end{array}$ & $\begin{array}{l}735 \\
735\end{array}$ & & \\
\hline $\begin{array}{l}\text { TO4Q 5.0 } \\
\text { T0505.0 }\end{array}$ & $\begin{array}{l}480 \\
455\end{array}$ & $\begin{array}{r}9.55 \\
9.67\end{array}$ & $\begin{array}{l}9.71 \\
9.59\end{array}$ & $\begin{array}{l}24 \\
24\end{array}$ & $\begin{array}{l}4 \\
4\end{array}$ & $\begin{array}{l}63 \\
63\end{array}$ & $\begin{array}{l}707 \\
707\end{array}$ & & \\
\hline TO6Q6.0 & 455 & 8.29 & 24.6 & 17 & 10 & .63 & & 13 & 980 \\
\hline $\begin{array}{l}\text { TO } 0725.0 \\
\text { T0805.0 }\end{array}$ & $\begin{array}{l}465 \\
475\end{array}$ & $\begin{array}{r}11.8 \\
9.77\end{array}$ & $\begin{array}{l}9.83 \\
9.91\end{array}$ & $\begin{array}{l}6 \\
6\end{array}$ & $\begin{array}{l}11 \\
11\end{array}$ & $\begin{array}{r}63 \\
.63\end{array}$ & 511 & 16 & 400 \\
\hline $\begin{array}{l}T 0924.0 \\
T 10 Q 4.0\end{array}$ & $\begin{array}{l}503 \\
503\end{array}$ & $\begin{array}{l}9.80 \\
10.3\end{array}$ & $\begin{array}{l}2.96 \\
2.96\end{array}$ & $\begin{array}{r}4 \\
-\quad 4\end{array}$ & $\begin{array}{l}12 \\
12\end{array}$ & $\begin{array}{l}63 \\
63\end{array}$ & 483 & 262 & 133 \\
\hline $\begin{array}{l}T 11 Q 3.0 \\
T 12 Q 3.0 \\
T 13 Q 3.0 \\
T 14 Q 3.0\end{array}$ & $\begin{array}{l}495 \\
495 \\
495 \\
438\end{array}$ & $\begin{array}{l}9.10 \\
13.5 \\
11.3 \\
10.3\end{array}$ & $\begin{array}{l}1.02 \\
1.02 \\
1.02 \\
1.00\end{array}$ & $\begin{array}{l}4 \\
4 \\
4 \\
4\end{array}$ & $\begin{array}{l}12 \\
12 \\
12 \\
12\end{array}$ & $\begin{array}{l}63 \\
63 \\
63 \\
63\end{array}$ & $\begin{array}{l}483 \\
483 \\
483 \\
483\end{array}$ & . & \\
\hline
\end{tabular}


DOG

NUMBER -

TOIQ3.DJ' SPECIAL STUDY

T02Q4.0

$103 Q 4.0$

T04Q5.0

T05Q5.0

TO6Q6:0 : PURPURA HEMORRHAGICA

TO7Q5:0

$10825.0=$

T09Q4.0

T10Q4.0

STA TUS. EPILEPTICUS

T11Q3.0

$T 1203.0$

T13Q3.0

T14Q3.0 : 
G. ANCI LLARY

DOS

NUMBER

F OL:A O.O 0

F 02A O. 0

MOSAO.O

M O4A: O:O

MOSAO.O

MOGAO.O

MOTAO.O

MO8A 0.0

F09A 0.0

FIOA 0.0

F11A0.0

F I2A0.0

F13A0.0

F14A0.0

F16A0.0

F17A0.0

F19A0.0

F20A0.0

M23AO. 0

M 24A 0.0

M26A0.:0

M27A0. 0

M28A0.0

F 32A0.0

F 33A0.0

F34A0. 0

M 35 A 0.0

M 36A0. 0

M 37A0. 0

$M 42 A 0.0$

F $43 A 0.0$

F 47A0. 0

MSOAO. 0

F $51 A 0.0$

F52A0.0

F54A0.0

MSGAO. 0

MS8A0.0

MS9A0. 0

M73A0.0

Y $86 A 0.0$
AT INJECTION

AGE WEIGHT INJECTED

(DAYS) : (KG) $\begin{array}{lc}\text { DATE } & \text { DAYS SINCE } \\ \text { INJECTED } & \text { INJECT ION } \\ \text { D MO YR } & 31 / 3 / 65 \text { DEATH }\end{array}$

DOSE TO

SKEL ETON

(RADS)
1383

2492

1451

3345

4713

5266

3896

3746

3719

2605

4198

4219

4527

3777

4415

2145

4166

2464

1741

3074

4133

2130

3114

1990

3282

25.84

529

1971

4089

1265

3881

1732

2264

1089

509

3190

701

767

567

569.5

499

*Time interval shown here is the animal's age. 
DOG

NUMBER COMMENTS ON DEAD DOGS

FO1A0.:0

F02A0. 0 MOZAO. 0 MO4AO.O MO5AO.O MOSA O. 0 MOTAO. 0 M O8A O. 0 FO9AO. 0 F10A0.0 FIIAO.O F12AO.O F13A0.0 F $14 A 0: 0$ F16AO. 0 F17A0.0 F 19A0.0 0 F 2OAO. 0 M.23A0. 0 M24A 0. 0 M 26A0.0 M27A0. 0 M 2840.0 F 32A 0. 0 F 33A 0. 0 F 34A 0. 0 M 35A 0.0 M 36A0.0 M37A 0.0 $M 42 A 0.0$ F $43 A 0.0$ F47A 0. 0 M SOA O.O F51AO.O F52A 0. 0 F 54 A O. 0 MSEAO. 0 M58A0.0 M5940.0 M 73AO.O M 86A O. 0
SPECIAL STUDY SPECIAL STUDY SPECIAL STLDY NOT DE IERMINED TRANS ITIONAL CELL CARC INOMA， NEPHRITIS, PNEUMONIA BRAIN HEMORRHAGE L. YMPHOSARCOMA PROGRESSIVE PARALYSIS, CAUSE UNKNOWN VAG INAL FIBROMA SPECIAL STUDY MAMMARY CARCII NOMA SE VERE OSTEDARTHRITIS SPECIAL STUDY OBTURATING EMBOLISM OF PORTAL VEIN SPECIAL STUDY JRA UMA

MAMMARY GLANO CARCI NOMA

SPECIAL STUDY

OBTURATING: PULMONARY EMBOLISM

SPECIAL STUDY

SEMINOMA

SPECIAL STUDY

SPECIAL STUDY LYMPHOSARC OMA

OB TURA TING: PULMONARY EMBGLISM

SPECIAL STUDY

SPECIAL STUDY

SPECIAL STUDY

SPECIAL STUDY

STATUS EPILEPTICUS

SPECIAL STUDY

SPECIAL STUDY

SPECIAL STUDY

SPECIAL STUDY

SPECIAL STUDY

SPECIAL STUDV

VOL VULUS + PERITONITIS

SPECIAL STUDY

SPECIAL STUDY

DEGENERATION OF ADRENAL GLAND + DIABETES MELL ITUS SPECIAL STUDY 
CURRENT CENSUS OF THE BEAGLE COLONY

March 31, 1965

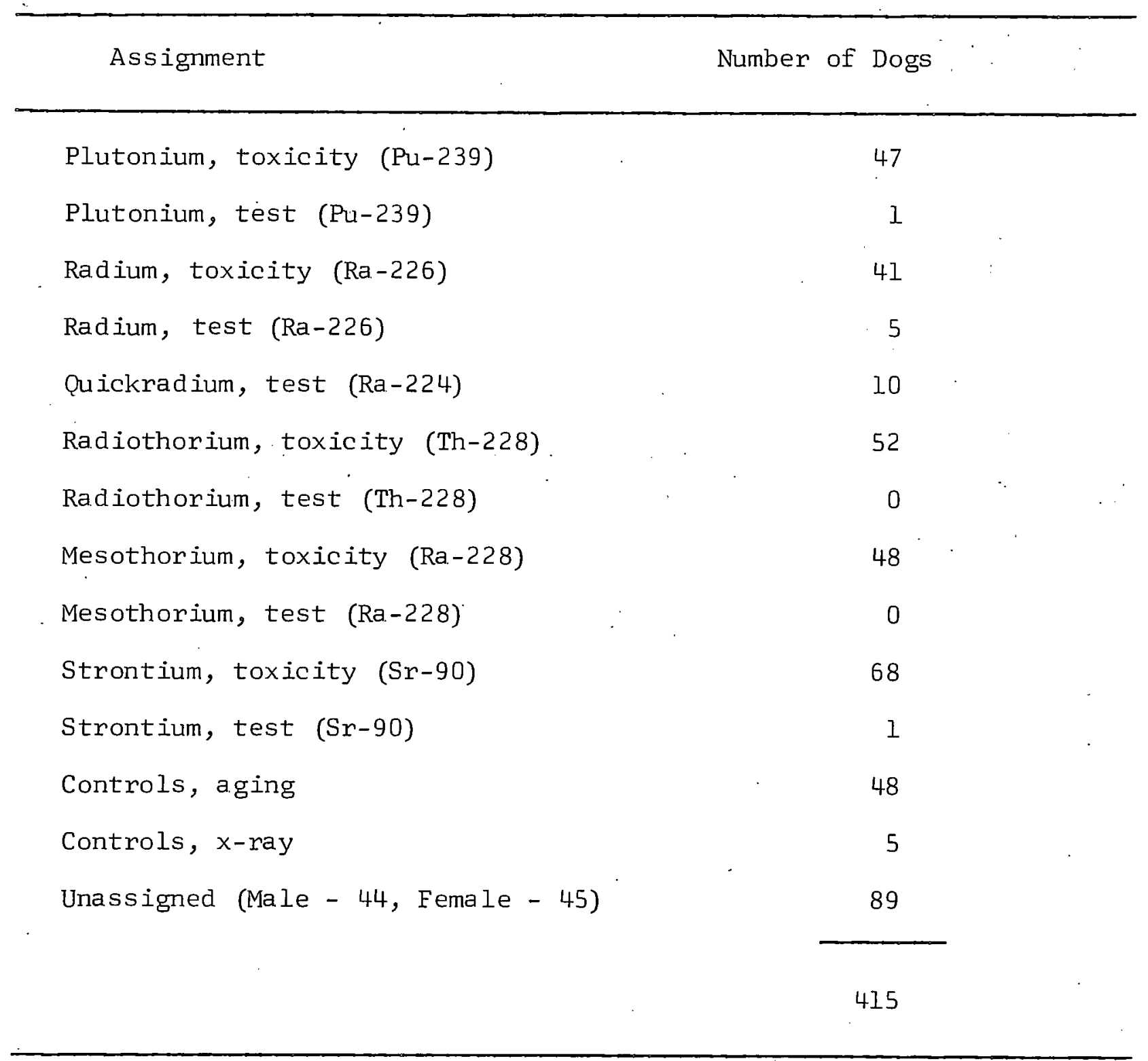


THE USE OF THERAPY IN EXPERIMENTAL ANIMALS

G. N. Taylor

\begin{abstract}
The use of prophylactic treatment and therapy in our large beagle colony is on much the same basis as would be expected in a human or veterinary practice and has been a significant factor in minimizing losses and variation from non-radiation induced factors. It has been indispensable in achieving the maximum life span in a high percentage of our animals. Also, it has been a significant feature in providing the most humane care for our colony.
\end{abstract}

Prophylactic and therapeutic care constitute one of the important aspects in the management of the large beagle colony at this laboratory. Such treatment has proved to be compatible with the objectives of our studies and has reduced the losses and variations that arise from naturally occurring diseases and accidental factors. Longevity is an important item in our investigation and the costliness of premature death from extraneous causes is obvious--especially in animals that have been observed for five to ten years. An additional consideration in our use of therapy is the manner in which it has facilitated humane treatment. It is very unlikely that such therapy and prophylaxis have influenced the pathogenesis of the radiation induced syndrome.

The prophylactic phase of our colony management has many facets, but two of the most important are isolation and immunization. A relatively isolated environment has been achieved by strict control of human and outside animal contact--especially dogs, the inclusion of a beagle breeding colony within the confines of our laboratory has been fundamental in this regard by removing the hazard of introducing outside animals, which in some instances can be analogous to the "Trojan horse". It has also provided us with a more uniform colony of known genotype, 
age and clinical history. The most serious gap in our environmental isolation and the most difficult to control is the presence of vermin. However, thus far, these agents have been kept to low numbers by the frequent application of high pressure steam, window and door screens, etc., and a high degree of cleanliness withị the kennel. Insecticides, etc., are not used in the proximity of the colony.

Oun immunization procedures are directed toward canine distemper, infectious canine hepatitis, and two strains of leptospirosis, three of the more common canine diseases. The respective antigens are given three times during the first year and annually, thereafter. Passive immunization is given if a severe challenge is suspected. Losses from these conditions are rare.

Closely related to the prophylactic procedures in our colony management is the provision of therapy. The indications include infections--usually non-contagious, trauma, neoplasia, senility, etc. Many of these are non-radiation induced and constitute fortuitous variables. However, their significance can oftentimes be markedly reduced by treatment and with a few exceptions it is the policy at this laboratory to employ such therapy. It can be argued that this in itself constitutes a variable", but we like' to think that our treatments are a little less severe than the disease; that a brief course of antibiotics as the alternative to a serious infection is the lesser of two evils. Based on this assumption, we treat most disease syndromes in much the same manner as they would be managed in a private veterinary hospital, including the use of well established drugs and surgical procedures. One of the most important indications for surgery has been the removal of soft tissue tumors--the incidence of which increases abruptly 
beyond six to seven years of age. We do not feel that this obscures any pertinent endpoints since the procedures can oftentimes be performed with few consequences and since our principal interest is in the incidence, the type of tumor, and its latent period--not its growth pattern, etc. We gain this information as long as the excised tissues are evaluated histologically.

A drug that is employed routinely, not therapeutically but for restraint purposes, is sodium pentothal*. It is used primarily in conjunction with radiology and whole body counting procedures. Serious compromises in certain aspects of our program would be necessary if this or a similar general anesthetic could not be used. Clinical, hematological, and blood chemistry studies have not indicated any measurable residual effects from this agent.

Notable exceptions in our use of therapy are bone tumors and radiation induced fractures. These are not treated except for the provision of individual housing, supportive therapy, and analgesics. Radiation induced blood dyscrasias are treated only in certain instances. Bone and/or marrow biopsies are not made. Radiation therapy is never used.

In summary it is the experience of this laboratory that prophylaxis and therapy are desirable if not indispensable factors in the man-? agement of our large canine colony--especially in those animals which are to be studied for long periods. Such.treatment is part of our overall attempt to provide an environment and care such that the maximum number of animals will die of radiation induced disease or senile changes and not from naturally occurring factors. 


\title{
DENTAL ERUPTION PATTERN OF THE BEAGLE
}

L. Shabestari, G. N. Taylor and W. Angus

\begin{abstract}
Eruption of the deciduous teeth began at three weeks and was completed by the end of the $f$ ifth week. The canines appeared first and were succeeded by the incisors and then the molars. Exfoliation of the temporary teeth began at $\sim 115$ days and was invariably preceded by eruption of upper permanent premolar 1. The last tooth of the. permanent dentition to appear was the third molar - erupting at $\sim 175$ days.
\end{abstract}

\section{INTRODUCTION}

Most studies which present the dental eruption pattern of the dog are a composite of observations taken from several breeds $(1,2)$. It is the purpose of this paper to present the eruption time as observed in a single breed, the beagle.

\section{METHODS}

Thirty-three healthy purebred beagles, raised at this laboratory, were used in this study. Observations were made triweekly from birth until the eruption of the permanent dentition.

Eruption was taken as the time of gingival perforation and tooth. loss as the time of natural exfoliation. Deciduous teeth were never extracted.

Identification of teeth was according to the following dental formulae $(3,4)$ :

$$
\frac{\text { Deciduous }}{\text { I } \frac{3}{3} \text { C } \frac{1}{1} \text { M } \frac{3}{3}} \quad \text { I } \frac{3}{3} \text { C } \frac{1}{1} \text { PM } \frac{4}{4} \text { M } \frac{2}{3}
$$

The first premolar was considered to erupt without a deciduous. precursor (5) (Figs. 1 and 2). 


\section{RESULTS}

The eruption patterns are summarized in Tables 1 and 2 . These data indicate the following.

During the third week of life firm swellings were palpable beneath the gumss on the occlusal surface. The canines, generally the upper, were the first to appear, followed by the corner, intermediate, and centralincisors. The upper arcade erupted first.

As the last of the incisors appeared, the cheek teeth erupted deciduous molar 2 first, followed by deciduous molar 3 and deciduous molar 1. Ünlike the canines and incisors the lower cheek teeth erupted before the upper counterpart. By the end of the 5 th week a full set of deciduous teeth was present.

Little change occurred during the next two months. However, the $\vdots$ space between the teeth widened as the length of the jaws increased.

The exfoliation and replacement of the deciduous teeth was preceded by the eruption of permanent upper premolar 1 . This was a constant feature. Shortly thereafter the incisors were lost - first the central, followed by the intermediate and corner incisors. The order was opposite to the sequence in which they erupted. Permanent incisors appeared a day or two after their precursors were lost.

Molar 1 and lower premolar 1 were the next teeth to appear. Deciduous molars were then exfoliated - generally the upper before the lower. The permanent teeth appeared in a few days following exfoliation. However, permanent premolar 2 was occasionally visible medial to deciduous molar 1 for several days before the latter was lost.

The permanent canines erupted about the same time as the cheek teeth. Exfoliation of the lower deciduous canine revealed its underlying 
permanent successor. However, the upper deciduous canine remained posterior to the permanent tooth for several days and occasionally for several weeks. The time of its loss was quite variable.

Permanent molar 2 erupted about 2 weeks after the first molar. The last tooth to appear was molar 3 which generally erupted about three weeks after the other dentition was present.

Table 1. Age in days at eruption (T) and of exfoliation (L) of deciduous teeth. Standard deviations $(t)$ are shown in parentheses.

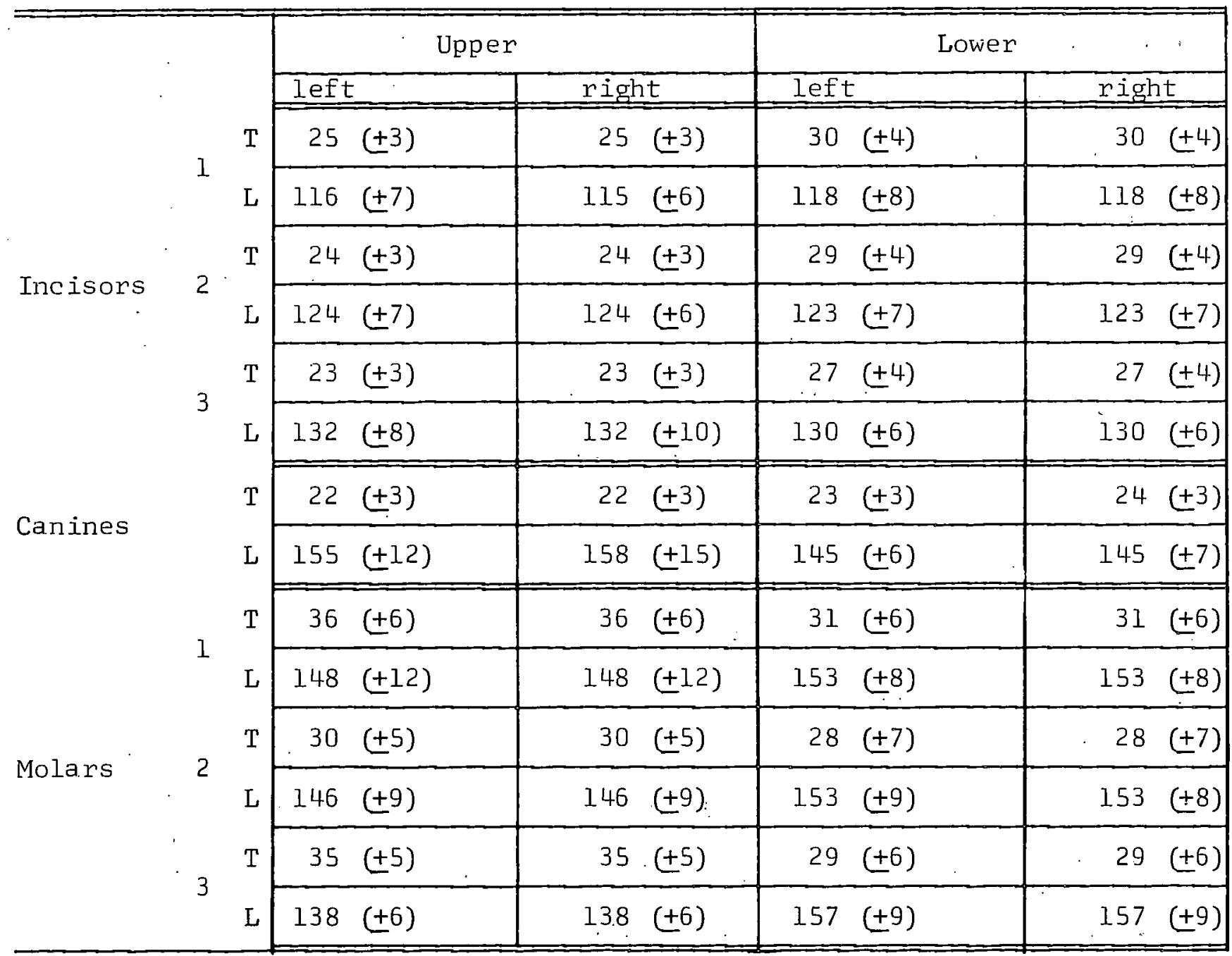


Table 2. Age in days at eruption of permanent dentition. Standard deviations (+) are shown in parentheses.

\begin{tabular}{|c|c|c|c|c|c|}
\hline & & \multicolumn{2}{|c|}{ Upper } & \multicolumn{2}{|c|}{ Lower } \\
\hline & & left & right & left & right \\
\hline \multirow{3}{*}{ Incisors } & 1 & 120 & $120(+8)$ & 118 & $118(+7)$ \\
\hline & 2 & $124(+6)$ & $125( \pm 5)$ & $125( \pm 6)$ & $125(+6)$ \\
\hline & 3 & $132(+7)$ & $133 \biguplus 6)$ & $135(+7)$ & $135( \pm 7)$ \\
\hline \multirow[t]{3}{*}{ Canines } & & $147 \quad(+8)$ & $147 \quad(+8)$ & $145(+6)$ & $145(6)$ \\
\hline & 1 & $111( \pm 10)$ & $111(+10)$ & $129(+11)$ & $129(+11)$ \\
\hline & 2 & $144( \pm 10)$ & $144( \pm 10)$ & $138(+11)$ & $138(+10)$ \\
\hline \multirow{5}{*}{ Premolars } & 3 & $153(+9)$ & $153(+10)$ & $155(+7)$ & $156(+8)$ \\
\hline & 4 & $136( \pm 8)$ & $137(+8)$ & $155( \pm 9)$ & $155( \pm 9)$ \\
\hline & 1 & $136(+8)$ & $136 \quad+8)$ & $130(+6)$ & $130( \pm 7)$ \\
\hline & 2 & $155( \pm 6)$ & $155(+6)$ & $149 \quad(+8)$ & $149( \pm 8)$ \\
\hline & 3 & & & $174( \pm 14)$ & $174(+14)$ \\
\hline
\end{tabular}

REFERENCES

1. E. M. Crawford, Preliminary study of dentition in dogs, Veterinary Medicine, $32: 212-217$ (1937) .

2. L. Arnall, Some aspects of dental development in the dog: Calcification of crown and root in the deciduous dentition, J. Small Animal Practice, 1:169-173 (1961) .

3. M. E. Miller, Guide to the Dissection of the Dog, ed. 2, Ithaca, New York, Edward Brothers, Inc., pp. 32-34 (1952).

4. S. Sisson and J. D. Grossman, The Anatomy of the Domestic Animals, W. B. Saunders Co., Philadelphia and London, pp. 972 (1938).

5. L. E. St. Clair and N. D. Jones, Observations on the cheek teeth of the dog, J.A.V.M.A. 130:275-279 (1957) . 


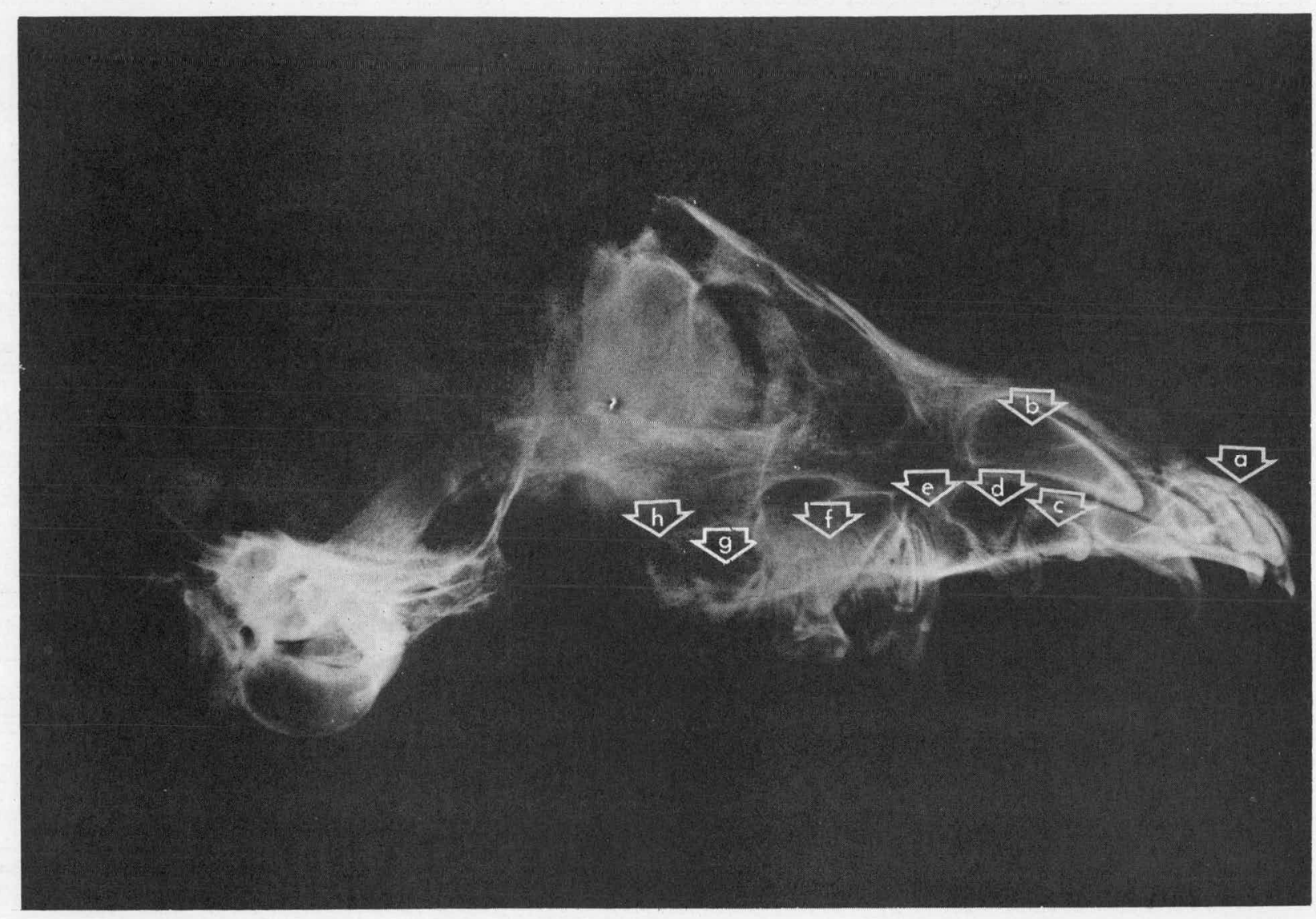

Fig. 1. Radiograph of purebred beagle showing complete deciduous dentition of the upper arcade and the underlying non-erupted permanent incisors (a), canine (b), premolars (c-f) and molars $(\mathrm{g}-\mathrm{h}) \cdot 83$ days age. 


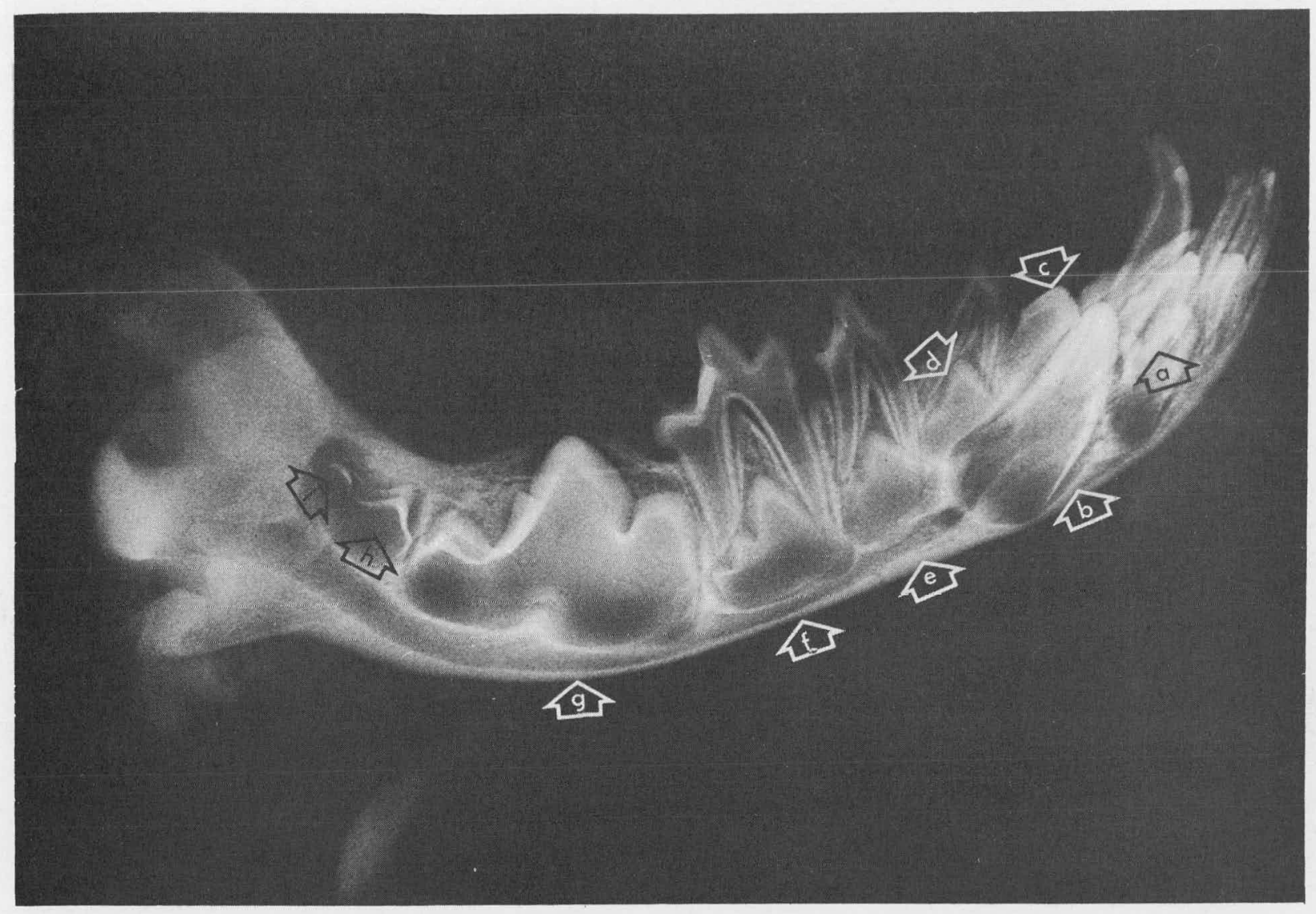

Fig. 2. Radiograph of purebred beagle showing deciduous incisors, canines, and molar teeth of lower arcade and the underlying non-erupted permanent incisors (a), canine (b), premolars (c-f) and molars (g,h,i). Same dog as Fig. 1 . 


\section{THORIUM-228 INDUCED FRACTURES IN BEAGLES}

G. N. Taylor, W. S. S. Jee, W. R. Christensen, C. E. Rehfeld and N. Nebeker

Abstract: Significant numbers of pathological fractures were induced in beagles by a single intravenous injection of $\sim 0.3 \mu \mathrm{c} / \mathrm{kg}$ or $\sim 0.9 \mu \mathrm{c} / \mathrm{kg} \mathrm{Th}^{228}$. Fractures were not observed at the next higher level, $2.7 \mu \mathrm{c} / \mathrm{kg}$ because of early death from radiation induced nephritis and/or blood dyscrasia. Only one fracture occurred at the $0.1 \mu \mathrm{c} / \mathrm{kg}$ level in nine dogs observed and no fractures were observed below this dose. This lowest level at which a fracture occurred was approximately 6 times higher than the dose which has induced osteosarcomas, thus far.

\section{INTRODUCTION}

Five of the most obvious lesions induced by $\mathrm{Th}^{228}$ in the dog are osteosarcoma $^{(1)}$, radiation induced nephritis (2), blood dyscrasia (3), ulcerative gingivitis (4), and pathological fractures. It is the purpose of this paper to summarize the latter category according to the incidence and anatomical distribution of such fractures.

\section{METHODS}

All of the animals used in this study were purebred beagles that were born and reared on this project. The cause of death in most instances was osteosarcoma, but notable exceptions occurred in the 2 highest levels (see Injection Tables that preface this report).

The fracture incidence was determined from post mortem radiographs of the defleshed skeleton. These terminal films facilitated fracture recognition. Also, the total number of fractures was a maximum value for the respective dogs. Evaluation of some healed fractures that were known to have occurred several years previously indicated recognition was still unmistakable at autopsy. In vivo radiographs spaced at approximately 6 month intervals were used to determine the earliest fracture. 
The percentages illustrated in the Tables and Figures were cal-: : culated by dividing the totall number of fractures occurring in a.specific bone by the total number of these bones present in the given.dose level being considered and multiplying by 100. For example, if. 7 dogs were observed at a given dose level the total number of bones used in computing the percentage of ilial fractures would be 14 . Twenty-six ribs per dog was used in computing the percentage rib fractures.

Incomplete or fatigue-like fractures were omitted. Those shown for the thoracic vertebrae were limited entirely to the dorsal spinous processes, and those of the lumbar vertebrae involved only the transverse prọesses.

The photomicrographs are of celloidin sections, prepared from decalcified bone, and stained with.hematoxylin and eosin.

At the time of injection all epiphyses except those of the ribs were closed. In many cases additional growth occurred at the costochondral region following treatment with the radionuclide.

Administration of the radionuclide was via a single intravenous injection prepared according to methods described elsewhere ${ }^{(5)}$. The word "dose" as used in this study refers to this injected $\mu \mathrm{c}$ dose.

\section{RESULTS AND DISCUSSION}

A significant number of pathological fractures occurred in 2 of the doses studied $-0.3 \mu \mathrm{c} / \mathrm{kg}$ and $0.9 \mu \mathrm{c} / \mathrm{kg}$ (Fig. 1 and Table 1 ). Short survival times resultant to radiation induced blood dyscrasia, nephritis, and other less clearly apparent lesions precluded fractures at higher levels. Only one fracture was observed below these doses - a rib fracture in a dog injected with $0.0879 \mu \mathrm{c} / \mathrm{kg}$.

Individual variation in the "incidence and distribution was marked. 
The total number of fractures per animal varied from 4 to 36 at the 0.9 $\mu \mathrm{c} / \mathrm{kg}$ dose, and 0 to 19 at the $0.3 \mu \mathrm{c} / \mathrm{kg}$ dose. Three of the 10 dogs observed at this latter level did. not develop any fractures.

In the $\mathrm{rib}$ cage one important cause of such variation was the different degree of rib growth that occurred after injection of the radionuclide. As noted under METHODS, the costochondral epiphysis in many of the animals had not closed by the time of radionuclide treatment - a factor that was influenced by individual growth patterns, etc., and especially by the nonuniform ages at injection (Table 2). The junction between the pre-injection and post-injection bone in this area was highly susceptible to fracture and the incidence was in direct relationship to the amount of post-injection bone growth. Such fractures have been referred to as "hot line" fractures (6).

The growth potential that oftentimes existed in the ribs at the time of injection also accounted for an interesting dose effect. This is shown in Table 3, which categorizes the rib fractures according to the quarter of the rib in which they occurred. Fractures induced by the $0.9 \mu \mathrm{c} / \mathrm{kg}$ treatment were limited to the proximal three-fourths. Those produced by the $0.3 \mu \mathrm{c} / \mathrm{kg}$ dose occurred in all regions, but dominantly as "hot line" fractures in the distal quarter. This dose effect was the result of radiation induced modification of rib growth in the costochondral region. No apparent change was induced by the $0.09 \mu \mathrm{c} / \mathrm{kg}$ dose (Fig. 2). Elongation continued following the $0.3 \mu \mathrm{c} / \mathrm{kg}$ dose, but a very prominant "hot line" was formed (Fig. 3) and remodeling in the post-injection bone was abnormal. The remodeling defect was evidenced, in part, by the presence of cartilaginous cores in many of the trabecula.e a feature which was most extreme in the region of the "hot line.". (Fig. 4) . 
The "hot line". was further characterized by a high percentage "of necrotic bone and a fibrous marrow. This zone was the most susceptible fracture site in the rib cage. An abrupt transition into viable marrow and viable bone occurred in the post-injection bone immediately distal to this "line", denoting that the uptake of thorium daughters $(7,8)$ was below the amount required to destroy these types of tissue. The next higher dose, $0.9 \mu \mathrm{c} / \mathrm{kg}$, completely prevented post-injection growth in this region and "hot line" fractures did not occur, although they were numerous in the proximal three-fourths (Fig. 5).

Individual variation plus the relatively small number of dogs observed prevented precise conclusions relative to specific bones, etc. Nevertheless, the data indicated the following more general factors:

1) Thorium-228 induced fractures were distributed over a wide range of anatomical sites in both the appendicular and axial skeleton.

2) The threshold above which fractures were induced was approximately $0.09 \mu \mathrm{c} / \mathrm{kg}$.

3) The high number of long bone fractures induced by the 0.9 $\mu \mathrm{c} / \mathrm{kg}$ dose was one:of the extreme aspects of this dose level, and was a cause for euthanasia in several instances.

4) The tendency toward fracture repair was low.

5) Thorium-228 induced fractures produced a minimal inflammatory response. The slight amount of pain associated with them was especially obvious - a feature in common with radium $\left(\mathrm{Ra}^{226}\right.$ and $\mathrm{Ra}^{228}$ ) and $\mathrm{Pu}^{239}$ induced fractures ${ }^{(9-11)}$.

6) In comparison to 4 other bone-seeking radionuclides studied at this laboratory ( $\mathrm{Ra}^{226}, \mathrm{Ra}^{228}, \mathrm{Pu}^{239}$, and $\mathrm{Sr}^{90}$ ) $\mathrm{Th}^{228}$ 
fractures most nearly resembled those of $\mathrm{Ra}^{228}$ except for the unique "hot line" fractures produced by the $0.3 \mu \mathrm{c} / \mathrm{kg}$ dose which were similar to those of $\mathrm{Pu}^{239}$. Except for the "hot line" rib fractures, differentiation between $\operatorname{Th}^{228}$ and $\mathrm{Ra}^{228}$ fractures based on the anatomical distribution, healing incidence and general morphological features of the fractures would not be possible.

7) The dose, which produced only 1 fracture in 9 dogs, $.09 \mu \mathrm{c} / \mathrm{kg}$, was approximately 6 times higher than that at which osteosarcomas have occurred thus far. Since many of the lower level animals are still living, this span may become even greater. Thus the occurrence of even a single pathological fracture was a very ominous sign.

8) The earliest fracture was observed within the following postinjection intervals (days):

\begin{tabular}{|c|c|c|}
\hline Dose Level & $\begin{array}{c}\text { Axial } \\
\text { Skeleton } \\
\end{array}$ & $\begin{array}{c}\text { Append icular } \\
\text { Skeleton }\end{array}$ \\
\hline$\sim 0.9 \mu \mathrm{c} / \mathrm{kg}$ & --- to 294 (rib) & 395 to 477 (ulna) \\
\hline$\sim 0.3 \mu \mathrm{c} / \mathrm{kg}$ & 197 to $366 \cdot C_{\text {proc }}^{\text {spin }}$ & 386 to 591 \\
\hline$\sim 0.1 \mu \mathrm{c} / \mathrm{kg}^{*}$ & 972 to 1108 (rib) & (none) \\
\hline
\end{tabular}

* Only one fracture occurred at this level in nine dogs observed. ACKNOWLEDGEMENTS

The authors wish to thank P. Petermann and W. Angus for their technical assistance.

\section{REFERENCES}

1. T. F. Dougherty, Incidence of bone cancer in internally irradiated dogs, Some Aspects of Internal Irradiation, Pergamon Press, Oxford, pp, 47-61 (1962) . 
2. T. H. Cochran, Histopathological findings, University of Utah, Radiobiology Laboratory Report, AECU-3522, pp 73-84 (Mar 1957) .

3. J. H. Dougherty, Some hematologicall responses to internal irradiation in the beagle, Some Aspects of Internal Irradiation, Pergamon Press, Oxford (1962).

4. G. N. Taylor, W. R. Christensen, W. S. S. Jee, and C. E. Rehfeld, Gingival ulceration in beagles induced by $\mathrm{Ra}-226$, Ra-228 or Th-228, J. Dental Res., 43:35-43 (1964).

5. T. F. Dougherty, B. J. Stover, J. H: Dougherty, W. S. S. Jee, C. W. Mays, C. E. Rehfeld, W. R. Christensen, and H. C. Goldthorpe, Studies of biological effects, of $\mathrm{Ra}^{226}, \mathrm{Pu}^{239}, \mathrm{Ra}^{228}$ (MsTh), $\mathrm{Th}^{228}$ (RdTh), and $S r^{90}$ in adult beagles, Radiation Res., 17:625-681 (1962).

6. W. S. S. Jee and J. S. Annold, The toxicity of plutonium deposited in skeletal tissues of beagles. (I), Lab. Invest. 10:797-825 (1961).

7. B. J. Stover, D. R. Atherton, N. Keller, and D. Buster, Metabolism of the Th-228 decay series in adult beagle dogs, Radiation Res. 12: $657-671(1960)$.

8. C. W. Mays, R. Halden, and M. A. Van Dilla, Thoron exhalation in radiothorium-burdened beagles, Radiation Res. $\underline{9}: 439-444$ (1958).

9. G. N. Taylor, W. R. Christensen, W. S. S. Jee, C. E. Rehfeld and W. Fisher, Anatomical distribution of fractures in beagles injected with Pu-239, Health Physics, $\underline{8}: 609-613$ (1962).

10. G. N. Taylor, W. R. Christensen, W. S. S. Jee, C. E. Rehfeld and. P. Petermann, Intercomparison of pathological fractures in beagles. injected with Ra-226, Ra-228, Pu-239 or Sr-90, Health'Physics (in press).

11. C. E. Rehfeld, B. J. Stover, G. N. Taylor and C. W. Mays, Fracture incidence in beagles receiving single injections of radium or plutonium, Some Aspects of Internal Irradiation, Pergamon Press, Oxford (1962). 
Table 1. Incidence and distribution of healed $(\mathrm{H})$ and unhealed (U) fractures following a single intravenous injection of $\mathrm{Th}^{228}$. The values indicate the fractures per site that occurred in the number of dogs indicated in parentheses.

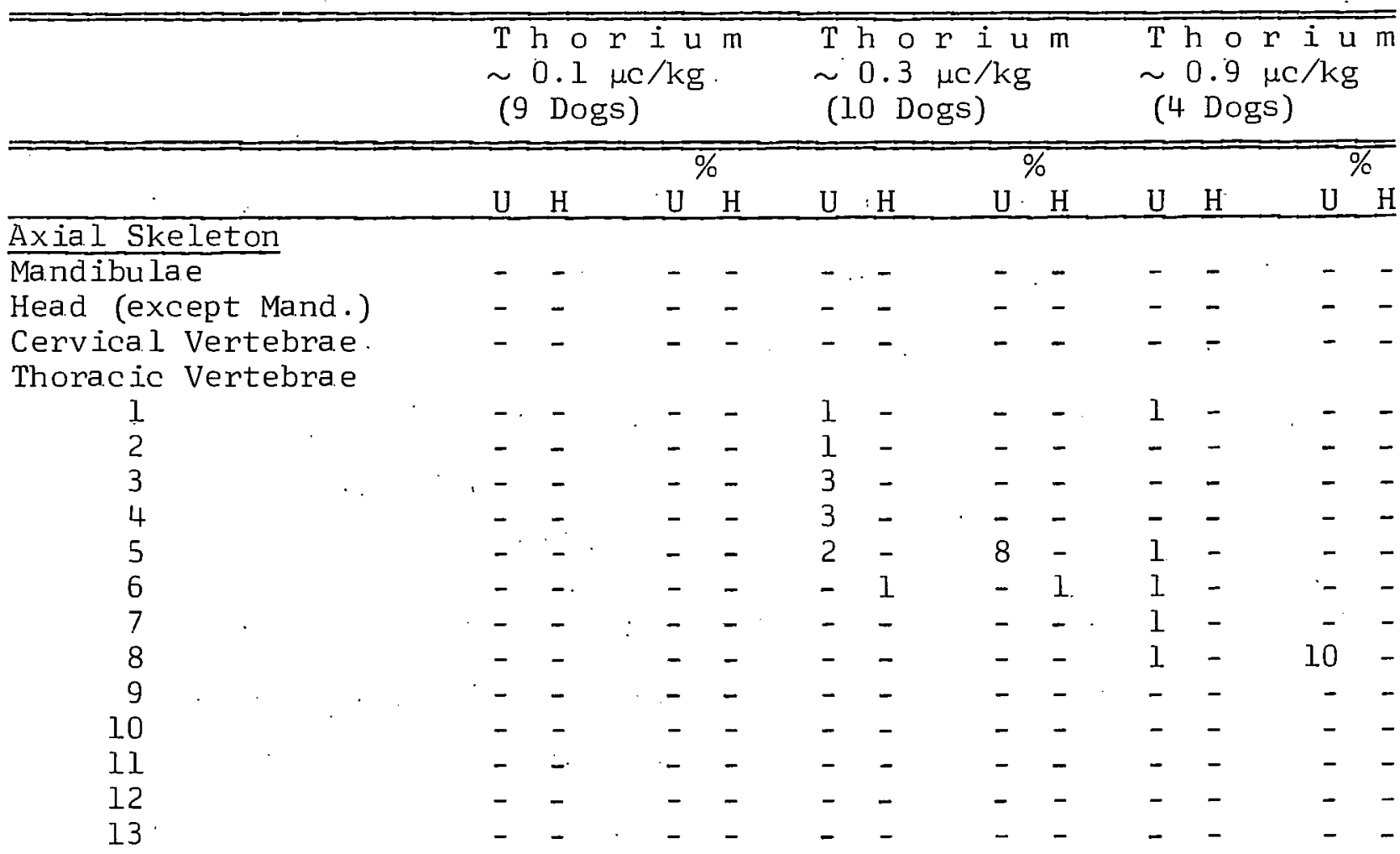

Ribs

$\begin{array}{lllllllllllll}1 & - & - & 0.4 & - & 4 & - & - & - & 3 & - & - & - \\ 2 & - & - & - & - & 3 & 1 & - & - & 3 & - & - & - \\ 3 & - & - & - & - & 1 & 2 & - & - & 2 & - & - & - \\ 4 & - & - & - & - & 3 & 3 & - & - & 3 & - & - & - \\ 5 & - & - & - & - & 3 & 4 & - & - & 3 & - & - & - \\ 6 & - & - & - & - & 4 & 2 & - & - & 4 & - & - & - \\ 7 & - & - & - & - & 3 & 1 & - & - & 6 & 1 & - & - \\ 8 & - & - & - & - & 3 & 4 & - & - & 7 & - & - & - \\ 9 & - & - & - & - & 6 & 6 & - & - & 7 & - & - & - \\ 10 & - & - & - & - & 5 & 3 & - & - & 4 & - & - & - \\ 11 & - & - & - & - & 2 & 1 & - & - & 5 & - & - & - \\ 12 & - & - & - & - & 3 & - & 16 & 10 & 5 & - & - & - \\ 13 & - & - & - & - & - & - & - & - & 2 & - & 52 & 1\end{array}$

Lumbar Vertebrae

1
2
3
4
5
6
7

Sacral Vertebrae

Coccygeal Vertebrae 
Table 1. Continued -

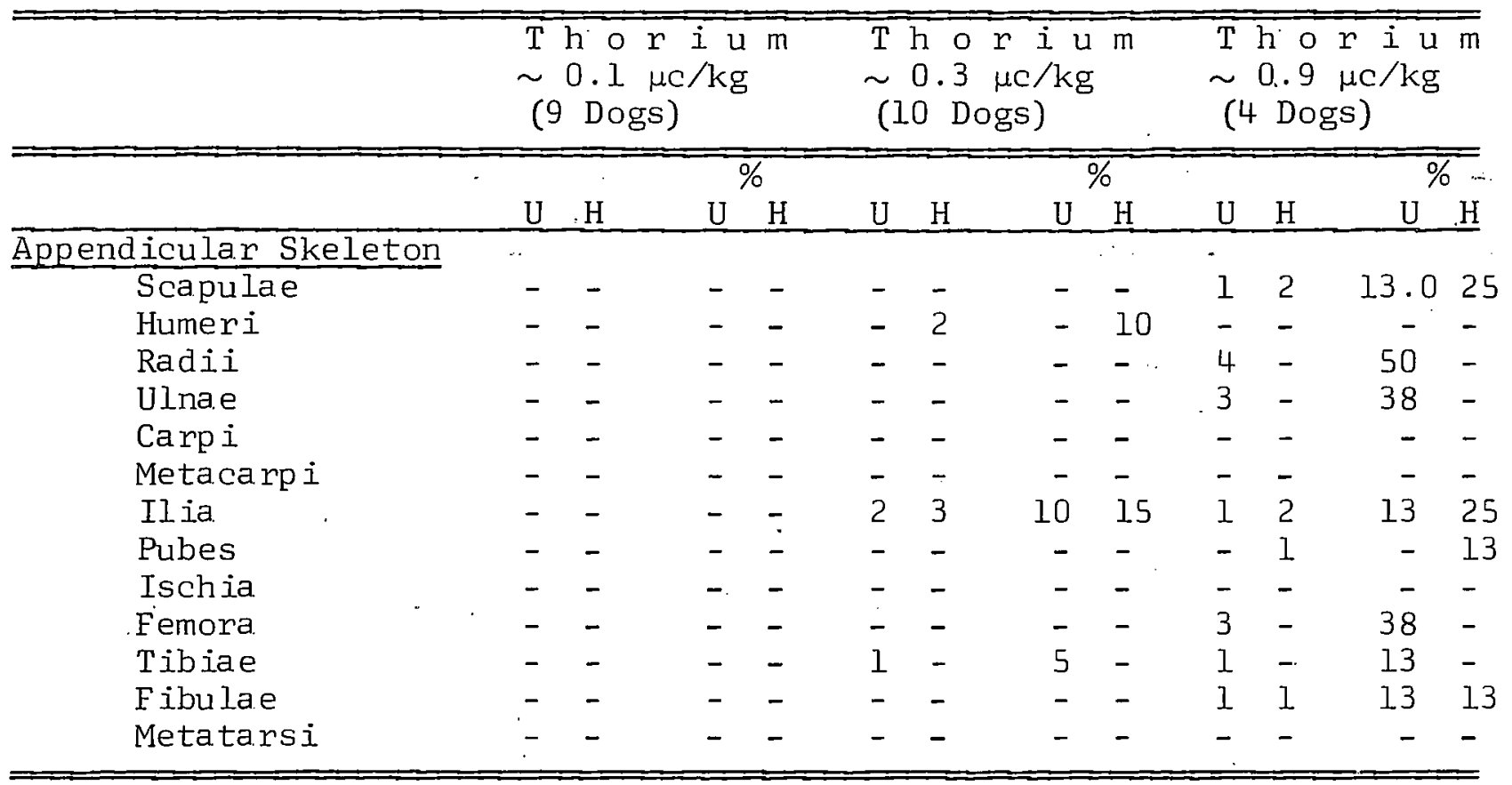

Table 2. Days age and days post-injection of dogs presented in this study.

\begin{tabular}{|c|c|c|c|c|c|c|}
\hline \multirow[b]{2}{*}{ Injection Dose } & \multicolumn{3}{|c|}{$\begin{array}{l}\text { Age at Injection } \\
\text { (days) }\end{array}$} & \multicolumn{3}{|c|}{ Days Post Injection } \\
\hline & $\overline{\text { Average }}$ & & $\overline{\text { Range }}$ & $\overline{\text { Average }}$ & & $\overline{\text { Range }}$ \\
\hline Thorium-228 & & & & & & \\
\hline Level 2 & 513 & 451 & -598 & 1041 & 1015 & -1541 \\
\hline 3 & 481 & 314 & -606 & 882 & 547 & -1156 \\
\hline 4 & 501 & 458 & -606 & 758 & 645 & -833 \\
\hline 5 & 468 & 455 & -483 & 122 & 65 & $-\quad 212$ \\
\hline
\end{tabular}


Table 3. Position of rib.fractures according to"their incidence in the respective quarters of the ribs. The values indicate the totals per given site occurring in the number of dogs shown in parentheses.

\begin{tabular}{lllllllllllllll}
\hline Rib Number & 1 & 2 & 3 & 4 & 5 & 6 & 7 & 8 & 9 & 10 & 11 & 12 & 13 \\
\hline
\end{tabular}

$\sim 0.9 \mu \mathrm{c} / \mathrm{kg} \mathrm{Th}-228$

(4 Dogs)

$\begin{array}{lllllllllllllll}\text { Proximal fourth } & 1 & 3 & 2 & - & - & - & 1 & 2 & 1 & - & 2 & 1 & 1 \\ \text { Second fourth } & 1 & - & - & 2 & 2 & 2 & 5 & 5 & 5 & 4 & 3 & 3 & - \\ \text { Third fourth } & 1 & - & - & 1 & 1 & 2 & 1 & - & 1 & - & - & 1 & 1 \\ \text { Distal fourth } & - & - & - & - & - & - & - & - & - & - & - & - & -\end{array}$

$\sim 0.3 \mu \mathrm{c} / \mathrm{kg}$ Th -228

(10 Dogs)

$\begin{array}{lllllllllllllll}\text { Proximal fourth } & 3 & 4 & 2 & 4 & 3 & - & - & - & - & - & - & 3 & - \\ \text { Second fourth } & - & - & - & - & - & 1 & - & - & 2 & 1 & 1 & - & - \\ \text { Third fourth } & 1 & - & - & - & - & - & - & - & - & 1 & - & - & - \\ \text { Distal fourth } & - & - & 1 & 2 & 4 & 5 & 4 & 7 & 10 & 6 & 2 & - & -\end{array}$

$\sim .1 \mu \mathrm{c} / \mathrm{kg}$ Th-228

(9 Dogs)

Proximal fourth 1 Second fourth Third fourth Distal fourth 


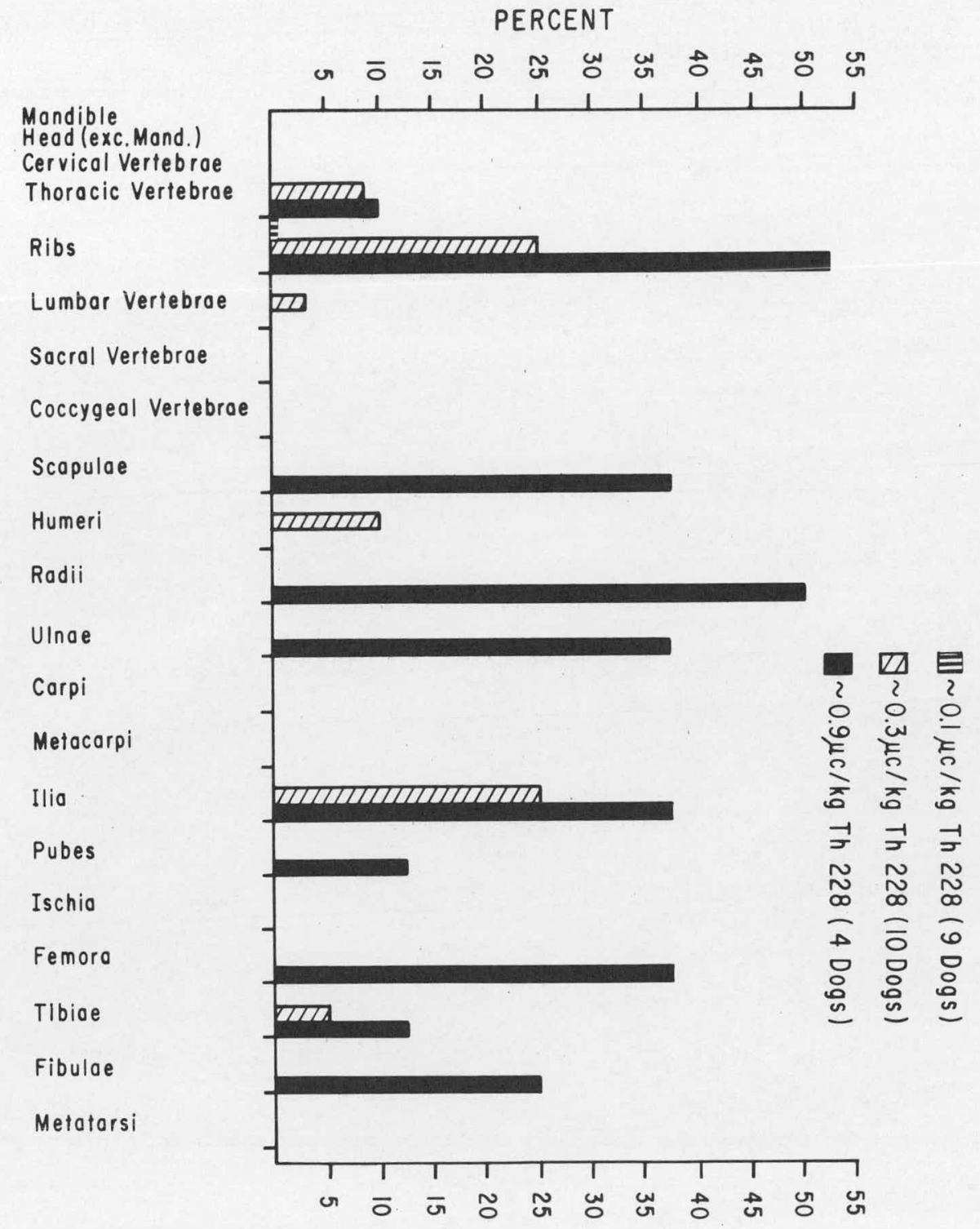

Fig. 1. Fracture distribution in beagles treated with a single intravenous injection of $\mathrm{Th}^{228}$. 


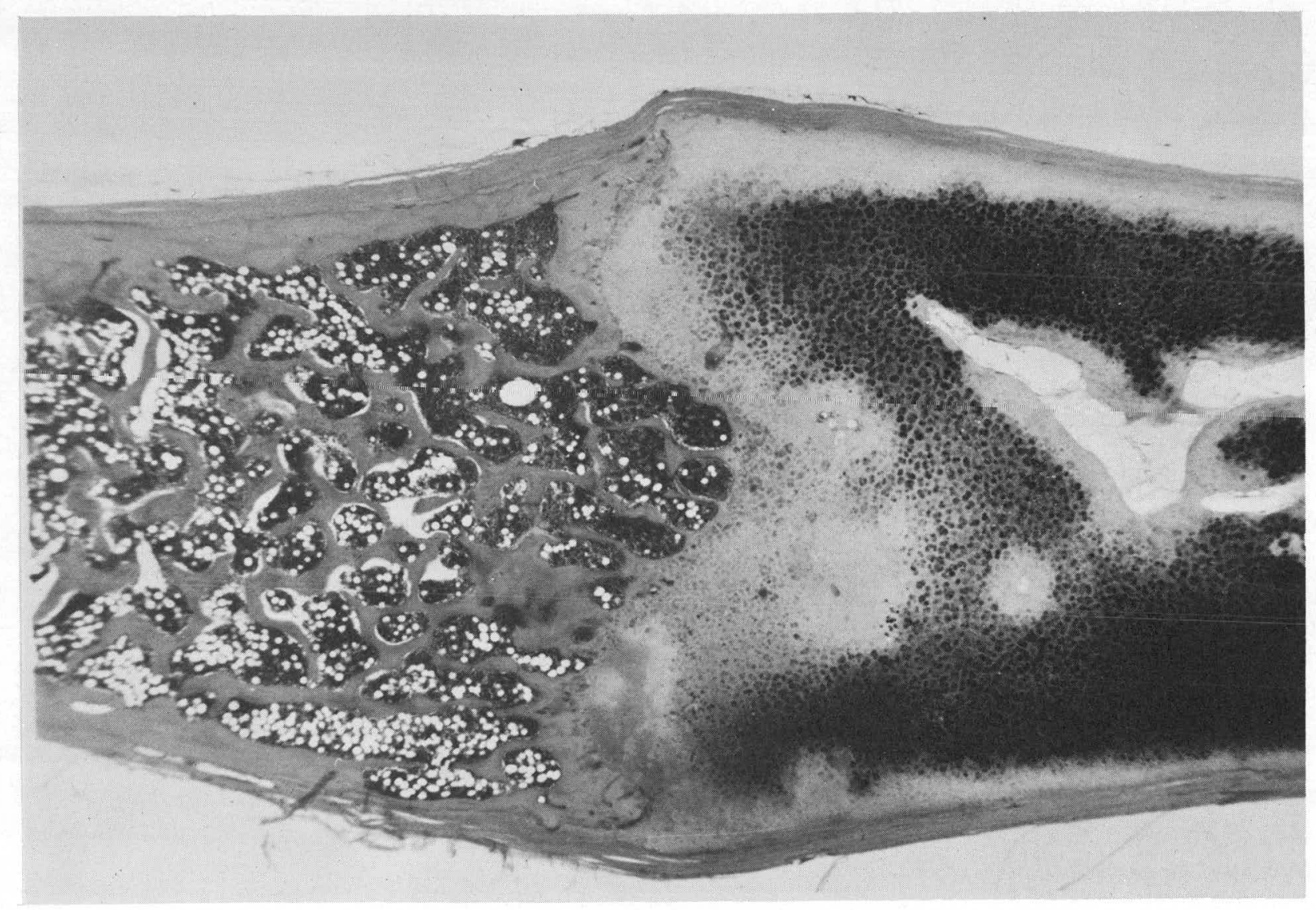

Fig. 2. Microphotograph of costochondral region of rib showing essentially normal structure. $0.089 \mu \mathrm{c} / \mathrm{kg}, 1222$ days post-injection. $H \&$ E. XI7. 


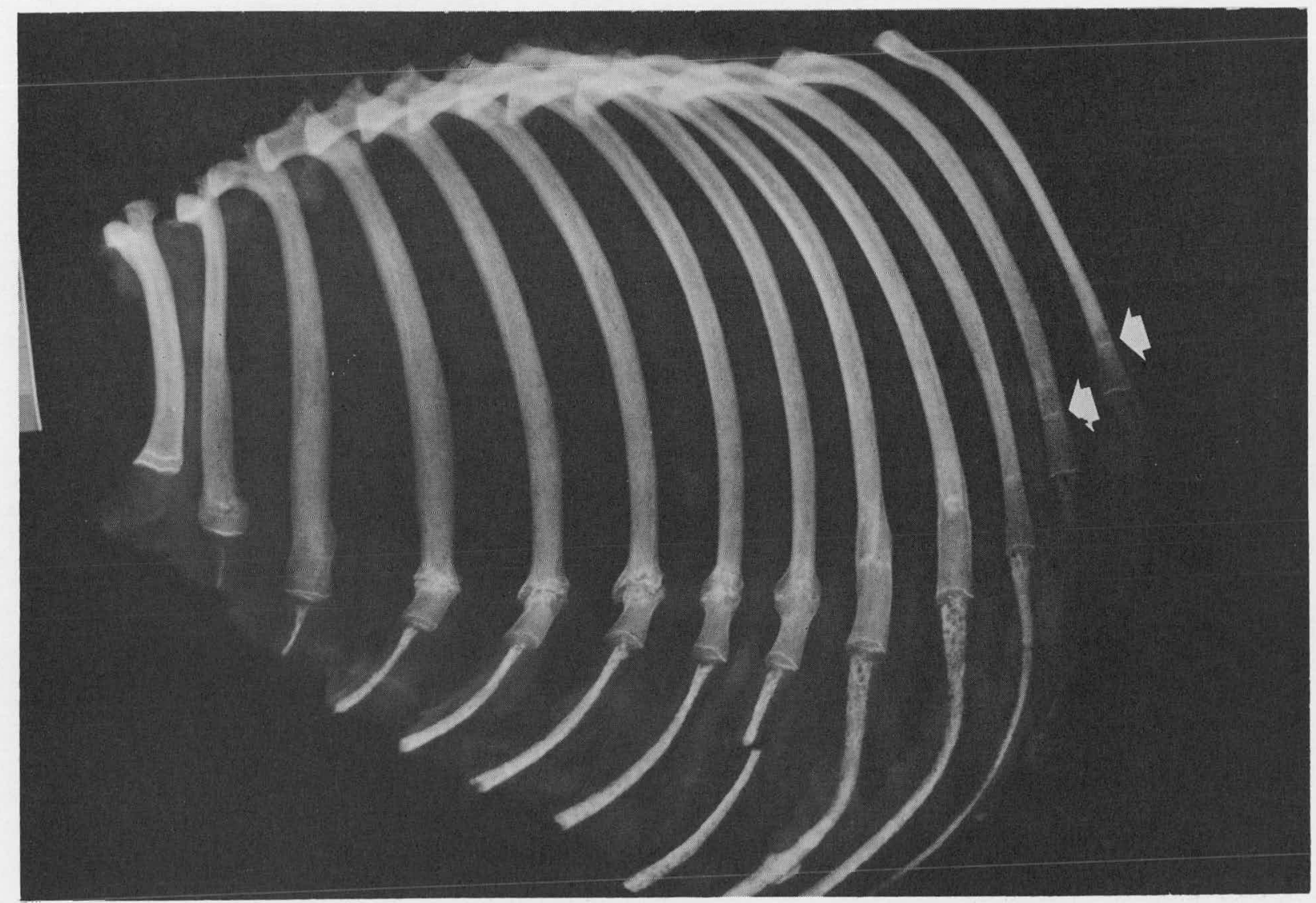

Fig. 3. Radiograph showing "hot line" fractures, both healed and unhealed, and "hot lines" (arrows) in some of the unfractured ribs. The bone distal to the radio-opaque line represents growth that occurred after the radionuclide treatment. $0.3 \mu \mathrm{c} / \mathrm{kg} .988$ days post-injection. 


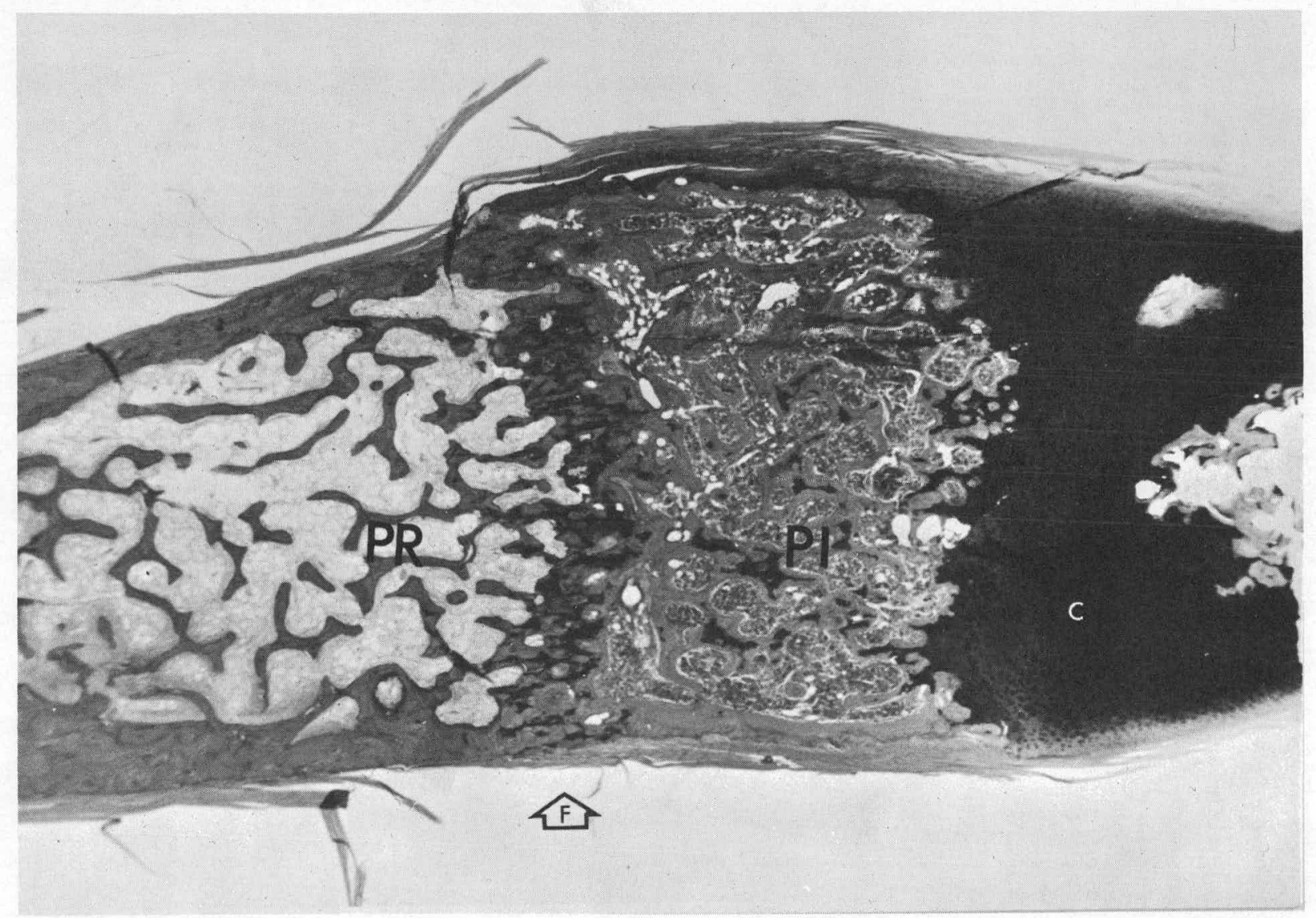

Fig. 4. Microphotograph of distal aspect of rib showing pre-injection bone with fibrous marrow (PR), post-injection bone containing viable marrow (PI), and the costal cartilage (C). The postinjection bone is characterized by a thinner cortex and cartilaginous cores in many of the trabeculae. The "hot line", the most likely fracture site, is indicated (F) . Dog received 0.272 $\mu \mathrm{c} / \mathrm{kg} \mathrm{Th}^{228}$. 547 days post-injection. $\mathrm{H} \& \mathrm{E} . \quad \mathrm{X} 17$. 


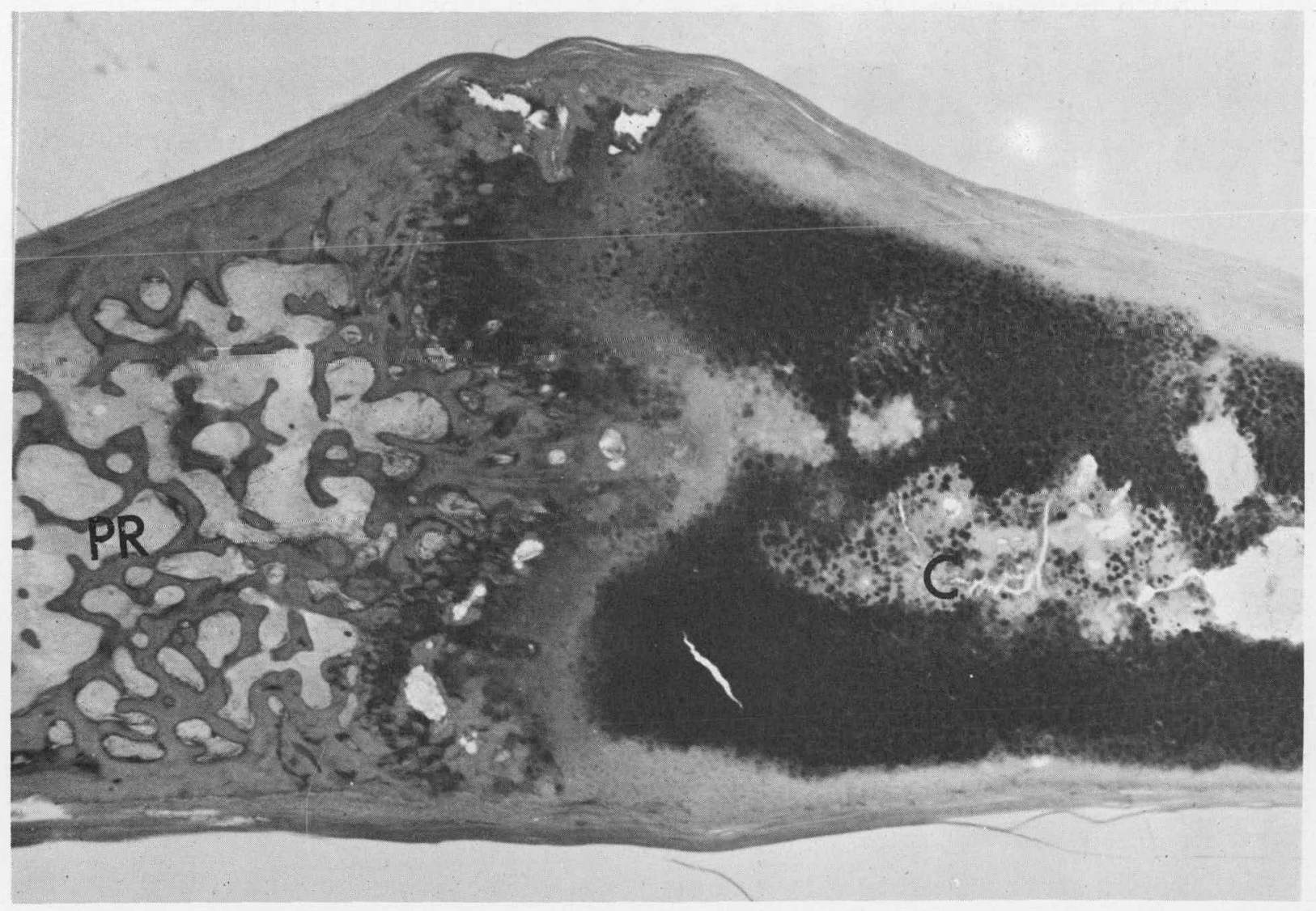

Fig 5. Microphotograph of distal aspect of rib showing pre-injection bone devoid of marrow (PR), costal cartilage (C), and absence of post-injection bone growth. Cartilaginous cores are present in many trabeculae at the tip of the rib. $0.835 \mu \mathrm{c} / \mathrm{kg} \mathrm{Th}{ }^{228}$. 793 days post-injection. $\mathrm{H} \& \mathrm{E} . \quad \mathrm{X} 17$. 
THE CORRELATION OF BONE STRENGTH WITH RADIATION DOSE FROM INTERNAL EMITTERS AND BONE RESORPTION

David H. Taysum, Webster S. S. Jee and David O. Clarke*

\section{INTRODUCTION}

Investigations of the physical properties of beagle tibiae that contain radionuclides incorporated during life have indicated thus far only tendencies toward weakening with increasing radiation dose $(1,2)$.

The physical properties were determined by using regularly shaped specimens subjected to pure tensile forces. The measurements made were of force per unit area (stress) and increase in length per unit length (strain)

The specimens were tested to failure, but only the values of the proportional limit were used. The proportional limit is also named the elastic limit.

\section{MATERIALS AND METHODS}

The amount of bone actually present was determined by taking the specimens previously tested ${ }^{(2)}$ so that the relationship of area and strength could be determined. A cross section was obtained as close to the break area as was possible. This is recognized as being an approximation since the obviously weakest place was where the break occurred and the only course remaining was to examine the site nearest the point of failure. This cross section was ground to approximately $100 \mu$ thickness and was radiographed using $10 \mathrm{~K} . V . P . x$-rays.

The resulting radiograph of a 0.050 inch diameter specimen was enlarged photographically to fifteen inches. The unequivocally radiolucent areas were carefully cut out and weighed. The weights were translated, 
by appropriate conversion factors, into areas. The percent of bone not present in the cross section was determined for twenty-nine controls and thirty-two irradiated specimens.

To evaluate the effect of the area of bone not present, the percent of bone missing, or porosity, was plotted against: (a) stress, (b) radiation dose, and (c) age, for control and irradiated. A plot of force versus area (micrometer measurement) is also provided. $\because$

RESULT S

In the initial study (2), the diameter of the test specimen was cletermined with a micrometer. The area calculated on the basis of this measurement was used as the denominator of stress. No correction was made for the fraction of the area that was not bone such as: (a) resorption areas.; (b) Haversian canals, (c) Volkmann canals, and (d) nutrient vessel channels, (e) osteocytes, and (f) lacunae. The data of this study when plotted exhibited a great deal of scatter. The scatter was not confinr.d to measurements between different bones alone, for specimens from the same tibia showed wide variation in strength and energy absorbing capacity.

The variation in properties appeared to be as great in control specimens as it was in irradiated specimens. It was felt that part of this variation must be due to variations in the amount of bone actually present.

A graph of force (Fig. 'l) versus total area (micrometer measurement). reveals an apparent difference between control and irradiated. This graph is actually a representation of Hooke's law wherein the deflection to the proportional limit is proportional to the applied force and hence zero force should correspond to zero area. 
Extension of the least squares fit lines so far from the mean of the data points is done to allow inferences to be made and not to. imply that the intercept values are anything but approximations. The means of percent. missing and stress of controls and irradiated are compared in Table $\mathrm{I}$.

TABLE I

\begin{tabular}{|c|c|c|}
\hline & $\begin{array}{l}\text { Average } \\
\text { Percent Bone } \\
\text { Missing }\end{array}$ & $\begin{array}{c}\text { Stress } \\
\mathrm{lbs} / \mathrm{in}^{2} \times 10^{3}\end{array}$ \\
\hline Controls . : & 4.16 & 18.30 \\
\hline Irradiated & 5.18 & 16.86 \\
\hline $\begin{array}{l}\text { Differences and } \\
\text { Significance of the } \\
\text { Differences. }\end{array}$ & $\overline{1.02 P}=[0.05$ to 0.10$]$ & $1.44 \mathrm{P}=[0.05$ to 0.10 \\
\hline$\frac{\text { Irradiated }}{\text { Control }}$ & $\therefore$ & $92 \%$ \\
\hline
\end{tabular}

Table I. shows the following:

a. Specimens from irradiated animals are significantly more porous (radiolucent) than are appropriate controls. The order of magnitude for the tibial compacta examined is approximately a $24 \%$ increase in porosity for irradiated versus control.

b. Specimens from irradiated animals are significantly weaker then are control specimens. The order of magnitude of the difference is approximately an $8 \%$ decrease in strength for the irradiated bone. The decrease in strength by $8 \%$ to. $10 \%$ is not believed to be acceptable as an explanation for the 
spontaneous fractures which some of the animals of the colony have exhibited.

A plot of percent missing (Fig. 2) versus stress revealș a difference between control and irradiated. Healthy control bones show increasing strength with decreasing percent missing $\left(\mathrm{P}_{:}<01\right)$, compared with irradiated which show much greater loss of strength without the corresponding magnitude of percent missing. $(\mathrm{P}<0.01)$ This indicates again that removing the obvious radiolucent areas may not. have removed all of the area that was non-functional as stress and energy absorbing bone.

A plot of percent missing versus radiation dose (Fig. 3) shows an increase in percent missing with increasing dose. $(\mathrm{P}<0.01)$ Thus radiation causes an increase in the percent missing which in turn is reflected in a loss of structural quality. Cjontrols show insignificant change.

A plot of percent missing versus age (Fig. 4) confirms the previous plot and shows that there is no significant increase $(P>0.70)$ in percent missing with age for controls over the times used in this study. For irradiated bones, the seeming increase in \% missing with age $(P \cong 0.50)$ is ascribed to the increase in cumulative dose with time after injection.

Table II is supplied to show total average skeletal dose, age, range of doses and range of ages.

\section{SUMMARY}

Radiation dose delivered to the animal by the incorporation, during life, of radionuclides in bone causes an increase in the porosity of bone with subsequent weakening being manifested. 


\section{REFERENCES}

1. H. Hollingshaus and C. W. Mays, Changes in mechanical strength of bone due to" internally deposited radioelements, Radiobiology Liboratory Annual Progress Report C00-215, 158-179 (1958).

2. D. H. Taysum, F. G. Evans, W. M. Hammer, W. S. S. Jee, C. E. Rehfeld and L. W. Blake, Radionuclides and"Bone Strength in Some Aspects of Internal Irradiation, 145-158, Pergamon Press, 1962. 
All of the observed loss of strength is not believed to be attributable to porosity since there are indications that some of the bone substance may not contribute to strength.

TABLE II

Values for dogs which were regarded as controls because of their low skeletal dose from internal emitters.

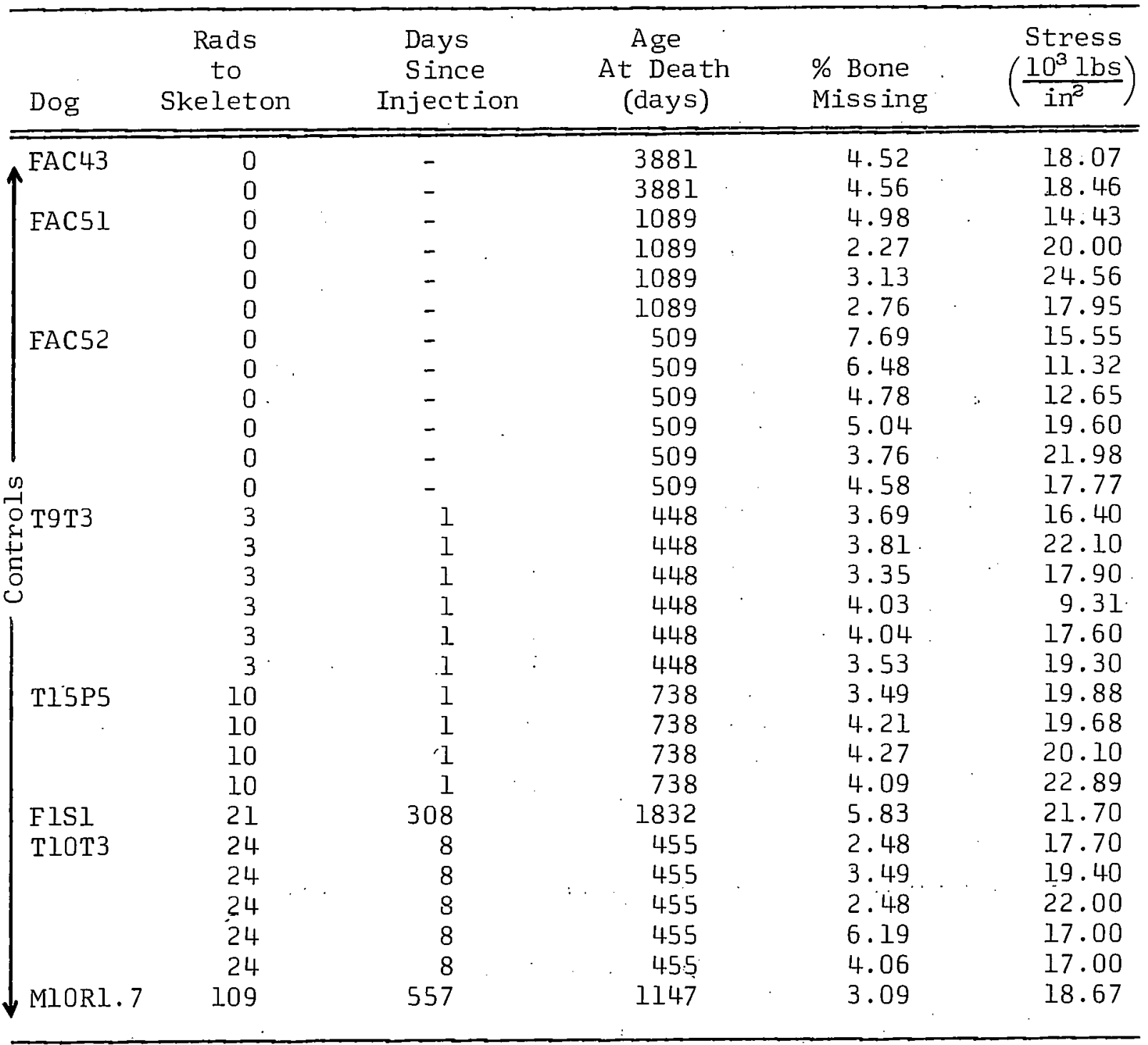


TA BLE II (Cont' ${ }^{\prime}$ d)

VALUES FOR SIGNIFICANTLY IRRADIATED DOGS

\begin{tabular}{|c|c|c|c|c|c|c|}
\hline Dog & $\begin{array}{c}\text { Rads } \\
\text { to } \\
\text { Skeleton }\end{array}$ & & $\begin{array}{c}\text { Days } \\
\text { Since } \\
\text { Injection }\end{array}$ & $\begin{array}{l}\text { Age } \\
\text { At Death } \\
\text { (days) }\end{array}$ & $\begin{array}{l}\% \text { Bone } \\
\text { Missing }\end{array}$ & $\begin{array}{c}\text { Stress } \\
\left(\frac{10^{3} I b s}{i n^{2}}\right)\end{array}$ \\
\hline \multirow[t]{3}{*}{ M6S5 } & 647 & & 35 & 539 & 3.67 & 15.78 \\
\hline & 647 & & 35 & .539 & 3.32 & 19.48 \\
\hline & 647 & & 35 & 539 & 5.02 & 14.28 \\
\hline \multirow[t]{4}{*}{ F6P3 } & 670 & & 1617 & 2032 & 6.38 & 15.09 \\
\hline & 670 & & 1617 & 2032 & 3.96 & 13.77 \\
\hline & 670 & & 1617 & 2032 & 2.63 & 21.27 \\
\hline & 670 & & 1617 & 2032 & 4.09 & 22.44 \\
\hline F1M2 & 870 & & 1780 & 2456 & 2.65 & 21.42 \\
\hline \multirow[t]{2}{*}{ M8P4 } & 1560 & & 1157 & 1808 & 8.92 & 16.38 \\
\hline & 1560 & & 1157 & 1808 & 3.56 & 16.03 \\
\hline \multirow[t]{4}{*}{ M3M4 } & 1795 & & 418 & 997 & 6.64 & 16.80 \\
\hline & 1795 & & 418 & 997 & 4.94 & 12.70 \\
\hline & 1795 & & 418 & 997 & 3.66 & 20.00 \\
\hline & 1795 & & 418 & 997 & 4.72 & 11.90 \\
\hline \multirow[t]{4}{*}{ F $2 M 4$} & 2272 & & 778 & 1238 & 3.99 & 17.10 \\
\hline & 2272 & & 778 & 1238 & 6.06 & 12.70 \\
\hline & 2272 & & 778 & 1238 & 2.05 & 18.40 \\
\hline & 2272 & & 778 & 1238 & 4.82 & 17.30 \\
\hline \multirow[t]{3}{*}{ M4M4 } & 2680 & & 896 & 1505 & 2.27 & 21.70 \\
\hline & 2680 & & 896 & 1505 & 2.74 & 20.90 \\
\hline & 2680 & . & 896 & 1505 & 1.69 & 17.70 \\
\hline \multirow[t]{2}{*}{ F $8 R 4$} & 4615 & & 1324 & 1798 & 4.49 & 17.45 \\
\hline & 4615 & & 1324 & 1798 & 5.39 & 16.66 \\
\hline \multirow[t]{4}{*}{ F9P5 } & 4750 & & 1145 & 1697 & 5.21 & 13.88 \\
\hline & 4750 & & 1145 & 1697 & 4.58 & 15.95 \\
\hline & 4750 & & 1145 & 1697 & 8.78 & 22.14 \\
\hline & 4750 & & 1145 & 1697 & 5.97 & 16.88 \\
\hline \multirow[t]{2}{*}{ M8P5 } & 4840 & & 1192 & 1689 & $15: 89$ & 11.78 \\
\hline & 4840 & & 1192 & 1689 & 11.55 & 12.33 \\
\hline \multirow[t]{3}{*}{ T2M4. 5} & 5097 & & 755 & 1218 & 5.98 & 15.00 \\
\hline & 5097 & & 755 & 1218 & 5.92 & 17.80 \\
\hline & 5097 & . & 755 & 1218 & $4 . .47$ & $16.70^{\circ}$ \\
\hline
\end{tabular}

\section{ACKNOWLEDGEMENTS}

The assistance of Renate Tegge in preparing the ground bone specimens and $x$-ray plates is gratefully recognized. 


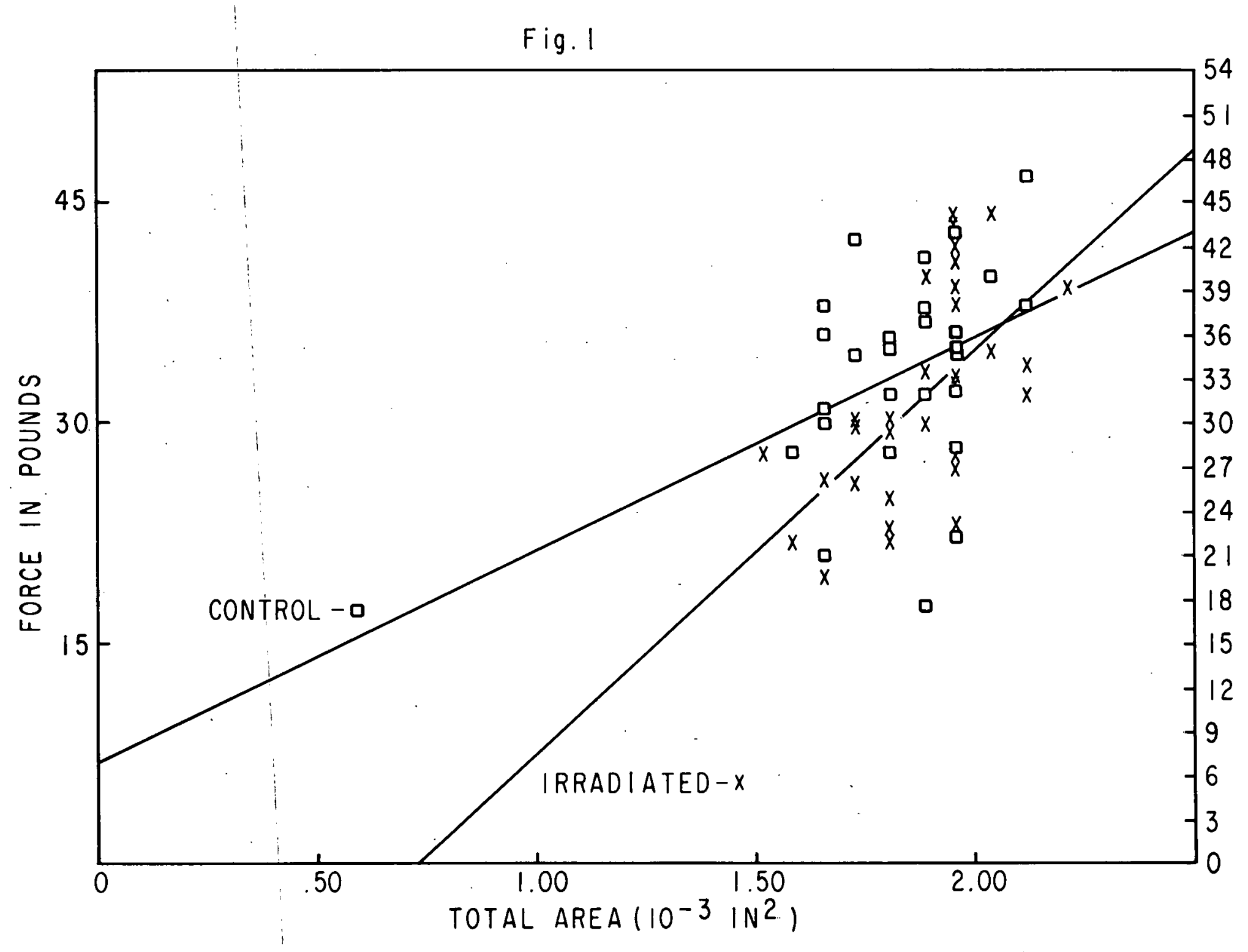


Fig. 2

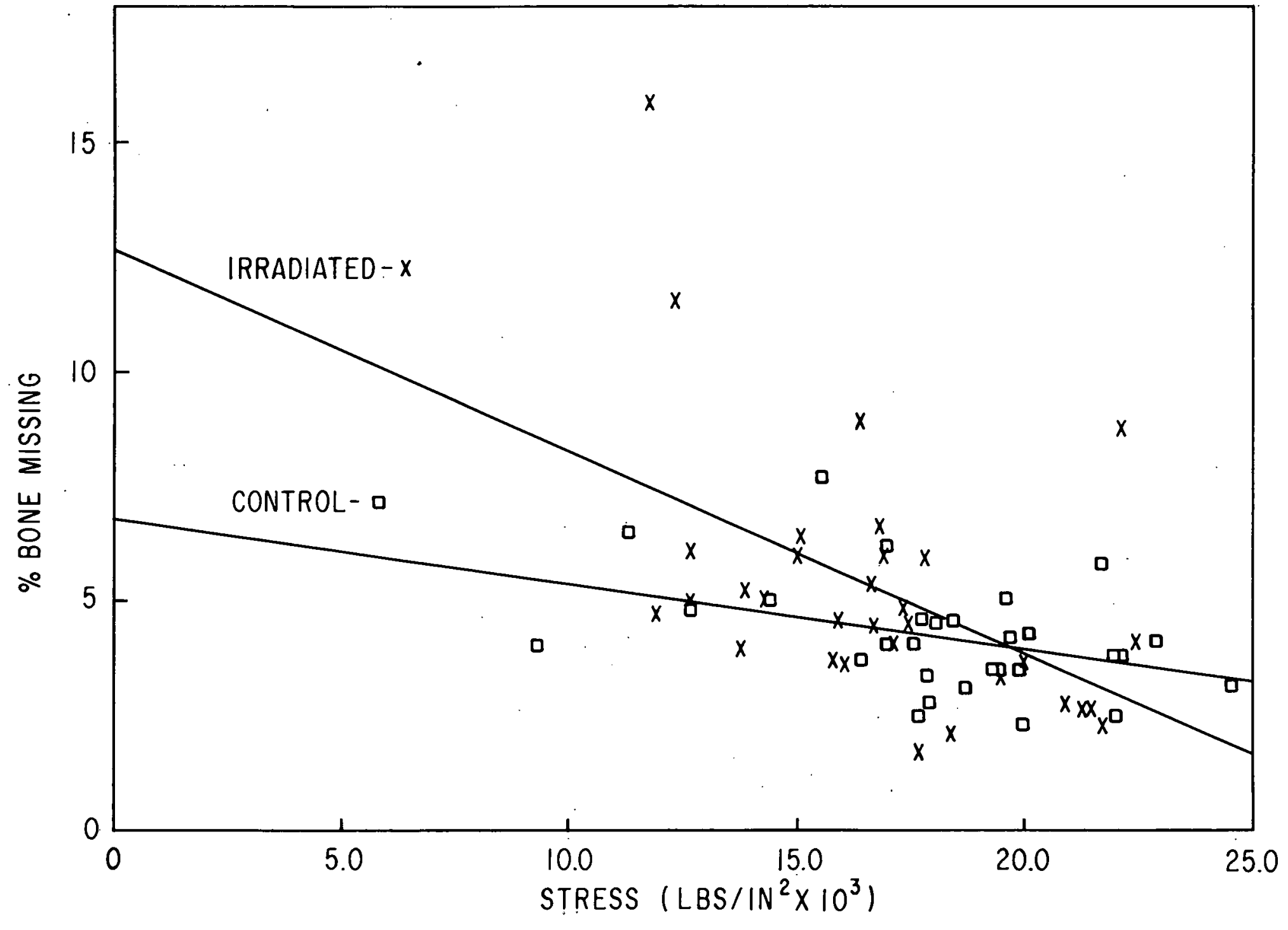


Fig. 3

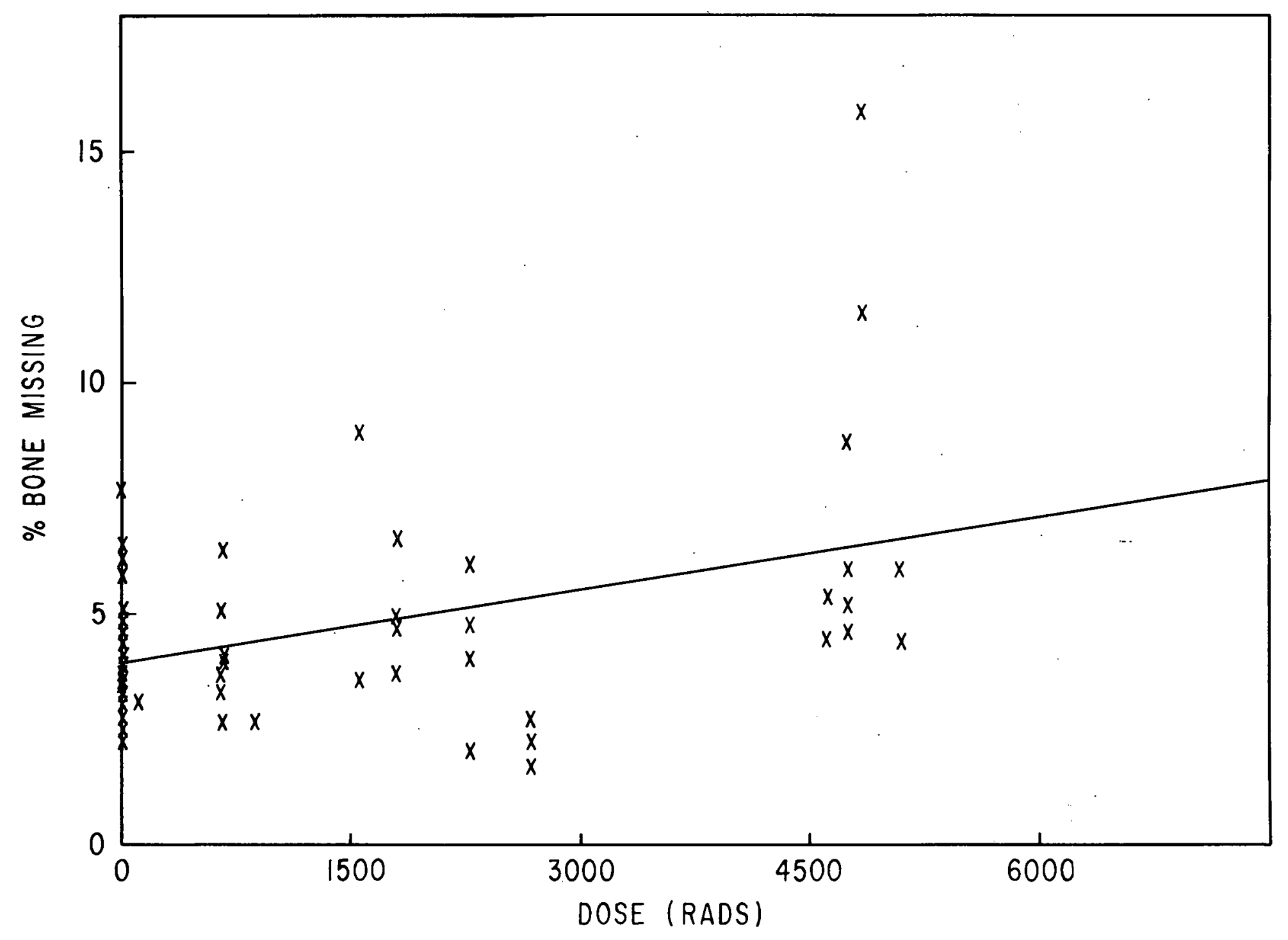

1
0
1 
Fig. 4

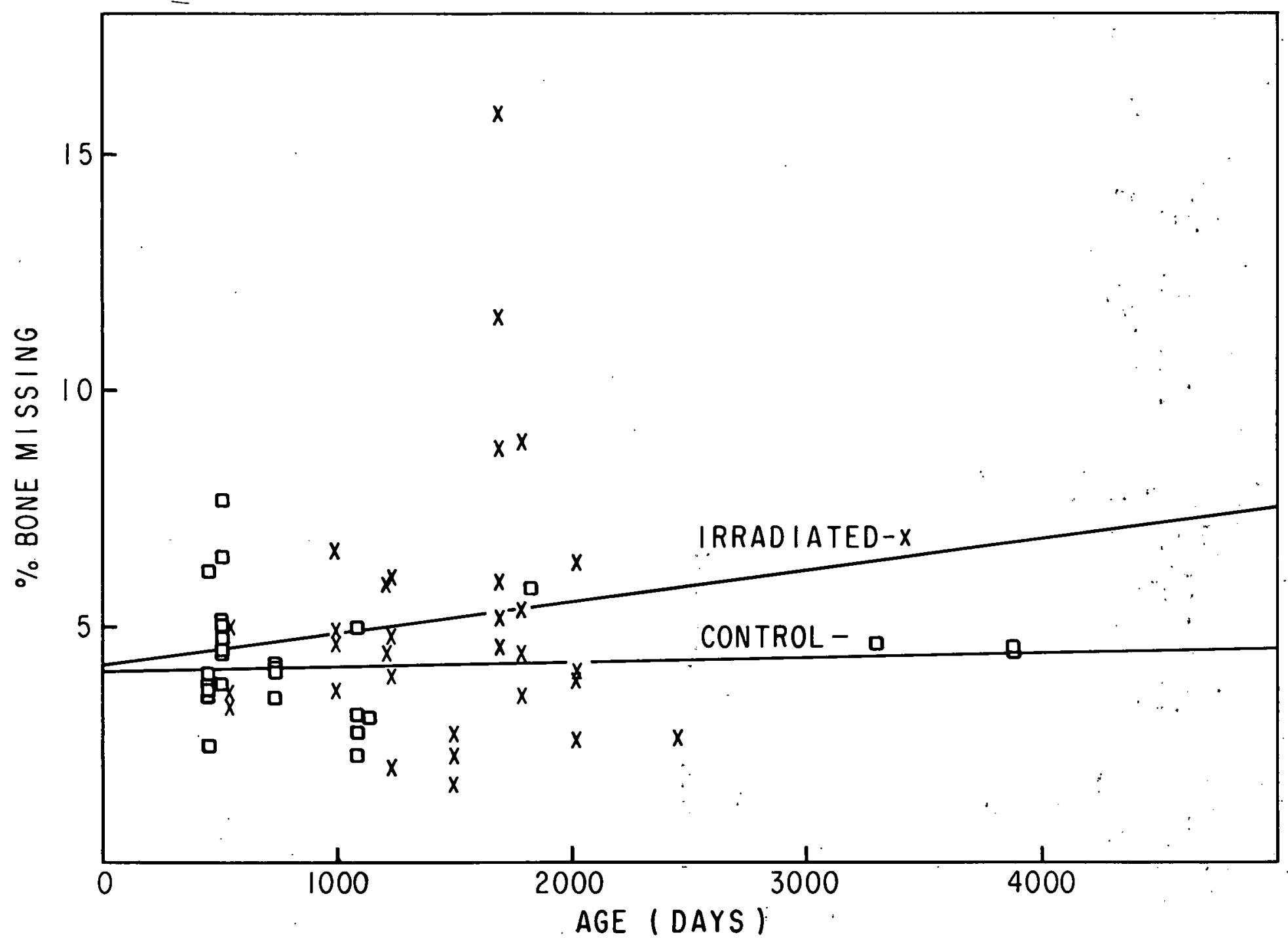




\section{STUDIES OF TRABECULAR BONE IN BEAGLES AND HUMANS}

W. S. S. Jee, R. G. Bromley, N. L. Dockum, M. Lowe, R. Burggraaf,

R. Mical, Kẹdra Dedekind: and. J. S. Arṇold *

Abstract: The relationship between the percent of osteoid seams, the percent of osteoid seams in the central portion of the vertebral body, the percent of bone and the total bone surface perimeter within the periosteal envelope of lumbar vertebral bodies with age was studied. Specimens included 72 human and 40 Beagle lumbar vertebral bodies. In the human, the percent of centrally located osteojd seams was $12 \%$ at 2 years, $3 \%$ at ages 28 to 38,2 to $14 \%$ at ages 40 to 50, and approximately 5\% thereafter. In the Beagle the distribution of osteoid seams with age resembled that for the human. The depression of osteoid seams occurred at 28 to 38 years in human and 4.1 to 5.4 years in Beagles. The percent of osteoid seams in the entire vertebral body of humans paralleled that of the central portion, but was generally higher. In humans the percent of bone within the periosteal envelope decreased slower with age than it does in the dog (human slope $=-0.0987 \mathrm{vs}$. dog slope $=-0.810$ ). In humans the total bone perimeter was small in the young, increased rapidly to age 40 years, then decreased gradually with age. In the dog the total bone surface perimeter remained almost constant over its life span.

\section{INTRODUCTION}

This is a part of a continuing program to study the alteration in cancellous bone with age (1). These changes in spongy bone with age must be characterized before the toxic effects of very low doses of internally deposited bone seeking radionuclides upon the skeleton can be evaluated.

The present report describes a study which characterize the changes in bone, bone surface and osteoid seams in the lumbar vertebral body as a function of time.

\section{MATERIALS AND METHODS}

The raw material for these studies included human lumbar vertebrae collected from 72 routine autopsies at the Providence. Hospital in Portland, Oregon, by Drs. J. S. Arnold and T. H. Cochran, and from 40 dogs 
from the control colony of Beagles at the Division of Radiobiology, University of Utah. Various causes were responsible for death. Most of the subjects and all the dogs were thoroughly autopsied, providing evaluations of the measurements of the vertebral specimens (1). Preparation of Human Material:

The frozen human second vertebral body was sawed longitudinally in the sagittal plane into slabs of 5 to $7 \mathrm{~mm}$. A band saw with a skip tooth blade was used, producing a clean cut surface with no packing of the saw blade or detectable homogenization of the adjacent tissue. Cutting the tissue in the frozen state prevents the forcing of bone chips into adjacent tissue. The still frozen bone slabs were placed in cold absolute acetone, defatted and dehydrated by five changes of absolute acetone ether and ten changes of diethyl ether. The specimens were dried and embedded in a mixture of $45 \%$ ethyl and $55 \%$ butyl methacrylate with $0.9 \%$ catalyst. The undecalcified embedded specimens were sectioned at 8 microns by a heavy duty Jung, model " $K "$ microtome. The sections were adhered to gelatinized microscope slides using $70 \%$ ethanol as a wetting agent. The methacrylate was then removed by daily changes of chloroform.

Undecalcified sections were stained by the Von Kossa mineralized bone method and counterstained with a mixture of eosin and safranin for osteoid seams and cytological features (1). Fig. 1 illustrates typical human second lumbar vertebrae from a 2.5 and a 53 year old person and compares percent of bone, total osteoid seams and central osteoid seams.

Mineralized bone stained brown or black, while osteoid seams appeared as red smooth strips with sharp borders along the edge of the brown staining trabeculae. Cellular elements appeared pink with purplish nuclei. 


\section{Preparation of Dog Bones:}

The preparation and handling of the dog bones was slightly different from that of human bones. Details of the procedure have been described in a previous communication (1). These sections were stained with May-Grünwald-Giemsa and Von Kossa's stains.

Four different quantitative studies were conducted on lumbar vertebral bodies: (I) measurement of the percent osteoid seams in the entire second Iumbar vertebral body; (2) measurement of the percent osteoid seams in the central portion of the vertebral body; (3) measure-ment of the percent bone in the periosteal envelope; and (4) measurement of the bone perimeter within the periosteal envelope.

\section{Quantitative Methods:}

The stained lumbar vertebral section consisting of cortical and trabecular bone were projected a standardized distance on to uniformly thick tracing paper after which the bone surfaces were traced. Utilizing a microscope properly calibrated with the tracing for known distances, the measured osteoid seam lengths and widths were recorded in the proper position on the tracing. Bone surface perimeter was measured by a mechanical map measuring device calibrated in centimeters. The percent of endosteal surface covered by osteoid seams was calculated by dividing the total seam length in microns by the total exposed bone surface perimeter in microns. The second method of calculating the percent of osteoid seams and bone perimeters involving sampling surface measurements using the Zeiss integrating eyepiece $(2,3)$. The osteoid seam percent was determined microscopically by counting the number of intersections by the horizontal lines of a calibrated ocular micrometer with osteoid seams and dividing it by the number of intersections with trabecular surfaces 
(bone perimeter). The bone perimeter in microns was calculated by the equation $\frac{\pi}{2} \times \mathrm{H} \times$ a. The number of intersections (hits) equals " $\mathrm{H}$ ". The distance between horizontal lines in microns is represented by "a". Histological sections were sampled in the following manner. Every other square was counted and the number of hits were multiplied by 2 to represent the entire vertebral section. The sampling was thus uniformly distributed to represent the variation in quantity of seams in different regions. In small sections every field was counted.

The percent of total area composed of bone was measured from a second tracing of the original projected stained slide. The marrow area vias cut out and separated from the bone and the representative paper. fraction weighed on an analytical balance. The percent of bone was calculated from the weight of bone fraction divided by the combined weight of bone and marrow fractions (Method I).

The above procedure was too tedious and consequently a second method (Method II) was used in which the percent osteoid seams of bone was calculated by projecting stained sections of vertebrae on a grid divided into $2 \mathrm{~cm}$ squares. The total number of grid intersections lying within the periosteum was counted. This number was divided into the number of intersections lying on mineralized bone. A mechanical rotating slide holder was used to rotate the slide and counts were repeated at six equally varying positions through a 90 degree arc. The six results were then averaged at the $95 \%$ confidence limits determined by the range. Comparison of Methods:

Table I lists the percent bone, osteoid seams, bone perimeter and the calculated percent osteoid seams for the two methods. The percent bone is in reasonable agreement with a tendency in method II (microscopic 
sampling) to obtain higher figures. Sampling by method II (microscopic) of bone surface occupied by் osteoid seams and bone perimeter in comparison to the tracing method (Method I) was found to be more variable with the greatest variability in small samples. When the percent of seams is less than $5 \%$ the microscopic sampling method was found to be consistently higher.

Percent Bone Within Periosteal Envelope of Human Second Lumbar Vertebral Body:

The percent bone in the periosteal envelope from 58 cases is plotted. as a function of age in Fig. 2 revealing a progressive loss of bone as a function of age. The females appeared to have less bone than males the 2 -year-olds contain $25 \%$ bone which decreases progressively to $15 \%$ at age 80 years; . The slope of the line has been found by the least squares method to be -.0986 . When the slope of the entire population is extrapolated, it appears that bone reaches zero bone at about 235 years.

Individuals containing a high percent of bone in the periosteal envelope (greater than 22\% after age 40) arie cases dying from heart failure, aortic aneurysm, and acute vascular and pancreatic disturbances. Conversely, individuals with low percent of bone values (values less than $13 \%$ after age 40 ) represent cases of cirrhosis of the Iiver, chronic pulmonary disease, meningitis with adrenal involvement, simultaneous kidney and vascular disease, and a case of multiple myeloma.

Total Bone Peirimeter (bone surfaces) in Human Lumbar Vertebral Bodies:

The total bone perimeter from 62 cases is plotted as a function of age and sex in Fig. 3. It is small at ages 2 and 3 months, increases rapidly up to the age of 49 years and decreases until age 80 years. "At age 3 the bone perimeter is approximately $450,000 \mu, 760,000 \mu$ at age 8 , 
$1,300,000 \mu$ at age 12, peaking at 1,700,000 $\mu$ at age 40 then decreasing to an average of $1,000,000 \mu$ at age 80 . In Fig. 4 the bone perimeter values are normalized to the smallest periosteal envelope to corriect for variations in size. Surprisingly, the bone perimeter values decrease gradually over 9 decades. At age 2 the normalized bone perimeter is about $500,000 \mu$ and decreases to about $200,000 \mu$ at age 90 .

Percent of Osteoid Seams in Human Vertebral Bodies:

The percent of bone surface occupied by osteoid seams in human lumbar vertebral bodies, is plotted in Figs. 5, 6, 7 and. 8. Figs. 5 and 6 are osteoid seam counts restricted to the central portion of the vertebral body (trabecular bone only) from 29 acute cases and 61 acute and chronic cases, respectively. Figs. 7 and 8 are seam counts of the entire vertebral body from 24 acute cases and 72 combined acute and chronic cases, respectively.

The plot of the centrally located osteoid seams from the 29 acute cases shows $12 \%$ at 2 years, $3 \%$ seams at ages 28 to 38 , and varying 2 to $14 \%$ at ages 40 and 50 and approximately 5\% thereafter (Fig. 5). When all 61 cases were plotted, the low value for percent of seams at age 28 to 38 was still apparent except for a male with a chronic kidney disease who had a $14 \%$ seam count (Fig. 6). After 50 years, the osteoid seam values are more variable ranging as high as 20\%. In both plots (Figs. 5 and 6), the males consistently exhibited a higher percent of osteoid seams than the females.

The percent of seam values of centrally located seams (trabecular bone) were consistently lower than the values for osteoid seams which included trabecular and cortical bone from 24 acute and 58 combined acute and chronic cases. The latter values showed a greater percent of seam 
spread (Figs. 7 and 8). Osteoid seam values as high as 33\% were plotted for individuals with kidney diseases in Fig. 8. At any rate, the low osteoid seam values remained apparent between ages 28 to 38 years.

High osteoid seam values were observed in cases with chronic diabetes, asthma, myocardial infarcts, kidney disease, and some vascular diseases (Figs. 6 and 8). Low osteoid seam counts were noted in cases of partialt paralysis, cirrhosis of the liver, irradiation therapy coupled with the loss of one testis and a case of multiple myeloma.

In the four liver cases plotted for central and total osteoid seams, it was noted that two cases of cirrhosis of the liver had the lowest pencent of osteoid seams. One exhibited $0.8 \%$ and the other $0.65 \%$ central osteoid seams, respectively (Fig. 6). Two other cases, one involving centrolobular necrosis of the liver showed $2.3 \%$ seams while a case with hepatic cysts registered a high $13 \%$ seams.

The cases with a history of kidney disease showed an extremely high percent of osteoid seams. Generally, individuals inflictëd: with:some vascular disease (arteriosclerosis) and some form of kidney disease exhibited the highest percent of osteoid seams, namely $22 \%$ for centrally located areas and 33\% for entire vertebral bodies (Figs。 6 and 8). Percent of Bone in Lumbar Vertebral Bodies of Adult Beagles:

The young Beagle (500 days or 1.37 years of age) possesses $45 \%$ bone in its lumbar vertebral body as opposed to $22 \%$ in 30 year-old humans (Fig. 9). This value of $45 \%$ gradually decreases to $30 \%$ over a span of 4500 days (12.3 years). This is a 15\% loss of bone over a span of 12 years. Man loses the same 15\% over a span of 90 years. On extrapolation the percent of bone reaches zero in the dog at 54.5 years. The slope of line is calculated to be -.8097 . Female Beagles tend to possess less bone than the male. 
Total Bone Perimeter in Lumbar Vertebral Bodies of Adult Beagles:

The total bone perimeter of young adult Beagles averaged around 500,000 $\mu$ between 250-5700 days of age and showed very little variation (Eig. 10). Over a span of 5700 days (15.6 years) there was no loss of bone perimeter in the dog.

Percent of Osteoid Seams in Adult Beagles:

Fig. Il shows the variation in frequency of osteoid seams with age and sex in which the percent of bone surface occupied by osteoid seams is plotted on the ordinate against the age in days on the abscissa. The plot indicates that between ages 500-800 days, the percent of osteoid seams is about 10\%, dropping to approximately 7\% at 1000-1500 days and diminishing to less than 5\% between 1500-2000 days. Subsequently, between the ages of 2500-3500 days, the osteoid seam values show a rapid rise, followed by a decline at from 3500-5700 days. The shape of the slope resembles the human plot except that the low value of percent of osteoid"seams occurs at 1500-2000 days or from 4.1 to 5.4 years as compared to 28-38 years for the human. The same percent increase in osteoid seams is observed at 3000 days ( 8.2 years) for dogs as compared to age 50-60 for humans. 
TABLE I

Comparison

\begin{tabular}{|c|c|c|c|c|c|c|c|c|}
\hline No. & $\begin{array}{c}\% \text { Bone } \\
I *\end{array}$ & $\begin{array}{c}\% \text { Bone } \\
\text { II** }\end{array}$ & $\begin{array}{c}\text { Microns } \\
\text { Seams } \\
\text { I* }\end{array}$ & $\begin{array}{c}\text { Microns } \\
\text { Perimeter } \\
\text { I* }\end{array}$ & $\begin{array}{c}\text { Microns } \\
\text { Seams } \\
\text { II } * *\end{array}$ & $\begin{array}{c}\text { Microns } \\
\text { Perimeter } \\
\text { II } * *\end{array}$ & $\begin{array}{c}\% \\
\text { Seams } \\
\text { I* }\end{array}$ & $\begin{array}{c}\% \\
\text { Seams } \\
\text { II** } \\
\end{array}$ \\
\hline 107 & 16.3 & 23.8 & \multicolumn{6}{|c|}{ (Not Computed) } \\
\hline 108 & (Not & Computed) & 196,172 & 571,900 & 196,000 & 625,000 & 34.3 & 31.5 \\
\hline 121 & (Not & Computed) & 44,165 & $1,372,707$ & 47,600 & 920,000 & 3.2 & 5.2 \\
\hline 139 & 15.4 & 16.0 & 165,413 & $1,082,041$ & 139,000 & 970,000 & 15.3 & 14.4 \\
\hline 165 & (Not & Computed) & 9,415 & 260,000 & 11,000 & 223,000 & 3.6 & 4.9 \\
\hline 173 & 13.1 & 11.2 & 6,592 & $1,380,000$ & 17,500 & $, 040,000$ & .5 & $1.7^{\circ}$ \\
\hline 178 & 14.8 & 16.8 & 16,859 & 839,942 & 16,500 & 680,000 & 2.0 & 2.4 \\
\hline
\end{tabular}

* Method I, tracing method

** Method II, microscopic sampling

\section{DISCUSSION}

Although the study is incomplete, there are a few observations which warrant some discussion. These include some comments on the technique in measuring the percent of bone in the lumbar vertebral body and the comparison of percent of bone and osteoid seams in Beagles and man as a function of age.

Studies describing changes in cancellous bone with age have been reported. Arnold (4) showed excellent illustrations of cleaned vertebral. trabecular bone from a normal and osteoporotic individuals. In the osteoporotic, the trabeculae were very much thinner and are delicate with cross bridges of bone greatly reduced. Recently, Johnson (5) reported similar findings that there was a progressive regression of cancellous bone from heavy bars to "delicate filigrees that preceeded 
complete removal of portions with reinforcement of remaining portions with age". There are studies by. Trotter, et al. (5), and Arnold (4) which quantified the changes in trabecular bone with age. Trotter, et al., described a progressive decrease in bone densities ( $\left.\frac{\cdots \text { wight }}{\text { volume }}\right)$ in cervical, thoracic, lumbar and sacral vertebrae in whites and negros as a function of age. Arriold described the progressive loss of ash content (gm/cc) and a slight increase in density (gm/cc) of vertebral medullary tissue (trabecular bone only) as a function of age (4): 'To our knowledge the present study was the first attempt to quantitate the percent of bone in a lumbar vertebral body from a histological section. This method, with further refinement, may be quite useful in determining loss of bone with disease or radiation. Although the method cannot be applied to the living, the present study could contribute findings which gives us a better understanding of impressions gained from the living.

The comparison of the percent of bone with age in man and Beigle showed marked differences. Human beings started with less bone (23.2\%) and lost it at a slower rate (regression coefficient [slope] = -0.0987) while the beagle began with more bone (44.1\%) and lost it faster (regression coefficient $=-0.810)$. The slope of decrease in bone for man when extrapolated reached zero at 235 years, while the Beagle reached it at 54.5 years. This is a factor of 4.33 difference between dog and man. There is a safety factor of $3.33\left(\frac{235}{70}=3.33\right)$ for man with a normal life span of 70 years, while the Beagle has a safety factor of $3.63\left(\frac{54.5}{15}=3.63\right)$ for a life span of 15 years. These numbers are surprisingly close. In reality, the Beagle lumbar vertebral body contains greater percentage of bone at age 15 than human lumbar vertebral centra ever contained in their life span. 
It was reassuring to find that in both man and Beagle there was a depression at young adulthood in the percent of trabecular bone surface occuppied by osteoid seams. The depression occurred between 28 ..to 38 years in man and 4 to 6 years in Beagles. This finding is similar to depressions observed at age 35 in the compacta of human ribs by Frost (7), and at 21 to 30 years in the compacta of mandibles by Sissons et al. (8), and Manson (9) .

The present data substantiated the study of human mandibles by Manson and Lucas (10). They reported that bone surfaces involved in. deposition of new bone dropped to $2 \%$ at age $30^{\circ}$ to 40 and rose to $5 \%$ at the fifth decade. The changes in percent of osteoid seams in human lumbari vertebral bodies were much more variable than in the mandible or femur. For example, Manson reported that the percent of osteoid seam never exceeds $5 \%$ of the bone surfaces while in the lumbar vertebral bodies osteoid seams exceeding 5\% were not uncommon after age 40 (9).

It is difficult to explain the observed increase of osteoid seams after the fifth decade. The fact that more seams were observed in older bones does not mean more bone was being formed. It could mean that bone apposition and/or mineralization of osteoid were taking place more slowly.

Finally the authors feel that it is not appropriate at: this time to discuss the relationship of incidence of osteoid seams and percent bone to disease even though there were obvious differences reported for certain diseases. 


\section{REFERENCES}

1. W. S. S. Jee, R. S. Mical, N. L'. Dockum, R. Tegge, M. Lowe and

B. Burggraaf; Quantitative studies of trabecular bone remodelling, Research in Radiobiology, C00-119-229, p. 111-126 (1964):

2. A. Hennig, A critical survey of volume and surface measurement in microscopy. Zeiss Werḳzeitschrift, No: 30, 78-87 (1958).

3. K. Michel, Zeiss integrating eyepieces, Carl Zeiss Oberkochen/württ 40-195 e.

4. J. S. Arnold, Quantitation of mineralization of bone as an organ and tissue in osteoporosis, Clin. Orthopaedic, 17:167-175 (1965).

5. L. C. Johnson, Morphologic Analysis in Pathology; The kinetics of disease and general biology of bone in Bone Biodynamics, (ed. H. M. Frost) p. 543-654, Little Brown \& Co., Boston, Mass..(1964) .

6. M. Trotter, G..E. Broman and R. R. Peterson, Densities of bones of white and negro skeletons, J. of Bone and Joint Surgery 42A:50-58 (1960).

7. H. M. Frost, Bone Remodeling Dynamics, Charles C. Thomas, Springfield, Illinois (1963).

8. H. A. Sissons, J. Jowsey and L. Stewart, The microradiographic appearance of normal bone tissue at various ages in $X$-ray Micro scopy and X-ray Microanalysis (ed. by A. Engstrom, V. Cosslett and H. Pattee), p. 206-215, Elsevier Publishing Co., Amsterdam (1960) .

9. J. D. Manson, Age changes in bone activity in the mandible in Bone and Tooth, Proceedings of the First European Symposium, p. 343-349, Macmillian Co., New York (1964).

10. J. D. Manson and.R. B...Lucas, A microradiographic study of age changes in the human mandible. Arch. Oral Biol, 7:761-769 (1962). 


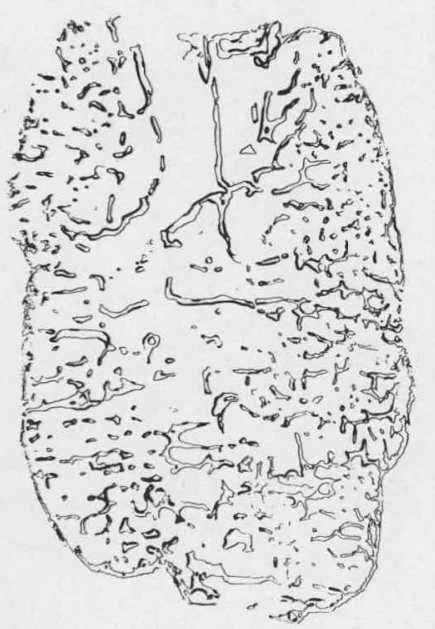

CASE \# 177

2.5 years old $23.7 \%$ BONE

$21.7 \%$ TOTAL OSTEOID SEAMS

$12.9 \%$ CENTRAL OSTEOID SEAMS

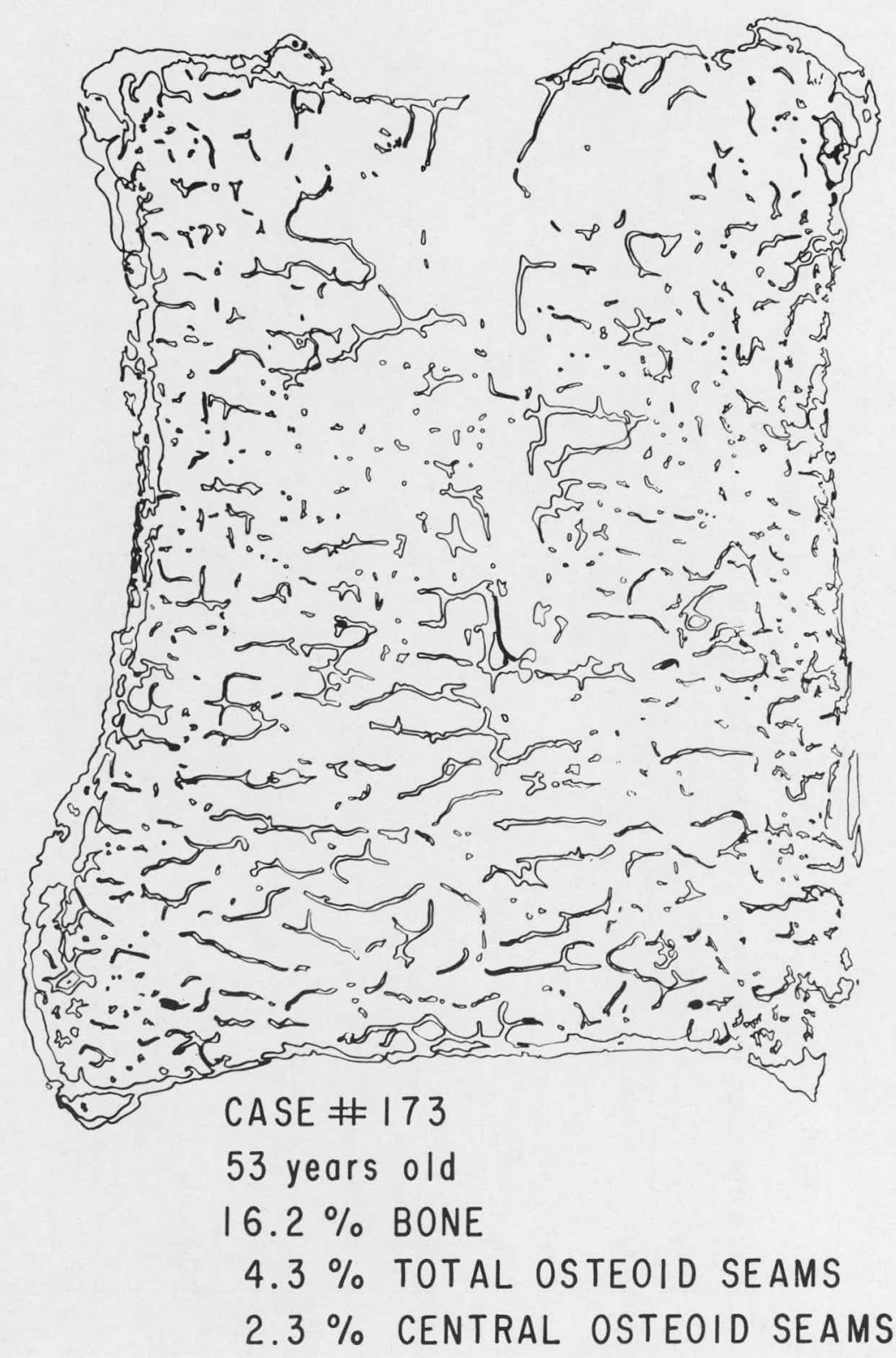

Figure 1. Comparative projection tracings of the second lumbar vertebrae from a 2.5 year old child and a 53 year old man showing per cent of bone, total osteoid seams and central osteoid seams. (X4) 


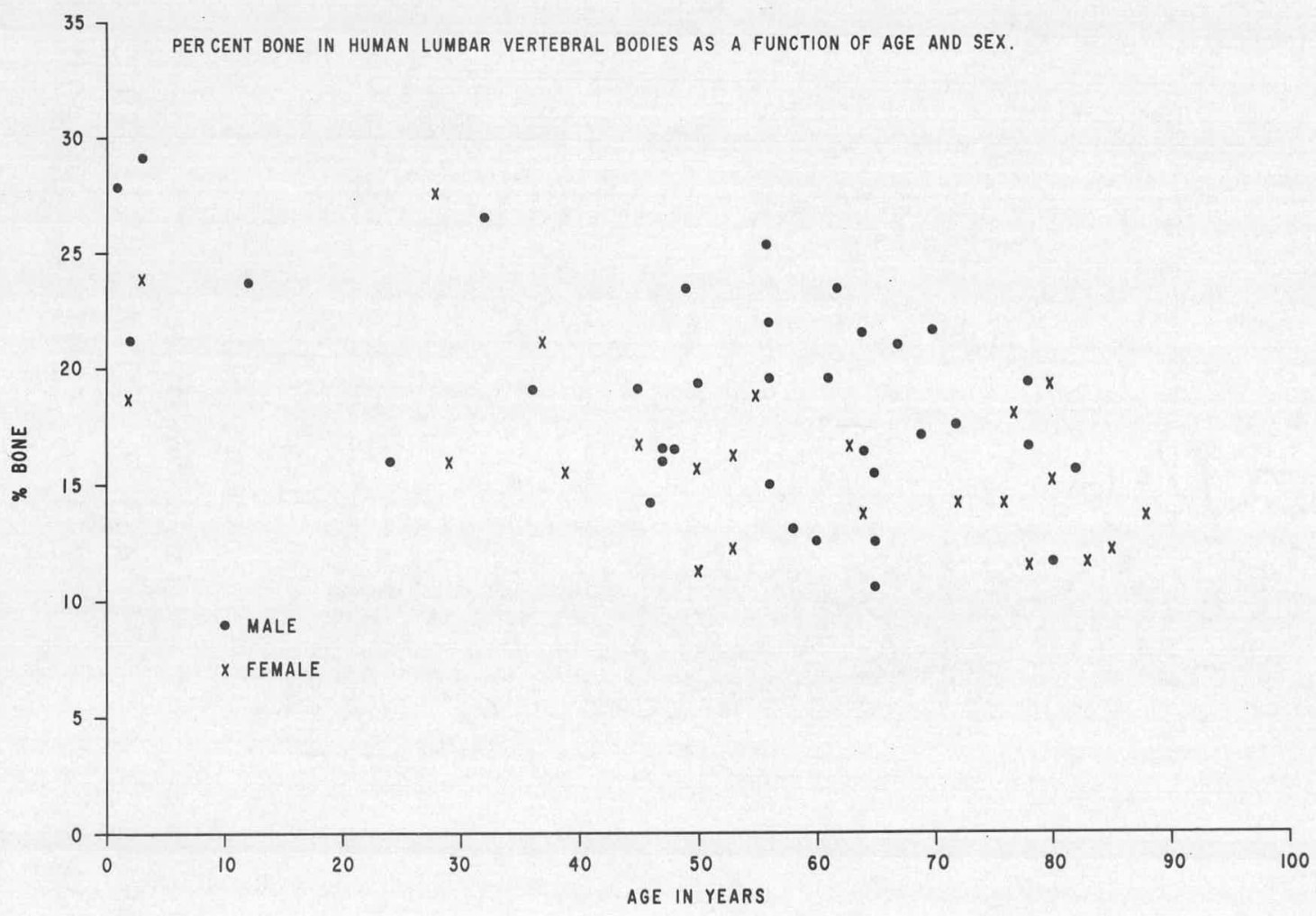

Figure 2. Percent bone in human lumbar vertebral bodies as a function of age and sex. There is a progressive loss of bone as a function of age (slope $=-0.0987$ ). 


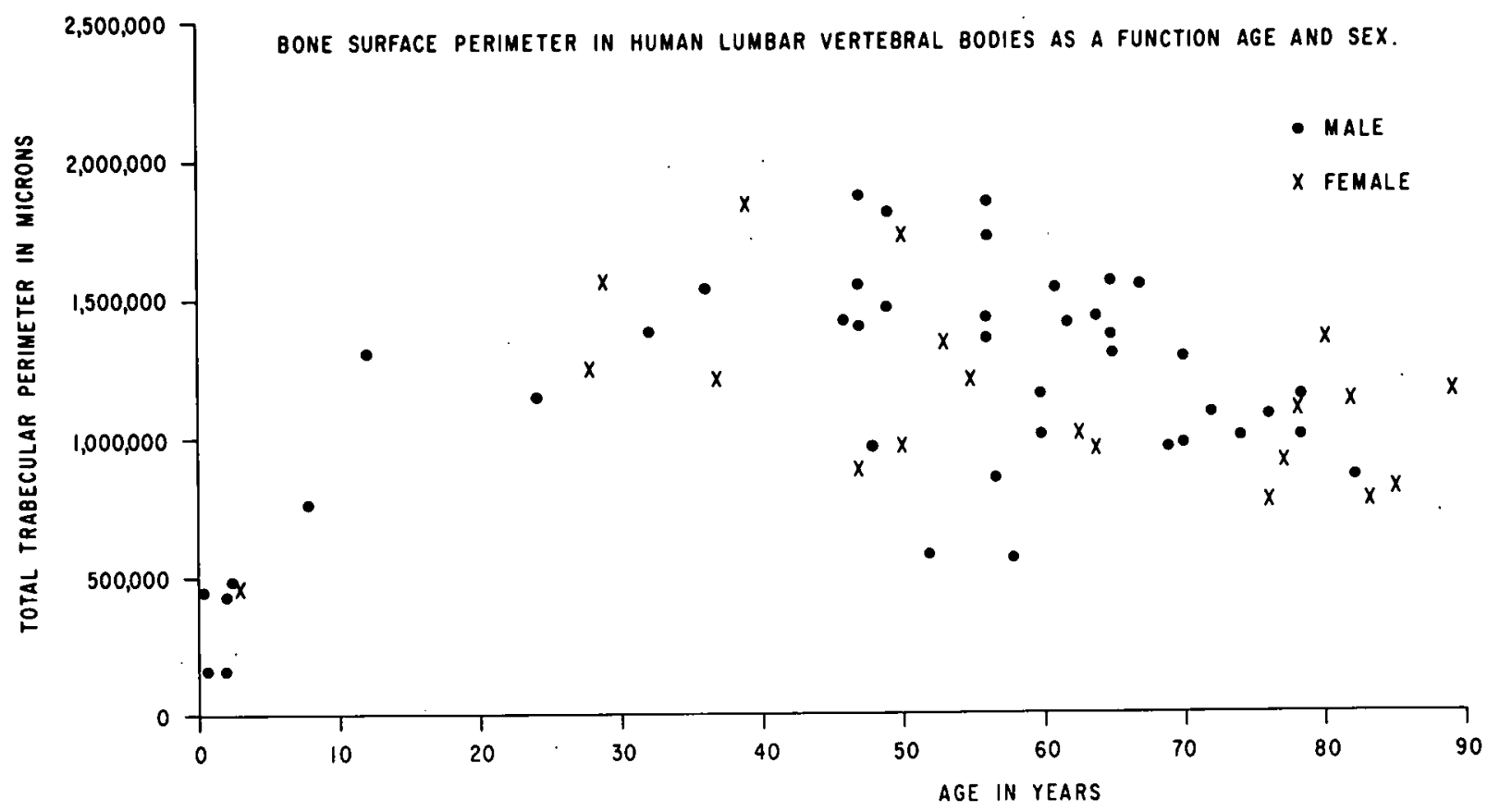

Figure 3. Bone surface perimeter in human lumbar vertebral bodies as a function of age and sex. It is small at early ages, increases rapidly to 40 years and decreases until age 80 years. 
BONE SURFACE PERIMETER IN HUMAN LUMBaR VERTEBRAL bOOIES AS A FUNCTION OF AGE AND SEX (NORMALIZEO DATA)

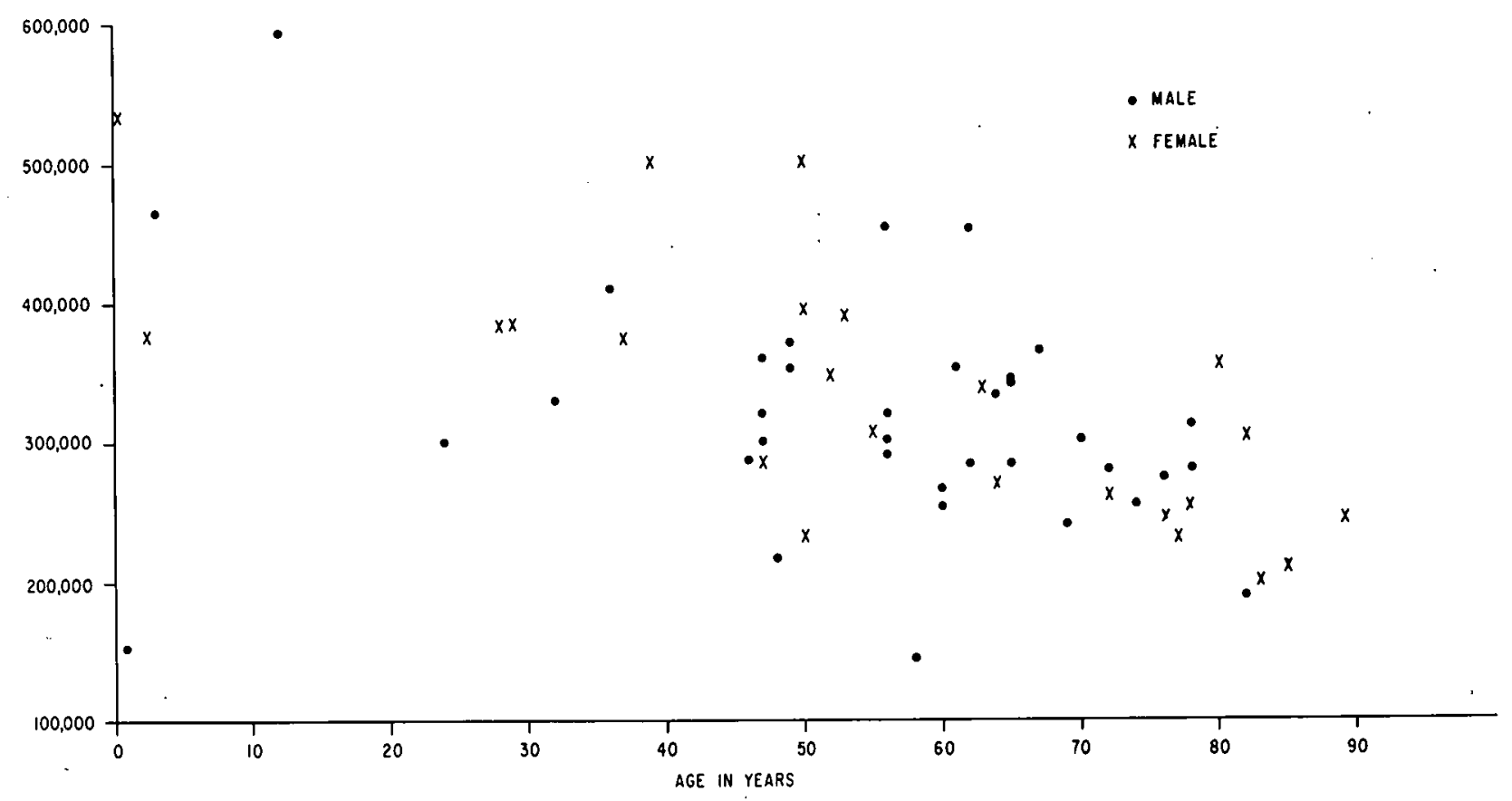

Figure 4. Bone surface perimeter in human lumbar vertebral bodies as a function of age and sex (normalized data). Data normalized to smallest periosteal envelope to correct for variations in vertebrae size. Bone perimeter values decrease gradually over nine decades. 


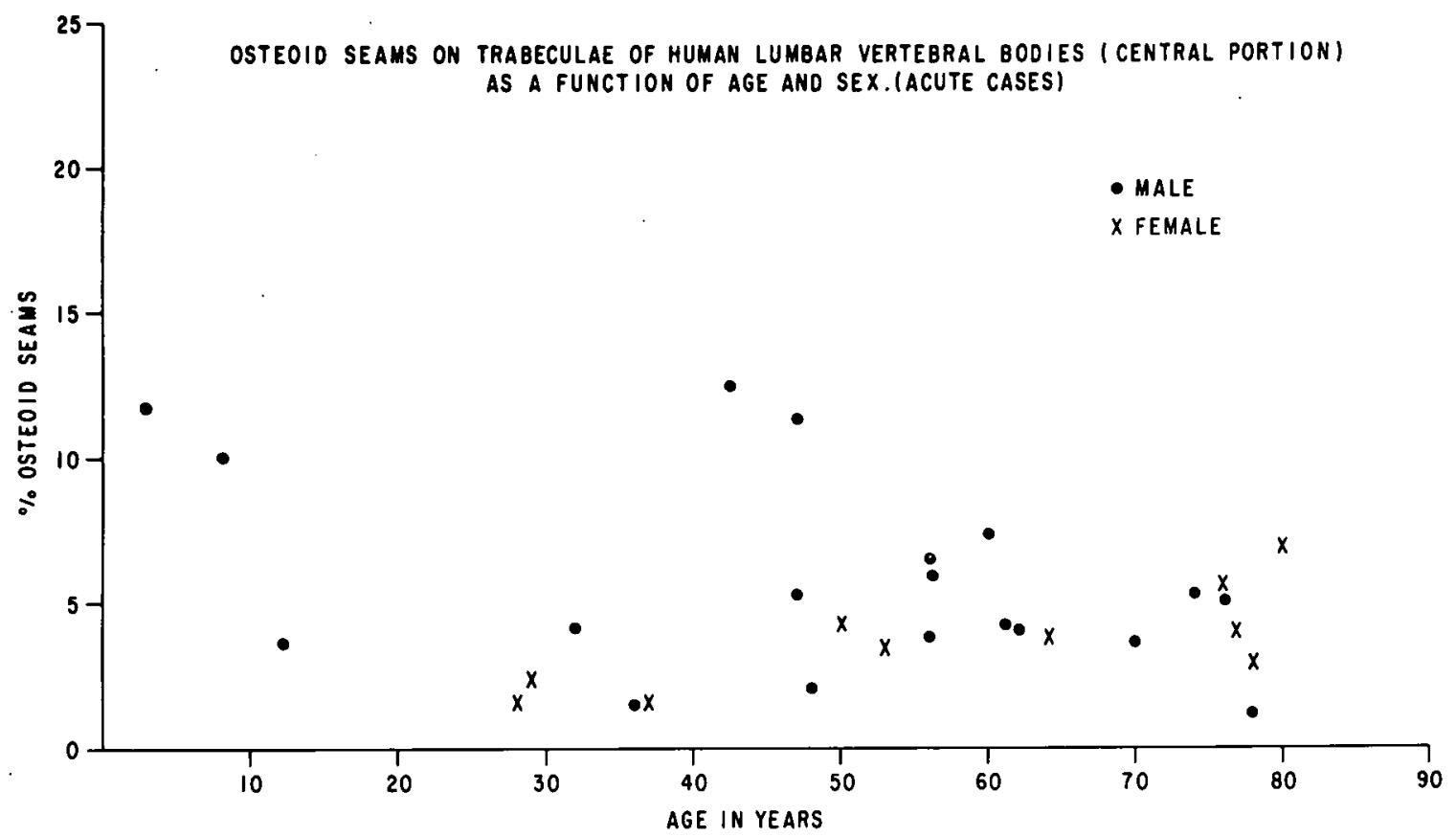

Figure 5. Osteoid seams on trabeculae of human lumbar vertebral bodies (central portion) as a function of age and sex (acute cases). 


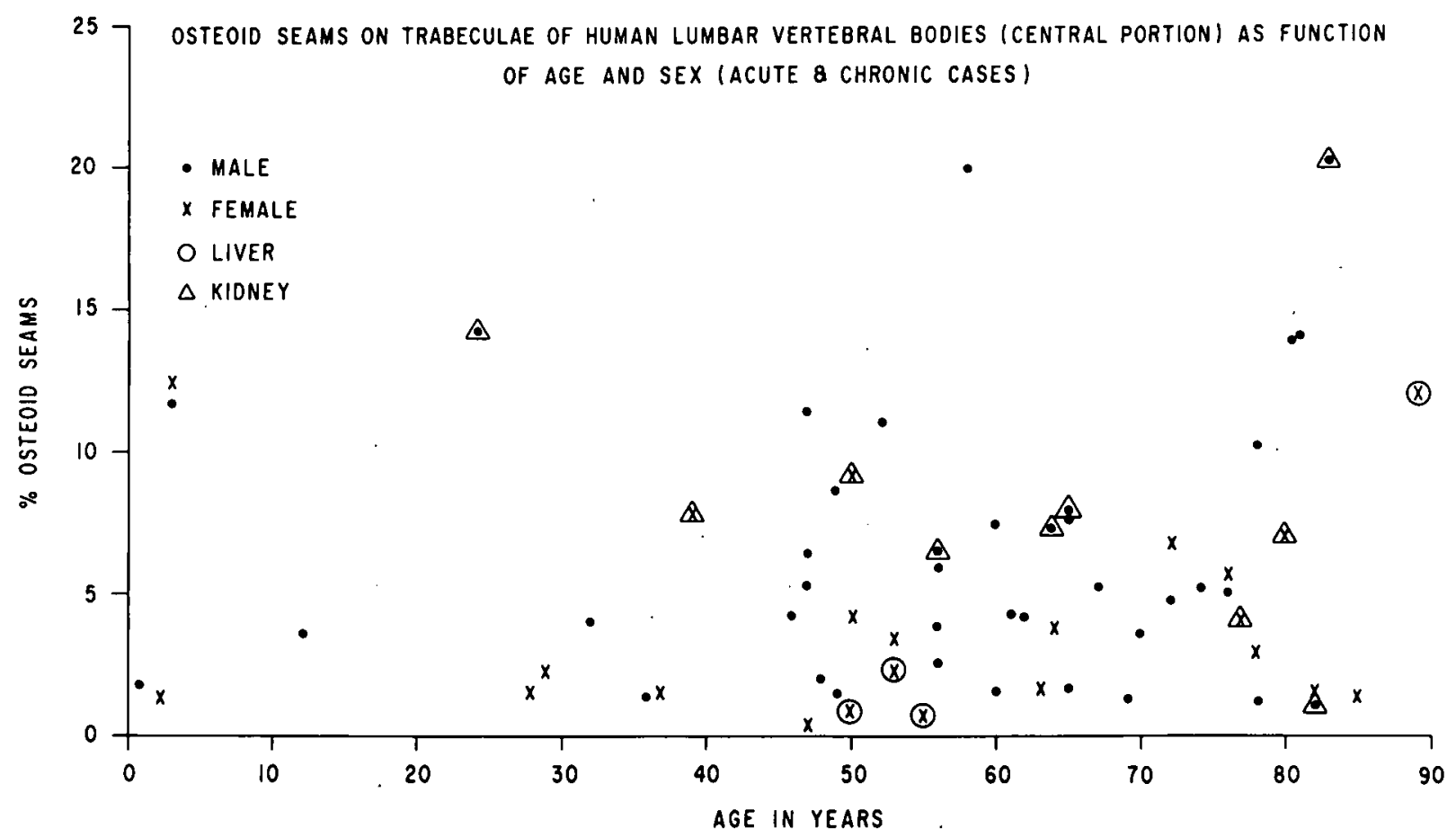

Figure 6. Osteoid seams on trabeculae of human lumbar vertebral bodies (central portion) as a function of age and sex (acute and chronic cases). Males exhibited higher percent osteoid seams than females. 


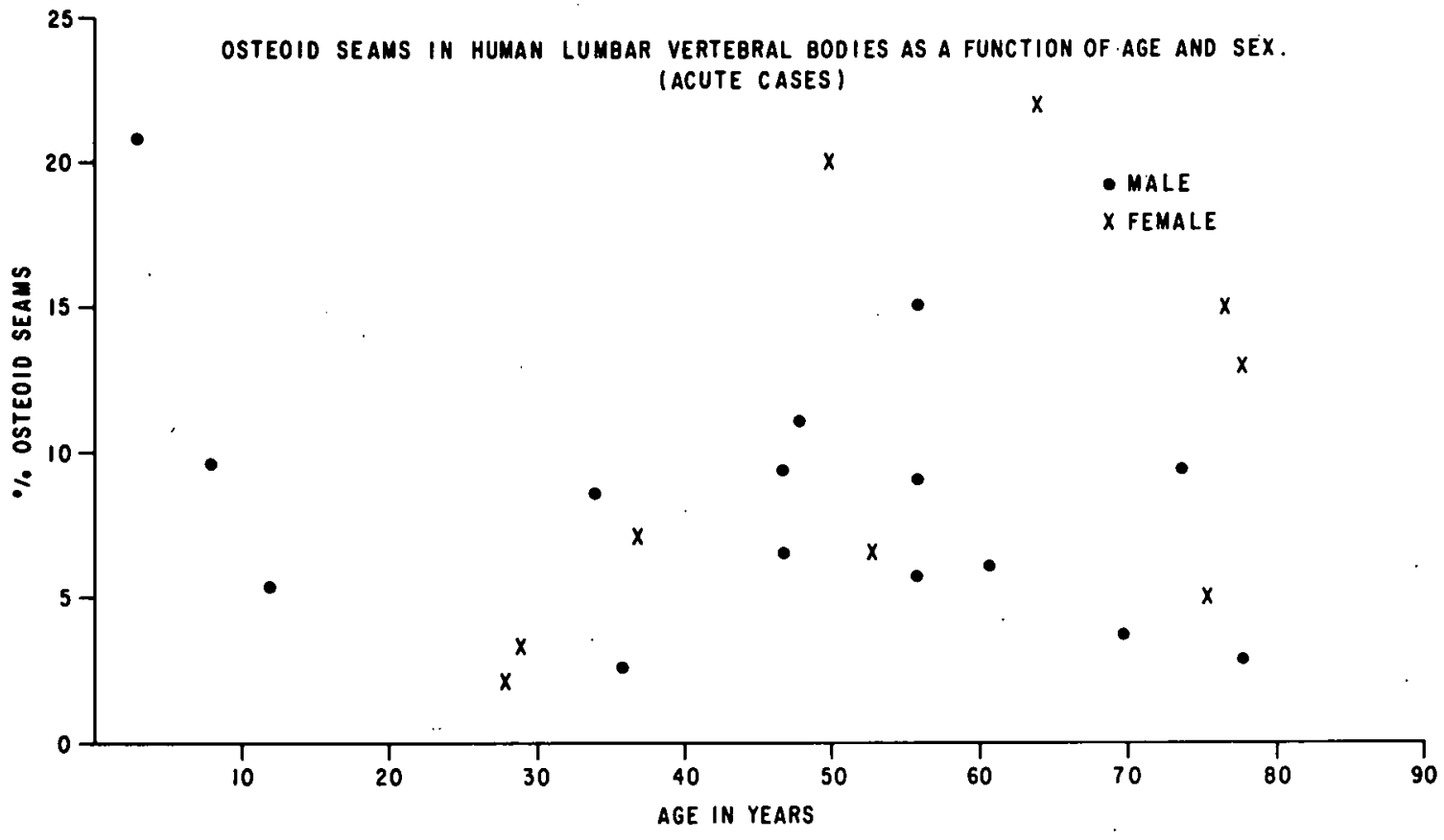

Figure 7. Osteoid seams in human lumbar vertebral bodies as a function of age and sex (acute cases). 


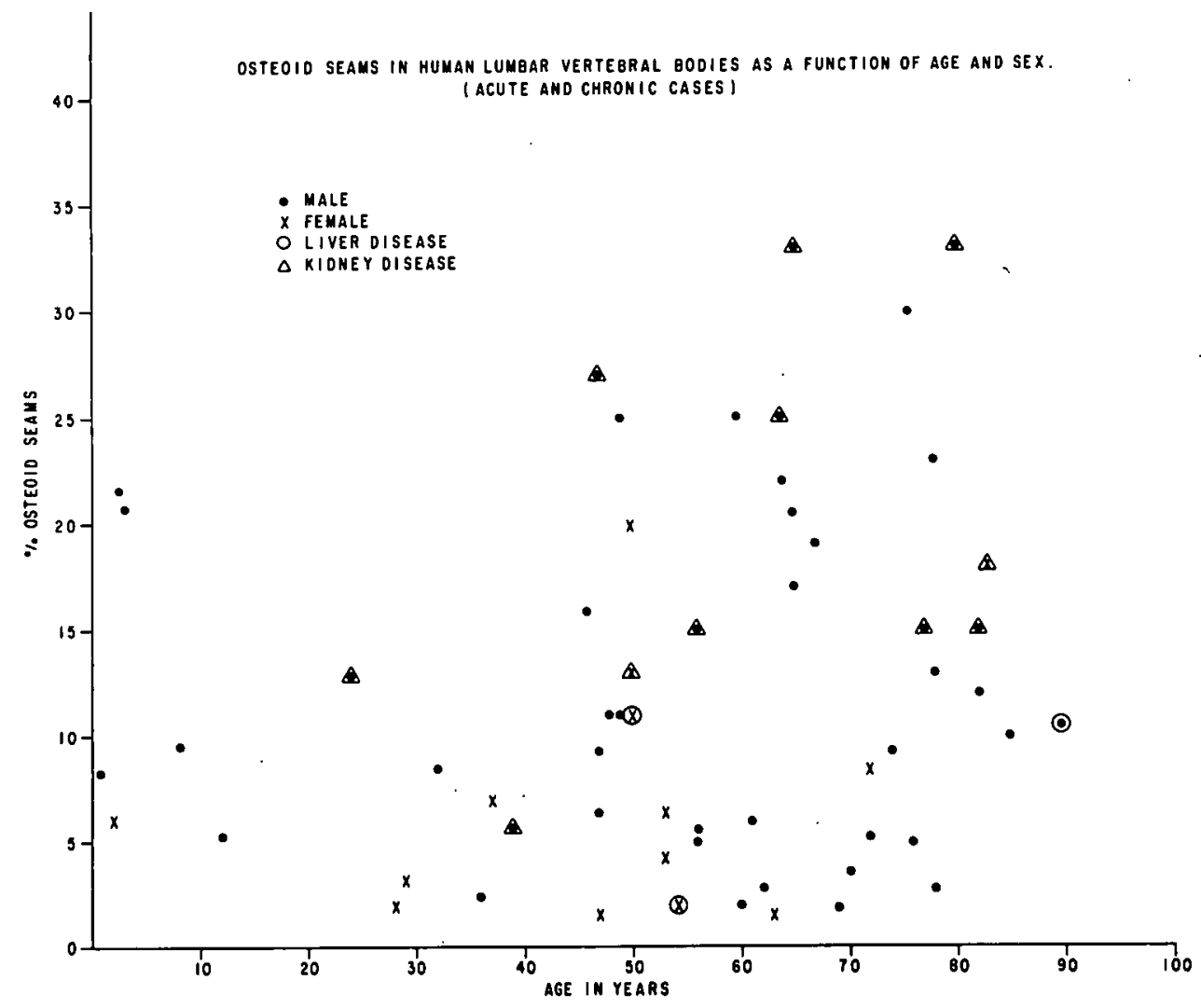

Figure 8. Osteoid seams in human lumbar vertebral bodies as a function of age and sex (acute and chronic cases). Individuals with kidney diseases have high osteoid seam values. 
PER Cent bone in Beagle lumbar vertebral bodies as a function of aGe and seX.

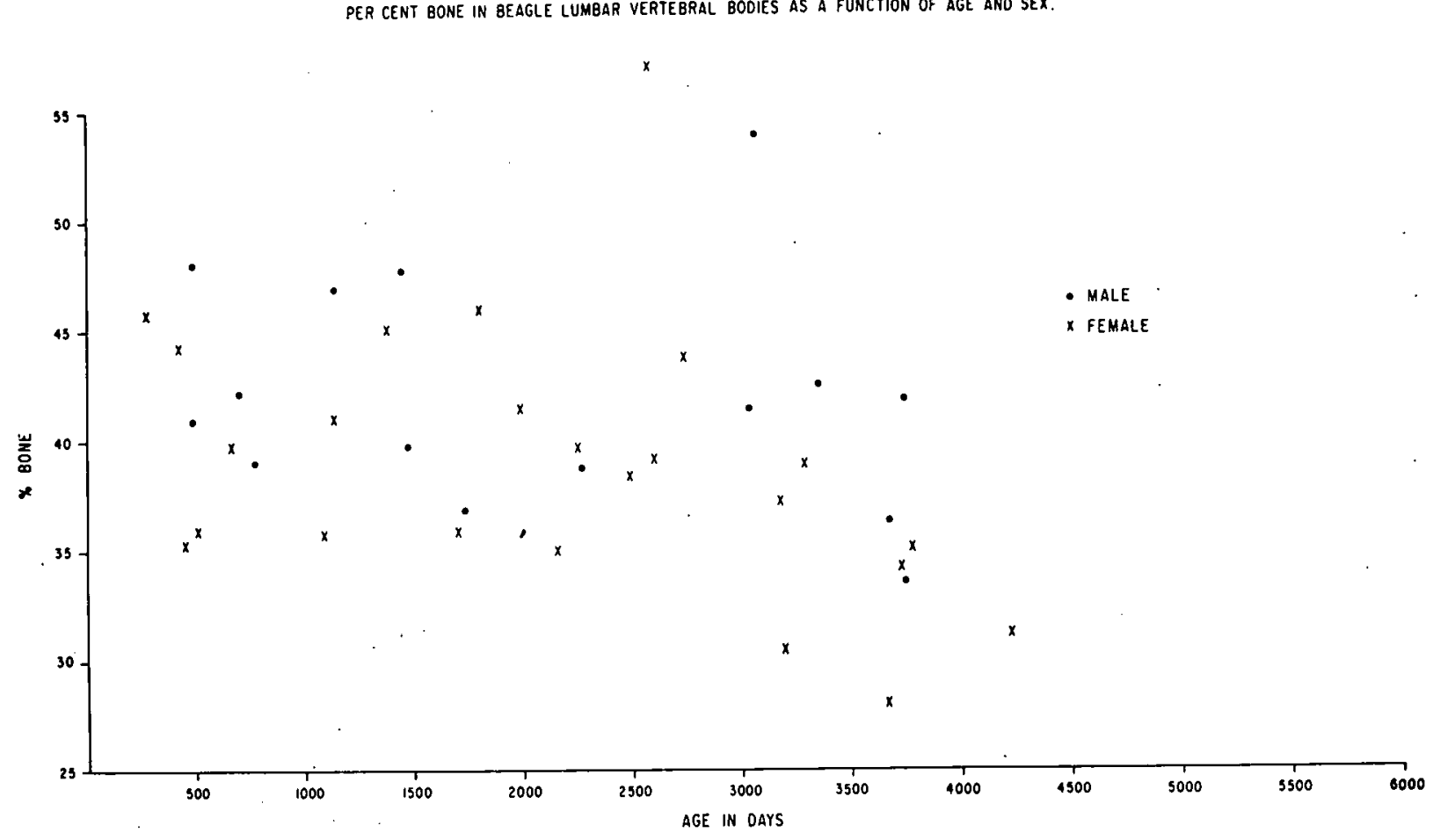

Figure 9. Percent of bone in Beagle lumbar vertebral bodies as a function of age and sex. There is a general decrease in the percent of bone with age (slope $=$ $-0.810)$. 


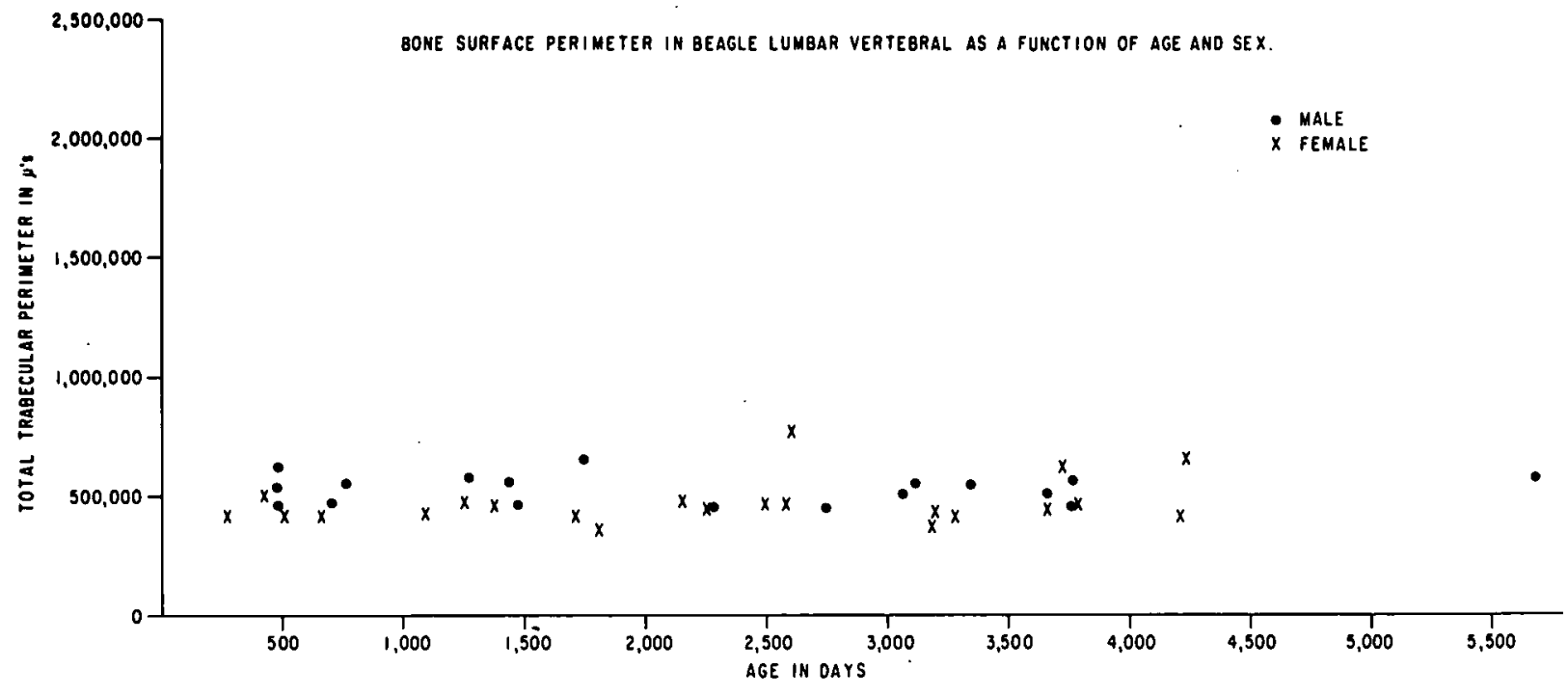

Figure 10. Bone surface perimeter in Beagle lumbar vertebral bodies as a function of age and sex. Very little variation in the amount bone surface is evident as a result of age. 


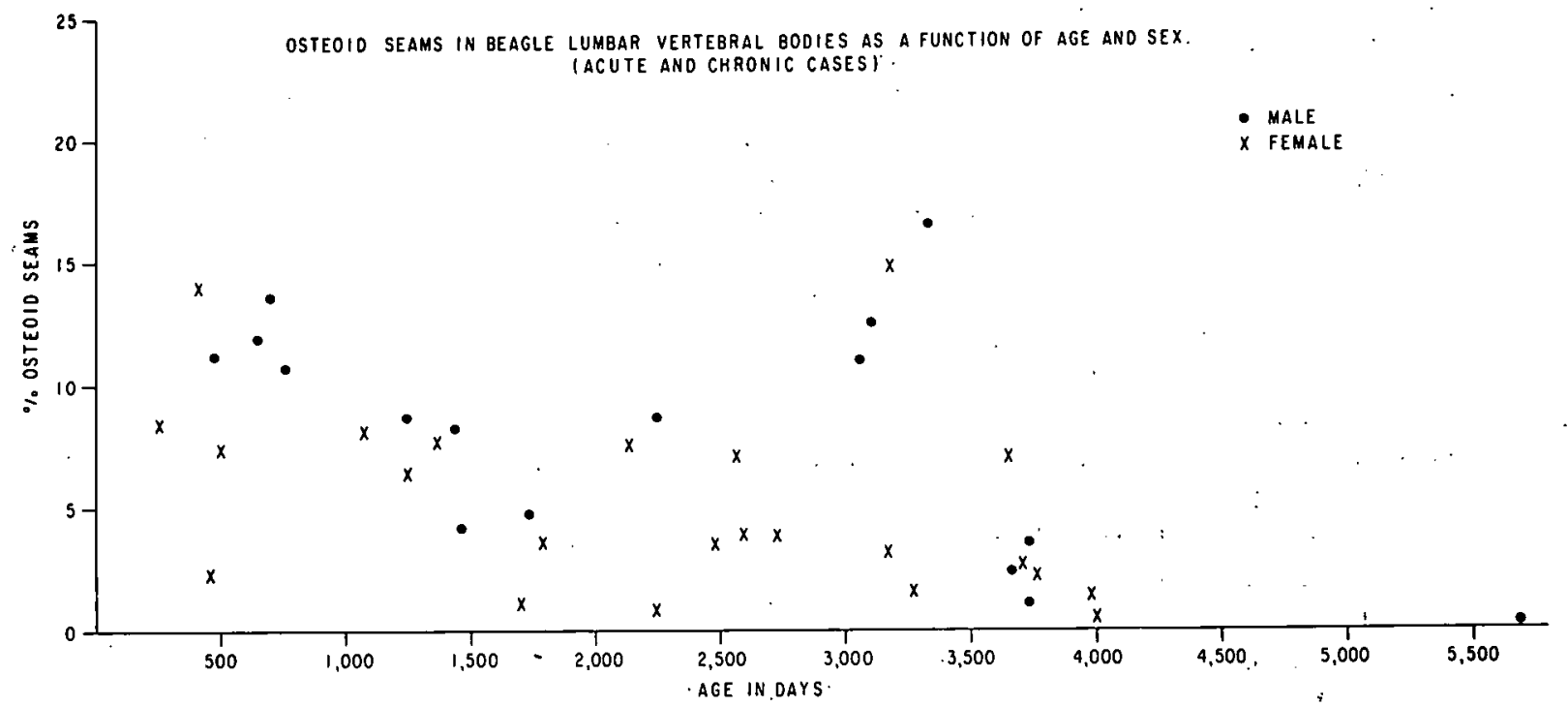

Figure 11: Osteoid seams in Beagle lumbar vertebral bodies as a function of age and sex (acute and chronic cases). 


\section{BIOASSAY OF THE INFLUENCE OF CORTISOL IN BONES OF GROWING RABBITS}

W. S. S. Jee, E. L. Blackwood*, Renate Tegge, N. L. Dockum, R. Haslam and F. A. Kincl**

Abstract: Microradiographs of distal femurs, femoral shafts and calvaria from growing rabbits fed a normal or rachitogenic diet plus $0,1,5,15 \mathrm{mg}$ cortisol $/ \mathrm{kg} /$ day for 15 days were analyzed for epiphyseal plate thickness, presence of growth arrest plate, regression of metaphyseal trabeculae, thickness of metaphyseal trabeculae, and porosities of femoral shafts and calvaria (bone atrophy). Rabbits fed a normal diet plus $1,5,15 \mathrm{mg}$ of cortisol exhibited epiphyseal plate of $0.73,0.47$ and 0.37 times as thick as their controls, while rabbits fed a deficient diet plus 1 and $5 \mathrm{mg}$ of cortisol exhibited epiphyseal plate 0.76 times as thick as their controls. Growth arrest plates appeared in rabbits fed a normal or deficient diet plus 5 and $15 . \mathrm{mg}$ of cortisol. Regression of metaphyseal trabeculae occurred only in rabbits fed a normal diet and treated with 5 and $15 \mathrm{mg}$ of cortisol. Porosity values of femoral cortices differed at all dose levels, while porosity values of calvaria differed only in animals fed normal diets plus 5 and $15 \mathrm{mg}$ of cortisol. The dose response relationships between porosities of femoral cortices and graded doses of cortisol exhibited slope values of 1.25 for rabbits fed normal diets and a value of 2.22 for rabbits on deficient diets. There was an advantage in using the rachitogenic diet in the femoral porosity analysis, but the use of the rachitogenic diet was a distinct disadvantage in the analyses of epiphyseal plate thickness, length of metaphysis and calvarium porosity.

\section{INTRODUCTION}

One of the principle undesirable side effects of contisol is a marked loss in mass of bone (osteoporosis or bone atrophy) accompanied by fractures. Since cortisol and related synthetic glucocorticoids are used prominently for a wide spectrum of diseases, it would be valuable to develop a bioassay technique which would quantify the bone resorption

\footnotetext{
*NIDR predoctoral fellow (NIH Training Grant \# 1TlDE-151-01). ** Syntex Laboratories, Palo Alto, California.
} 
induced by these corticoids in the hope that an effective anti-inflammatory drug can be developed without the untoward side effect upon bone. A better understanding of the dose response of bone tissues to the osteolytic effect of various glucocorticoids will be very informative in determining whether these drugs would be useful as agents in the removal of bone seeking radionuclides from the skeleton. The present communication describes methods for evaluating the effects of cortisol on the elongation of a long bone (growth) and bone atrophy in compact and spongy bones using contact microradiography and quantitative histology. The study compares the response of three dose levels of cortisol in rabbits fed a normal or a rachitogenic diet. Rabbits fed a rachitogenic diet are used because of a previous finding by Storey which showed that bone resorption induced by cortisone was accểlerated by a decreased dietary uptake of calcium and phosphorus (1). MATERIALS AND METHODS

I. Diets and Treatment:

Seventy-two, 6 to 8 week old New Zealand white rabbits weighing about $1000 \mathrm{~g}$ were divided into 8 experimental groups (Table I). The rabbits were fed either a normal or a rachitogenic diet No. 2,. U.S.P.* and injected subcutane ously in the inner thigh with $0,1,5$, or $15 \mathrm{mg}$ of cortisol per kg daily for 15 days. The animals were euthanized on day 16. The femur, tibia, and skull were removed, defleshed, and bone sections $5 \mathrm{~mm}$ thick were sawed and fixed in acetone. The adrenals and thymus were also removed and weighed. Only 2 out of the 8 animals survived the rachitogenic diet with $15 \mathrm{mg} / \mathrm{kg}$ of cortisol daily.

*Yellow corn meal, $76 \%$; wheat glutin, $20 \% ; \mathrm{CaCO}_{3}, 3 \%$; and $\mathrm{NaCl} 1 \%$. 
TABLE I

Treatment of Rabbits

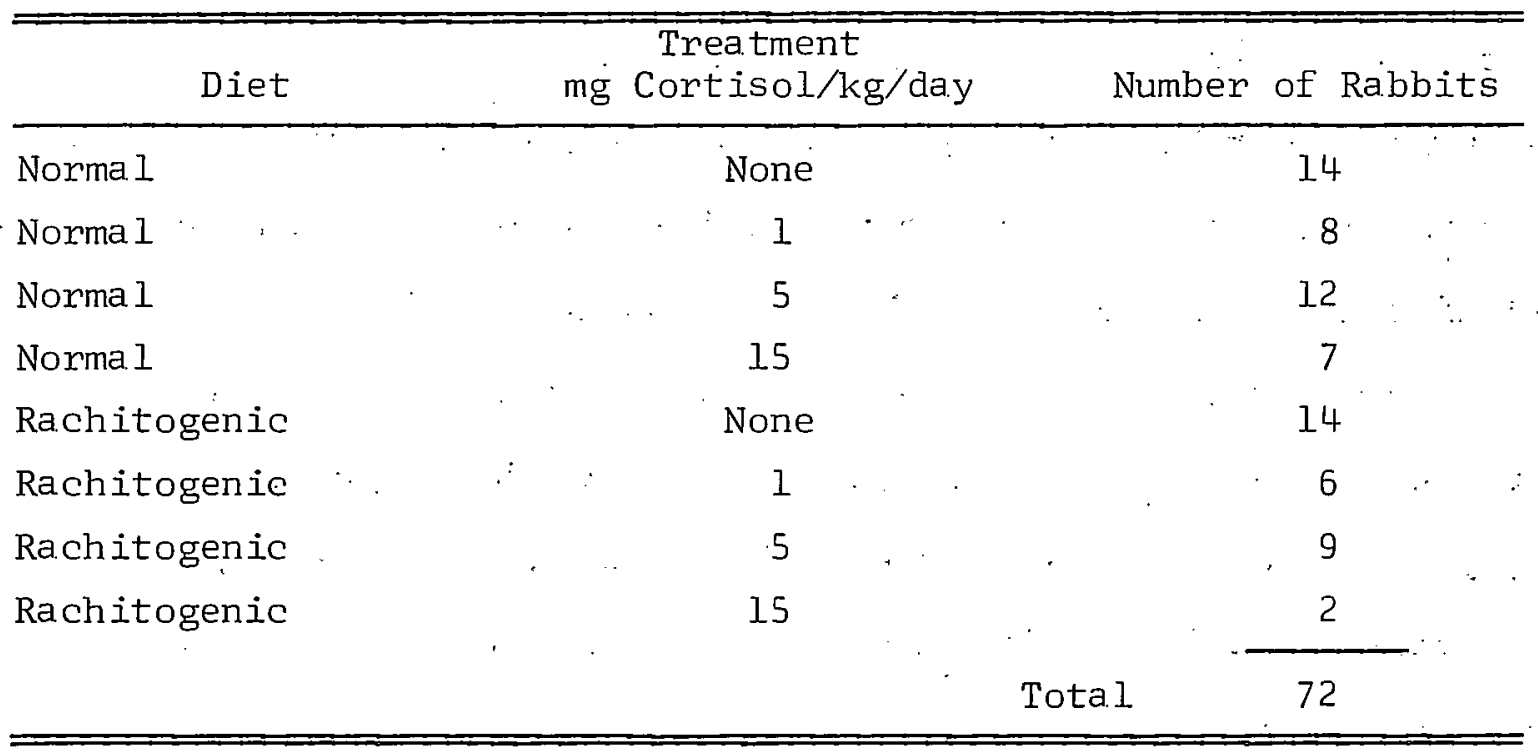

II. Quantitative Histology:

1. Porosity studies of mid-femoral shaft and calvarium. 'Cross sections were taken from the mid-diaphysis (shaft) of the femur, and from a frontal section of the right half of the skull (calvarium) at the point of fusion of the zygomatic arch and temporal bone." The bone section of the skull included the temporal and parietal bones with squamosal suture. The sections were fixed in acetone, defatted in ether and embedded' in bioplastic. They were then sawed and ground to a thickness of 100 microns and contact microradiographed (Figs.' 1 and 2) .

To quantify the bone resorption activity of the steroid upon the femoral diaphysis, the microradiographs of the shaft were projected on paper at a magnification' of 90 :: The outlines of the endosteal and periosteal bone surfaces and bone resorption holes and canals larger than 3 $\mathrm{mm}$ were traced and the area occupied by the ring of cortical bone (assuming nọ bone resorption) was cut out and weighed. The holes and 
canals with diameter larger than $3 \mathrm{~mm}$ (on the tracing) were considered to be resorption spaces and were removed as porosities. The areas of porosity were then cut out and the resulting bone ring was weighed again. The percent porosity was determined by dividing the weight of the bone ring without holes with the weight of the bone ring with holes and multiplying by a 100 .

The microradiographs of the calvaria $(1.77 \mathrm{~mm}$ of the temporal and $4.4 \mathrm{~mm}$ of the parietal bones measured from the squamosal. suture) were projected on paper at a magnification of 62 . Next the outlines of the periosteal and endosteal bone surfaces of the inner and outer tables and the trabeculae in the diploic spaces along with resorption spaces and canals with diameters larger than $2 \mathrm{~mm}$ were traced. The calvarium consisting of inner and outer tables and its diploic spaces was. cut out and weighed. Then the areas occupied by the marrow in the diploic spaces and the holes in the compacta (resorption spaces and canals) were cut out and the paper representing the remaining calvarium. was weighed again. The percent porosity was determined from the weights of the calvarium with and without holes and marrow in the same manner as with the femoral shaft.

\section{Distal Femur Analyses. The distal femurs were sawed in the} sagittal plane and fixed in acetone. One half. was processed, as outlined above, for.contact microradiography, while the other half was decalcified in $10 \%$ sulfosalicylic acid, doubled embedded in celloidin and paraffin, and sectioned at $8 \mu$, and stained with hematoxylin and eosin.

The microradiographs of the distal femur were analyzed for epiphyseal plate thickness, presence and thickness of growth arrest plate, length of metaphysis, and thickness of metaphyseal trabeculae at 
various intervals from the epiphyseal plate.

The qualitative and quantitative analyses of the hematoxylin and eosin stained distal femurs will be documented in another report.:

A. Distal femoral epiphyseal plate thickness.. The distal femoral epiphyseal plate was seen as a radiolucent region (black). between the bony plates of the epiphysis and the fine trabeculae of the metaphysis in the microradiographs of distal femur in figures 3 and 4. Some 12 or more measurements at $120 . \mu$ intervals were made across: the plate to obtain a mean thickness.

B. Presence and thickness of growth arrest plate. The growth arrest plate was a transverse stratum of bone at the junction of the metaphysis and epiphyseal growth plate (Figs. 3 and 4). The mean. width of the growth arrest plate was determined by twelve or more measurements at $120 \mu$ intervals.

C. Length of distal femoral metaphysis. A line was drawn traversing the metaphyseal spongiosa connecting a point where the epiphyseal plate dips proximally (Fig. 3) and a point located between the anterior and posterior walls of the distal femoral shaft some $12 \cdot \mathrm{mm}$ proximal to the epiphyseal plate. The length of the metaphysis under this line was measured microscopically.

D. Metaphyseal trabecular thickness at $520 \mu$ intervals from the distal femoral epiphyseal plate. The mean thickness of metaphyseal trabeculae which traverse the $520 \mu$ wide lines drawn at $520 \mu$ intervals from the epiphyseal growth plate were measured along. the line utilized to determine the width of the metaphysis described above (Fig. 4). Metaphyseal trabeculae thicknesses were measured.beginning $1040 \mu$ from the epiphyseal plate to avoid the huge error involved in measuring the 
very thin trabeculae at $520 \mu$ in the control specimen.

\section{RESULTS}

I. Effect of cortisol on body; adrenal and thymus weights:

Body, adrenal, and thymus weights are listed in Table II. The rabbits injected daily with 0 and $\mathrm{l} \mathrm{mg}$ of cortisol/ $\mathrm{kg}$ and fed a normal diet gained weight normally $(+396$ and $+353 \mathrm{~g}$, respectively). The rabbits injected with $5 \mathrm{mg}$ of cortisol/ $\mathrm{kg}$ showed some weight gain (+235 g.) while the $15 \mathrm{mg}$ of cortisol/kg showed a very slight weight loss (-22 g). In contrast, the animals fed a rachitogenic diet and injected with 0,1 , and $5 \mathrm{mg}$ of cortisol/ $\mathrm{kg}$ all showed consistent dose dependent $\because$ weight losses (-86, -130 and $-230 \mathrm{~g}$, respectively).

\section{TABLE, II}

Effect of Subcutaneously. Administered Cortisol to Immature Male Rabbits on Body, Adrenal and Thymus Weights

\begin{tabular}{|c|c|c|c|c|c|c|}
\hline Diet & $\begin{array}{c}\text { No. } \\
\text { Rabbits }\end{array}$ & $\begin{array}{l}\text { Treatment-mg } \\
\text { Cortisol/kg }\end{array}$ & $\begin{array}{l}\text { Body wt. } \\
\text { Initial }\end{array}$ & $-\frac{(g+S \cdot E \cdot)}{\text { Final }}$ & $\begin{array}{l}\text { Tissue } \overline{w t} \\
\text { Adrenals }\end{array}$ & $\left.-\frac{(m g+S}{\text { Thymus }} \cdot \mathrm{E} \cdot\right)$ \\
\hline$\overline{\text { Norma I }}$ & 14 & 0 & $1020 \pm 70$ & $1416 \pm 38$ & $101 \pm 4.9$ & $2074 \pm 211$ \\
\hline Norma 1 & 8 & 1 & $1049 \pm 64$ & $1402 \pm 39$ & $66.9 \pm 5.1$ & $987 \pm 84$ \\
\hline Norma l & 12 & 5 & $988 \pm 56$ & $1224 \pm 64$ & $70.6 \pm 7.6$ & $262 \pm 62$ \\
\hline Norma 1 & 7 & 15 & $1044 \pm 36$ & $1020 \pm 38$ & $53.6 \pm 2.7$ & $94 \pm 13$ \\
\hline$-\ldots$ & - & $--\cdots$ & - & $-\cdots$ & - & $--\cdots$ \\
\hline Rachitogenic & c 12 & 0 & $975 \pm 61$ & $958 \pm 32$ & $79.7 \pm 5.4$ & $318 \pm 33$ \\
\hline Rachitogenic & c 6 & 1 & $1005 \pm 60$ & $875 \pm 51$ & $66.3 \pm 5.3$ & $136 \pm 34$ \\
\hline \multirow[t]{2}{*}{ Rachitogenic } & c 8 & 5 & $1015 \pm 39$ & $847 \pm 30$ & $51.4 \pm 3.4$ & $93 \pm 12$ \\
\hline & & Tot & $24 \pm 36$ & & & \\
\hline
\end{tabular}

Terminal adrenal and thymus weights are also listed in Table II. The cortisol treatment produces adrenal atrophy and thymic involution. The rachitogenic diet alone results in some $20 \%$ reduction in adrenal weight and some $90 \%$ decrease in thymus weight. There is less involution of the thymus when a rachitogenic diet and cortisol treatment are 
employed compared to the same dose level on the normal diet, but the final weights are significantly lower.

II. Porosity study of mid-femoral shafts:

Microradiographs of the femoral mid-diaphysis of a control and a rabbit treated with $15 \mathrm{mg}$ cortisol/ $\mathrm{kg} /$ day are shown in Figure 1 and the results of the porosity measurement from various treatments are listed in Table III.

TABLE III

Statistical Data on Femoral Shafts Porosities Induced with Graded Doses of Cortisol

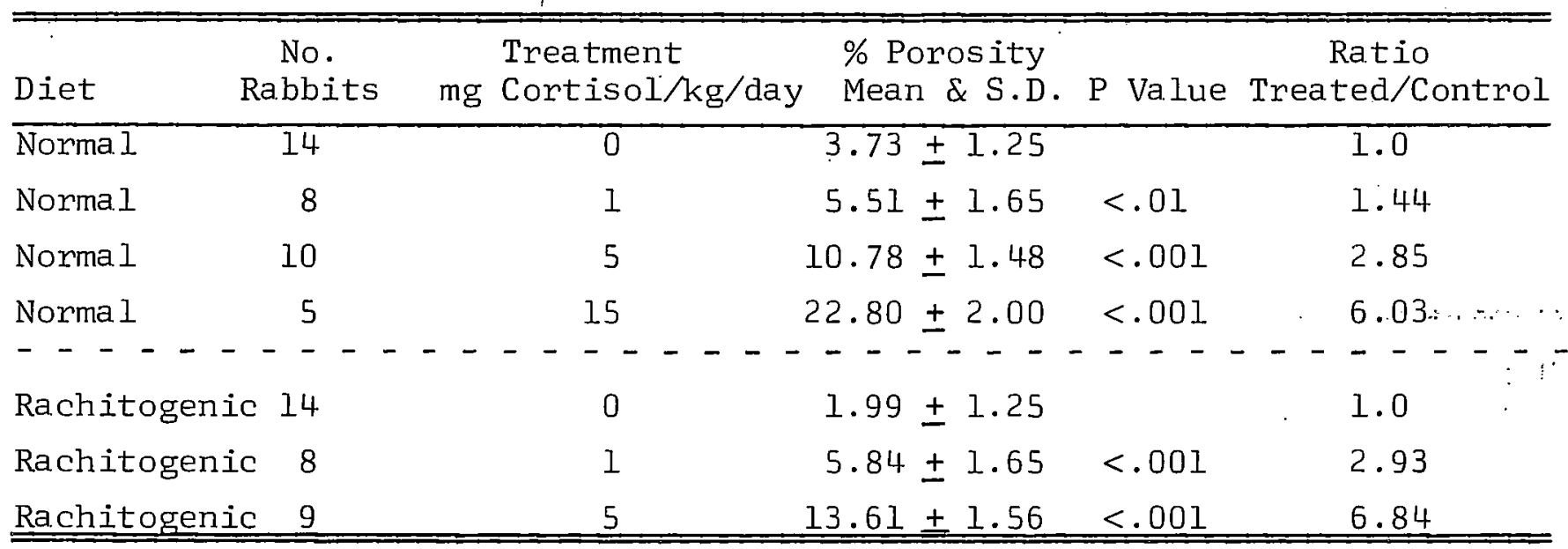

Table III shows that the femoral shaft porosities are all statistically different from their respective controls. The ratios of treated to control porosities for rabbits on normal diets are $1.44,2.85$ and 6.03 for 1,5 and $15 \mathrm{mg}$ of cortisol/ $\mathrm{kg}$, respectively. Higher ratios of 2.9.3 and 6.84 are calculated for the 1 and $5 \mathrm{mg}$ of cortisol/ $\mathrm{kg}$ dose levels on rachitogenic diet. The dose response line for the normal diet is +1.25 as compared to a slope of +2.2 for the rachitogenic diet (Fig. 5).

The data indicate the combined rachitogenic and cortisol treatment is more effective for differentiating femoral shaft porosities. This is substantiated by the steeper dose response line for rachitogenic 
diet and higher ratios of treated to control porosity values for identical dose levels for rabbits fed a rachitogenic diet. The steeper slopes and higher ratios are due to the porosity suppressing effect of the rachitogenic diet alone and the enhanced bone resorption observed with $5 \mathrm{mg}$ of cortisol and a rachitogenic diet. In Table: III, the femoral shaft porosity of the controls on rachitogenic diet is $1.99 \pm 1.25$ in contrast to $3.73 \pm 1.25$ for the controls on normal diet, while the $5 \mathrm{mg}$ of cortisol and rachitogenic diet group shows an increased porosity value of $13.61 \pm 1.56 \%$ to $10.75 \pm 1.48 \%$ of its counterpart on a normal diet (statistically different $\mathrm{p}<.001$ )

\section{TABLE IV}

Statistical Data on Calvaria Porosities

Induced by Graded Doses of Cortisol

\begin{tabular}{|c|c|c|c|c|c|c|}
\hline Diet & $\begin{array}{c}\text { No. } \\
\text { Rabbits }\end{array}$ & $\mathrm{mg}$ & $\begin{array}{l}\text { Treatment } \\
\text { Cortisol/kg/day }\end{array}$ & $\begin{array}{l}\% \text { Porosity } \\
\text { Mean \& S.D. }\end{array}$ & P Value & $\begin{array}{c}\text { Ratio } \\
\text { Treated/Control }\end{array}$ \\
\hline Norma I & 7 & & $\overline{0}$ & $39.22 \pm 6.41$ & --- & 1.0 \\
\hline Norma 1 & 8 & & 1 & $38.33 \pm 4.66$ & --- & 0.97 \\
\hline Normal & 8 & & 5 & $50.22 \pm 11.0$ & $<.025$ & 1.51 \\
\hline Norma I & 4 & & 15 & $65.58 \pm 6.91$ & $<.001$ & 1.68 \\
\hline$--\ldots-\cdots$ & - & - - & $-\cdots-\cdots$ & $\ldots \ldots$ & --- & $-\cdots-\cdots$ \\
\hline Rachitogenic & c 8 & & 0 & $42.07 \pm 5.16$ & -- & -- \\
\hline Rachitogenic & c 8 & & 1 & $47.40 \pm 8.31$ & $<.10$ & 1.13 \\
\hline Rachitogenic & c 7 & & 5 & $49.43 \pm 9.16$ & $<.10$ & 1.17 \\
\hline Rachitogenic & C 2 & & 15 & $53.63+1.59$ & $\leq .001$ & 1.27 \\
\hline
\end{tabular}

III. Porosity studies of calvaria:

The statistical data for the calvaria porosities are listed in Table IV. Only the 5 and $15 \mathrm{mg}$ cortisol groups fed normal diets and the $15 \mathrm{mg}$ cortisol group fed a rachitogenic diet show statistically different porosity values from their controls. Surprisingly, the porosity depressing effect of the rachitogenic diet alone and the enhanced 
bone resorption from the combined cortisol and rachitogenic diet treatments are not apparent. On the contrary, the majority of the ratios of rachitogenic diet treated to rachitogenic diet control calvaria porosities are lower and the slope of the dose response line is less steep than for their counterparts fed a normal diet. The slopes are +1.83 for normal diet and t0.63 for rachitogenic diet, respectively. (Fig. 6). The calculated ratios of treated to control calvaria porosity never exceeded 1.68 (Table IV). This is in marked contrast to calculated ratios in excess of 6 for the femoral shaft porosities (Table III). IV. Influence of cortisol on the distal femur:

1. Epiphyseal Plate Thickness. There is common agreement that cortisol produces an adverse effect upon the growth apparatus resulting in retarded growth in young growing animals $(2,3,4,5,6,7)$. In a short span of two weeks, the influence on the epiphyseal growth plate is detected by a measurement of the width. Table $\mathrm{V}$ lists the statistical data on distal femoral epiphyseal plate thicknesses. Rabbits treated with 1,5 , or $15 \mathrm{mg}$ of cortisol $/ \mathrm{kg} /$ day and fed a normal diet all have significantly decreased $(p<.001)$ epiphyseal plate thickness compared to the controls. They are 75,47 and $37 \%$ as thick as their control and their calculated ratios of epiphyseal plate thickness of controls to treated are $1.37,2.13$, and 2.58 for the 1,5 , and $15 \mathrm{mg}$ cortisol group, respectively.

In the rabbits fed the rachitogenic diet alone, the epiphyseal plate thicknesses are reduced to $6.3 \%$ of their normal thickness which markediy reduced the usefulness of rabbits on rachitogenic diet to determine the effect of cortisol on the epiphyseal growth plate. Both the $\mathrm{l}$ and $5 \mathrm{mg}$ cortisol groups show calculated control to treated 
epiphyseal plate thickness ratios of 0.76 and plate thicknesses of about 220 microns. These thicknesses are significantly different from the control at the $\mathrm{p}<.025$ level. Figure 6 depicts the type of plot obtained from the dose response to epiphyseal plate thickness data on control and rachitogenic diets.

\section{TABLE V}

Statistical Data on Distal Femoral Epiphyseal Plate Thickness Induced with Graded Doses of Cortisol

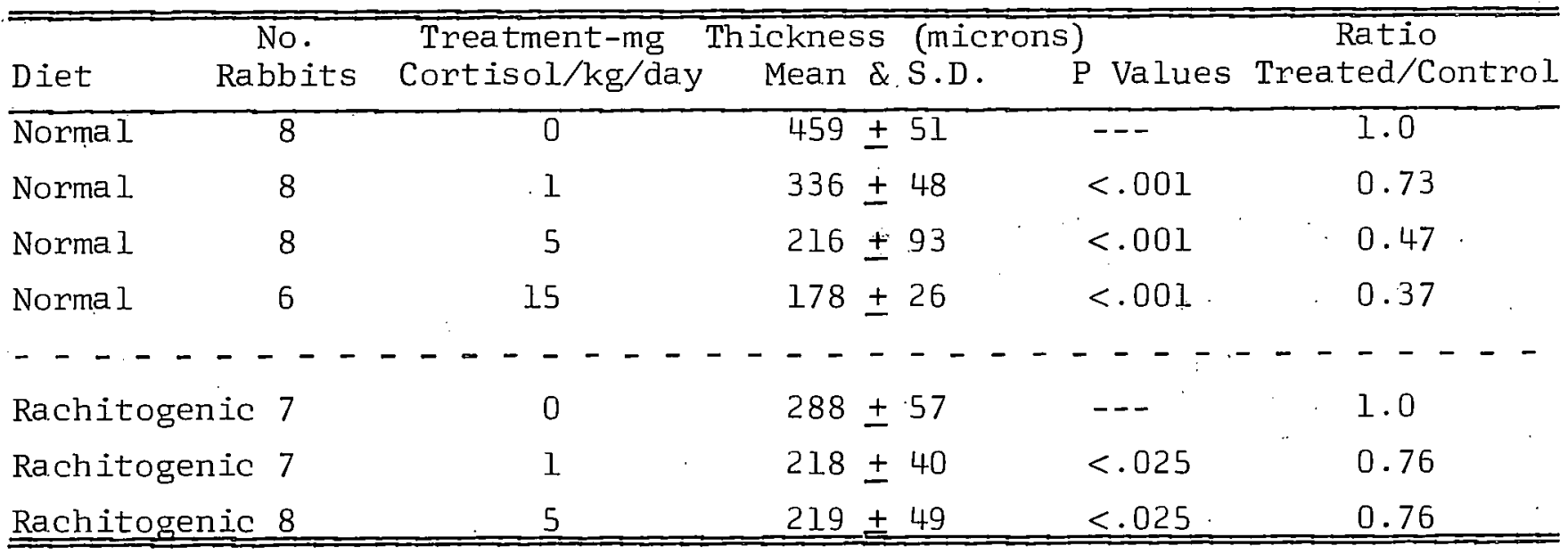

A least squares fit of the points results in a dose response line with slopes of -0.155 for the normal diet and -.026 for the rachitogenic diet. It may well be best to fit the point with lines of two slopes. One line between 0 and 1 or $5 \mathrm{mg}$ of cortisol and another at $5 \mathrm{mg}$ to $15 \mathrm{mg}$ of cortisol.

2. Presence and Thickness of Growth Arrest Plate. The formation of a growth arrest plate (a transverse stratum of bone at the epiphyseal -metaphyseal junction) beneath the epiphyseal growth plate represents another form of disturbance to the growth plate apparatus similar to closure of epiphyses. Bone apposition occurs at the calcified transverse cartilage bars where normally such matrix is dissolved in growing animals. This apposition of bone upon transverse as well as longitudinal calcified 
cartilaginous matrix cores results in a growth arrest plate. Histologically the arrest plate is made up of calcified cartilage and lamellar: : bone.

There is an apparent threshold level for the formation of a. growth arrest plate. Only the animals treated with 5 and $15 \mathrm{mg}$ of cortisol fed a normal diet, and $5 \mathrm{mg}$ of cortisol fed a rachitogenic diet show growth arrest plates (Table VI). All these plates are about 160 microns in thickness, individually ranging between $152.5 \pm 2.3 .3$ to $17.0 \pm$ 40.2 microns.

TABLE VI

Statistical Data on Formation of Growth Arrest Plate Induced with Graded Doses of Cortisol

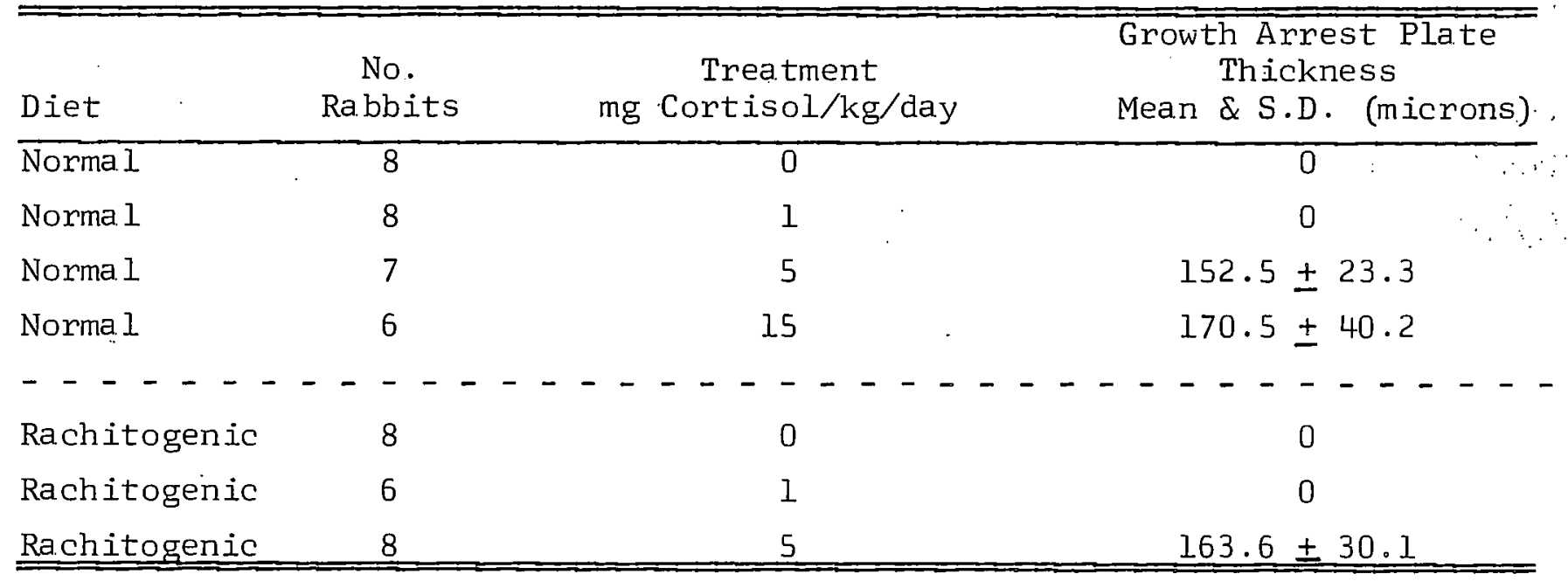

3. Effect Upon Width of Metaphyseal Trabeculae.

A. Effect on length of metaphyses. Sissons and Hadfield noted that the influence of cortisone on the spongy bones of human and rabbits includes the loss of trabeculae in the metaphysis (7), and since bone atrophy (osteoporosis) was an uncontested effect upon the cortical bone from treatment of cortisol in these same animals, regression or atrophy of metaphyseal trabeculae was anticipated, but our measurements prove 
to be surprising. In the group fed a normal diet, the rabbits treated with $1 \mathrm{mg}$ of cortisol show no bone atrophy, while rabbits fed 5 $(\mathrm{p}<.075)$ and $15(\mathrm{p}<.10) \mathrm{mg}$ of cortisol show significant reductions in the width of the metaphysis (Table VII). The treated groups fed a rachitogenic diet show no decrease in metaphyseal trabeculae. In fact, there is a trend toward a significantly wider metaphyseal space in rabbits treated with $1 \mathrm{mg}$ of cortisol daily $(\mathrm{p}<.075)$.

\section{TABLE VII}

Statistical Data on Length of Metaphysis After Graded Doses of Cortisol

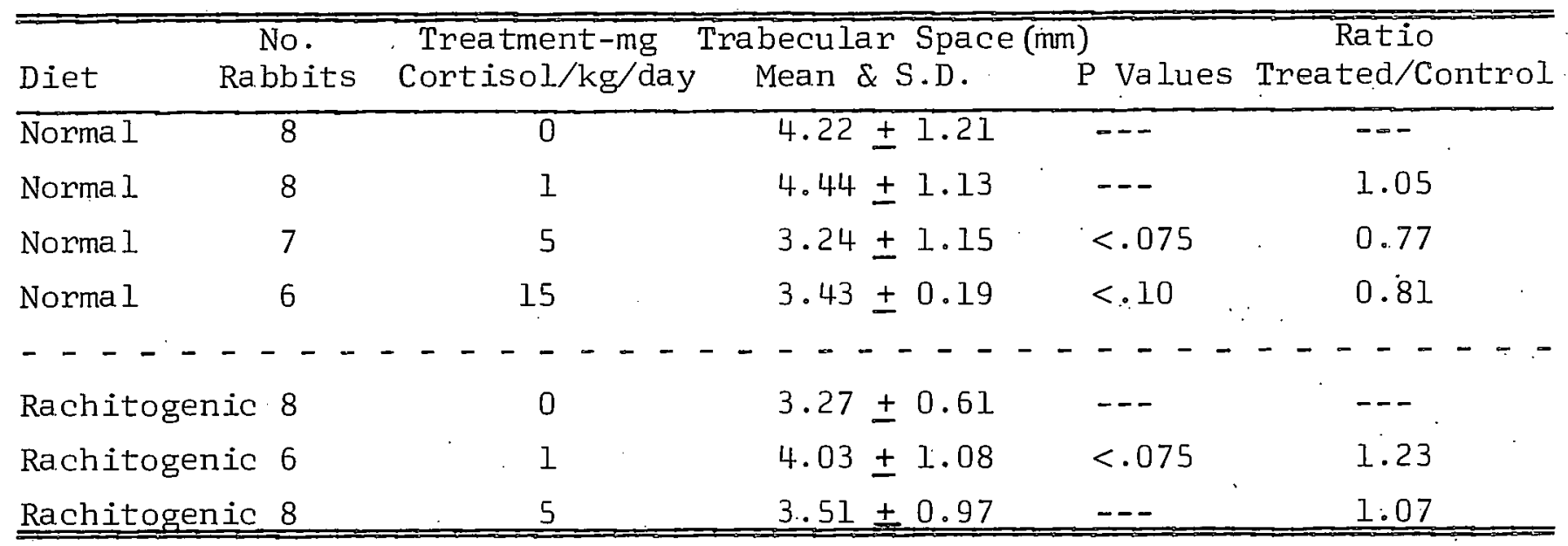

B. Width of metaphyseal trabeculae at various distances. from epiphyseal growth plate. Since only a slight regression in metaphyseal width occurred in rabbits treated with 5 and $15 \mathrm{mg}$ of cortisol/kg daily, there exists the possibility that the steroid may produce partial resorption of the metaphyseal trabeculae resulting in thinned trabeculae, instead of total loss of trabeculation. Thus, the thickness of metaphyseal trabeculae at $520 \mu$ intervals from the epiphyseal plate are measured and listed in Table VIII.

The metaphysis consists of a series of progressively thicker trabeculae beginning from beneath the epiphyseal plate (Fig. 3). In 
Table VIII, the metaphyseal trabeculae are listed as being $23.2 \pm .3 .4 \mu$ thick at $1040 \mu$ and are progressively. increased in thickness to $7.0 .2 \pm$ $17.2 \mu$ at $4680 \mu$ from the plate. At distances greater than $3640 \mu$, the trabeculae are quite variable in thickness and comparisons with the treated groups are difficult.

Changes in metaphyseal trabecular thickness can best be seen in Table IX in which increase in trabecular thickness is denoted by an $\uparrow$, decrease in thickness by $\downarrow$, no change by 0 , significant changes by * $(\mathrm{p}<.20)$ and statistically significant changes by $* *(p<.05)$. Thus in the $1 \mathrm{mg}$ cortisol group, at $3640 \mu$ from the plate, the trabeculae are statistically thinner than the trabeculae from controls.

In general the rabbits treated with $1 \mathrm{mg}$ of cortisol and fed a normal diet show slightly thickened trabeculae at $1040 \mu$ and from 2080 to $4680 \mu$ from the plate a rather consistent thinning of trabeculae (Table IX). The same dual response occurred with the 5 and $15 \mathrm{mg}$ groups. It differs only in the thicker trabeculae up to $2080 \mu$ from the plate and the thinner trabeculae are restricted to between 2600 to $3640 \mu$. These values indicate that the spongiosa located proximal to the epiphyseal plate have undergone more bone apposition than bone resorption, while the more distal portion of the spongiosa have undergone more bone resorption than bone apposition subsequent to cortisol treatment. The implication of these findings will be discussed later.

The twofold response is not apparent with cortisol treatment along with a rachitogenic diet (Table IX). Thicker trabeculae are found in the metaphyseal spongiosa up to $2600 \mu$ from the epiphyseal plate. Thinned trabeculae occur only at $3120 \mu$ from the plate in the $5 \mathrm{mg}$ of cortisol group, which indicates that the combined cortisol and rachitogenic diet treatment inhibits osteoclastic activity. 
TABLE .VIII

Statistical Data on the Metaphyseal Trabecular Thickness at $520 \mu$ Interval from the Distal Femoral Epiphyseal Plate After Various Doses of Cortisol

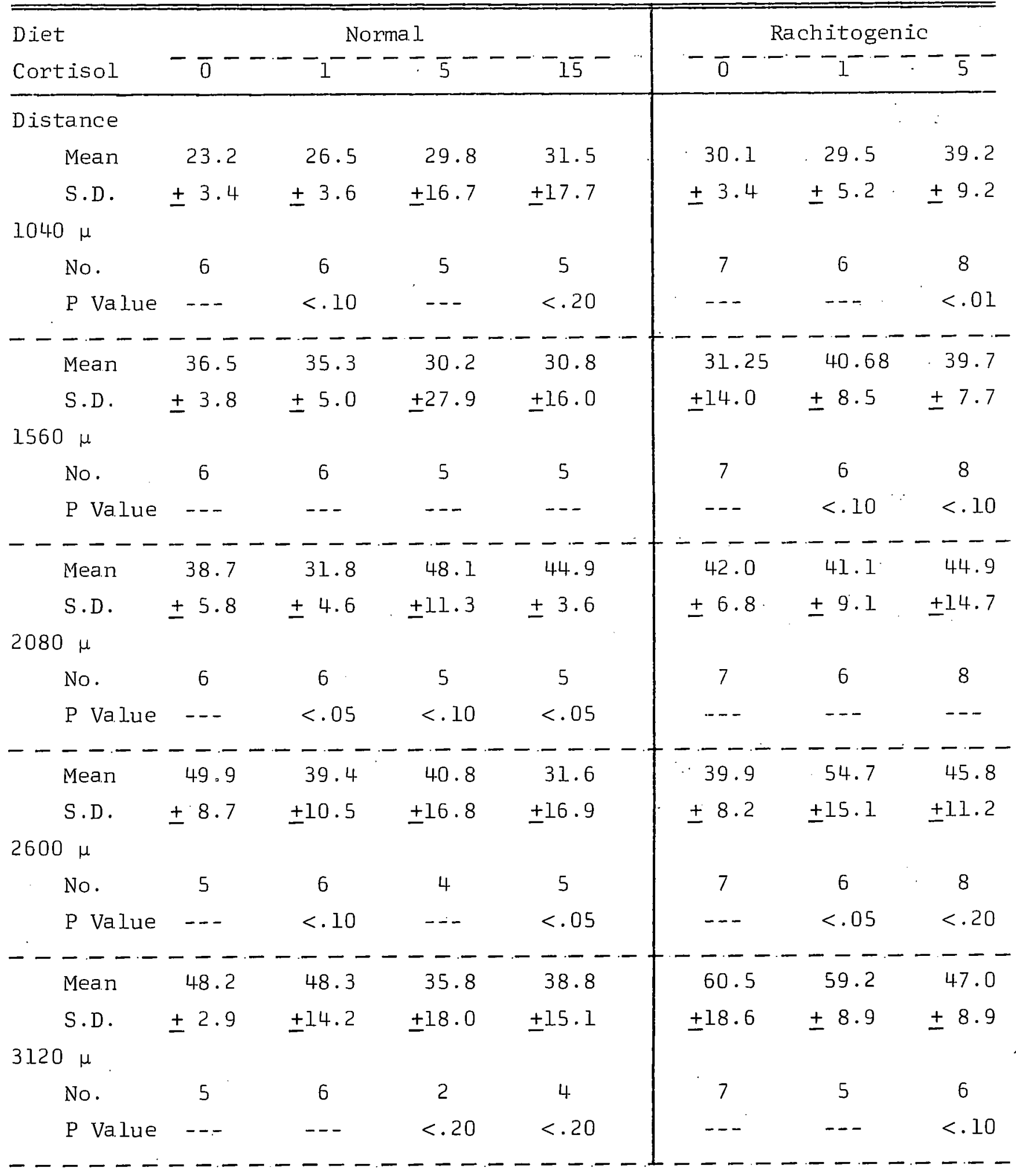


TABLE VIII (Con't.)

Statistical Data on the Metaphyseal Trabecular Thickness at $520 \mu$ Interval from the Distal Femoral Epiphyseal Plate After Various Doses of Cortisol

\begin{tabular}{|c|c|c|c|c|c|c|c|}
\hline \multirow{2}{*}{$\begin{array}{l}\text { Diet } \\
\text { Cortisol } \\
\text { Distance }\end{array}$} & \multicolumn{4}{|c|}{$-\overline{0}----_{1}----\frac{\text { Normal }}{5}---\frac{1}{15}-$} & \multicolumn{3}{|c|}{$-\overline{0}-\frac{\text { Rachitogenic }}{1}--\frac{5}{5}-$} \\
\hline & & & & & & & \\
\hline Mean & 63.4 & 52.7 & 42.3 & 39.5 & 49.0 & 56.6 & 47.1 \\
\hline S.D. & \pm 17.7 & \pm 4.2 & \pm 13.8 & --- & \pm 27.4 & \pm 13.7 & \pm 12.3 \\
\hline \multicolumn{8}{|l|}{$3640 \mu$} \\
\hline No. & 4 & 5 & 2 & 1 & 4 & 4 & 5 \\
\hline P Value & --- & $<.001$ & $<.10$ & $<.20$ & --- & -- & $-\cdots$ \\
\hline$--\frac{---}{\text { Mean }}$ & $-\frac{-}{65.0}$ & $\frac{-.-}{55.4}$ & $-\frac{-1}{47.7}$ & $\frac{--1}{52.0}$ & ---7 & $-\frac{-1}{67.2}$ & $-\frac{--}{57.1}$ \\
\hline S.D. & \pm 32.2 & \pm 7.3 & --- & --- & --- & \pm 16.9 & \pm 22.0 \\
\hline \multicolumn{8}{|l|}{$4160 \mu$} \\
\hline No. & 4 & 3 & 2 & 1 & 1 & 3 & 3 \\
\hline $\mathrm{P}$ Value & --- & -- & --- & $\cdots$ & -- & $-\cdots$ & $\cdots$ \\
\hline$--\frac{---}{\text { Mean }}$ & $-\frac{-}{70.2}$ & ---7 & $-\frac{-}{39.0}$ & 55.0 & --- & $-\overline{85.0}$ & ---7 \\
\hline S.D. & \pm 17.2 & \pm 24.6 & --- & --- & --- & \pm 29.1 & --- \\
\hline \multicolumn{8}{|l|}{$4680 \mu$} \\
\hline No. & 2 & 3 & 1 & 1 & --- & 3 & 1 \\
\hline $\mathrm{P}$ Value & --- & $<.20$ & -- & --- & --- & --- & --- \\
\hline----- & $-\frac{-}{52.0}$ & 55.0 & -- & --- & $--\cdots$ & $-\frac{-}{10.0}$ & $--\cdots$ \\
\hline S.D. & --- & --- & -- & -- & --- & --- & --- \\
\hline \multicolumn{8}{|l|}{$5200 \mu$} \\
\hline No. & 2 & 1 & --- & --- & -- & $\therefore$ & $\cdots$ \\
\hline $\mathrm{P}$ Value & --- & --- & --- & --- & --- & --- & --- \\
\hline
\end{tabular}


TABLE IX

Differences in Metaphysea i Trabecular Thickness from Their Controls at Varying Intervals from the Distal Femoral Epiphyseal Plate

After Various Doses of Cortisol

\begin{tabular}{|c|c|c|c|c|c|c|c|}
\hline \multirow{2}{*}{$\begin{array}{l}\text { Distance } \\
\text { From Plate } \\
\qquad(\mu)\end{array}$} & \multicolumn{4}{|c|}{ Normal Diet Plus } & \multicolumn{3}{|c|}{ Rachitogenic Diet } \\
\hline & $1 \mathrm{mg} / \mathrm{kg}$ & $5 \mathrm{mg} / \mathrm{kg}$ & 15 & $\mathrm{mg} / \mathrm{kg}$ & $1 \mathrm{mg} / \mathrm{kg}$ & 5 & $\mathrm{mg} / \mathrm{kg}$ \\
\hline 1040 & $\uparrow *$ & 0 & . & $\uparrow *$ & 0 & & $\uparrow *$ \\
\hline 1560 & 0 & 0 & & 0 & $\uparrow *$ & & $\uparrow *$ \\
\hline 2080 & $\downarrow * *$ & $\uparrow *$ & & $\uparrow * *$ & $\uparrow \%$ & & $\uparrow *$ \\
\hline 2600 & $\downarrow *$ & 0 & & $\downarrow * *$ & $\uparrow * *$ & & $\uparrow *$ \\
\hline 3120 & 0 & $\downarrow *$ & & $\downarrow *$ & 0 & & $\downarrow *$ \\
\hline 3640 & $\downarrow * *$ & $\downarrow * \quad$ & & $\downarrow *$ & $\therefore$ & & 0. \\
\hline 4160 & 0 & 0 & & 0 & 0 & & 0 \\
\hline 4680 & $\downarrow *$ & 0 & & 0 & $\mathrm{Y}$ & & Y \\
\hline 5200 & 0 & $\mathrm{~N}$ & & $\mathrm{~N}$. & $Y$ & & $Y:$ \\
\hline
\end{tabular}

$\uparrow \quad$ Trabeculae thicker than control.

$\downarrow \quad$ Trabeculae thinner than control.

* $\mathrm{p}<.20$

$* * \quad \mathrm{p}<.05$

0 No difference in trabecular thickness.

$\mathrm{N}$ No values.

$Y \quad$ No control values to compare with.

V. Comparison of rabbits fed control and rachitogenic diets:

Table $X$ lists the statistical data of the principal parameters. All the ratios of rachitogenic to normal diet are less than one except for calvaria porosity. Only the epiphyseal plate thickness is statistically different. It is interesting to note the diametrically opposed responses of femoral shaft and calvaria to the rachitogenic diet alone.

The effect of cortisol and rachitogenic diet on survival is not listed. There is a $40 \%$ and a $90 \%$ mortality in animals treated with 5 
or $15 \mathrm{mg}$ of cortisol/ $\mathrm{kg}$ daily and a rachitogenic diet, respectively.

\section{TABLE $X$}

Statistical Data on Measurements of the Properties of Distal Femurs, Mid-Diaphysis of Femurs, and Calvaria of Animals Fed Normal and Rachitogenic Diets

\begin{tabular}{lrcc}
\hline Parameters & $\begin{array}{c}\text { Control } \\
\text { Diet }\end{array}$ & $\begin{array}{c}\text { Rachitogenic } \\
\text { Diet }\end{array}$ & $\begin{array}{c}\text { Ratio } \\
\text { Rachitogenic/Normal }\end{array}$ \\
\hline $\begin{array}{l}\text { Femoral shaft } \\
\text { porosity }\end{array}$ & $3.78 \pm 1.25 \%$ & $1.99 \pm 1.25 \%$ & 0.53 \\
$\begin{array}{l}\text { Calvaria porosity } \\
\begin{array}{l}\text { Ep iphyseal plate } \\
\text { thickness (femur) }\end{array}\end{array}$ & $\begin{array}{r}49.22 \pm 6.41 \% \\
\text { Femoral metaphysis }\end{array}$ & $4.22 \pm 1.07 \pm 5.16 \%$ & 1.09 \\
\hline
\end{tabular}

$*$ p $<.001$

VI. Summary of the influence of cortisol on growing rabbits:

Table XI lists the significant effects at the $95 \%$ confidence level of the various parameters in each treatment group. The + represents significant differences from its diet control and 0 represents an insignificant response. Except for weight losses and survival, the table lists no apparent qualitative differences for the influence of cortisol upon bone tissues in rabbits fed normal or rachitogenic diets; however, cortisol in animals fed a normal diet induces a greater quantitative response in bone than in the comparable group fed a rachitogenic diet. 
TABLE XI

Significant Differences $(p<.05)$ in the Influence of Cortisol Upon Growing Bone

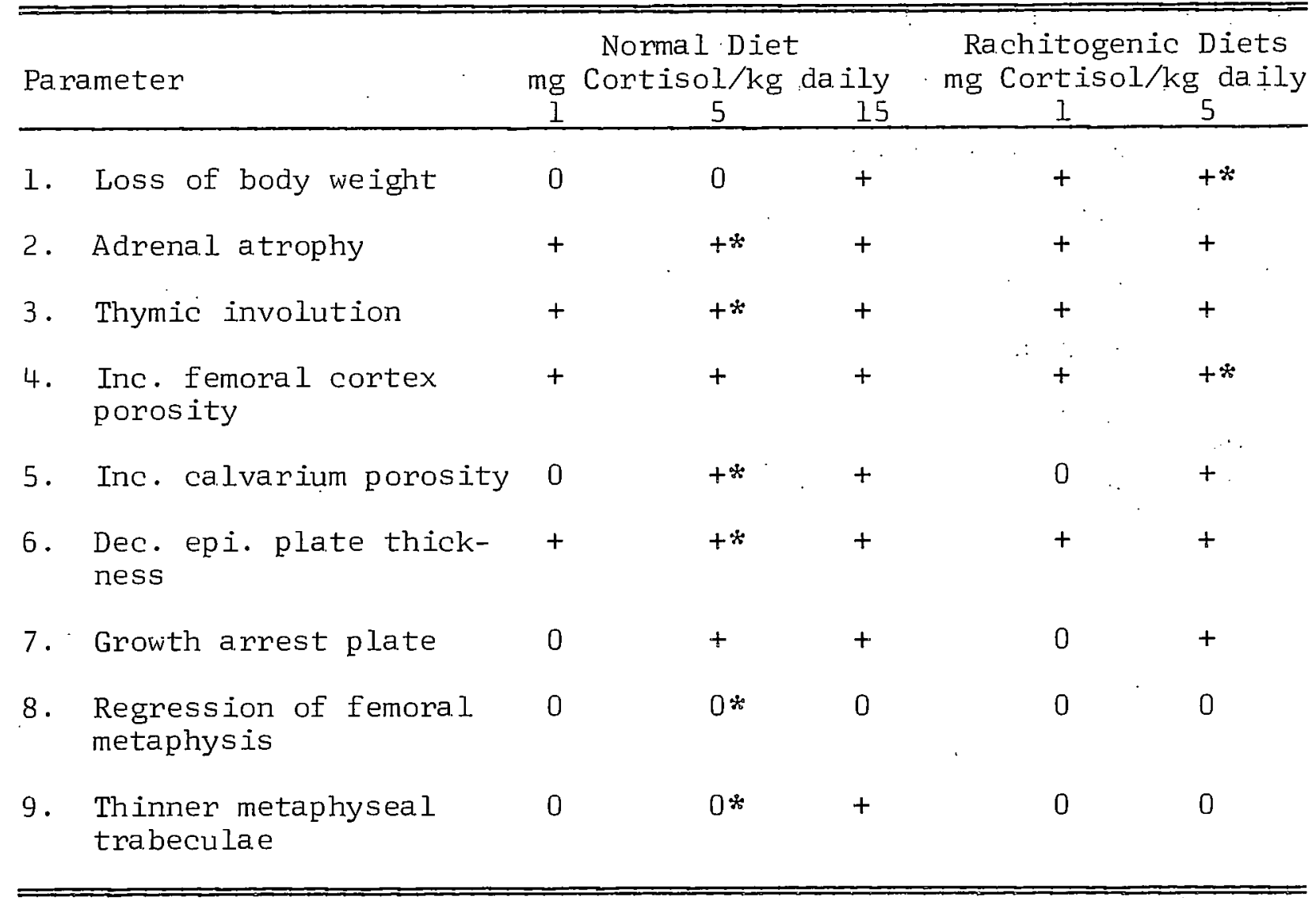

*Magnitude of response greater than comparable treatment group fed a different diet.

\section{DISCUSSION}

One of the aims of this report was to establish a relatively rapid quantitative histological bioassay for the influence of cortisol. on the skeleton in growing rabbits. By employing contact microradiography, it was feasible to establish various test systems in the skeleton which proved quite useful and scientifically stimulating. Decalcification and embedding adjacent areas in celloidin and paraffin was a. Iso performed with the hope of defining the cellular population related to 
these bony changes; however, these techniques were far too time consuming. Any future attempts to determine the influence of various glucocorticoids upon the growing bones of rabbits will be restricted to measurements of femoral cortex porosity, the epiphyseal plate thickness, presence of growth arrest plate, length of femoral metaphysis and metaphyseal trabeculae thickness at various distances from the epiphyseal plate. With these six endpoints, it was possible to evaluate the osteoporotic influence upon cortical and spongy bones (femoral shaft porosity, length of distal femoral metaphysis and thickness of metaphyseal trabeculae) and the influence on the longitudinal growth of long bones (the epiphyseal plate thickness and presence of growth arrest plate) . Another aim was to test whether animals fed a decreased calcium and phosphorus diet resulted in an increased osteolytic effect of cortisol. This was based on the finding of Storey who observed in weanling rabbits that a diet deficient in calcium and phosphorus will enhance the osteolytic effect of cortisol upon the calvarium (1). The combined effect of the rachitogenic diet plus cortisol enhanced the osteolytic effect of cortisol upon the femoral shafts, but not in the calvaria. Animals treated with $5 \mathrm{mg}$ of cortisol exhibited a statistical increase in the osteolytic effect of cortisol upon the femoral shaft when combined with the rachitogenic diet. For instance, the rachitogenic diet resulted in a greater porosity with the treatment of $5 \mathrm{mg}$ cortisol daily compared to the same dose with a normal diet. In general; the slope of the dose response line of rachitogenic diet plus cortisol was steeper than the slope of the dose response line of normal diet plus cortisol. Moreover, the increased osteolytic effect of the rachitogenic diet plus, $1 \mathrm{mg}$ of cortisol was due to the depression of 
its control. In other words, the rachitogenic diet alone resulted in less porosity. On the contrary, the calvarium porosity studies showed that the slope of the dose response line to cortisol plus the rachitogenic diet was much less steep than the slope of the dose response line to cortisol and a normal diet. In summary, the study showed that there was some advantage in using the rachitogenic diet in the femoral shafts porosity analysis while with the calvaria there was a distinct disadvantage in using a rachitogenic diet. What little advantage is gained by the use of a rachitogenic diet in the analysis of the femoral shaft porosity was lost by the fact that animals treated with a rachitogenic diet plus 5 or $15 \mathrm{mg}$ of cortisol have very poor survival rates. There was also an obvious disadvantage in using the combined treatment of the rachitogenic diet and cortisol for the measurements of epiphyseal plate thickness, length of metaphysis, adrenal atrophy and thymic involution.

The effect of glucocorticoids (cortisone) in inhibiting the growth of developing animals was described long ago by Wells and Kendall (2). More detailed studies have been done on rats, guinea pigs, and rabbits by other authors $(4,5,6,7)$. In fact, Cavallero, Bertazzoli, Rossi, and Sala briefly' noted histologic changes of narrowing of the epiphyseal plate (5). Follis also described changes in all the above species receiving cortisone $(3,4)$. More recently Sissions and Hadfield measured the thickness of the epiphyseal plate in histological sections of animals treated with various doses of cortisone (7). There was general agreement that a reduction in hypertrophic cartilage and cessation of proliferation of cells of the cartilage columns existed (7) . Our next report will deal with quantifying the cellular population in the decalcified histological sections and it would be interesting to 
observe whether the findings will support past investigators.

The growth arrest plate appeared to be identical to the plate formed in the process of the closure of the epiphyseal plate. The manner by which the growth arrest plate was formed cannot be elucidated by the present material. Nevertheless, observations from decalcifüed sections suggest that the following events could contribute: to the formation of a plate. Cortisol could conceivably depress the osteoclasts and chondrocy tes ability to destroy calcified cartilage: or limit the supply of new osteoclasts and chondrocytes. The suppression of these events can result in the persistence of calcified cartilaginous matrix.. : Also, cortisol does not seem to alter the function of the existing population of osteoclasts and osteoblasts in the primary spongiosa and the large number of osteoblasts and the smal.1 number of osteoclasts in this region will result in a net gain of bone. The apposition of more bone and the persistence of more calcified cartilage adds up to a growth arrest plate.

The lack of pronounced osteolytic effect on the distal femoral metaphysis was most surprising. Sissons and Hadfield have reported an osteolytic sequence in which the entire metaphysis was wiped out in 24 days with $10 \mathrm{mg}$ of cortisone daily (7). Contrary to the above finding, the femoral metaphysis was slightly reduced and it was not statistically significant. Indeed, the metaphysis consisting of spongy bone is an exciting site of action of cortisone. Follis has reported a lack of resorption of metaphyseal bone in mice, guinea pigs and rabbits (5) while Sissons and Hadfield showed inconsistent findings in the metaphyseal regions of rats in two series of experiments. In an earlier experiment they reported the loss of trabeculation and in the second experimental run there was a thickening of metaphyseal trabeculae (7). 
Under the present experimental conditions, the persistence of the. femoral metaphysis may be due to such variables as the duration. of ... treatment, dose, strain of rabbits and/or the use of cortisol instead of cortisone.

The lack of statistically significant reduction in femoral metaphysis was coupled with the observations of thickened trabeculae in the primary spongiosa and thinner trabeculae in the secondary spongiosa. In an attempt to explain the above observations it must be kept in mind that it is our belief cortisol suppresses the transformation of both osteoblasts and osteoclasts from mesenchymal or progenitor.cells and that existing cells at the time of cortisol injection will survive and. continue to function. In the primary spongiosa there are many móre osteoblasts than osteoclasts, and conversely there are more osteoclasts than osteoblasts in the secondary spongiosa. Therefore, the result is, if the source of new osteoblasts and osteoclasts were dried up or slowed down and the elongation of the bone was stopped, a metaphysis in frozen animation (the spongiosa existing at day 0 still remains at day 16 ); then, the existing osteoblast and osteoclast population could produce thicker trabeculae in the primary spongiosa due to the dominant population of osteoblasts and thinned trabeculae in the secondary spongiosa due to the dominant population of osteoclasts. A preliminary study of the primary spongiosa of the proximal tibial metaphysis tend to support the above sequence. There was a significant decrease in the number of osteoclasts with 5 and $15 \mathrm{mg}$ of cortisol and a statistically signif.icant increase in the thickness of the trabeculae.

A further discussion of the three sites chosen for quantitative analyses of the osteolytic effect of cortisol could be of value in an 
attempt to clarify the differential responses of these areas of the skeleton. Briefly the three sites consist of the distal femoral metaphysis made up entirely of spongy bone, the femoral shaft made up entirely of compact bone and the calvarium made up with a mixture of cortical and spongy bone. Moreover, the study showed that the femoral shaft was more readily resorbed than the calvarium, which in turn was more easily resorbed than the femoral metaphysis. The differential osteolytic capacity of these sites to cortisol may be related to the bone surfaces available for resorption. Most bone histologists accept the fact that bone lined with osteoid is resistant to osteoclastic activity. In the femoral shaft, there are very few surfaces lined with osteoid, while in the metaphysis and especially in the primary spongiosa nearly every bone surface is lined with osteoid. The decrease in bone surface for bone resorption coupled with a decrease in the number of osteoclasts will result in the retardation. of the normal osteolytic sequences in the metaphysis. Conversely, the femoral shaft consisted of primary haversian systems with very few bone surfaces lined with osteoid and with increased doses of cortisol, the number of osteoclasts increase. Why there was an increase in the number of osteoclasts in the compacta and a concomitant decrease in osteoclasts in the metaphysis is most puzzling?

The calvarium is a site made up of both compact arid spongy bone. It consists of predominantly cortical bone and few trabeculae in the diploic areas. The inner and outer tables of cortical bone contain very irregular endosteal bone surfaces which make an analysis of this bone almost impossible. It may be more valid to say that the present analytical procedure needs refinement to detect porosity in the calvarium rather than the conclusion that the calvarium is less sensitive than the 
femoral shaft to the osteolytic effect of cortisol.

\section{ACKNOWLEDGEMENTS}

The authors wish to thank Mr. Fred Goldthorpe and Miss Susan Dickman for their invaluable technical assistance.

\section{REFERENCES}

1. E. Storey, Cortisone-induced bone resorption in the rabbit, Endocrinology 68:533-542 (1961).

2. B. B. Wells and E. C. Kendall, The influence of corticosterone and $\mathrm{C}_{17}$ hydroxydehdrocorticosterone (compound $\mathrm{E}$ ) on somatic growth, Proc. Mayo Clin. 15:324-328 (1940).

3. R. H. Follis, Effect of cortisone on growing bones of the rat. Proc. Soc. Exp. Biol. 76:722-723 (1951).

4. R. H. Follis, Non-effect of cortisone on growing bones of mice, guinea pigs and rabbits. Proc. Soc. Exp. Biol. 78:723-724 (1951).

5. C. Cavallero, C. Bertazzoli, L. Rossi and G. Sala. Studio sperimentale sugh effetti del cortisone. II. Effetti morfologici generali sul ratto normale. Sperimentale, 101:209-225 (1951).

6. H. A. Sissons and G. J. Hadfield, The influence of cortisone on the repair of experimental fractures in the rabbit. Brit. J. Surg. 39: $172-178$ (1951).

7. H. A. Sissons and G. J. Hadfield. The influence of cortisone on the structure and growth of bone. J. Anatomy, 89:69-78 (1955). 

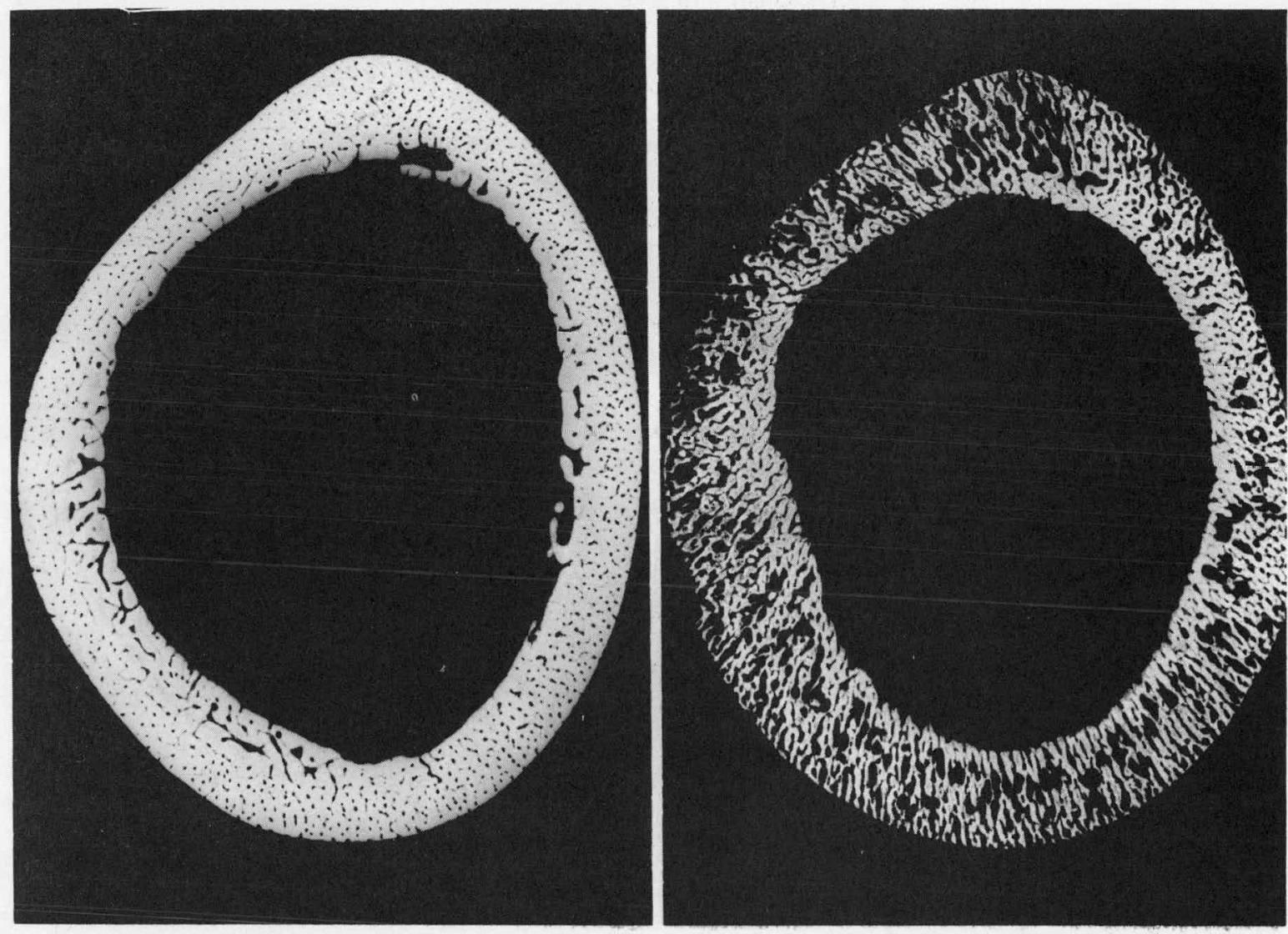

Control

$15 \mathrm{mg} / \mathrm{kg} /$ Day Cortisol

Fig. 1. Contact microradiographs of $100 \mu$ thick bone section of midfemoral shaft. The radio-opaque regions are white and the radiolucent regions are black. Note the increased numbers of radiolucent areas in the treated specimen (15 mg of cortisol/ $\mathrm{kg} /$ day). This is an extreme case (X 15). 

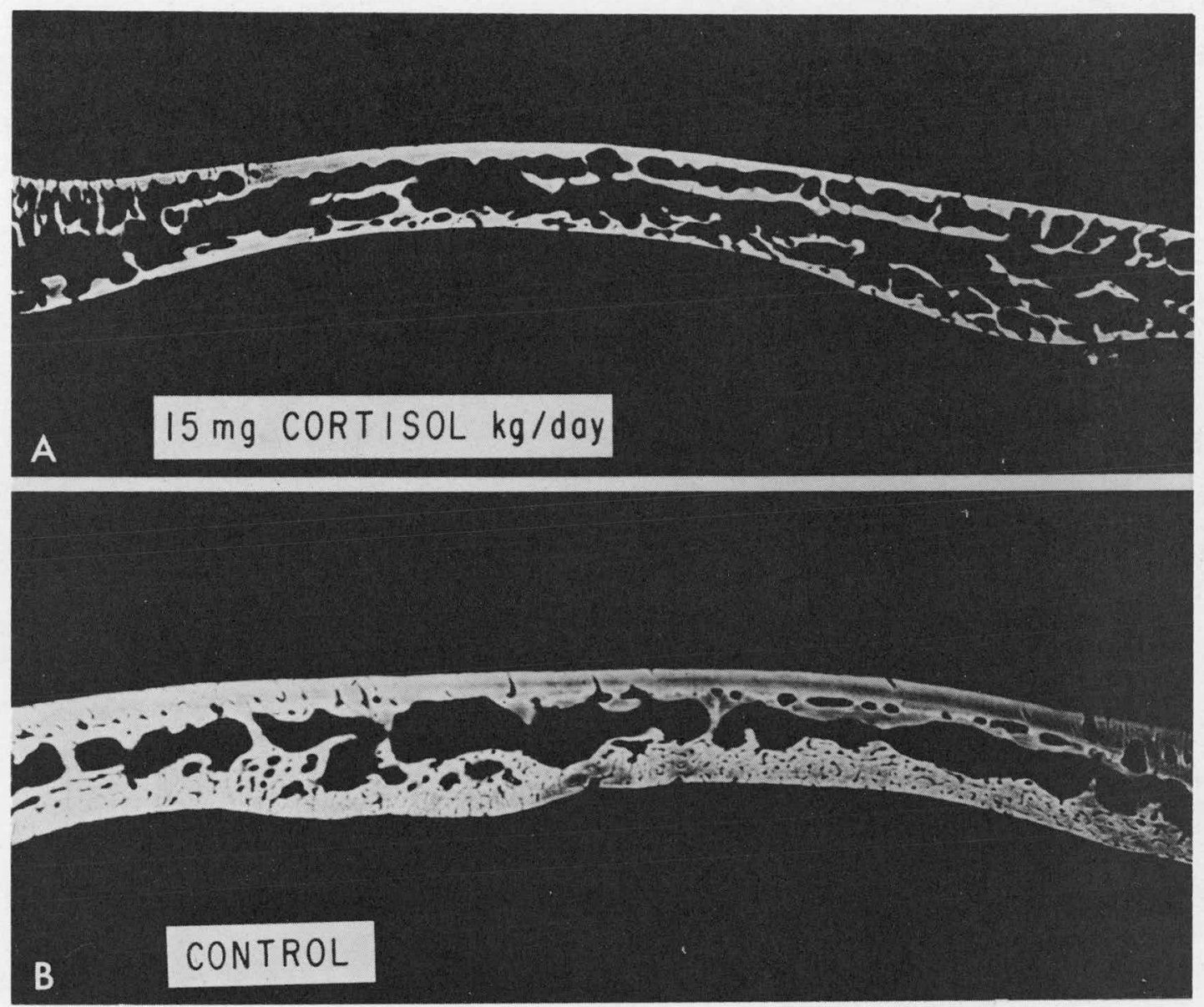

Fig. 2. Contact microradiographs of a portion of calvaria showing massive resorption in a rabbit injected with $15 \mathrm{mg}$ of cortisol/ $\mathrm{kg} /$ day. Note in the control bone the inner (inferior) and outer (superior) tables of compact bone and the few interconnecting spicules of bone in the diploic spaces ( $X$ 18). 


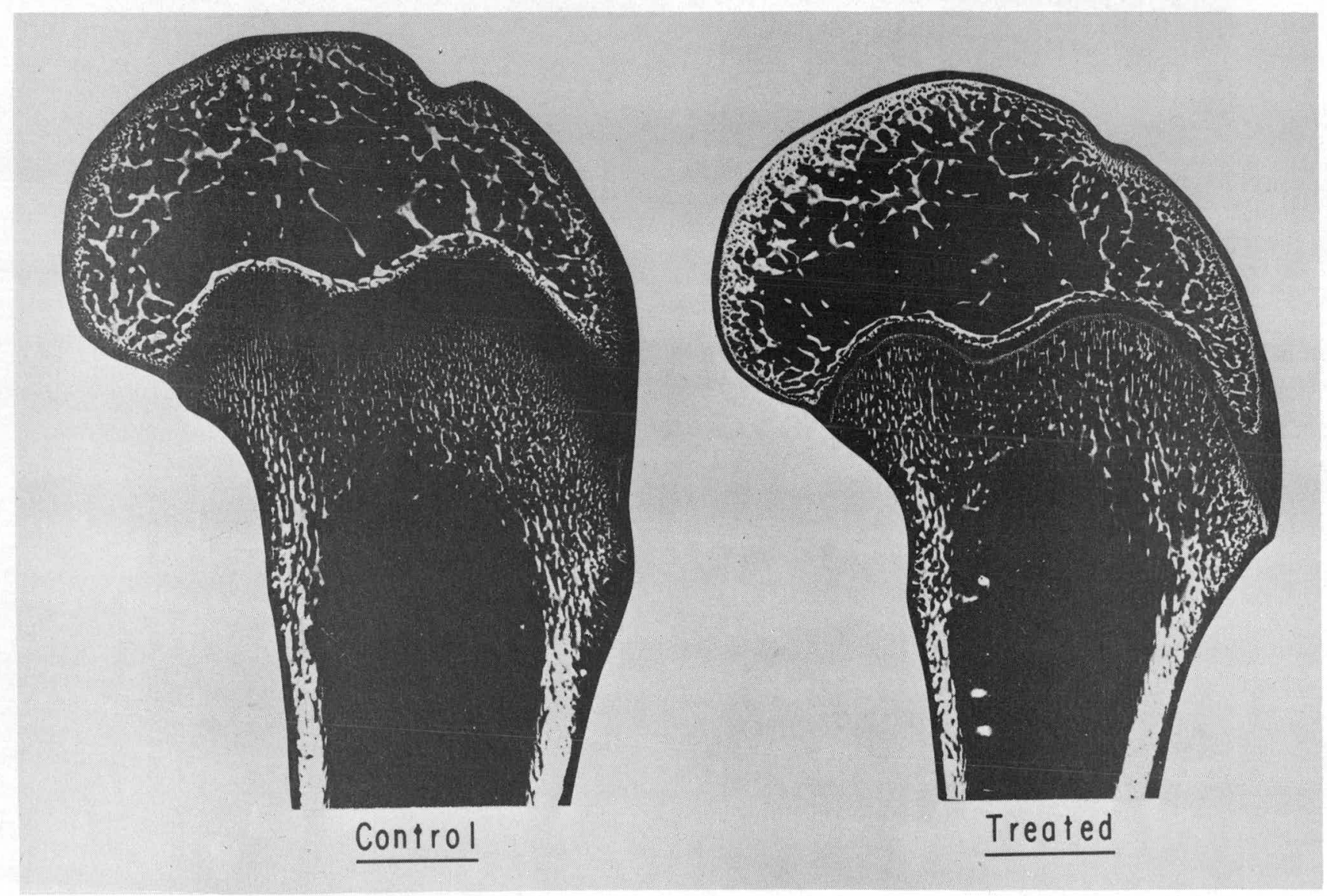

Fig. 3. Representative contact microradiographs of longitudinal sections of the distal femur. Note the radiolucent region between the epiphysis and the spongy bone of the metaphysis in both the control and the treated specimens. Observe the obvious decrease in thickness of the epiphyseal growth plate in the treated animal (5 mg of cortisol/kg/day) (X 6 ) . 


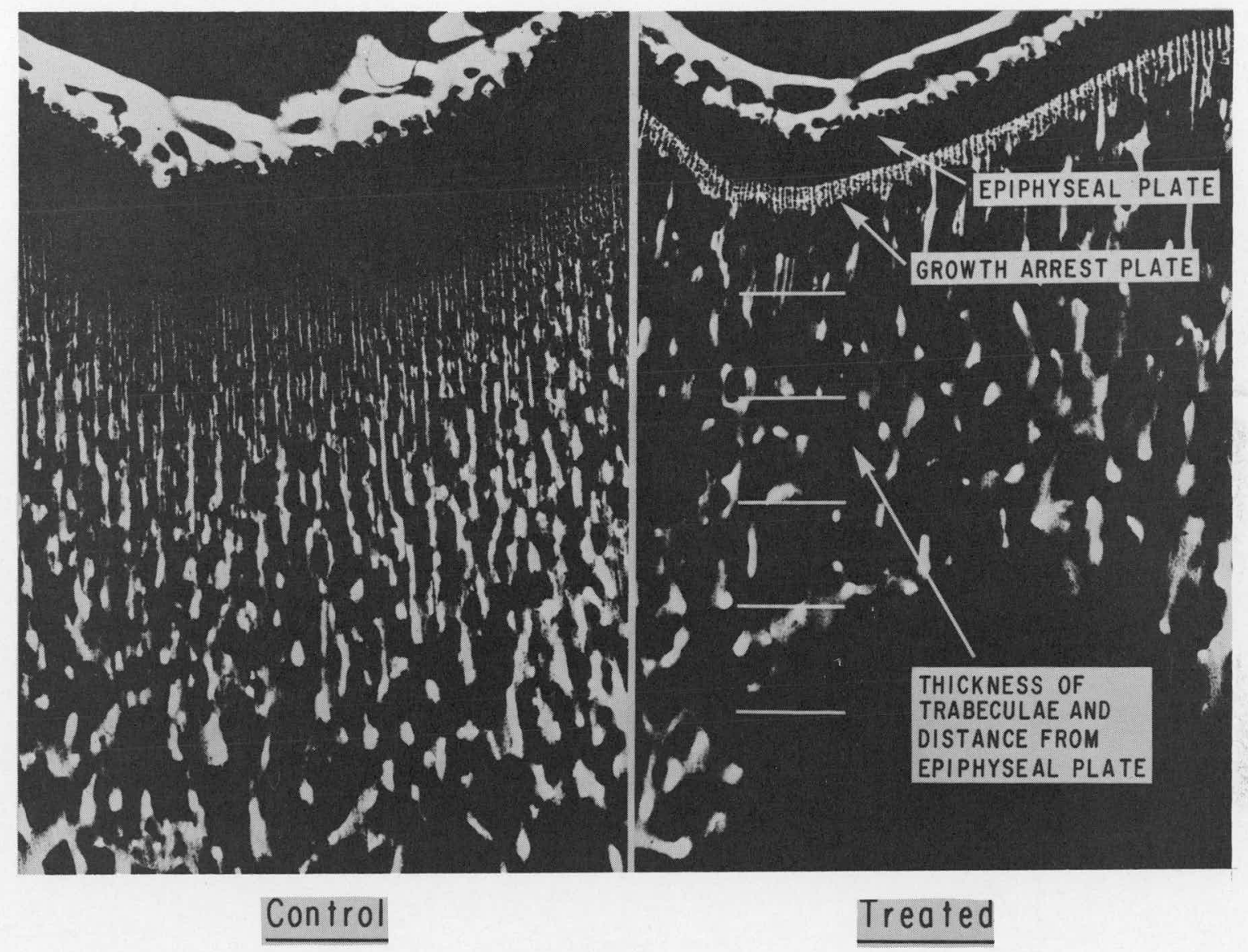

Fig. 4. Higher magnifications of Fig. 3. Note the thinned epiphyseal plate and the obvious growth arrest plate in the treated rabbit. The horizontal white lines are $520 \mu$ wide and are drawn at $520 \mu$ intervals from the epiphyseal plate. The individual trabecular widths were determined at these sites (X 24). 
FEMORAL SHAFTS POROSITIES IN RABBITS ON NORMAL AND RACHITOGENIC DIETS RECEIVING CORTISOL.

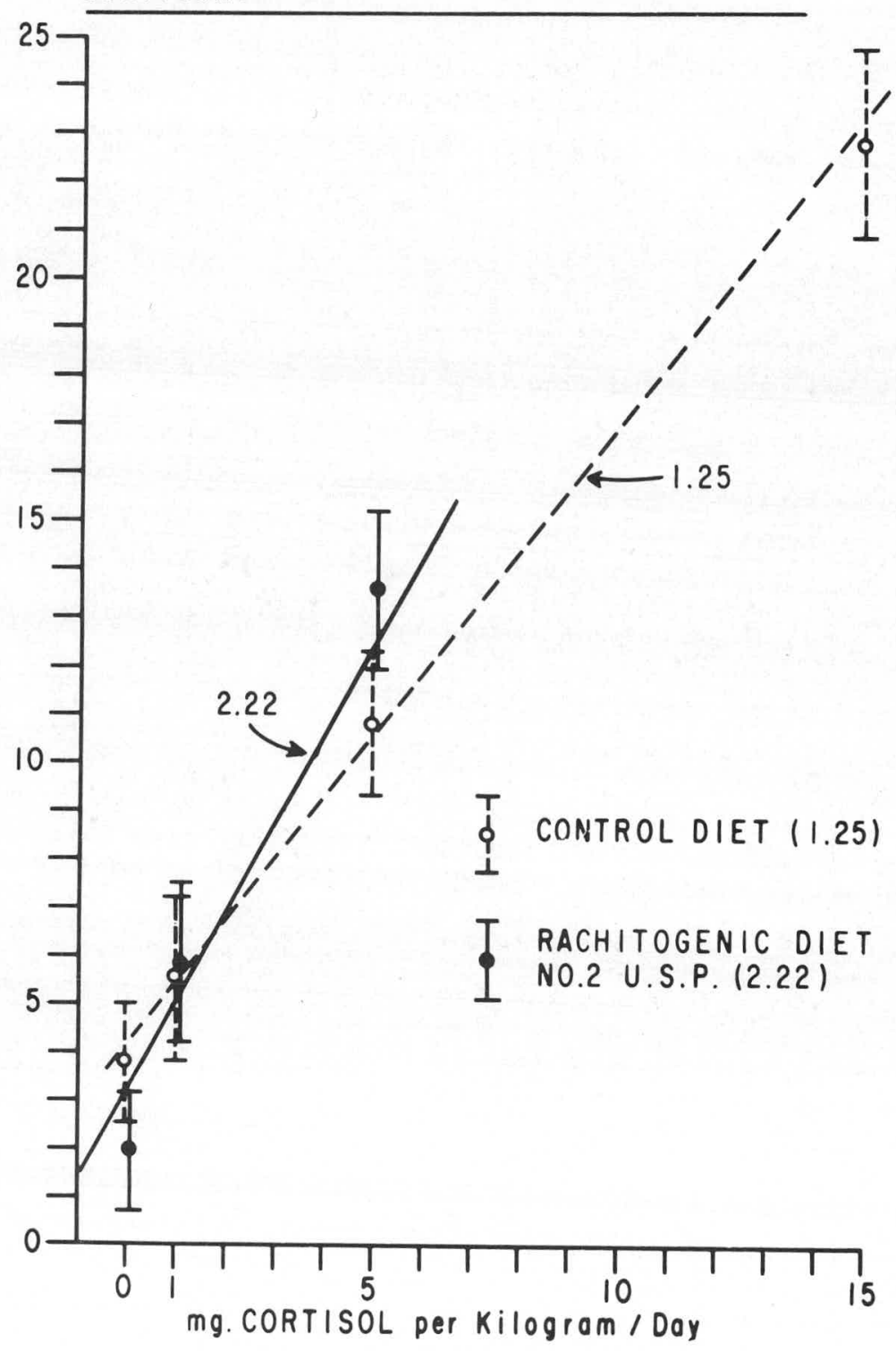

Fig. 5. Linear dose-response plot of femoral shafts porosities in rabbits fed control or rachitogenic diets. The \% porosity is plotted on the ordinate and the dose in mg cortisol per kilogram on the abscissa. Note the steeper slope of the dose response line from rabbits fed a rachitogenic diet. The I represents the standard deviation of the mean. 
CALVARIA POROSITIES IN RABBITS ON NORMAL AND RACHITOGENIC DIETS RECEIVING CORTISOL

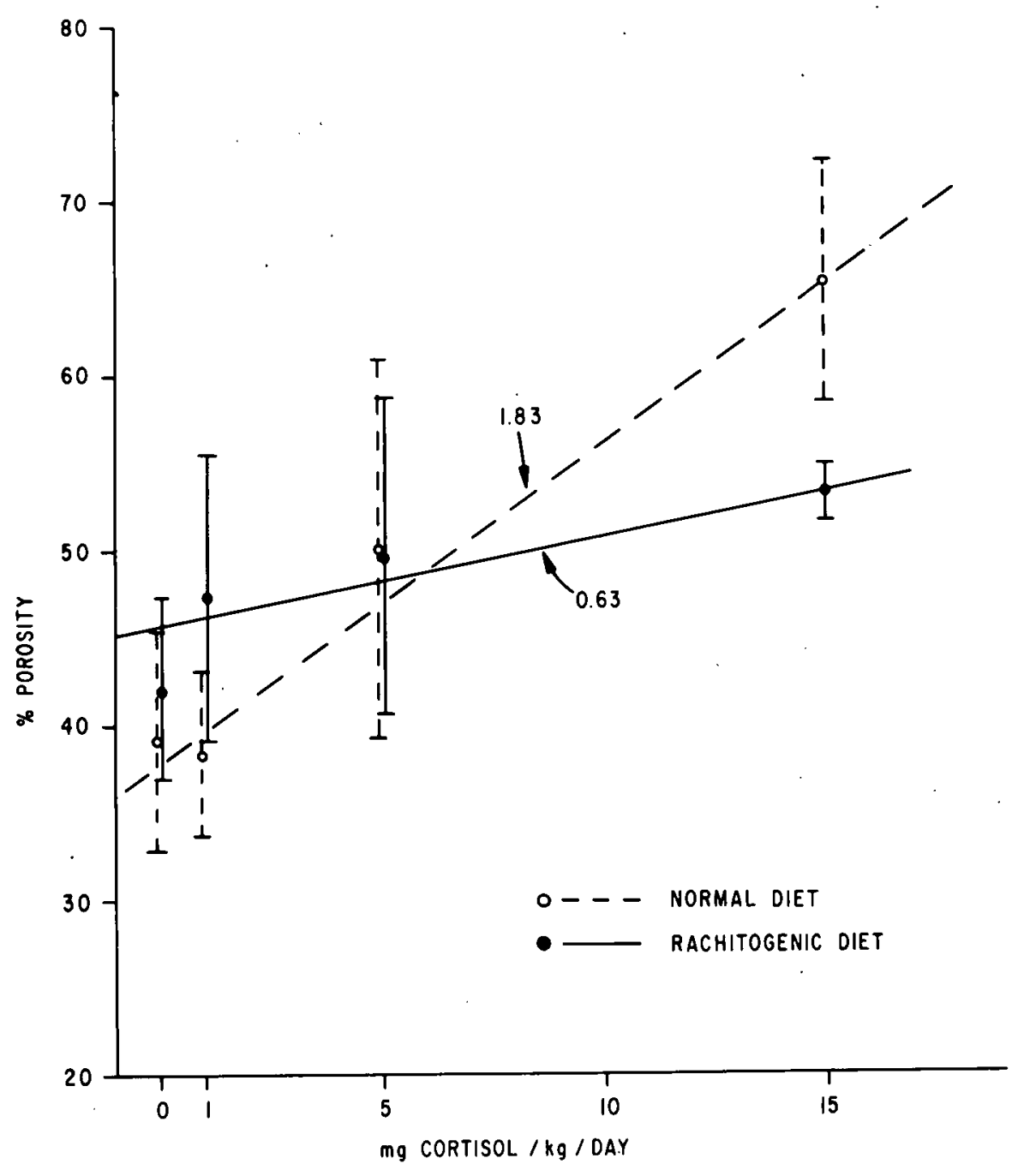

Fig. 6. Linear dose response plot of calvaria porosities in rabbits fed normal or rachitogenic diets. Note the steeper slope of the dose response plot from rabbits fed a normal diet. The I represents the standard deviation of the mean. 


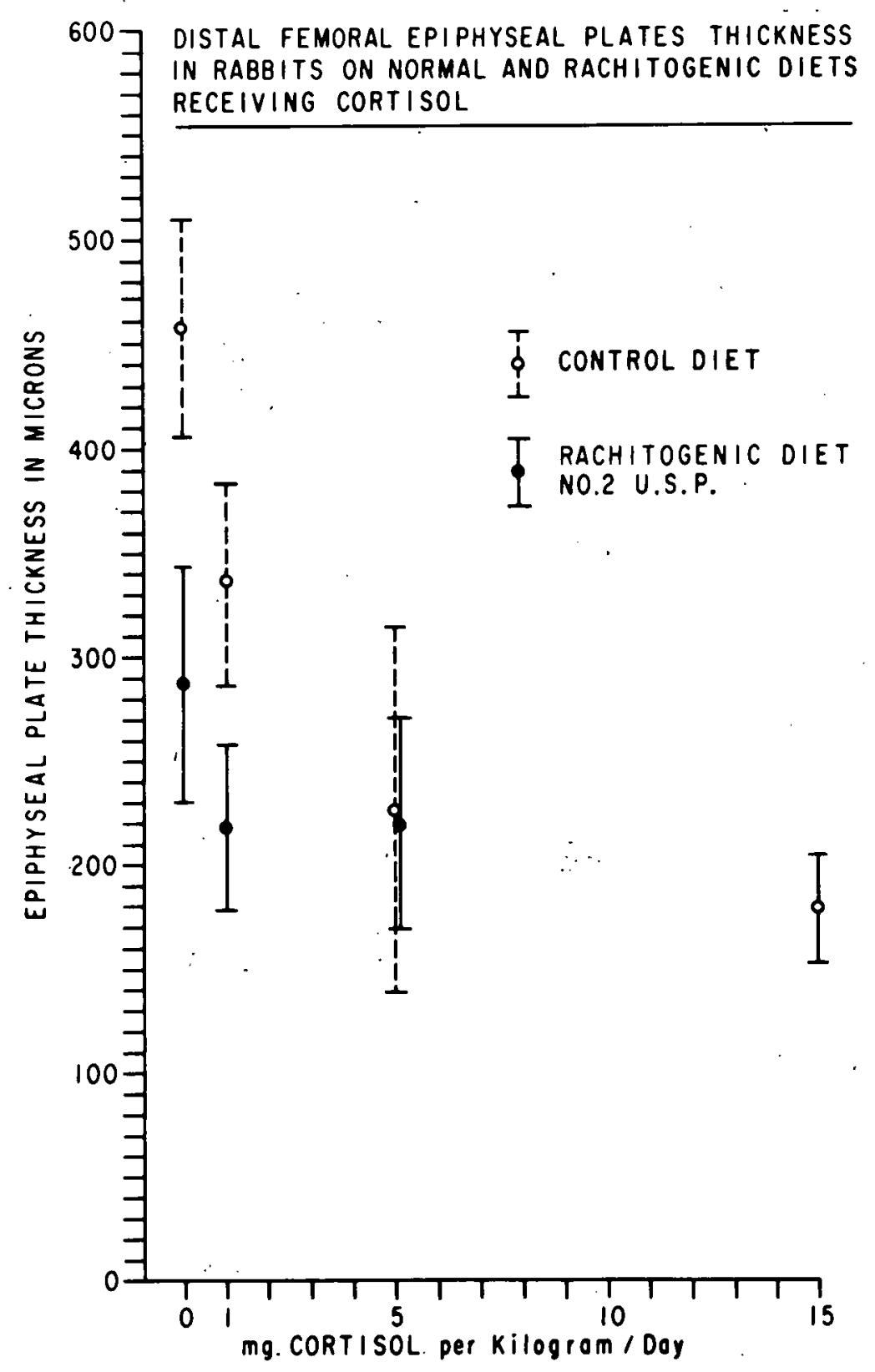

Fig. 7. Linear dose response plot of distal femoral epiphyseal thickness in rabbits fed control or rachitogenic diets. Although the lines are not plotted, a least squares fit of the points results in a dose response line with slopes of -0.155 for the normal diet and - .026 for the rachitogenic diet. The I represents the standard deviation of the mean. 
THE EFFECTS OF IRRADIATION ON ENDOCRINE CELLS V. A COMPARISON BETWEEN THE EFFECTS OF INANITION AND IRRADIATION ON ANDROGEN PRODUCTION BY MURINE TESTICULAR TISSUE

David L. Berliner ${ }^{1}$ and LeGrande C. Ellis ${ }^{2}$

\begin{abstract}
Male rats (Holtzman strain) were individually fed 7.5 grams of Laboratory Chow daily for 20 days. Control animals were fed the same ration, and water was given ad libitum to both groups of rats. Treatment was initiated when the animals were 15 weeks of age. Testicular tissue from both groups of animals was incubated with 5-pregnenolone- $7 \alpha-H^{3}$ and progesterone-4- $\mathrm{C}^{14}$. Incubations from both groups of animals were made with and without added cofactors. After 20 days of treatment, body weights, testicular weights, and seminal vesicle weights were diminished. Also, the in vitro biosynthesis of androgens was markedly diminished as a result of this treatment. The effects of inanition on androgen biosynthesis differed from that observed previously for irradiation in that the effects were not reversed by the addition of a NADPH-G-S. The reduction in androgen biosynthesis observed in this investigation was attributed to a lack of enzymes required for the biotransformation of 5-pregnenolone and progesterone into androgens. Evi-. dence was observed for a diminished desmolase (i.e., side-chain splitting) activity. The diminished enzyme activity of the testis was attributed to a lack of gonadotrophins. Thus, it would appear that inanition does diminish androgen production by the testis, but the effect differs from that observed for irradiation.
\end{abstract}

\title{
INTRODUCT ION
}

Recent investigations have shown that the biotransformation of steroids by murine testicular tissue is altered after various modes of irradiation $(1-3)$. It has also been shown (4) that death resulting from localized irradiation to the heads of rats can be prevented by introducing feed into the stomachs of these animals via a gastronomy tube. Other workers (5) indicate that vitamin B deficiency or partial inanition results in a diminished androgen synthesis in male rats as indicated by prostatic:and seminal vesicle weights. Head irradiated 
and total-body irradiated animals may undergo body weight losses due to a self-imposed restricted feed intake due to lesions of the oral cavity $(4,6)$ or the alimentary canal. Therefore, it was deamed advisable to ascertain if inanition will alter the biotransformation of steroids by rat testicular tissue, and to ascertain if this response differs from that observed after irradiation.

MATERIALS AND METHODS

Five male rats (Holtzman strain - 15 weeks of age) were individually fed 7.5 grams of Laboratory Chow (Ralston Purina Co.) daily for 20 days. Four additional rats were fed the same ration ad libitum, and both groups received water ad libitum. At the end of the treatment, both groups of rats were euthanized by ether anesthesia, and the testes were removed, chilled, trimmed, minced, and incubated with 5pregnenolone- $7 \alpha-\mathrm{H}^{3}$ and progesterone-4- $\mathrm{C}^{14}$ as described elsewhere (1) . Testicular mince from each group of rats was incubated without added cofactor; with $2.5 \mu$ moles of $\mathrm{NADPH}$, and with $2.5 \mu$ moles of NADPH plus $2.5 \mu$ moles of glucose-5-phosphate. In this manner, each treatment was replicated four times with each rat donating $0.5 \mathrm{gm}$ of tissue for each of the three incubations mentioned above.

The steroids were extracted, separated by chromatography and derivative formation, and characterized as previously described in the literature $(1,7)$. Radioactive samples were counted in a liquid scintillation spectrometer (Packard Inst. Co.), and the data were calculated with a digital computer (IBM Model-7040) (1). Statistical comparisons of the data for groups of two only (i.e., body weights, etc.) were made by using a "t" test (8). The remaining data were analyzed according to the method of analysis of variance Model I (8). If the 
"F" value calculated from the data were significant, a multiple range test or "Q" test was employed (8) to find where the differences between means were. The $95 \%$ level of significance was used throughout the entire procedure. High-polar steroid compounds were estimated by the method of triangulation (9).

\section{RESULTS}

Restriction of the feed intake of mature, male rats to 7.5 grams of feed per day for 20 days diminished body weight by approximately one-third. A similar decrease in testicular weight and seminal vesicle TABLE'I. Carcass Weights and Organ Weights of Control and Feed Deprived Rats

Measurement
Control

(gm)

$327 \pm 6.6^{*}$

$3.26 \pm 0.18$

$1.20 \pm 0.08$

$1.00 \pm 0.06$
Inanition

(gm)

Body weight ${ }^{+}$

Testicular weight ${ }^{1}$

Seminal vesicle weight ${ }^{2}$

Testicular weight (gm/100gm body wt.)

* Mean \pm standard error of mean

${ }^{+} \mathrm{P}<0.001$

$I_{\mathrm{P}}<0.05$

${ }^{2} \mathrm{P}<0.001$

${ }^{3} \mathrm{P}<0.001$

weight was observed for the animals on the restricted feed intake. The decrease in testicular weight was not proportional to the loss in body weight as cen be seen in Table I, when testicular weight was expressed on a grams/100 grams of body weight basis. As can be seen in Fig. 1 
and Table I, androstenedione and total androgen production was diminished for the treated animals. The addition of either NADPH or a NADPH-G-S increased the androstenedione, testosterone, and total androgen production for both the control and the treated animals. However,

$\mathbb{N}$ CONTROL

目 INANITION

I STANDARD ERROR OF MEAN

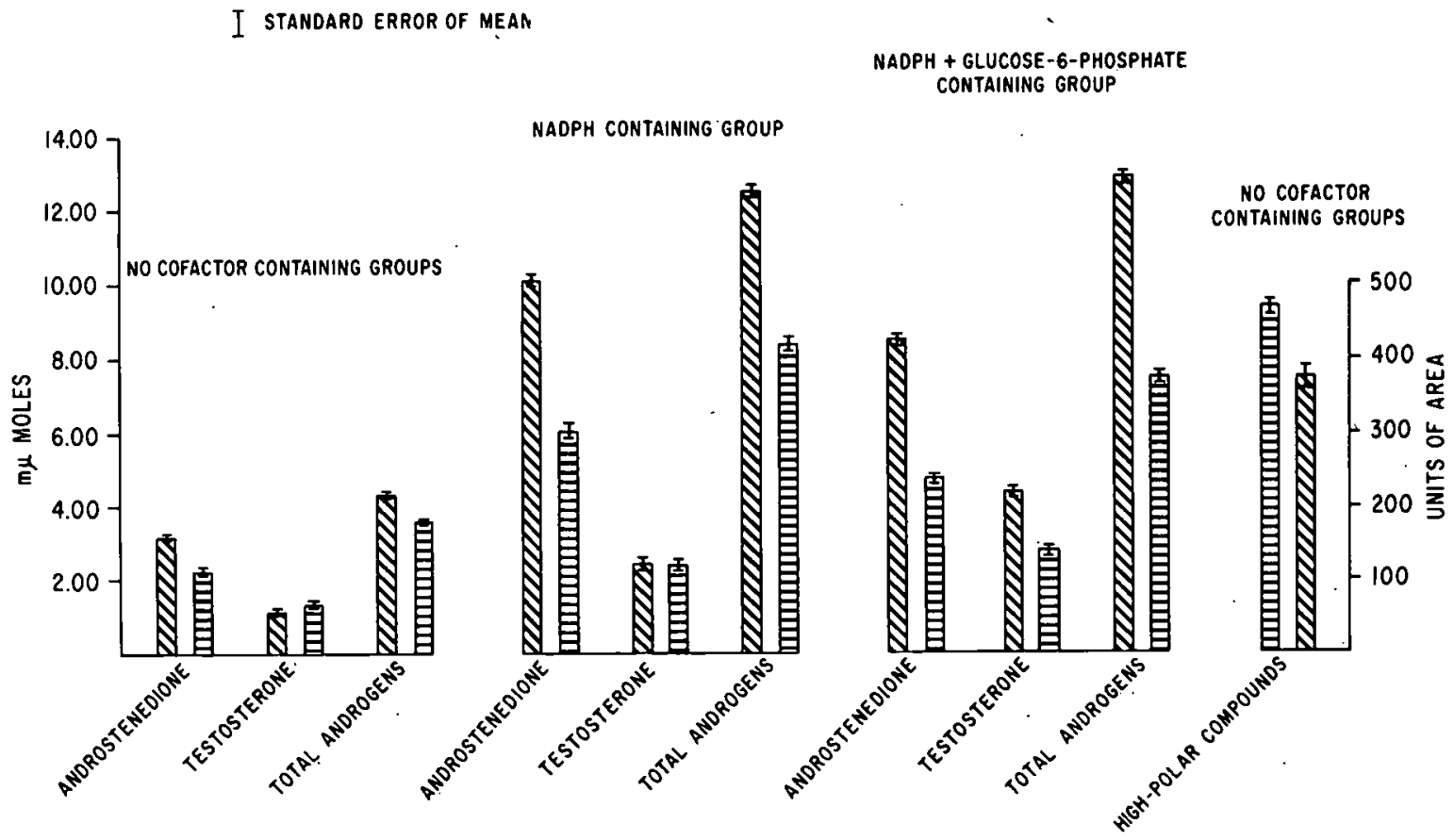

Fig. 1 .

there was a greater response to the addition of NADPH or NADPH-G-S by testicular tissue from control animals than for similar tissue from treated rats. It is interesting to note that there was no difference in testosterone production between the control and fasted animals when 
NADPH was added to the incubation mixture. There was, however, a difference in testosterone production between the two groups when. the NADPH-G-S was added to the incubation mixture.

The addition of either the NADPH or the NADPH-G-S to the incubation mixture increased the biotransformation of progesterone and 17 hydroxyprogesterone into androgens for the control animals. Similarly, TABLE II. Statistical Comparisons of the Data in Figure 1 for Control Versus Inanition

No cofactor containing groups

Androstenedione

Testosterone

Total Androgens
$\mathrm{P}<0.05$

$\mathrm{P}>0.05$

P. $<0.05$

NADPH containing groups

Androstenedione

$$
P<0.05
$$

Testosterone

$P>0.05$

Total Androgens

$\mathrm{P}<0.05$

$\mathrm{NADPH}+$ glucose-6-phosphate containing groups

Androstenedione

$\mathrm{P}<0.05$

Testosterone

$\mathrm{P}<0.05$

Total Androgens

an increase in the biotransformation of progesterone and $17 \alpha$-hydroxyprogesterone into androgens was observed for the treated animals. There was; however, less $17 \alpha$-hydroxyprogesterone biotransformed into androgens by the treated animals as compared to the control group indicative of a diminished side-chain splitting activity. The biotransformation of 5-pregnenolone- $7 \alpha-\mathrm{H}^{3}$ and progesterone-4- $\mathrm{C}^{14}$ into 
high-polar compounds (i.e., compounds with a polarity greater than testosterone) was significantly less $(P<0.001)$ for the treated animals than for the control animals (Fig. 1).

\section{ISCUSSION}

The data from this investigation show that restricting the feed intake of rats to 7.5 grams per day for 20 days reduces body weight, testicular weight, and seminal vesicle weight. Androgen production is also reduced as indicated by the diminished seminal vesicle weights of the treated rats and the in vitro biotransformation of 5-pregnenolone$7 \alpha-\mathrm{H}^{3}$ and progesterone-4- $\mathrm{C}^{14}$ into androstenedione and total androgens (androstenedione and testosterone). Androstenedione and testosterone were combined into a total androgen fraction since it has been shown that in murine species androstenedione is almost as effective an androgen as testosterone (10). In addition, both of the above compounds are considered to be true secretory products of the mammalian testis (11). Thus, these data show that restriction of feed intake of rats resulted in a diminished biosynthesis by testicular tissue. However, the alteration in steroid biotransformations observed in this investigation differs from that observed for direct irradiation of testes (2) or that observed for direct irradiation to the heads of rats (3). In the two investigations above, the addition of a NADPH-G-S to the incubation mixture reversed most of the defects noticed following irradiation. These data (Fig. 1) show the opposite effect. Instead of reversing the effects of restricting. feed intake on androgen biosynthesis, these effects were amplified. In the previous investigations $(2,3)$ the effects of irradiation on androgen biosynthesis by testicular tissue was attributed to the lack of an efficient NADPH-G-S. The data from 
this investigation support this conclusion and indicate that :in feedrestricted animals, the defect is a lack of steroid biotransforming enzymes and not a diminished cofactor content. The data (Table I) indicate that desmolase (i.e., the enzyme responsible for side-chain splitting of 17 $\alpha$-hydroxyprogesterone to androstenedione) activity is diminished following inanition as indicated by the incubations containing the added cofactors. Letham (12), in his excellent review of the subject, has pointed out that acute and chronic starvation results in a gonadal hypofunction due to diminished circulating levels of gonadotrophins. Furthermore, the endocrine response of the testis to inanition has been termed "psuedohypophysectomy" due to the similarity. of the response of the animal to these two treatments (12). Thus, these data show that inanition can diminish androgen production by rat testicular tissue as judged by a diminished accessory organ weight and the diminished in vitro biotransformation of 5-pregnenolone and progesterone into androgens. However, this response differs from that observed for irradiation in that it is not reversed by the addition. of a. NADPH-G-S. 
TABLE III. Average Quantities of 5-Pregnenolone-7 $\alpha-\mathrm{H}^{3}$ and Progesterone-4- $\mathrm{C}^{14}$ Biotransformed into Androgens and Their Immediate Precursors by Testicular Tissue as Expressed on a Per Rat Basis

\begin{tabular}{|c|c|c|c|c|}
\hline Steroid Isolated & $\begin{array}{l}\text { Mu Moles 5-Pregnenolone- } \\
7 \alpha-\mathrm{H}^{3}\end{array}$ & $\underset{4-C^{14}}{\text { Moles Progesterone- }}$ & Total & $\begin{array}{l}\mathrm{H}^{3} / \mathrm{C}^{14} \\
\text { Ratio }\end{array}$ \\
\hline \multicolumn{5}{|l|}{ No cofactor containing group } \\
\hline \multicolumn{5}{|l|}{ NADPH containing group } \\
\hline 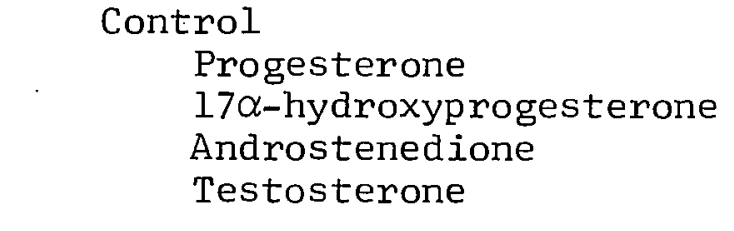 & $\begin{array}{l}0.19 \\
0.53 \\
3.43 \\
0.91\end{array}$ & $\begin{array}{l}0.27 \\
0.27 \\
6.69 \\
1.50\end{array}$ & $\begin{array}{r}0.46 \\
0.80 \\
10.12 \\
2.40\end{array}$ & $\begin{array}{l}0.70 \\
1.96 \\
0.51 \\
0.61\end{array}$ \\
\hline $\begin{array}{l}\text { Inanition } \\
\text { Progesterone } \\
\text { 17 } \alpha \text {-hydroxyprogesterone } \\
\text { Androstenedione } \\
\text { Testosterone }\end{array}$ & $\begin{array}{l}0.44 \\
1.42 \\
1.77 \\
0.76\end{array}$ & $\begin{array}{l}0.32 \\
1.47 \\
4.24 \\
1.60\end{array}$ & $\begin{array}{l}0.76 \\
2.89 \\
6.01 \\
2.36\end{array}$ & $\begin{array}{l}1.38 \\
0.97 \\
0.42 \\
0.48\end{array}$ \\
\hline
\end{tabular}


TABLE III. Continued...

\begin{tabular}{|c|c|c|c|c|c|}
\hline Steroid I & Isolated & $\begin{array}{l}\text { M } \mu \text { Moles 5-Pregnenolone- } \\
7 \alpha-\mathrm{H}^{3}\end{array}$ & $\begin{array}{l}\text { Mu Moles Progesterone- } \\
4-C^{14}\end{array}$ & Total & $\begin{array}{l}\mathrm{H}^{3} / \mathrm{C}^{14} \\
\text { Ratio }\end{array}$ \\
\hline \multicolumn{6}{|c|}{$\mathrm{NADPH}+$ glucose-6-phosphate containing group } \\
\hline \multicolumn{6}{|c|}{ Control } \\
\hline & Progesterone & 0.32 & 0.57 & 0.89 & 0.56 \\
\hline & $17 \alpha$-hydroxyprogesterone & 0.18 & 0.13 & 0.31 & 1.38 \\
\hline & Androstened ione & 2.91 & 5.63 & 8.54 & 0.52 \\
\hline \multicolumn{6}{|c|}{ Inanition } \\
\hline & Progesterone & 0.29 & 0.42 & 0.71 & 0.69 \\
\hline & $17 \alpha$-hyddoxyprogesterone & 0.57 & 0.50 & 1.07 & 1.14 \\
\hline \multirow{2}{*}{ - } & Androstenedione & 1.53 & 3.17 & 4.70 & 0.48 \\
\hline & Testosterone & 0.98 & 1.77 & 2.75 & 0.55 \\
\hline
\end{tabular}




\section{FOOTNOTES}

1. U. S. Public Health Service Research Career Development Awardee. $(1-\mathrm{K} 6-\mathrm{CA}-22,57-01)$.

2. U. S. Public Health Fellow (Training Grant \# 5 Tl GM-958-03). Present address: Department of Zoology, Utah State University, Logan, Utah.

3. In this paper, the following abbreviations are used: 5-pregnenolone, 5-pregnen-3ß-ol-20-one; progesterone, 4-pregnene-3,20-dione; $\mathrm{NADPH}$, reduced form of nicotinamide adenine dinucleotide phosphate; NADPH-G-S, reduced nicotinamide adenine dinucleotide phosphategenerating system; 17 $\alpha$-hydroxyprogesterone, 4-pregnen-17 $\alpha$-ol-3,20dione; androstenedione, 4-androstene-3,20-dione; testosterone, 4androsten-17B-01-3-one. 


\section{REFERENCES}

1. L. C. Ellis and D. L. Berliner, The effects of ionizing radiations on endocrine cells. I. Steroid biotransformations and androgen production by testes from irradiated mice. Radiation Res. 20, 549$563(1963)$

2. D. L. Berliner, L. C. Ellis, and G. N. Taylor, The effects of ionizing radiations on endocrine cells. II. Restoration of androgen production with a reduced nicotinamide adenine dinucleotide phosphate-generating system following. irradiation of rat testes. Radiation $\underline{\text { Res. }}$ 22, 345-356 (1964).

3. L. C. Ellis and D. L. Berliner, The effects of ionizing radiations on endocrine cells. III. Restoration of testosterone production. with a reduced nicotinamide adenine dinucleotide-phosphate generating system after localized irradiation to heads of rats. Radiation Res. (In Press - 1964).

4. R. Goepp and F. Fitch, Prevention of death in mice after lethal irradiation of the head. Radiation Res. 19, 670-675 (1963).

5. C. R. Moore and L. T. Samuels, The action of testis hormone in correcting changes induced in the rat prostate and seminal vesicles by vitamin B deficiency or partial inanition. Am. J. Physiol. $\underline{96}$, $278-288(1931)$

6. R. Goepp and F. Fitch, Pathological study of oral radiation death in mice. Radiation Res. 16, 833-845 (1962).

7. D. L. Berliner, The microchemical identification of steroids from biological media. In Advances in Tracer Methodology, (Ed. S. Rothchild) Vol. II, Plenum Press, New York (In Press - 1964).

8. G. W. Snedecor, Statistical Methods. Iowa State College Press, Iowa, (1959) . 
9. D. L. Berliner, 0. V. Dominquez, and G. Westenskow, Determination of carbon-14 steroids on paper chromatograms: Anal. Chem. 29, 1797-1800 (1953).

10. R. I. Dorfman and R. A. Shipley, Androgens. pp. 116-128, John Wiley and Sons, New York (1956).

ll. C. D. West, V. P. Hollander, T. H. Kritchevsky, and K. Dobriner, The isolation and identification of testosterone, $\Delta^{4}$-androstenedione-3, 17, and 7-ketocholesterol from spermatic vein blood. I. Clin. Endocrinol. Metab. 12, 915-916 (1952).

12. J. H. Letham, Nutrition and accessory sex organs. I. Natl. Cancer Inst. Mono. 12, 201-210 (1963). 
A COMPARISON OF TWO METHODS OF ANALYZING THE HEMATOLOGICAL DATA FROM STRONT IUM-90 INJECTED BEAGLES

Jean H. Dougherty, Leon S. Rosenblatt*, and Peter J. Mikolaj

Abstract: Selected hematological data from the strontium injected beagles were subjected to two methods of statistical analysis, a randomized block and a one-way analys is of variance. The experimental dogs were compared both to strontium 0-level dogs and to pooled 0-level dogs from all radionuclides. Comparable results were obtained with either control group in terms of significant differences. The randomized block design analysis of variance was found to be the more sensitive type of analysis and will be the method of choice for subsequent analyses of hematological changes following internal irradiation.

\section{INTRODUCTION}

Two statistical methods have been used in an attempt to get meaningful significance values for the relationship of the various hematological traits of control (0-level) dogs to those injected with the different dose levels of the various radionuclides as well as the relationships between the dose levels. The small number of animals at each dose level as well as the fact that the 12 groups of each radionuclide were injected over a long period of time and some dose levels were not added until much later than others in their group are a few of the complicating factors that must be considered in any type of analysis. The strontium dogs were chosen for the preliminary analysis since this is the only radionuclide in which all dose levels in a group were injected at the same time (with the exception of FlSl.7 and a few replacement dogs - i.e., FISIA, M5S1.7A, etc.). Thus, with this radionuclide the effect of time as a variable could be ruled out. This was

\footnotetext{
*Biological Frontiers Institute, Livermore, California.
} 
found to be important since time trends have been found in many of the hematological traits $(1)$.

The first strontium analyses were made by Drs. Leon S. Rosenblatt and Fred T. Shultz of Biological Frontiers Institute of Livermore, California, several years ago (1962). They selected the following hematological traits for their preliminary analysis: volume of packed red cells (VPRC), segmented polymorphonuclear neutrophils (pmns) and lymphocytes and compared the mean values from the seven dose levels at six month intervals (from 6 through 48 months post-injection). Analyses were not run beyond 48 months since there were not sufficient dogs on the experiment beyond this time. The data was analyzed by a randomized block design analysis of variance.

During the past year, using the IBM 7040-1401 computer system at the University of Utah Computer Center, we have reanalyzed the same traits from the strontium dogs using a one-way analysis of variance and covering the same time intervals after injection.

METHODS

\section{Analyses by Biological Frontiers Institute. Two types of} analyses were made: A. Strontium dogs at each dose level $(0,1,1.7$, $2,3,4,5)$ were tested against the strontium 0 -level dogs, and B. Strontium dogs at each level were tested against the.0-level dogs of all radionuclides. This pooled group of 0 -level controls will be called the "master controls". They were used to increase the sensitivity of the analysis by providing a larger sample size at the 6 month intervals. Since the 0 -level dogs have been introduced into the experiment from 1952-1963, the counts were corrected for the time trends mentioned previously. These correction factors were derived from regression equations 
utilizing the yearly means of pre-injection counts of all dogs over this ten year period. The details of the method are given in a previous semi-annual report ${ }^{(2)}$.

\section{Ana.lysis A. Strontium Dogs vs. Strontium 0-Level Controls. A} series of analyses of variance using the randomized block design were made. Thé technics employed were described in an earlier semi-annual report ${ }^{(3)}$ and will not be given in detail here. In general, where there were missing values they were estimated by a least squares estimation. The standard errors obtained were utilized in making a series of Duncan's multiple range tests (4) so that each dose level could be tested against every other dose level. The experimental design of the toxicity experiment permitted these pairwise comparisons of the different dose levels. The number of dogs at each time interval is given at the top of Table la. The results of the analysis are seen in Tables 2a (VPRC), 2b (pmns), and 2c (lymphocytes). The means for each dose level, are included in the top half of the tables. Significance levels $(.05, .01$, and .001$)$ are inserted only where significant differences were found. A dash indicates that there were insufficient data available (see (Table 1). For these analyses no calendar time correction was necessary and none was made. For this reason the sets of means found in Tables 2 and 3 (see below) for the same traits are not identical. 
Table la

Number of Dogs in Randomized Block Analysis of Variance

\begin{tabular}{|c|c|c|c|c|c|c|c|c|}
\hline \multirow{2}{*}{$\begin{array}{l}\text { Dose } \\
\text { Level }\end{array}$} & \multicolumn{8}{|c|}{ Months Post-Injection } \\
\hline & 6 & 12 & 18 & 24 & 30 & 36 & 42 & 48 \\
\hline 0.0 & 10 & 12 & 12 & 10 & 7 & 6 & 6 & 5 \\
\hline 1.0 & 12 & 12 & 12 & 11 & 8 & 7 & 6 & 5 \\
\hline 1.7 & 12 & 11 & 12 & 11 & 8 & 7 & 6 & 5 \\
\hline 2.0 & 11 & 12 & 12 & 11 & 8 & 7 & 6 & 5 \\
\hline 3.0 & 12 & 12 & 12 & 10 & 8 & 7 & 6 & 5 \\
\hline 4.0 & 12 & 12 & 12 & 11 & 8 & 7 & 5 & 5 \\
\hline 5.0 & 13 & 12 & 12 & 11 & 8 & 4 & 2 & - \\
\hline $\begin{array}{l}\text { Master } \\
\text { Control }\end{array}$ & 44 & 46 & 45 & 43 & 38 & 39 & 38 & 35 \\
\hline
\end{tabular}

Master Control used in Analysis B.

Table lb

Number of Dogs in One-Way Analysis of Variance

\begin{tabular}{|c|c|c|c|c|c|c|c|c|}
\hline \multirow{2}{*}{$\begin{array}{l}\text { Dose } \\
\text { Level }\end{array}$} & \multicolumn{8}{|c|}{ Months Post-Injection } \\
\hline & 6 & 12 & 18 & 24 & 30 & 36 & 42 & 48 \\
\hline 0.0 & 12 & 13 & 13 & 10 & 11 & 11 & 11 & 11 \\
\hline 1.0 & 12 & 11 & 12 & 11 & 11 & 12 & 12 & 12 \\
\hline 1.7 & 12 & 12 & 13 & 12 & 12 & 12 & 12 & 12 \\
\hline 2.0 & 11 & 12 & 12 & 12 & 12 & 12 & 12 & 12 \\
\hline 3.0 & 12 & 12 & 12 & 12 & 12 & 12 & 11 & 12 \\
\hline 4.0 & 12 & 12 & 12 & 12 & 12 & 11 & 12 & 12 \\
\hline 5.0 & 13 & 12 & 12 & 1.2 & 11 & 9 & 6 & 4 \\
\hline $\begin{array}{l}\text { Master } \\
\text { Control }\end{array}$ & 55 & 58 & 57 & 53 & 51 & 53 & 52 & 48 \\
\hline
\end{tabular}

*Master Control used in place of 0.0 level for Analyses 3 and 4. 
Table 2a (Analysis A)

Results of Duncan's Multiple Range Test for VPRC

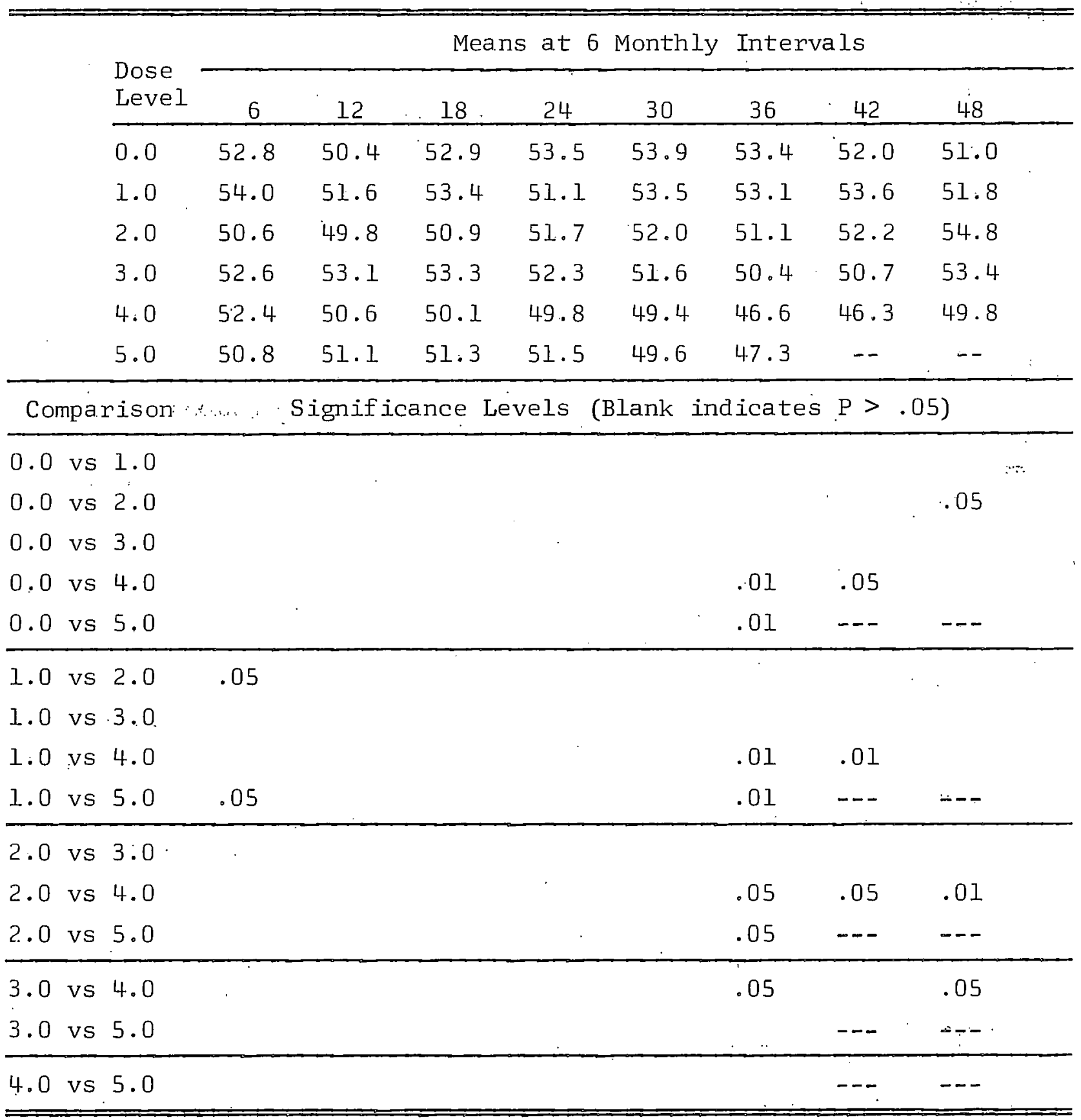


Table 2b (Analysis A)

Results of Duncan's Multiple Range Test for Pmns $\left(\mathrm{Xl} 0^{3}\right)$

\begin{tabular}{|c|c|c|c|c|c|c|c|c|c|}
\hline & \multirow{2}{*}{$\begin{array}{l}\text { Dose } \\
\text { Level }\end{array}$} & \multicolumn{8}{|c|}{ Means at 6 Monthly Intervals } \\
\hline & & 6 & 12 & 18 & 24 & 30 & 36 & 42 & 48 \\
\hline & 0.0 & 7.13 & 5.73 & 6.26 & 5.11 & 5.48 & 5.00 & 4.05 & 3.94 \\
\hline & 1.0 & 6.60 & 6.01 & 5.39 & 4.78 & 4.98 & 6.86 & 4.43 & 4.66 \\
\hline & 2.0 & 6.65 & 5.69 & 5.52 & 5.39 & 5.10 & 5.61 & 4.42 & 5.02 \\
\hline & 3.0 & 5.12 & 5.11 & 4.69 & 5.52 & 4.79 & 4.81 & $3: 80$ & 3.40 \\
\hline & 4.0 & 3.97 & 3.96 & 3.45 & 3.73 & 3.80 & 4.71 & 4.47 & 5.22 \\
\hline & 5.0 & 3.21 & 2.83 & 3.04 & 2.67 & 3.51 & 3.34 & 4.63 & -- \\
\hline Compary & rison & & Signifi & ance & vels & ank & dicates & $\mathrm{P}>$ & $.05)$ \\
\hline $0.0 \mathrm{vs}$ & 1.0 & & & & & & & & \\
\hline $0.0 \mathrm{vs}$ & 2.0 & & & & & & & & \\
\hline $0.0 \mathrm{vs}$ & 3.0 & .05 & & .01 & & & & & . \\
\hline $0.0 \mathrm{vs}$ & 4.0 & .001 & .01 & .001 & .05 & & & & \\
\hline $0.0 \mathrm{vs}$ & 5.0 & .001 & .001 & .001 & .001 & .05 & & & \\
\hline $1.0 \mathrm{vs}$ & 2.0 & & & & & & & & \\
\hline $1.0 \mathrm{vs}$ & 3.0 & & - & & & & & & \\
\hline $1.0 \mathrm{vs}$ & 4.0 & .01 & .01 & .001 & & & & & \\
\hline $1.0 \mathrm{vs}$ & 5.0 & .001 & .001 & .001 & .001 & & .05 & & \\
\hline $2.0 \mathrm{vs}$ & 3.0 & & & & & & & & \\
\hline $2.0 \mathrm{vs}^{\circ}$ & 4.0 & .01 & .01 & .001 & .01 & & & & . \\
\hline $2.0 \mathrm{vs}$ & 5.0 & .001 & .001 & .001 & .001 & & & & \\
\hline $3.0 \mathrm{vs}$ & 4.0 & .05 & .001 & .05 & .01 & & & & \\
\hline $3.0 \mathrm{vs}$ & 5.0 & & & .01 & .001 & & & & \\
\hline $4.0 \mathrm{vs}$ & 5.0 & & & & .05 & & & & \\
\hline
\end{tabular}


Table 2c (Analysis A)

Results of Duncan's Multiple Range Tests for Lymphocytes $\left(\mathrm{XlO}^{3}\right)$

\begin{tabular}{|c|c|c|c|c|c|c|c|c|c|}
\hline & \multirow{2}{*}{$\begin{array}{l}\text { Dose } \\
\text { Levê }\end{array}$} & \multicolumn{8}{|c|}{ Means at 6 Monthly Intervals } \\
\hline & & 6 & 12 & 18 & 24 & 30 & 36 & 42 & 48 \\
\hline & 0.0 & 3.67 & 3.68 & 3.52 & 3.10 & 3.70 & 3.17 & 3.32 & 2.97 \\
\hline & 1.0 & 3.60 & 3.31 & 3.18 & 2.94 & 2.90 & 2.39 & 2.43 & 1.99 \\
\hline & 2.0 & 3.34 & 3.12 & 3.35 & 3.02 & 2.94 & 2.61 & 3.02 & 2.94 \\
\hline & 3.0 & 2.78 & 3.10 & 2.95 & 2.98 & 2.82 & 2.51 & 2.76 & 2.88 \\
\hline & 4.0 & 2.88 & 3.03 & 2.42 & 2.50 & 2.63 & 2.58 & 2.89 & 2.96 \\
\hline & 5.0 & 2.16 & 2.07 & 1.95 & 2.29 & 2.46 & 2.13 & 1.90 & -- \\
\hline Compa & rison & \multicolumn{8}{|c|}{ Significance Levels (Blank indicates $\mathrm{P}>.05$ ) } \\
\hline $0.0 \mathrm{vs}$ & 1.0 & & & & & & .05 & .05 & .01 \\
\hline $0.0 \mathrm{vs}$ & 2.0 & & & & & & & & \\
\hline $0.0 \mathrm{vs}$ & 3.0 & .05 & & & & .05 & & & \\
\hline $0.0 \mathrm{vs}$ & 4.0 & & & .01 & & .05 & & & \\
\hline $0.0 \mathrm{vs}$ & 5.0 & .001 & .001 & .001 & .05 & .01 & .01 & .01 & $\cdots$ \\
\hline $1.0 \mathrm{vs}$ & 2.0 & & & & & & & & .01 \\
\hline $1.0 \mathrm{vs}$ & 3.0 & .05 & & & & & & & .01 \\
\hline $1.0 \mathrm{vs}$ & 4.0 & & & .05 & & & & & .01 \\
\hline $1.0 \mathrm{vs}$ & 5.0 & .001 & .001 & .001 & & & & & $\cdots$ \\
\hline $2.0 \mathrm{vs}$ & 3.0 & & & & & & & & \\
\hline $2.0 \mathrm{vs}$ & 4.0 & & & .01 & & & & & \\
\hline $2.0 \mathrm{vs}$ & 5.0 & .01 & .01 & .001 & .05 & & & .01 & $\cdots$ \\
\hline $3.0 \mathrm{vs}$ & 4.0 & & & & & & & & \\
\hline $3.0 \mathrm{vs}$ & 5.0 & & .01 & .01 & & & & .05 & $\cdots$ \\
\hline $4.0 \mathrm{vs}$ & 5.0 & & .01 & & & & & .05 & $\cdots$ \\
\hline
\end{tabular}


Analysis B. Strontium Dogs vs. Master Controls. The comparisons of strontium dogs to master controls were made by a series of individual t-tests, testing each strontium dose level against the master controls (see Table la for number of master controls). Since the master control data was corrected for time trends, the data on the strontium dogs was also corrected for calendar year. The assumption was made that the same factor or factors producing the time trends on the control dogs were operating on the experimental ones and in the same manner. No pairwise comparisons were made (i.e., between levels) on the corrected data. Tables $3 a, 3 b$, and $3 c$ give the means of the corrected data and the results of the t-tests. The latter are given in terms of probability values. Asterisks indicate that a significant difference has been observed. It may be seen from these tables that the strontium 0-level controls are not significantly different from the master controls not containing the strontium 0 -level controls). In fact, the means are very. nearly alike. This is an absolutely necessary condition before one can legitimately test the various injection levels against the master controls. Whether this will hold true for the o-level of all radionuclides has not as yet been ascertained. 
Table 3a VPRC (Analysis B)

Strontium Dogs vs. "Master Controls"

\begin{tabular}{|c|c|c|c|c|c|c|c|c|}
\hline \multirow{2}{*}{$\begin{array}{l}\text { Dose } \\
\text { Level }\end{array}$} & \multicolumn{8}{|c|}{ Means at 6 Monthly Intervals } \\
\hline & 6 & 12 & 18 & 24 & 30 & 36 & 42 & 48 \\
\hline $\begin{array}{l}\text { Master } \\
\text { Control }\end{array}$ & 49.7 & 48.8 & 49.4 & 48.7 & 48.7 & 48.7 & 47.3 & 46.2 \\
\hline 0.0 & 50.1 & 47.2 & 49.6 & 49.8 & 51.0 & 49.5 & 48.3 & 46.1 \\
\hline & 50.6 & 47.1 & 49.3 & 47.0 & 48.5 & 48.0 & 48.8 & 48.6 \\
\hline & 50.5 & 46.4 & 46.5 & 47.6 & 47.9 & 48.0 & 48.5 & 48.0 \\
\hline & 47.5 & 46.7 & 47.6 & 48.4 & 48.5 & 47.6 & 48.5 & 51.2 \\
\hline & 49.7 & 49.9 & 50.0 & 48.6 & 48.1 & 46.9 & 47.0 & 49.8 \\
\hline & 49.5 & 47.5 & 46.8 & 46.5 & 45.9 & 44.0 & 42.0 & 47.4 \\
\hline & 47.5 & 47.8 & 47.7 & 47.7 & 47.2 & 43.0 & 43.0 & $\because-$ \\
\hline
\end{tabular}

Ranges of Significance (Probability Values) from t-test of Individual Dose Levels Against "Master Controls"

\begin{tabular}{|c|c|c|c|c|c|c|c|c|}
\hline \multirow{2}{*}{$\begin{array}{l}\text { Dose } \\
\text { Level }\end{array}$} & \multicolumn{8}{|c|}{ Months Post-Injection } \\
\hline & 6 & 12 & 18 & 24 & 30 & 36 & 42 & 48 \\
\hline 0.0 & $.80-.90$ & $.20-.30$ & $.80-.90$ & $.50-.60$ & $.20-.30$ & $.60-.70$ & $.50-.60$ & $.90^{+}$ \\
\hline 1,0 & $.50-.60$ & $.20-.30$ & $.90^{+}$ & $.30-.40$ & $.90^{+}$ & $.60-.70$ & $.30-.40$ & $.20-.30$ \\
\hline 1.7 & $.60-.70$ & $.05-.10$ & $.05-.10$ & $.50-.60$ & $.60-.70$ & $.70-.80$ & $.40-.50$ & $.90^{+}$ \\
\hline 2.0 & $.10-.20$ & $.05-.10$ & $.20-.30$ & $.80-.90$ & $.90^{+}$ & $.50-.60$ & $.40-.5: 0$ & $.01-.02$ \\
\hline 3.0 & $.90^{+}$ & $.30-.40$ & $.60-.70$ & $.90^{+}$ & $.70-.80$ & $: 30-.40$ & $.80-.90$ & $: 20-.30$ \\
\hline 4.0 & $.90^{+}$ & $.30-.40$ & $.10-.20$ & $.20-.30$ & $.10-.20$ & $.001-.0 * 1$ & $.001-.01$ & $.50-.60$ \\
\hline 5.0 & $.10-.20$ & $.30-.40$ & $.30-.40$ & $.50-.60$ & $.30-.40$ & $.01-.02$ & $.05-.10$ & --- \\
\hline
\end{tabular}


Table 3b Pmns (Analysis B)

Strontium Dogs vs. "Master Controls"

\begin{tabular}{|c|c|c|c|c|c|c|c|c|}
\hline \multirow{2}{*}{$\begin{array}{l}\text { Dose } \\
\text { Level }\end{array}$} & \multicolumn{8}{|c|}{ Means at 6 Monthly Intervals } \\
\hline & 6 & 12 & 18 & 24 & 30 & 36 & 42 & 48 \\
\hline \multirow{7}{*}{$\begin{array}{l}\text { Master } \\
\text { Contro }\end{array}$} & 8.58 & 8.58 & $: 7.58$ & 7.54 & 7.30 & 7.34 & 7.21 & 7.16 \\
\hline & 8.74 & 7.19 & 7.85 & 6.53 & 6.97 & 6.80 & 5.80 & 5.74 \\
\hline & 8.08 & 7.28 & 7.14 & 6.53 & 6.40 & 8.30 & 6.35 & 6.50 \\
\hline & 7.81 & 7.26 & 7.21 & 6.88 & 7.00 & 8.07 & 6.68 & 7.44 \\
\hline & 8.10 & 7.16 & 7.12 & 7.04 & 6.74 & 7.31 & 6.17 & 6.82 \\
\hline & 6.47 & 6.57 & 6.28 & 7.20 & 6.42 & 6.51 & 5.55 & 5.20 \\
\hline & 5.32 & 5.42 & 5.04 & 5.39 & 5.45 & 6.43 & 6.16 & 7.02 \\
\hline 5.0 & 4.48 & 4.38 & 4.43 & 4.35 & 4.85 & 4.92 & 7.20 & -- \\
\hline
\end{tabular}

Ranges of Significance (Probability Values) from t-test of Individual Dose Levels Against "Master Controls"

\begin{tabular}{|c|c|c|c|c|c|c|c|c|}
\hline \multirow{2}{*}{$\begin{array}{l}\text { Dose } \\
\text { Level }\end{array}$} & \multicolumn{8}{|c|}{ Months Post-Injection } \\
\hline & 6 & 12 & 18 & 24 & 30 & 36 & 42 & 48 \\
\hline 0.0 & $.80-.90$ & $.10-.20$ & $.10-.20$ & $.10-.20$ & $.70-.80$ & $.50-.60$ & $.10-.20$ & $.05-.10$ \\
\hline 1.0 & $.50-.60$ & $.10-.20$ & $.30-.40$ & $.10-.20$ & $.20-.30$ & $.30-.40$ & $.30-.40$ & $.30-.40$ \\
\hline 1.7 & $.20-.30$ & $.10-.20$ & $.40-.50$ & $.30-.40$ & $.70-.80$ & $.40-.50$ & $.50-.60$ & $.70-.80$ \\
\hline 2.0 & $.50-.60$ & $.10-.20$ & $.30-.40$ & $.40-.50$ & $.40-.50$ & $.90^{+}$ & $.20-.30$ & $.60-.70$ \\
\hline 3.0 & $.001-.01$ & $.01-.02$ & $.01-.02$ & $.60-.70$ & $.30-.40$ & $.30-.40$ & $.05-.10$ & $.001-.01$ \\
\hline 4.0 & $.00 \stackrel{*}{1}$ & $.00 \stackrel{*}{*}$ & .001 & $.001-.0 \stackrel{*}{1}$ & $.02-.0 \frac{*}{5}$ & $.30-.40$ & $.30-.40$ & $.80-.90$ \\
\hline 5.0 & $.00 \stackrel{1}{1}$ & $.00 \stackrel{+}{1}$ & $.00 \stackrel{*}{1}$ & $.00 \stackrel{*}{1}$ & $.001-.0 \%$ & $.02-.0 \stackrel{*}{5}$ & $.90^{+}$ & --- \\
\hline
\end{tabular}


Table 3c Lymphocytes. (Analysis B)

Strontium Dogs vs. "Master Controls"

\begin{tabular}{|c|c|c|c|c|c|c|c|c|}
\hline \multirow{2}{*}{$\begin{array}{l}\text { Dose } \\
\text { Level }\end{array}$} & \multicolumn{7}{|c|}{ Means at 6 Monthily Intervals } & \\
\hline & 6 & 12 & 18 & 24 & 30 & 36 & 42 & 48 \\
\hline \multirow{8}{*}{$\begin{array}{l}\text { Mastex } \\
\text { Contro }\end{array}$} & 4.40 & 4.37 & 4.40 & 4.20 & 4.25 & 4.26 & 4.30 & 4.30 \\
\hline & 4.53 & 4.48 & 4.38 & 4.01 & 4.75 & 3.97 & 4.27 & 3.95 \\
\hline & 4.36 & 4: 06 & 3.98 & 3.82 & 3.72 & 3.36 & 3.39 & 3.65 \\
\hline & 4.38 & 4.49 & 4.17 & 4.20 & 4.65 & $4: 35$ & 4.42 & 4.55 \\
\hline & 4.12 & 3.91 & 4.21 & 3.92 & 3.83 & 3.53 & 3.72 & 3.92 \\
\hline & 3.51 & 3.89 & 3.80 & 3.92 & 3.71 & 3.43 & 3.97 & 3.86 \\
\hline & 3.62 & 3.57 & 3.28 & 3.40 & 3.52 & 3.50 & 3.84 & 3.94 \\
\hline & 2.87 & $2: 90$ & 2.88 & 3.00 & 3.25 & 3.18 & 3.25 & -- \\
\hline
\end{tabular}

Ranges of Significance (Probability Values) from t-test of Individual Dose Levels Against "Master Controls"

\begin{tabular}{|c|c|c|c|c|c|c|c|c|}
\hline \multirow{2}{*}{$\begin{array}{l}\text { Dose } \\
\text { Level }\end{array}$} & \multicolumn{8}{|c|}{ Months Post-Injection } \\
\hline & 6 & 12 & 18 & 24 & 30 & 36 & 42 & 48 \\
\hline 0.0 & $.70-.80$ & $.70-.80$ & $.90^{+}$ & $.50-.60$ & $.05-.10$ & $.40-.50$ & $.90^{+}$ & $.30-.40$ \\
\hline 1.0 & $.90^{+}$ & $.30-.40$ & $.20-.30$ & $.20-.30$ & $.05-.10$ & $.02-.05$ & $.02-.05$ & $.10-.20$ \\
\hline 1.7 & $.90^{+}$ & $.70-.80$ & $.40-.50$ & $.90^{+}$ & $.10-.20^{\circ}$ & $.80-.90$ & $.70-.80$ & $.30-.40$ \\
\hline 2.0 & $.40-.50$ & $.20-.30$ & $.50-.60$ & $.30-.40$ & $.10-.20$ & $.05-.10$ & $.20-.30$ & $.30-.40$ \\
\hline 3.0 & $.01-.02$ & $.10-.20$ & $.05-.10$ & $.30-.40$ & $.05-.10$ & $.02-.05$ & $.40-.50$ & $.20-.30$ \\
\hline 4.0 & $.02-.05$ & $.02-.05^{*}$ & $.00 \stackrel{*}{*}$ & $.01-.02$ & $.01-.02$ & $.05-.10$ & $.30-.40$ & $.30-.40$ \\
\hline 5.0 & $.00 \stackrel{*}{1}$ & . óoİ & .001 & $.00 \stackrel{*}{1}$ & $.001-.01$ & $.02-.05$ & $.10-.20$ & --- \\
\hline
\end{tabular}




\section{RESULTS OF ANALYSES A AND B}

The two methods give almost identical results - i.e., using master controls or 0 -level controls. There are a few cases where the t-test indicated significance at the .05 level of probability whereas the Duncan test did not and vice versa. These differences are due to random variables operating on the data. The time intervals studied here are too short to be concerned about whether a value at any one time interval or dose level is significant. One must look at the entire picture. A significant test scattered here and there across the face of the table does not mean very much. However, many significant values at any one dose level or over a long period of time do have "biological" as well as "statistical" significance.

In general, for VPRC the two higher dose levels show no significance until the 36th month. However, there are very few dogs at the 5.0-level at this time. The 2.0-level is higher at 48 months compared to the controls. This is probably a sampling error which is to be expected.

The pmn comparisons indicate highly significant differences during the first 18 months for the three highest levels, with "statistical" recovery (as opposed to "biological" recovery) by 24, 36, and 42 months for levels $3.0,4.0$ and 5.0, respectively. The lymphocytes (Tables 2c and 3c) behave similarly with significant decreases from the controls at the 4 and 5-level. The 3-level was affected but not to the same extent as the higher levels. The reason why the 1.0-level dogs are different from controls after 36 months is not known.

II. Analysis C Performed at the University of Utah Computer

Center. A one-way analysis of variance was performed using dose level 
as the independent variable. If the computed $F$ value. was significant when compared to the reference $F$ value at the 01 and .05 levels. of probability, (except in analysis 4 where only the .0l-level was used) the data was then further analyzed according to the distribution of studentized range ${ }^{(5)}$ to determine which dose levels were responsible for the significant differences.

This procedure was followed. for four different analyses in order to evaluate which one would provide the most efficient method. The oneway analysis of variance, assuming a completely randomized design, was chosen since the problem under consideration was one involving the. detection of differences among a colony of irradiated beagles. For: purposes of comparison, a small error mean square would indicate an efficient method. Analysis $C$ was subdivided as follows:

Analys is 1. The uncorrected values for each dose level of the strontium dogs were tested. against the strontium control (0-1evel) measurements. Analysis 2. Correction factors were added to individual measurements of both experimental and control dogs of Analysis l.and the results were computed.

In view of the earlier study (Analysis B of this report) which utilized the master controls, two further analyses were made using the master controls.

Analysis 3. The master control values (including the strontium 0 -level dogs) were tested against the uncorrected experimental dog measurements. Analysis 4. The master control data was tested against the time-trend corrected values for the 1.0 through 5.0 dose levels.

RESULTS OF ANALYSIS C

The results of Analyses. 1 and 4 are presented. in Tables 4 and 5 
$(\mathrm{a}, \mathrm{b}, \mathrm{c})$, respectively. The number of dogs at the different dose levels from 6 through 48 months post-injection are found in Table $1 \mathrm{~b}$.

Table 4 a (Analysis 1)

Mean VPRC

\begin{tabular}{lcccccccc}
\hline & \multicolumn{7}{c}{ Months Post-Injection } \\
\cline { 2 - 8 } $\begin{array}{l}\text { Dose } \\
\text { Level }\end{array}$ & 6 & 12 & 18 & 24 & 30 & 36 & 42 & 48 \\
\hline 0.0 & 52.8 & 50.3 & 52.8 & 54.2 & 53.3 & 52.3 & 52.4 & 50.8 \\
1.0 & 53.6 & 51.5 & 52.7 & 52.0 & 53.6 & 52.3 & 53.0 & 51.1 \\
1.7 & 53.7 & 50.2 & 50.2 & 51.6 & 51.8 & 52.1 & 53.4 & 51.5 \\
2.0 & 50.6 & 49.8 & 50.9 & 51.9 & 52.0 & 51.8 & 51.6 & 52.1 \\
3.0 & 52.7 & 53.1 & 53.3 & 52.6 & 52.8 & 51.3 & 52.4 & 52.9 \\
4.0 & 52.4 & 50.7 & 50.2 & 50.7 & 51.0 & 50.7 & 51.2 & 52.4 \\
5.0 & 50.8 & 51.0 & 51.3 & 51.9 & 52.2 & 51.6 & 50.5 & 51.3 \\
\hline
\end{tabular}

No significant differences in VPRC.

Since additional groups of strontium dogs were added to the project subsequent to 1962, and dogs had also been on experiment for a longer time, the sample sizes at the 6 month time intervals are somewhat larger. than those from the earlier analyses. In particular, the 1962 analyses did not have any 5.0-level dogs at 48 months while the later analyses did. The results from all four analyses were found to be quite similar. The data from Analyses 1 and 4 were chosen as being representative of the results obtained from all the tests. The first part of each table contains the mean values for the VPRC, pmns and lymphocytes while the remainder of the table shows where significant differences occur. A blank indicates that the probability of a difference is greater than .05 in Table 4 and .01 in Table 5.

The VPRC showed no significant differences except for a few 
scattered instances in Analysis 3. Although the mean values for pmns and lymphocytes were different (Tables 4 and 5) depending on whether the correction factors and/or the master controls were used, the results in terms of significant differences were quite similar. The combination of master control values (corrected) compared to uncorrected experimental data from Analysis 3 produced a few additional significant differences between the master controls and the injected dogs. However, the remainder of the comparisons - i.e., the pair-wise tests of the various combinations of levels from all four analyses, were very much alike. The results of Analysis $\mathrm{C}$ indicate that the application of correction factors to the individual measurements from both experimental and control dogs tends to increase the mean values for pmns and lymphocytes while the VPRC values decrease. The relative position of these values in relation to dose level, however, remains unchanged. 
Table 4b (Analysis 1)

Mean Values of Pmns $\left(\mathrm{XlO}^{3}\right)$

\begin{tabular}{|c|c|c|c|c|c|c|c|c|c|}
\hline & \multirow{2}{*}{$\begin{array}{l}\text { Dose } \\
\text { Level }\end{array}$} & \multicolumn{8}{|c|}{ Months Post-Injection } \\
\hline & & 6 & 12 & 18 & 24 & 30 & 36 & 42 & 48 \\
\hline & 0.0 & 7.08 & 5.73 & 6.23 & 4.73 & 5.02 & 5.23 & 4.85 & 4.74 \\
\hline & 1.0 & 6.73 & 5.93 & 5.53 & 4.83 & 5.12 & 4.82 & 4.52 & 4.43 \\
\hline & 1.7 & 6.23 & 5.83 & 5.60 & 5.25 & 5.31 & 5.70 & 4.65 & 5.11 \\
\hline & 2.0 & 6.69 & 5.69 & 5.53 & 5.44 & 5.16 & 5.05 & 4.42 & 5.22 \\
\hline & 3.0 & 5.13 & 5.11 & 4.69 & 5.45 & 4.98 & 4.70 & 4.61 & 4.48 \\
\hline & 4.0 & 3.98 & 3.96 & 3.45 & 3.66 & 4.05 & 3.54 & 4.47 & 4.42 \\
\hline & 5.0 & 3.04 & 2.88 & 2.80 & 2.58 & 2.94 & 3.02 & 3.68 & 3.55 \\
\hline Compari & ison & & & E & ank In & icates & $P>.05$ & & \\
\hline $0.0 \mathrm{vs}$ & 1.0 & & & .01 & & & & & \\
\hline $0.0 \mathrm{vs}$ & 1.7 & .01 & & .01 & .05 & & & & \\
\hline $0.0 \mathrm{vs}$ & 2.0 & & & .01 & .01 & & & & \\
\hline $0.0 \mathrm{vs}$ & 3.0 & .01 & .01 & .01 & .01 & & & & \\
\hline $0.0 \mathrm{vs}$ & 4.0 & .01 & .01 & .01 & .01 & .01 & .01 & & \\
\hline 0.0 vs & 5.0 & .01 & .01 & .01 & .01 & .01 & .01 & & \\
\hline $1.0 \mathrm{vs}$ & 1.7 & & & & .05 & & .01 & & \\
\hline $1.0 \mathrm{vs}$ & 2.0 & & & & .01 & & & & \\
\hline $1.0 \mathrm{vs}$ & 3.0 & .01 & .01 & .01 & .01 & " &. & & \\
\hline $1.0 \mathrm{vs}$ & 4.0 & .01 & .01 & .01 & .01 & .01 & .01 & & \\
\hline $1.0 \mathrm{vs}$ & 5.0 & .01 & .01 & .01 & .01 & .01 & .01 & & \\
\hline $1.7 \mathrm{vs}$ & 2.0 & & & & & & .05 & & \\
\hline $1.7 \mathrm{vs}$ & 3.0 & .01 & .01 & .01 & & & .01 & & \\
\hline 1.7 vs & 4.0 & .01 & .01 & .01 & .01 & .01 & .01 & & \\
\hline $1.7 \mathrm{vs}$ & 5.0 & .01 & .01 & .01 & .01 & .01 & .01 & & \\
\hline $2.0 \mathrm{vs}$ & 3.0 & .01 & .01 & .01 & & & & & \\
\hline $2.0 \mathrm{vs}$ & 4.0 & .01 & .01 & .01 & .01 & .01 & .01 & & \\
\hline $2.0 \mathrm{vs}$ & 5.0 & .01 & .01 & .01 & .01 & .01 & .01 & & \\
\hline $3.0 \mathrm{vs}$ & 4.0 & .01 & .01 & .01 & .01 & .01 & .01 & & \\
\hline $3.0 \mathrm{vs}$ & 5.0 & .01 & .01 & .01 & .01 & .01 & .01 & & \\
\hline $4.0 \mathrm{vs}$ & 5.0 & .01 & .01 & .01 & .01 & .01 & .05 & & \\
\hline
\end{tabular}


Table 4c (Analysis 1)

Mean Values of Lymphocytes $\left(\mathrm{XlO}^{3}\right)$

\begin{tabular}{|c|c|c|c|c|c|c|c|c|c|}
\hline & \multirow{2}{*}{$\begin{array}{l}\text { Dose } \\
\text { Level }\end{array}$} & \multicolumn{8}{|c|}{ Months Post-Injection } \\
\hline & & $\cdots \quad 6$ & 12 & 18 & 24 & 30 & 36 & 42 & 48 \\
\hline & 0.0 & 3.65 & 3.60 & 3.53 & $\ldots .22$ & $\ldots .3 .17$ & 3.08 & 3.09 & 2.56 \\
\hline & 1.0 & 3.62 & 3.28 & 3.11 & 3.06 & 2.86 & $2.8 ?$ & 2.71. & 2.55 \\
\hline & 1.7 & 3.97 & 3.58 & 3.31 & 3.31 & 3.38 & 3.12 & 2.95 & 2.85 \\
\hline & 2.0 & 3.35 & 3.12 & 3.35 & 2.99 & 2.83 & 2.59 & 2.57 & 2.75 \\
\hline & 3.0 & 2.78 & 3.10 & 2.95 & 3.01 & 2.69 & 2.52 & 2.97 & 2.73 \\
\hline$\cdot$ & 4.0 & 2.88 & 2.78 & 2.42 & 2.53 & $2 . .41$ & 2.35 & 2.55 & 2.36 \\
\hline & 5.0 & 2.12 & 2.08 & 2.00 & 2.09 & 2.19 & 2.04 & 1.89 & 1.69 \\
\hline Compari & ison & & & & lank In & dicates & $P>.05$ & & : \\
\hline $0.0 \mathrm{vs}$ & 1.0 & & .01 & .01 & & .01 & .05 & & \\
\hline $0.0 \mathrm{vs}$ & 1.7 & .05 & & & & .05 & & & \\
\hline $0.0 \mathrm{vs}$ & 2.0 & .05 & .01 & & & .01 & .05 & .05 & \\
\hline $0.0 \mathrm{vs}$ & 3.0 & .01 & .01 & .01 & 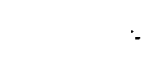 & $\ldots . .01$ & .05 & $\because$ & \\
\hline $0.0 \mathrm{vs}$ & 4.0 & .01 & .01 & .01 & .05 & .01 & .05 & .05 & \\
\hline $0.0 \mathrm{vs}$ & 5.0 & .01 & .01 & .01 & .05 & $\therefore .01$ & .05 & .05 & : \\
\hline $1.0 \mathrm{vs}$ & 1.7 & .05 & .05 & & & .01 & .05 & & \\
\hline 1.0 vs & 2.0 & .05 & & & & & & & \\
\hline $1.0 \mathrm{vs}$ & 3.0 & .01 & & & & & .05 & & \\
\hline $1.0 \mathrm{vs}$ & 4.0 & .01 & .01 & .01 & .05 & .01 & .05 & & \\
\hline $1.0 \mathrm{vs}$ & 5.0 & .01 & .01 & .01 & .05 & .01 & .05 & .05 & \\
\hline $1.7 \mathrm{vs}$ & 2.0 & .01 & .01 & & & .01 & .05 & & \\
\hline $1.7 \mathrm{vs}$ & 3.0 & .01 & .01 & .01 & & .01 & .05 & & \\
\hline 1.7 vs & 4.0 & .01 & .01 & .01 & .05 & .01 & .05 & . & \\
\hline $1.7 \mathrm{vs}$ & 5.0 & .01 & .01 & .01 & .05 & .01 & .05 & .05 & \\
\hline $2.0 \mathrm{vs}$ & 3.0 & .01 & & .01 & & & & & \\
\hline $2.0 \mathrm{vs}$ & 4.0 & .01 & .05 & .01 & .05 & .01 & & & \\
\hline $2.0 \mathrm{vs}$ & 5.0 & .01 & .01 & .01 & .05 & .01 & .05 & .05 & \\
\hline $3.0 \mathrm{vs}$ & 4.0 & 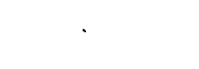 & .05 & .01 & .05 & .01 & & & \\
\hline $3.0 \mathrm{vs}$ & 5.0 & .01 & .01 & .01 & .05 & .01 & .05 & .05 & \\
\hline $4.0 \mathrm{vs}$ & 5.0 & .01 & .01 & .01 & .05 & .05 & .05 & .05 & . \\
\hline
\end{tabular}


Table 5a (Analysis 4)

Mean VPRC

\begin{tabular}{lcccccccc}
\hline & \multicolumn{7}{c}{ Months } & \multicolumn{7}{c}{ Post-Injection } \\
\cline { 2 - 8 } Level & 6 & 12 & 18 & 24 & 30 & 36 & 42 & 48 \\
\hline $\begin{array}{l}\text { Master } \\
\text { Control }\end{array}$ & 50.2 & 48.4 & 49.6 & 49.4 & 48.0 & 48.7 & 48.1 & 47.2 \\
1.0 & 51.4 & 49.1 & 50.1 & 49.3 & 50.6 & 49.2 & 49.7 & 47.6 \\
1.7 & 52.5 & 48.3 & 48.3 & 50.0 & 48.8 & 49.4 & 50.8 & 48.7 \\
2.0 & 48.4 & 47.5 & 48.4 & 49.2 & 49.1 & 48.8 & 48.3 & 48.6 \\
3.0 & 50.5 & 50.8 & 50.8 & 49.9 & 49.9 & 48.3 & 49.1 & 49.5 \\
4.0 & 50.3 & 48.4 & 47.6 & 48.0 & 48.1 & 47.6 & 47.9 & 49.0 \\
5.0 & 48.7 & 48.6 & 48.7 & 49.1 & 49.2 & 48.3 & 47.0 & 47.6 \\
\hline \hline
\end{tabular}

No significant differences in VPRC. 
Table 5b (Analys is 4):

Mean Values for Pmns $\left(X 10^{3}\right)$

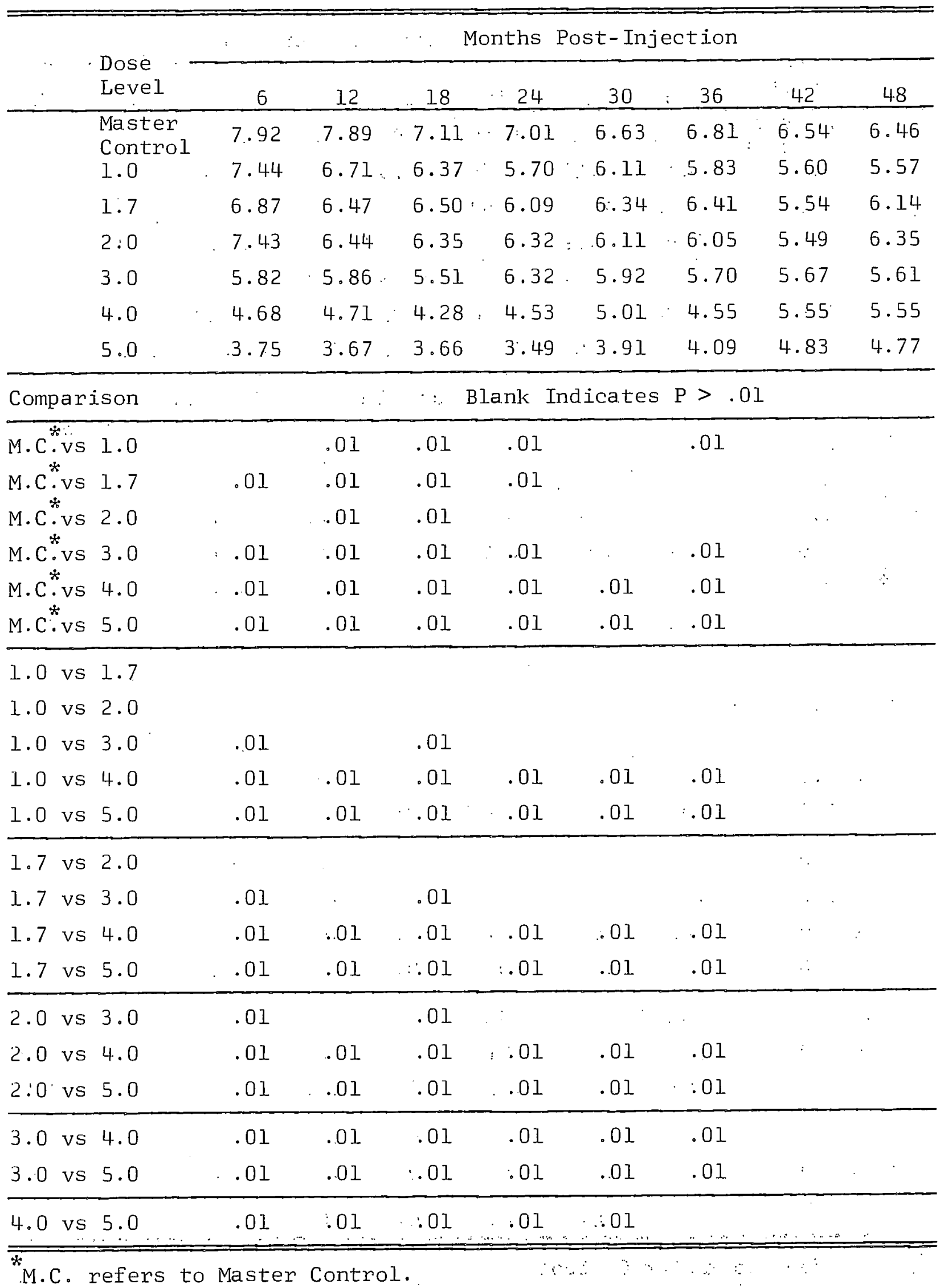


Table 5c (Analys is 4)

Mean Values for. Lymphocytes $\left(\mathrm{XlO}^{3}\right)$

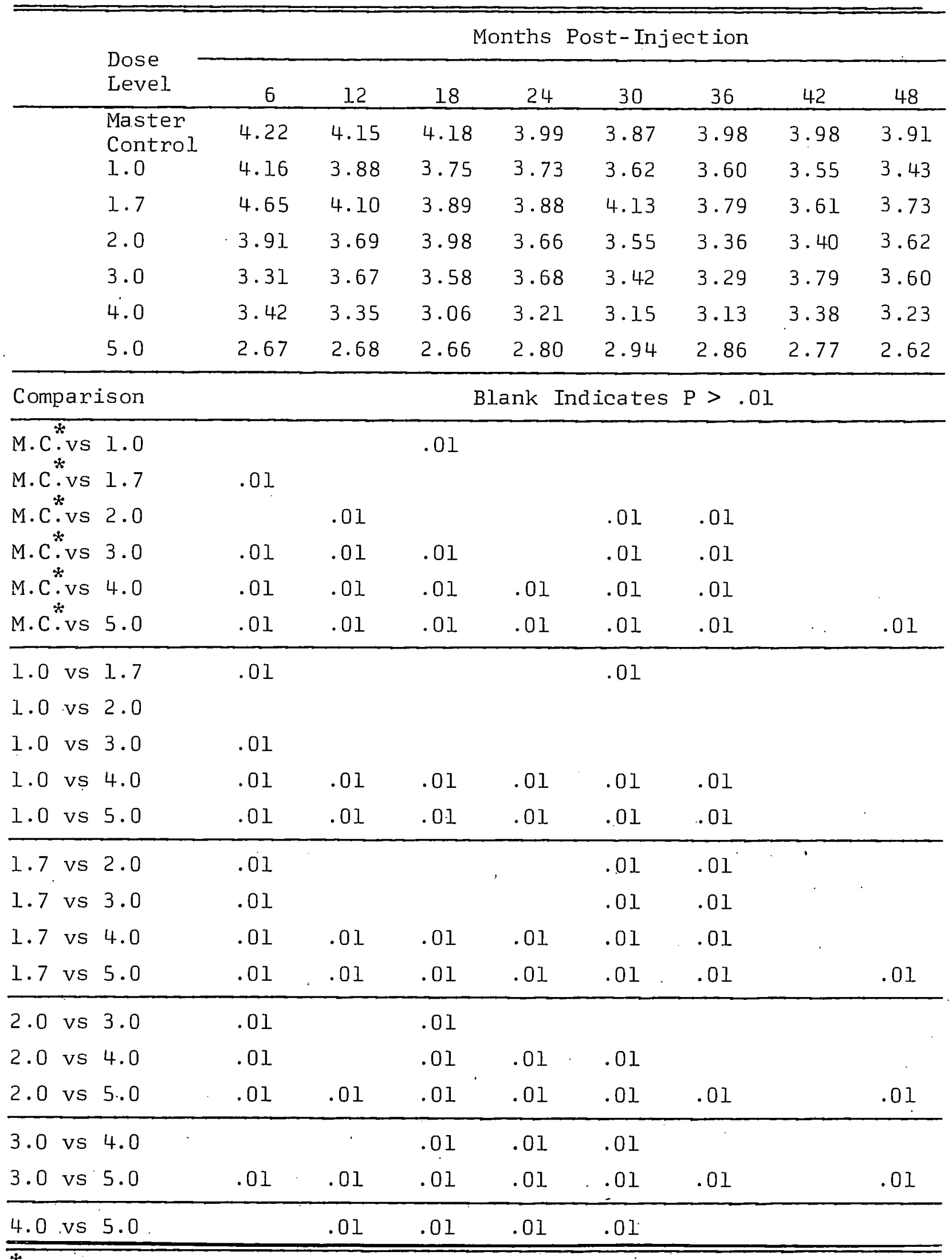

M.C. refers to Master Control. 


\section{DISCUSSION OF ANALYSES A AND C}

Investigation into the variance components of the four one-way analyses suggested that all of these methods were unsuitable in terms of minimizing the error mean squares. The values of this component for the periods up to 24 months post-injection are given in Table 6 .

Table 6

Error Mean Squares for Strontium Data

\begin{tabular}{|c|c|c|c|c|c|c|c|c|}
\hline & \multicolumn{4}{|c|}{ Pmns } & \multicolumn{4}{|c|}{ Lymphocytes } \\
\hline & $6^{\text {Mo. }}$ & $\begin{array}{c}\text { Post- } \\
12\end{array}$ & $\begin{array}{c}\text { njecti } \\
18 \\
\end{array}$ & 24 & $6^{\text {Mo. }}$ & $\begin{array}{c}\text { Post } \\
12 \\
\end{array}$ & $\begin{array}{c}\text { nject } \\
18 \\
\end{array}$ & 24 \\
\hline Analysis A & 3.95 & 1.92 & 1.26 & 1.45 & 0.78 & 0.58 & 0.60 & $0 . .58$ \\
\hline Analysis 1 & 3.77 & 2.15 & 1.65 & 1.53 & 0.98 & 0.92 & 0.76 & 0.74 \\
\hline Analys is 2 & 3.81 & 1.95 & 1.60 & 1.52 & 0.95 & 0.80 & 0.75 & 0.55 \\
\hline Analysis 3 & 3.82 & 4.43 & 1.93 & 3.05 & 1.05 & 0.98 & 0.82 & 0.67 \\
\hline Analys is 4 & 3.86 & 4.42 & 1.91 & 3.05 & 1.05 & 0.94 & 0.83 & 0.67 \\
\hline
\end{tabular}

Although the sample sizes differed, for purposes of comparison, the numbers of dogs were nearly the same from Analyses 1 and 2 of the oneway analysis and Analysis $A$ of the randomized block design. It was found in the 1962 analysis at 18 months post-injection for the pmns and 6, 12, and 18 months post-injection for the lymphocytes that the test for blocks indicated this component was highly significant. At these same intervals, the error mean squares from the randomized block design are seen to be much lower than those obtained from the four one-way analyses (Table 6). Thus, although block (group to group) differences may not be found at all the time intervals, when they are present, use of the one-way analysis of variance does not allow the elimination. of this source of variation. Because the underlying experimental design 
appears amenable to the randomized block design and after observing the smaller error mean squares obtained from the earlier analysis as compared to the ones more recently found, it is apparent that the former method will provide greater sensitivity in the detection of significant differences.

\section{GENERAL SUMMARY}

After comparing the results of the randomized block to the oneway analysis of variance, it appears that the former will provide more meaningful significance values. Perhaps the reason for this is that the experimental design of this project is essentially that of randomized blocks. One of the reasons this design was used was because of space problems in housing the dogs. It was anticipated that the several groups (blocks) of dogs entering the experiment would not only be different from each other initially but would álso experience different sets of environments. Initial differences would be due to (l) environmental conditions under which the pups were raised and differences in immunization procedures, (2) sex differences - each group consisted of dogs of the same sex, and (3) genetic differences - differences in studs and also each group usually contained some sets of sibs. In addition, after injection each group would be expected to share a more or less common environment which would not necessarily be the same as that experienced by dogs in another group. This is particularly true since it took several years to enter all groups for any given radionuclide into the project, i.e., in the case of strontium dogs which were entered from January 1955 to January 1960.

Statistically, the use of blocks permitted the removal of block to block (or group to group) variation when present and thus reduced the 
error. The greater number of significant differences found when using the one-way analysis of variance are in part, no doubt, the result of variability due to block. Eliminating this possible source of variation by use of the randomized block design will make the comparisons between the various combinations of dose levels within a radionuclide more precise. Since this is the more sensitive method of analysis it will be the method of choice for subsequent analyses of hematological changes following internal irradiation.

\section{REFERENCES}

1. Dougherty, J. H. and Rosenblatt, L. S., Changes in the hemogram of the beagle with age: J. of Gerontology 20, 13l-138 (1965) .

2. Dougherty, J. H., Rosenblatt, L. S. and Shultz, F. T., Analysis of the effects of age on the hemogram of the beagle. Radiobiology Laboratory, University of Utah Annual Report C00-228, 79-93 (September 1963).

3. Dougherty, J. H., Rosenblatt, L. S. and Welch, Q. B., A preliminary analysis of the dose-time relationship of selected hematological values. Radiobiology Laboratory, University of Utah Annual Report C00-224, 46-56 (September 1961).

4. Harter, H. L., Critical values for Duncan's new multiple range test. Biometrics 16, 671-685 (1960).

5. Pearson, E. S. and Hartley, H. O., Biometrica Tables for Statisticians. Vol. 1, 176-1.77. Published for the Biometrica Trustees at the University Press, Cambridge (1954). 
PILOT STUDY OF THE EFFECT OF CORTISOL

ON $\mathrm{Na}_{3} \mathrm{CaDTPA}$ ENHANCED EXCRETION OF $\mathrm{Pu}^{239}$ IN THE BEAGLE

D. R. Atherton, T. F. Dougherty, F. W. Bruenger, G. N. Taylor and B. J. Stover

Abstract: Two massive doses of cortisol were given to mobilize $\mathrm{Pu}^{239}$ to make it available for chelation by $\mathrm{Na}_{3} \mathrm{CaDTPA}$ and subsequent excretion. No practically significant increase in excretion was observed, and there was no significant removal of $\mathrm{Pu}^{239}$ from the dog's liver.

\section{INTRODUCTION}

In general chelating agents significantly increase the urinary excretion of various radionuclides, only if the chelate is administered soon after exposure when a large fraction of the radionuclide is still in the blood. As the blood level decreases, the chelate treatment becomes less effective. Further, as time increases the radionuclide often becomes more intimately trapped in the tissues as a consequence of both normal and radiation induced changes occurring in the tissues, and the effect of this is to decrease the chance of the radionuclide's returning to the blood.

In principle, a solution to this problem exists. It is the administration of an agent which stimulates biological activity of the tissue or tissues involved so that some of the intimately trapped radionuclide is released and available to the blood. Then follows administration of a chelate to bind the mobilized radionuclide and carry it to the kidneys to be excreted.

Following intravenous injection of PuIV citrate most of the $\mathrm{Pu}^{239}$ is retained in bone and liver. Cortisol acts on bone and the reticuloendothelial system. The chelating agent, trisodium calcium diethylynetriiaminepentaacetate, $\mathrm{Na}_{3} \mathrm{CaDTPA}$, enhances excretion of $\mathrm{Pu}^{239}$. Thus we have a test system. 


\section{EXPERIMENTAL METHODS}

Dog T21P5 was injected with $2.72 \mu \mathrm{c} \mathrm{Pu} 239 / \mathrm{kg}$ when it was 688. days old. The dog was used for calorimetric and blood protein measurements for about a year and a half. Following this the dog was available for other studies.

Expt. I. At 557 days the dog was put in a metabolism cage, and urine and feces were collected and analyzed for $\mathrm{Pu}^{239}$ for a 14 day period to determine the pretreatment excretion rates.

On the 15th day $0.133 \mathrm{~g} \mathrm{Na}_{3} \mathrm{CaDTPA}(\sim 0.0142 / \mathrm{kg})$ in $50 \mathrm{ml}$ isotonic saline pH 7 was given subcutaneously. The same treatment was given each :of the next three days $(16,17,18)$, then no treatment for three days, followed by four more days of treatment. The dog received $8 \times 0.133=$ $1.06^{\circ} \mathrm{g} \mathrm{Na}{ }_{3} \mathrm{CaDTPA}$ in 11 days. Urine and feces were collected and analyzed for 18 days at which time the dog was returned to its kennel.

Expt. II. At 7.60 days after injection the dog was returned to a metabolism cage, and a 14 day study of pretreatment urinary and fecal excretion rates was done as before. Beginning on the 15th day the same $\mathrm{Na}_{3} \mathrm{CaDTPA}$ treatment schedule described above was followed. In addition, on the first day of both four day $\mathrm{Na}_{3} \mathrm{CaDTPA}$ treatment periods, $618 \mathrm{mg}$ cortisol (50 $\mathrm{mg} / \mathrm{kg}$ ) were given intramuscularly one hour prior to the $\mathrm{Na}_{3} \mathrm{CaDTPA}$. The dog thus received $1.24 \mathrm{~g}$ cortisol and $1.06 \mathrm{~g} \mathrm{Na}_{3}$ CaDTPA. Urine and feces were collected and analyzed for 28 days.

At autopsy (939 days after injection) known fractions of liver, kidneys, and spleen were obtained and analyzed for $\mathrm{Pu}^{239}$.

The analytical method for $\mathrm{Pu}^{239}$ has been reported (1). 


\section{RE SULT S}

Excretion rate measurements.

The effects of the treatments of Expts. I and II on $\mathrm{Pu}^{239}$ excretion rates are best compared in relation to the 14 day baseline values for each experiment. The mean urinary, $\overline{\mathrm{U}}$, fecal, $\overline{\mathrm{F}}$, and total $\overline{\mathrm{U}+\mathrm{F}}=\overline{\mathrm{X}}$, excretion rates for the two 14 day periods are given in Table I, which also includes $\overline{\mathrm{F}} / \overline{\mathrm{U}}$. The fractional standard deviations of these means are of the order of 0.1. In Table I are given the calculated values derived from our extensive studies of $\mathrm{Pu}^{239}$ excretion by the beagle (2). During the first 14 day control period observed $\mathrm{Pu}^{239}$ excretion by. T21P5 was consistent with results of extensive long term studies. During. the second control period urinary excretion was lower than expected.

\section{TABLE I}

Comparison of T21P5 excretion rates

(\% injected $\mathrm{Pu}^{239}$ excreted per day) with expected rates (2)

\begin{tabular}{llllllllll}
\hline & & \multicolumn{2}{c}{ T21P5 } & \multicolumn{4}{c}{ Calculated } \\
$\mathrm{t}$ & $\overline{\mathrm{U}}$ & $\overline{\mathrm{F}}$ & $\overline{\mathrm{X}}$ & $\overline{\mathrm{F}} / \mathrm{U}$ & $\mathrm{U}$ & $\mathrm{F}$ & $\mathrm{X}$ & $\mathrm{F} / \mathrm{U}$ \\
\hline 564 & 0.0042 & 0.0077 & 0.0119 & 1.8 & 0.0045 & 0.0059 & 0.0104 & 1.3 \\
767 & 0.0017 & 0.0061 & 0.0078 & 3.6 & 0.0040 & 0.0049 & 0.0089 & 1.2 \\
\hline
\end{tabular}

The results of the $\mathrm{Na}_{3}$ CaDTPA treatment (Expt. I) are summarized in Fig. 1. Both urinary and fecal excretion increased relative to the 14 day pretreatment means, and the relative increases are shown in Fig. 1 . The highest daily urinary excretion was about 60 times the pretreatment urinary excretion, while the highest fecal increase was about 11 . Even 
RELATIVE EXCRETION OF Pụ ${ }^{23 \dot{9}}$ FOLLOWING $\mathrm{Na}_{3} \mathrm{CO}$ DTPA TREATMENT.

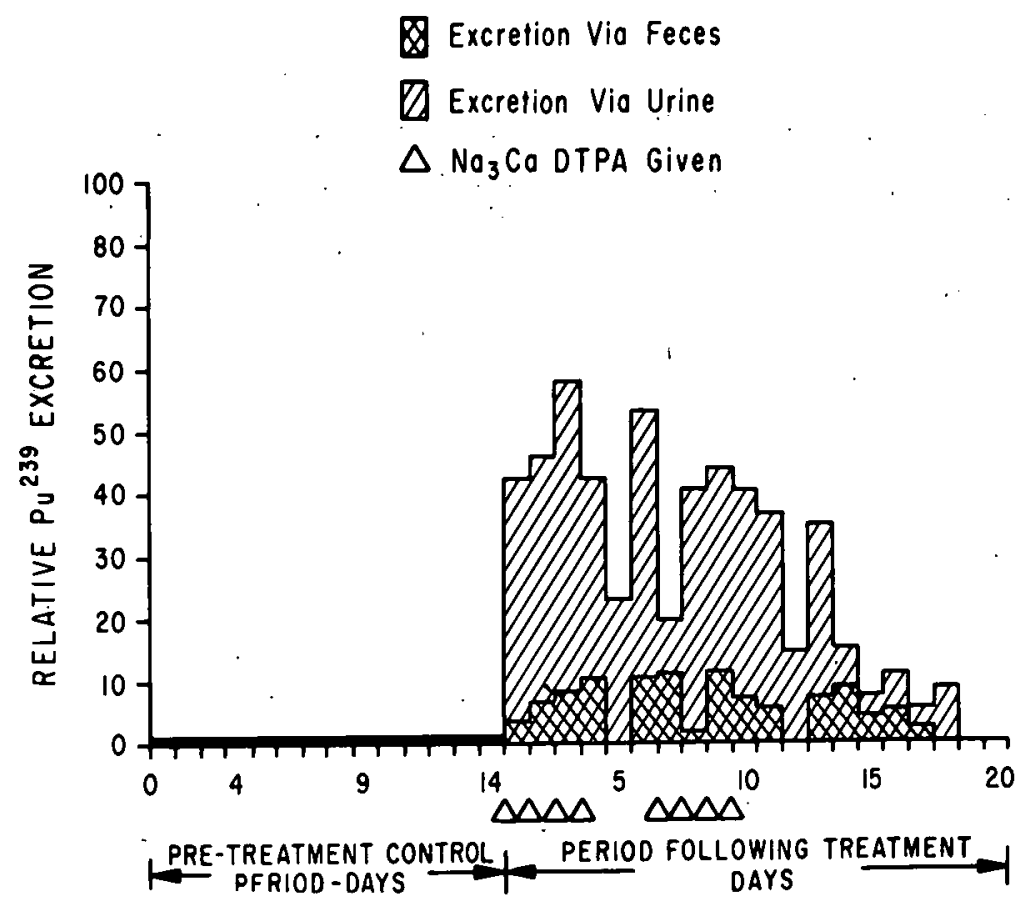

FIGURE 1

Relative increase in daily urinary and fecal excretion of $\mathrm{Pu}^{239}$ with $\mathrm{Na}_{3} \mathrm{CaDTPA}$ treatment. (Expt. I) . 
though these factors are impressive, the excretion rates are so low that much greater relative increases are needed to remove $\mathrm{Pu}^{239}$ significantly as shown in Table II.

TABLE II

\% Injected $\mathrm{Pu}^{239}$ removed by $\mathrm{Na}_{3} \mathrm{CaDTPA}$ treatment (Expt. I) in 18 days

\begin{tabular}{lllll}
\hline & $\sum_{U}$ & $\sum_{\mathrm{F}}$ & $\sum_{\mathrm{X}}$ & $\sum_{\mathrm{F}}$ \\
\hline Excreted with treatment & 2.30 & 0.78 & 3.08 & 0.34 \\
Ex pected without treatment & 0.08 & 0.14 & 0.22 & 1.8 \\
Net removal & 2.22 & 0.64 & 2.86 & - \\
Relative increase & 30 & 6 & 14 & - \\
\hline
\end{tabular}

The results of the combined $\mathrm{Na}_{3} \mathrm{CaDTPA}$ plus cortisol treatment (Expt. II) appear in Fig. 2. Again the results are presented as relative increases over the immediate pretreatment means. Greater relative increases in urinary excretion were observed with the highest being about 120, and the highest fecal increase was 9, about the same as in Expt. I. However, since the pretreatment urinary rate was considerably lower for Expt. II, the relative increase in urinary plus fecal excretion for 18 days was the same in Expts. I and II. The 18 and 28 day excretion totals are given in Table III. Comparison of Tables II and III shows that, while less $\mathrm{Pu}^{239}$ was removed in Expt. II, the relative increases in urinary plus fecal excretion were the same for Expts. I and II. 
RELATIVE EXCRETION OF PU ${ }^{239}$ FOLLOWING CORTISOL-NO ${ }_{3} \mathrm{CO}$ DTPA. TREATMENT.

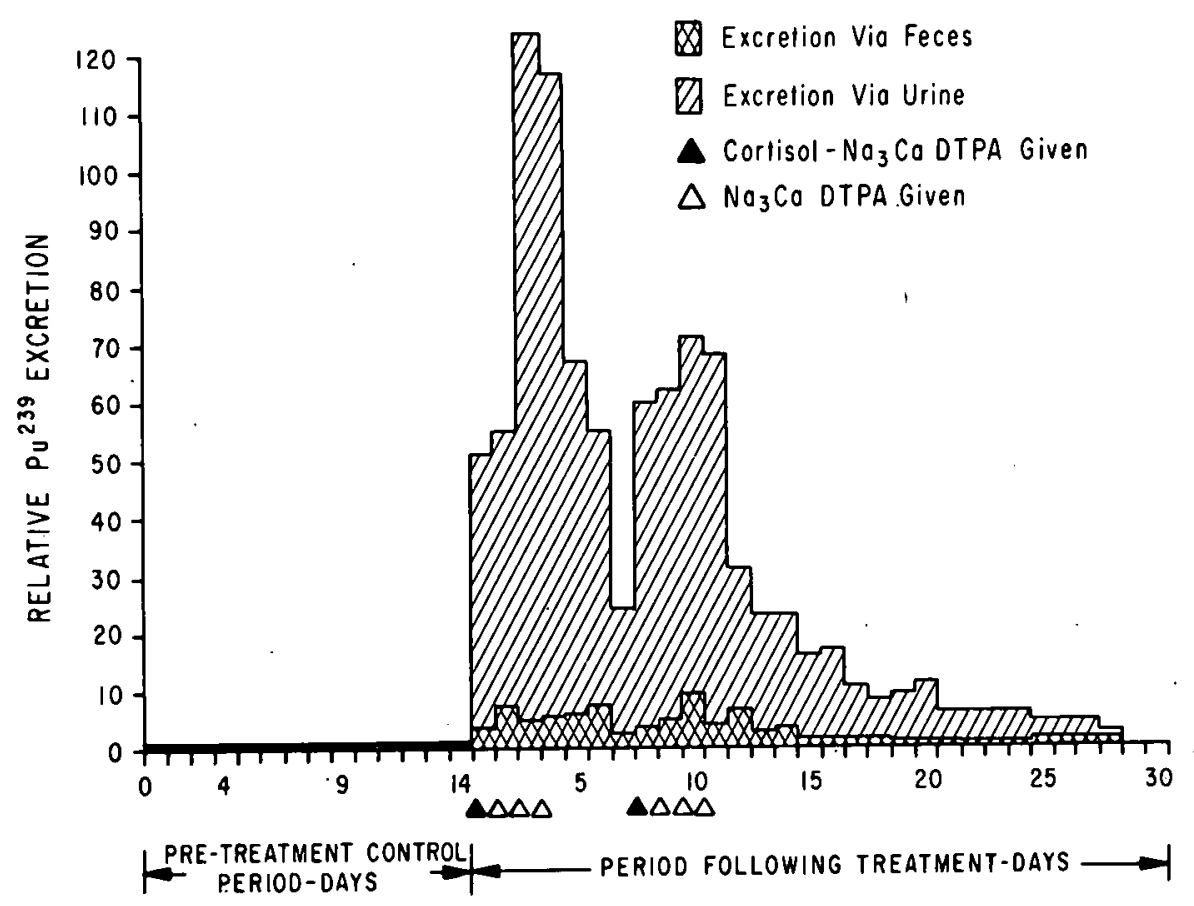

FIGURE 2

Relative increase in daily urinary and fecal excretion of $\mathrm{Pu}^{239}$ with Cortisol-Na ${ }_{3} \mathrm{DTPA}$ treatment. (Expt. II). 
TABLE III

\% Injected $\mathrm{Pu}^{239}$ removed by $\mathrm{Na}_{3} \mathrm{CaDTPA}$ and cortisol treatment (Expt. II)

\begin{tabular}{|c|c|c|c|c|}
\hline & $\sum \mathrm{U}$ & $\sum F$ & $\sum x$ & $\mathrm{~F} / \mathrm{SU}_{\mathrm{U}}$ \\
\hline & \multicolumn{2}{|c|}{18 day totals } & & \\
\hline Excreted with treatment & 1.47 & 0.45 & 1.92 & 0.31 \\
\hline Expected without treatment & 0.03 & 0.11 & 0.14 & 3.6 \\
\hline Net removal & 1.44 & 0.34 & 1.78 & - \\
\hline Relative increase & 48 & 4 & 14 & - \\
\hline Excreted with treatment & $\begin{array}{l}28 \text { day } \\
1.58\end{array}$ & $\begin{array}{l}1 \mathrm{~s} \\
0.51\end{array}$ & 2.09 & 0.32 \\
\hline Expected without treatment & 0.05 & 0.17 & 0.22 & 3.6 \\
\hline Net removal & 1.53 & 0.34 & 1.87 & - \\
\hline Relative increase & 33 & 3 & 10 & - \\
\hline
\end{tabular}

Following the large doses of cortisol there was an increase in the amount of urine per day as shown in Fig. 3. In the course of the $\mathrm{Pu}^{239}$ analyses a large increase in urinary excretion of chloride was noted.

\section{Tissue Analyses}

The liver weighed $371 \mathrm{~g}$ and contained $9.26 \%$ of the injected $\mathrm{Pu}^{239}$. The expected amount for a 5-level dog at 939 days after injection is $10.0 \%$ (3). The difference, $10.0-9.26$, is not significant, $0.9>\mathrm{p}>0.8 \%$ Thus the net effect of the treatment of Expts. I and II was no reduction in $\mathrm{Pu}^{239}$ in the liver.

\footnotetext{
*Important note: The 95\% confidence limits for the constants in the equation for liver retention of $\mathrm{Pu}^{239}$ in 5-level dogs in Ref. (3), $\mathrm{L}=29.8 \mathrm{e}^{-0.00116 t}$, are in error. They should be$$
b=0.0016 \pm 0.0029
$$$$
\log a=1.474 \pm 0.117
$$ 
DAILY VOLUME OF URINE FOLLOWING CORTISOL - $\mathrm{No}_{3} \mathrm{CO}$ OTPA TREATMENT.

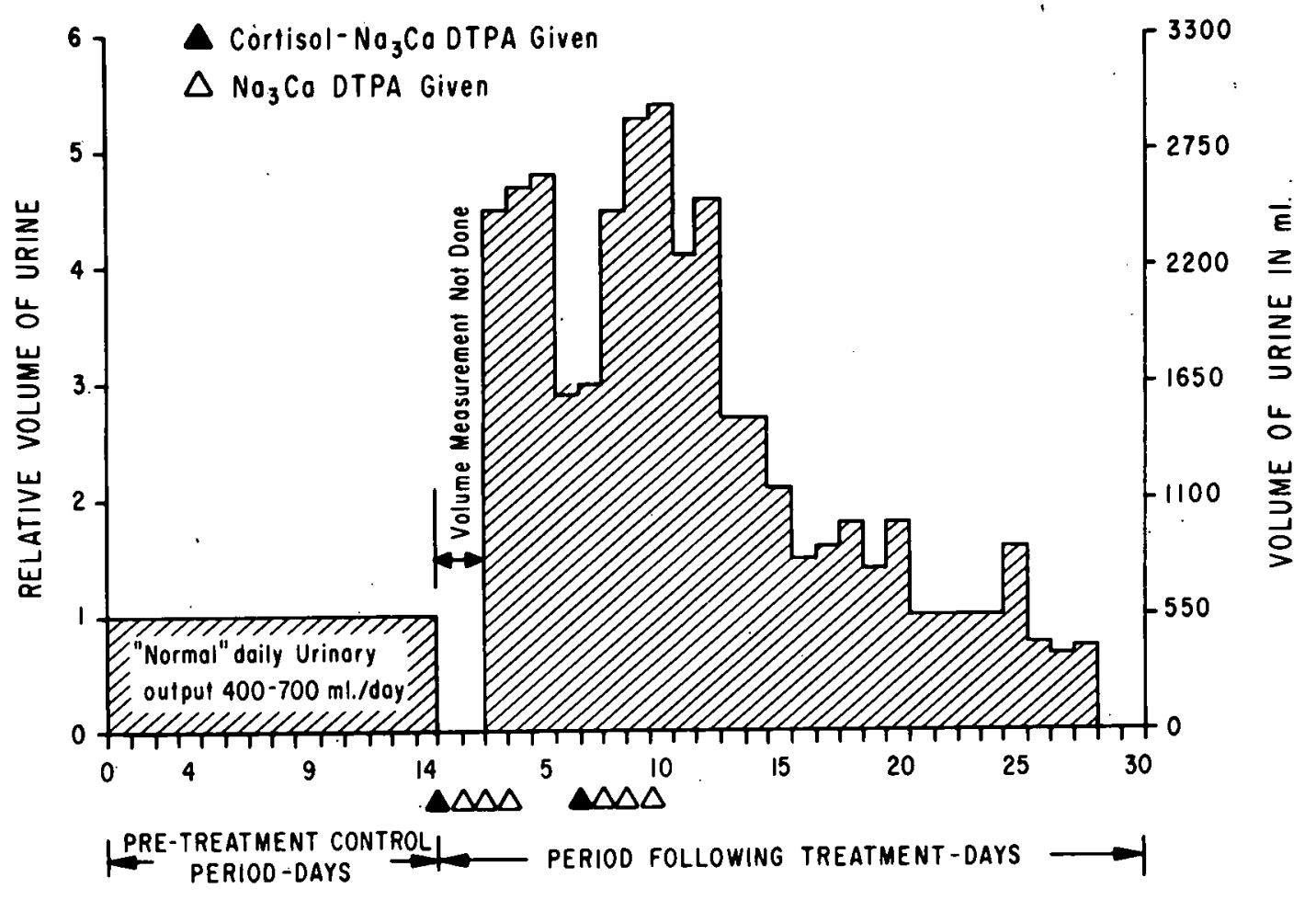

FIGURE 3

Increase in volume of urine voided daily with Cortisol- $\mathrm{Na}_{3} \mathrm{CaDTPA}$ treatment. Relative increase is seen on the left and absolute volume voided is seen on the right. (Expt. II). 
The spleen weighed $43 \mathrm{~g}$ and contained $0.46 \%$ of the injected $\mathrm{Pu}^{239}$. From our early studies the expected amount for 939 days is $0.17 \%$ (2). Better comparison can be made with the group of eight 5-level dogs which had a mean spleen content of $(0.19 \pm 0.12) \% \mathrm{Pu}^{239}$ at $1443 \pm 302$ days after injection. The difference, $0.46-0.19$, is on the borderline of significance, $p \sim 0.05$. Thus the treatments had little or no effect on the amount of $\mathrm{Pu}^{239}$ in the spleen.

The kidneys weighed $68 \mathrm{~g}$ and contained $0.34 \%$ of the injected $\mathrm{Pu}^{239}$. The early studies give $0.15 \%$ as the expected amount (2). The mean for the eight 5 -level dogs was $(0.14 \pm 0.006) \%$. This difference, $0.34-0.14$, is significant, $\mathrm{p} \sim 0.01$. Thus the treatments increased. slightly the amount of $\mathrm{Pu}^{239}$ in the kidneys. A considerable increase in the inorganic residue after ashing the kidneys was also noted. This was presumed to be calcium and phosphate.

Clinical Symptoms and Post Mortem Findings

Mild anorexia, polydipsia and polyuria were associated with these treatments. The latter two symptoms were unquestionably cortisone induced. All were transitory and apparent recovery occurred shortly after the treatments were completed.

The terminal illness began four months after the final hydrocortisone and $\mathrm{Na}_{3} \mathrm{CaDTPA}$ treatment and lasted approximately two weeks. This was characterized by nearly complete anorexia, high body temperature, cardiac arrythemia with multiple premature beats, protenuria and melena.

The post mortem findings included marked liver changes that were typical of those induced by $\mathrm{Pu}^{239}$; severe vegetative valvular endocarditis, involving both the aortic and pulmonary valves; massive kidney infarcts, many of which were calcified; myocardial infarcts; focal zones of myo- 
carditis; splenic infarcts; stomach ulceration; and enteritis. Except for the plutonium induced liver changes the most significant post mortem lesions appeared to be a consequence of the valvular disease and were not clearly related to the hydrocortisone and $\mathrm{Na}_{3} \mathrm{CaDTPA}$ ireatment.

\section{SCUSSION}

A number of studies have been made of the use of DTPA to enhance excretion of plutonium. Ballou, (4) for example, removed in 4 days a total of $76 \%$ of the $\mathrm{Pu}^{239}$ injected into rats by treating the animals once with DTPA 1 hour following injection. If treatment was delayed for 18 days, the same treatment with DTPA resulted in a 4 day excretion total of only $7 \%$ of the plutonium injected. Smith et al. in experimentis with pigs (5) delayed DTPA treatment until 60 days after injection of $\mathrm{Pu}^{239}$. These studies, which involved treatment with DTPA on 5 consecutive days resulted in 12 day totals of 11 and $19 \%$ removal of the injected plutonium.

When dog T21P5 became available, it seemed a good opportunity to study the effect of DTPA in a larger animal at a fairly long ( $1 / 2$ years) time after injection.

To be effective in practice, a treatment program should remove essentially all of the radionuclide. At 564 days the calculated fractional retention is 0.79 (2), and so the 8 doses of $\mathrm{Na}_{3}$ CaDTPA resulted in the removal of only $3.6 \%$ of the $\mathrm{Pu}^{239}$ in the dog. At 767 days retention is 0.77 so that only $2.3 \%$ was removed in the lst 18 days of the $\mathrm{Na}_{3}$ CaDTPA plus cortisol experiment. However, prior to the studies it was pointed out by W. S. S. Jee that a 5-level dog might prove to be a poor choice because of the peritrabecular fibrosis which occurs at this time at this relatively high dose level (6). Thus, it is possible that more $\mathrm{Pu}^{239}$ 
could be removed from a lower level dog.

The results of Expt. I are quite comparable with Norwood's (7) study of a human exposure case. At 30 weeks after exposure $\mathrm{Na}_{3} \mathrm{CaDTPA}$ initially increased urinary excretion by a factor of 55 and also resulted in an average fecal increase of 4. Comparable numbers for T2lP5 were 60 and 6, respectively. Since the baseline excretion rates in Norwood's case were $0.001-0.002 \%$ of the eștimated $\mathrm{Pu}^{239}$ in the subject, no effective removal was achieved in this case either.

Norwood (7) found that the effectiveness of $\mathrm{Na}_{3} \mathrm{CaDTPA}$ in removing $\mathrm{Pu}^{239}$ from the human decreases with time. The histograms (Fig. 1 and 2) presented here appear to indicate a similar tendericy. Extrapolation of a line determined by the two peaks shows that the treatment would be completely ineffective in less than 100 days. Considering this together with the fact that the pretreatment urinary excretion for Expt. II was considerably less than expected, suggests that treatment with $\mathrm{Na}_{3} \mathrm{CaDTPA}$ at long times after deposition of plutonium remove only a very limited amount, most of which ultimately would have been excreted. That is, the effect may be more an acceleration of excretion than an increase.

The failure of cortisol and $\mathrm{Na}_{3} \mathrm{CaDTPA}$ to act together to remove $\mathrm{Pu}^{239}$ may have resulted from having inadequate chelating agent at the sites of cortisol action. $\mathrm{Pu}^{239}$ released at these sites would have a number of substances competing for it and could be redeposited before it could react with the $\mathrm{Na}_{3}$ CaDTPA. 
REFERENCES

1. F. W. Bruenger, B. J. Stover, and D. R. Atherton, Determination of Plutonium in Biological Material by Solvent Extraction with Primary Amines. Anal. Chem。 35, 1671 - 1673 (1963).

2. B. J. Stover, D.R. Atherton, and N. Keller, Metabolism of $\mathrm{Pu}^{239}$ in Adult Beagle Dogs. Radiation Research 10, 130 - 147 (1959).

3. B. J. Stover, D. R. Atherton, F. W. Bruenger, and D. S. Buster, Further Studies of the Metabolism of $\mathrm{Pu}^{239}$ in Adult Beagles. Health Physics $\underline{8}, 589$ - 597 (1962).

4. J. E. Ballou, Removal of Deposited Plutonium by Triethylenete.tramine Hexaacetic Acid. Nature 193, 4822, 1303 - 1304 (1962).

5. Victor H. Smith, John E. Ballou, Wiliziam J. Clarke and Roy C. Thompson, Effectiveness of DTPA in Removing Plutonium from the Pig, Proc. Soc. Expt. Biol, \& Med. 107, 120 - 123 (1961).

6. T. F. Dougherty, B. J. Stover, J. H. Dougherty, W. S. S. Jee, C. W. Mays, C. E. Rehfeld, W. R. Christensen, and H. C. Goldthorpe, Studies of the Biological effects of $\mathrm{Ra}^{22 E}, \mathrm{Pu}^{239}, \mathrm{Ra}^{228}\left(\mathrm{MsTh}_{1}\right.$ ), $\mathrm{Th}^{228}$ (RdTh), and $\mathrm{Sr}^{90}$ in Adult Beagles. Radiation Research, 17:4, (1962).

7. W. Daggett Norwood, Long-Term Administration of DTPA for Plutonium Elimination, J. of Occupational Health 4, 3, 130 - 132 (1962). 


\section{EFFECT OF EDTA ON THE EXCRETION OF $\mathrm{Sr}^{90}$ AND $\mathrm{Y}^{90}$}

\section{R. Atherton}

Abstract: Administration of $\mathrm{Ca} \mathrm{Na}$ EDTA to four dogs which had been injected with $\mathrm{Sr}^{90} 0.7$ years previously failed to enhance the excretion of $\mathrm{Sr}^{\circ \circ}$ but did increase the urinary excretion of $\mathrm{Y}^{90}$ by a factor of about 5 .

\section{INTRODUCTION}

The effect of EDTA on the excretion of thorium, radium, and lead in dogs was reported previously (1) (2). From these studies and the work of Foreman (3), it seemed unlikely that EDTA would effect an enhancement of the urinary excretion of strontium but it did seem likely that the excretion rate of yttrium would be increased. In our studies dogs are injected with $\mathrm{Sr}^{90}$ which decays to $2.64 \mathrm{~d}$. $\mathrm{Y}^{90}$ and the two nuclides are quite close to being in equilbrium in the animal (4). If $\mathrm{Y}^{\circ 0}$ formed in vivo moves to the blood and then is redeposited, it could be chelated by EDTA while in the blood and subsequently excreted.

\section{EXPERIMENTAL}

Four beagles, F4S4, M5S4, F4S5 and M5S5, were given Sr ${ }^{90}$ intravenously in a sodium citrate-citric acid buffer solution, $0.08 \mathrm{M}$ in citrate, at pH 3.5. The $\mathrm{Sr}^{90}$ doses were $32.1,30.6,105$ and $95.2 \mu \mathrm{c} / \mathrm{kg}$, respectively.

On the 273rd day following injection M5S4 and M5S5 were placed in metabolism cages, 24 hour urine specimens were collected and analysed for its $\mathrm{Sr}^{90}$ and $\mathrm{Y}^{90}$ content. After collection of the urine specimen the animals were given $0.2 \mathrm{~g}$ EDTA in $50 \mathrm{ml}$ physiologic saline subcutaneously after first preparing the area to be injected with procaine. Urine on each dog was collected for 24 hours as a single sample following the EDTA treatment. 
On the 301 st day following injection the same procedure as outlined above was followed with F4S4 and.F4S5 except that the dose of EDTA was $0.1 \mathrm{~g}$.

$\frac{1}{2}$

Analyses were done by serially counting $1.0 \mathrm{ml}$ aliquots of the urine specimen in a plastic scintilator-well counter ${ }^{(5)}$ which responds to the high energy (2.2 mev) $\beta$ from the decay of $\mathrm{Y}^{90}$ but not to the low energy $(0.61 \mathrm{mev}) \beta$ of $\mathrm{Sr}^{90}$. The change in count rate with time together with a final steady state count rate obtained when $\mathrm{Sr}^{90}-\mathrm{Y}^{90}$. equilibrium is achieved provided the information with which the relative amounts of each nuclide was determined.

\section{RESULTS AND DISCUSSION}

The experiment provided the data summarized in Table 1 and contained no surprises. That the urinary excretion of $\mathrm{Sr}^{90}$ appears to have increased with the EDTA treatment is hardly to be considered as significant because the day to day variation is of the same magnitude as the tabulated increase. The increase in the urinary excretion of $\mathrm{Y}^{\circ \circ}$ with the EDTA treatment results in the urinary elimination of about equal amounts of $\mathrm{Y}^{90}$ and $\mathrm{Sr}^{90}$.

Once again the ineffectiveness of EDTA às a biological decontaminating agent for the alkaline earth elements has been shown. There is no question that this chelating agent would be more effective in the removal of $\mathrm{Y}^{90}$ if given earlier.

These results tend to support the earlier observation of Arnold et al (4) that $\mathrm{Y}^{90}$ produced in vivo from long term skeletal deposits of $\mathrm{Sr}^{90}$ in young dogs does not escape from the local areas of bone in which it is produced. If translocation did occur the yttrium concentration in the blood would be increased and, therefore, available for chelation by EDTA with subsequent excretion in the urine. 
TÄBLE 1

Urinary Excretion of $\mathrm{Sr}^{90}$ and $\mathrm{Y}^{90}$ as

Influenced by Administration of EDTA

\begin{tabular}{|c|c|c|c|c|c|c|c|}
\hline & $\begin{array}{c}\text { EDTA } \\
\text { Dose } \\
(\mathrm{g} \cdot)\end{array}$ & $\begin{array}{l}\text { Co } \\
\% / \text { day } \\
\mathrm{Sr}^{90}\end{array}$ & $\begin{array}{l}\text { rol } \\
10^{3} \\
Y^{90}\end{array}$ & $\frac{\mathrm{Sr}^{90} \text { Control }}{\mathrm{Y}^{90} \text { Control }}$ & $\mathrm{Sr}^{90}$ & $\frac{\text { EDTA }}{\text { Control }}$ & $\mathrm{Y}^{90} \frac{\text { EDTA }}{\text { Control }}$ \\
\hline F4S4 & 0.1 & 13. & 3.9 & 3.3 & & $1 . .2$ & 4.1 \\
\hline F4S5 & 0.1 & 6.0 & 1.2 & 5.0 & & 1.0 & 5.2 \\
\hline M5 S4 & 0.2 & 4.8 & 1.3 & 3.7 & & 1.5 & 5.6 \\
\hline M5S5 & 0.2 & 4.4 & 1.7 & 2.6 & & 1.5 & 5.4 \\
\hline
\end{tabular}

\section{REFERENCES}

1. B. J. Stover, D. R. Atherton, E. F. Holt and D. S. Buster, Radiobiology Laboratory Annual Progress Report, CO0-215, pp. 127-131, March 1958.

2. Ann G. Ruhmann, David R. Atherton and Betsy J. Stover, Effect of Chelating Agents on Excretion and Blood Level of $\mathrm{Pb}^{21}$ Formed in vivo, Rad. Res. 16, 584 (1962).

3. H. Foreman, Chelating Agents, Ind. Med. \& Surg., 24, 287-393 (1955).

4. J. S. Annold, B. J. Stover and M. A. Van Dilla, Failure of $\mathrm{Y}^{90}$ to escape from skeletally-fixed $\mathrm{Sr}^{90}$, Proc. Soc. Exptl. Biol. Med., $\underline{90}, 260-263$ (1955).

5. F. W. Bruenger, D. R. Atherton and Betsy J. Stover, Determination of $\mathrm{Sr}^{90}$ and $\mathrm{Th}^{2{ }^{8}}$ in Biological Materials, Health Physics $\underline{9}$, $232-235$, (1963). 
THE DETERMINATION OF HALF-PERIODS OF DOG SERUM PROTEINS US ING $S^{35}-\mathrm{L}$-METH IONINE

F. W. Bruenger, W. Stevens, and B..J. Stover

Abstract: The measurement of the half-periods of serum proteins is of interest due to the relationships between turnover of these proteins and the binding of heavy radionuclides by them. In order to measure these halfperiods we used $S^{35}-L$-Methionine injected I.V. into a young healthy beagle dog. Blood samples were taken from 2 hours through 42 days after injection. Total $\mathrm{S}^{35}$ activity of the serum and of the protein-bound $S^{35}$ was measured. The protein fractions were separated by two methods, electrophoresis and gel-filtration. The halfperiod of each protein fraction was then determined by measuring its $S^{35}$ activity over the period of 42 days. Single exponentials to describe the decrease of $\mathrm{S}^{35}$ were computed using the method of least squares.

\section{INTRODUCTION}

A study of the half-lives of canine plasma proteins is an important part of a more extensive investigation of the binding of PuIV to. plasma proteins in the dog. The task of determining meaningful turnover times of plasma proteins is a very difficult one. It has been pursued by a number of scientists for more than two decades, and a variety of methods has been applied $(1-9)$.

Until now none of these methods gave entirely satisfactory results. Administration of exogenously labeled proteins generally results in apparent half-lives which are short compared with those from studies using endogenously labeled proteins. Limitations of the exogenous. labeling methods are 1) there is no assurance that the protein being labeled by $\mathrm{I}^{131}$ or various other radioactive moieties will not suffer any chemical changes during the labeling procedure, and 2) the introduction of heavy or strongly negative groups into the protein.will alter its stereo-specificity (structurally or electronically) and will 
certainly have some influence on its breakdown pattern. Endogenously labeled proteins on the other hand, suffer from the fact that the label can be recycled and thus produce turnover times which are too long. The present study was carried out with endogenously labeled protein using a tracer dose of $\mathrm{S}^{35}$-L-methionine as the labeling agent.

\section{MATERIALS AND METHODS}

An adult beagle dog, 480 days old, from our colony was kept in a metabolism cage for 14 days. The dog was not fed for 24 hours prior to the injection of approximately $3 \mathrm{mC}$ of $\mathrm{S}^{35}$-L-methionine. The specific activity of this preparation was $53.7 \mathrm{mC} / \mathrm{mM},(3 \mathrm{mC}=26.7 \mathrm{mg})$. Thirty minutes before injection, the dog was given two grams of purified equine albumin suspended in water by stomach tube. The equine albumin contains all the necessary amino acids but little or no methionine ${ }^{(10)}$. Canine albumin is reported to contain 4 moles of methionine per mole of albu$\min (11)$.

It was assimed that 24 hours without food was sufficiently long to deplete the supply of amino acids required by the liver for synthesis of the blood proteins. The dog could then increase all its amino acids except L-methionine by metabolizing the equine albumin. This would result in a deficiency of L-methionine molecules relative to the other amino acids. Then, when the labeled $S^{35}$-L-methionine is given, there will be a relatively greater fraction of $\mathrm{S}^{35}$-L-methionine available for protein synthesis. Incorporation of $\mathrm{S}^{35}$-L-methionine will be increased since the chance that a labeled molecule is used is propor-.. tional to the fraction of that. kind of molecule that is labeled.

The $\mathrm{S}^{35}$-L-methionine was diluted to $10 \mathrm{ml}$ with isotonic saline solution and injected into the femoral vein. 
Beginning at two hours after injection blood samples of $12 \mathrm{ml}$ each were drawn for analysis. Collection of blood samples continued a.t increasing intervals for 42 days. The blood was allowed to clot and then the serum was separated by centrifugation. This procedure left : approximately $5 \mathrm{ml}$ of serum which were divided as follows:

$$
\begin{gathered}
2 \times 100 \lambda \text { for total } \mathrm{S}^{35} \text {-activity } \\
2 \times 500 \lambda \text { for protein-bound } \mathrm{s}^{35} \text {-activity } \\
2 \mathrm{ml} \text { for Gel-Filtration }
\end{gathered}
$$

Remaining serum was used for electrophoresis, (and duplication. if necessary). Protein bound $S^{35}$ was separated from the total serum $S^{3.5}$ by passing a known aliquot of serum through a small column, packed with the highly crosslinked resin "Sephadex G-25". A solution of $4 \%$ $\mathrm{NaCl}+0.1 \mathrm{M}$ Tris having a $\mathrm{pH} \approx 7.4$ was used as the elutriant. The elution volume was kept slightly larger than the void volume so that all components with a molecular weight $<25,000$ stayed on the column and components with a molecular weight $>25,000$ were eluted. Aliquots of this eluate containing the protein were then counted.

The $S^{35}$ content of the various protein fractions was determined by two different procedures: The first was the conventional fractionation of protein constituents by electrophoresis and subsequent analysis of the $S^{35}$ radioactivity. The second was the determination of the $S^{35}-$ radioactivity following separation of the serum proteins according to their molecular weights and sizes as described originally by Flodin (12). Electrophoresis was carried out on cellulose acetate membrane (Beckman Microzone). Each sample was applied sixteen times and, after development, the separated protein fractions were cut out and counted in a (Packard) liquid scintillation spectrometer. 
Gel-filtration was performed according to the following procedure. After addition of sucrose to $2 \mathrm{ml}$ of serum, the samples were layered on top of a system of two columns $(20 \times 500 \mathrm{~mm})$ filled with a suspension of Sephadex G-100 and G-200 in the same buffer as described for Sephadex G-25. The columns were kept.at a temperature of between . $0^{\circ}-5^{\circ} \mathrm{C}$ and the proteins were eluted in $3 \mathrm{ml}$ portions using a (Packard) fraction collector. The protein content of these fractions was determined spectrophotometrically at a wavelength of $280 \mathrm{~m} \mu$. The elution pattern was the same as described earlier (13). One ml aliquots were transferred to glass vials and counted. A standard curve relating absorbance and protein content on an arbitrary scale was evaluated for the concentration range of proteins encountered in this experiment. This curve was used in evaluation of the data. Appropriate corrections were applied.for $S^{35}$ decay and for depletion of the total amount of. $S^{35}$ in the dog from the drawing of a significant amount of blood.

\section{RESULTS}

Throughout the experiment, the $S^{35}$ content of the whole serum was slightly higher than that of the protein bound $S^{35}$. Material having a molecular weight $>25,000$ was considered protein; a molecular weight $<25,000$ was considered non-protein material. When plotted on a semilogarithmic scale, the slopes of the resulting two lines differed only slightly, giving half-periods of $19.6 \pm 0.6$ days for whole serum and $18.4^{\circ} \pm 0.8$ days for protein bound $S^{35}$. The difference in half-periods, however, was not significant. $(0.3>\mathrm{p}>0.2)$.

Of the protein fractions separated electrophoretically albumin had the longest half-period and the $\alpha$-globulin fraction the shortest. The $\beta_{1}$-globulin fraction half-period was also short and not significantly 


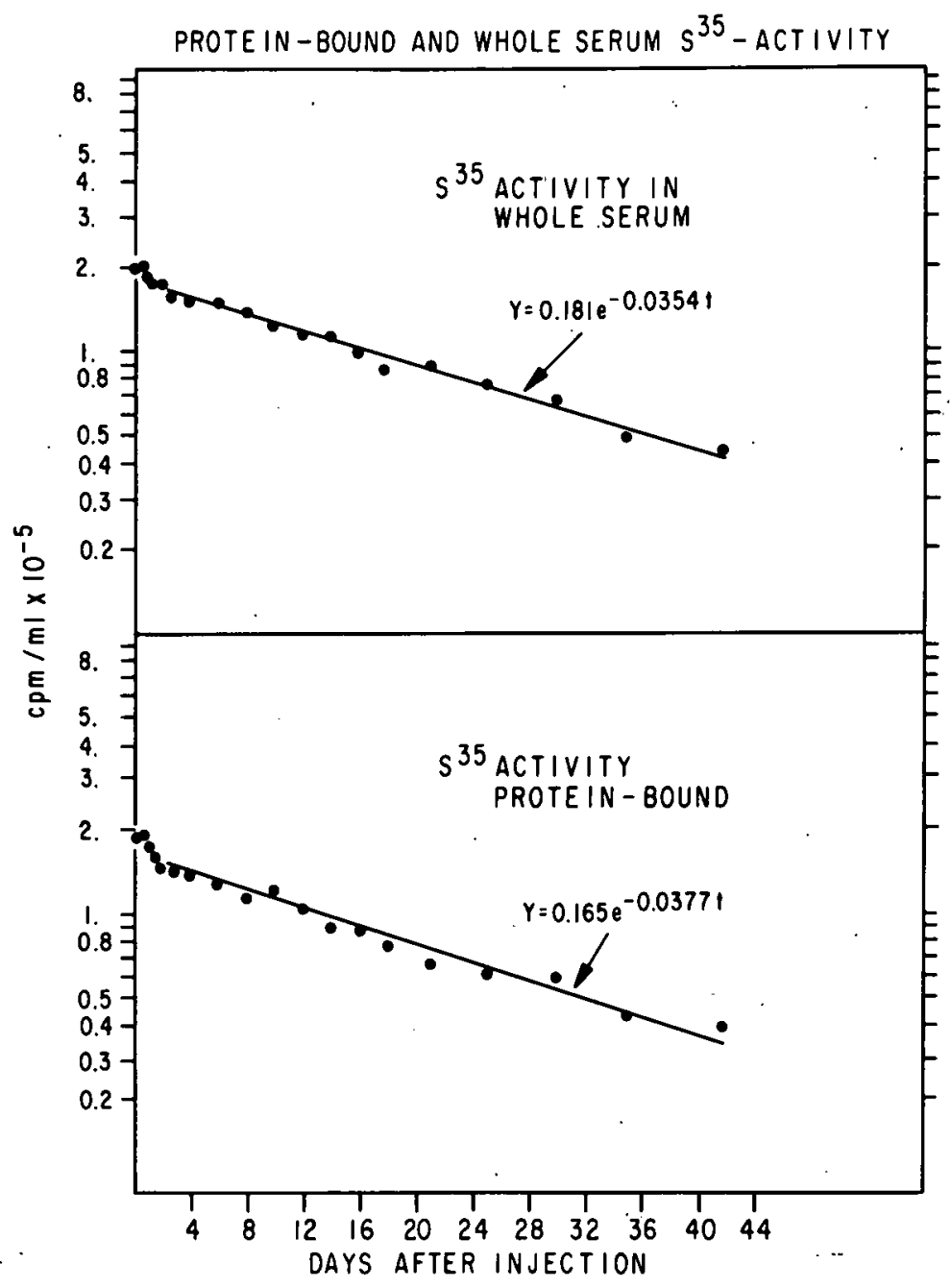

Fig. 1. Change of $S^{35}$ activity in whole serum and in the protein fraction of serum during the time from 0-45 days after administration of $\mathrm{S}^{35}$-L-methionine. 
different from that of the $\alpha$-globulins. The half-period for the $\beta_{2}$ globulins was slightly longer than that of the $\beta_{1}$-globulins. The halfperiod for the $\gamma$-globulins was significantly longer than those of the other globulins. The half-periods and their standard deviations are given in Table $I$ and the respective p-values for the significance of the differences of half-periods are given in Table II.

Table I

Half-Periods and 1 Day Activities of Protein Fractions Separated by Microzone Electrophoresis

\begin{tabular}{llccc}
\hline & $\begin{array}{c}\text { Total cpm } \\
\text { at } \\
\Delta \mathrm{T}=1 \text { Day }\end{array}$ & $\begin{array}{c}\mathrm{t}_{1 / 2} \\
\text { days }\end{array}$ & $\begin{array}{c}\sigma_{\mathrm{t}} \\
\mathrm{d}_{2} \\
\text { days }\end{array}$ & $\begin{array}{c}\% \text { of } \\
\text { Total } \\
\text { Protein }\end{array}$ \\
\hline Albumin & $1.716 \times 10^{3}$ & 23.3 & 4.0 & 54.01 \\
$\alpha$-Globulin & $1.292 \times 10^{3}$ & 12.8 & 1.4 & 16.78 \\
$\beta_{1}$-Globulin & $0.747 \times 10^{3}$ & 13.5 & 1.5 & 12.51 \\
$\beta_{2}$-Globulin & $0.727 \times 10^{3}$ & 15.6 & 0.9 & 10.45 \\
$\gamma$-Globulin & $0.537 \times 10^{3}$ & 19.5 & 2.2 & 6.25 \\
\hline $\mathrm{a}=14$ in all cases.
\end{tabular}

Table II

p Values for Significance of Difference of Half-Periods Given in Table I

\begin{tabular}{lcccc}
\hline & $\alpha$-Globulin & $\beta_{1}$-Globulin & $\beta_{2}$-Globulin & $\gamma$-Globulin \\
\hline Albumin & $<0.01$ & $<0.01$ & $0.02-0.01$ & $0.4-0.3$ \\
$\alpha$-Globulin & - & $0.8-.07$ & $0.2-0.1$ & $0.02-0.01$ \\
$\beta_{1}$-Globulin & & - & $0.3-0.2$ & $0.05-0.02$ \\
$\beta_{2}$-Globulin & & & - & $0.05-0.02$ \\
\hline
\end{tabular}

In the gel-filtration procedure protein fractions were eluted in three peaks as described earlier (13). Specific activities* were

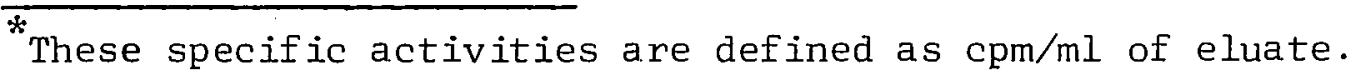




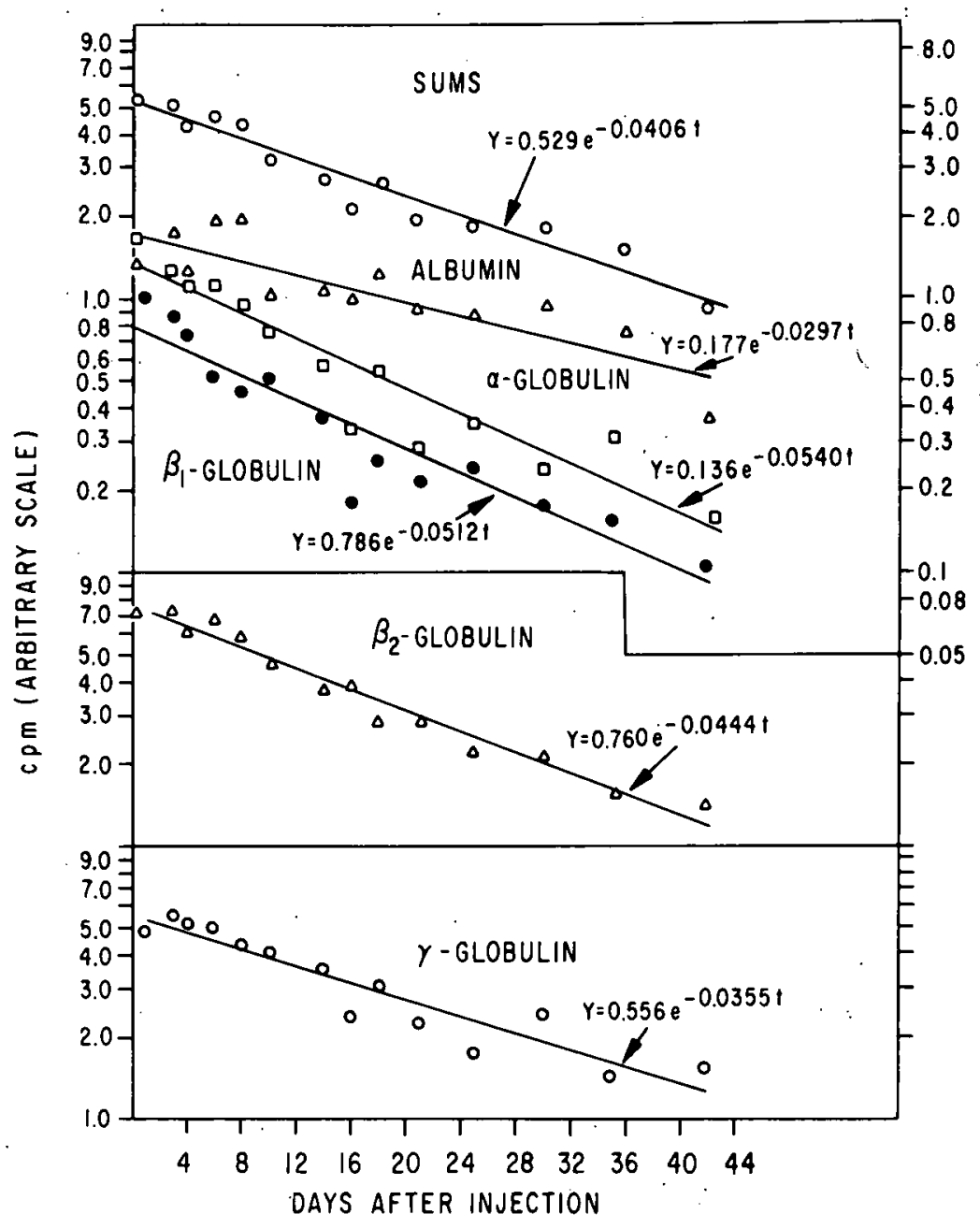

Fig. 2. Decrease in the radioactivity of the various $S^{35}$ labeled protein fractions and the sums of these fractions as determined by microzone electrophoresis.. 
evaluated for the fraction having the highest optical density of each of the three peaks and for the fractions on either side of the one with the highest optical density. These fractions were denoted as: "Ante-", "Maximum" and "Post-". Results are presented in Table III.

Table III

Half-Periods for Protein Fractions Separated by Gel-Filtration

\begin{tabular}{|c|c|c|c|}
\hline & $\mathrm{n}$ & $\begin{array}{l}t_{1 / 2} \\
\text { days. }\end{array}$ & $\begin{array}{l}O{ }_{t} \\
1 / 2 \\
\text { days }\end{array}$ \\
\hline Peak I - Macroglobulins and I & Lipoproteins & & \\
\hline $\begin{array}{l}\text { Ante } \\
\text { Maximum } \\
\text { Post }\end{array}$ & $\begin{array}{l}11 \\
15 \\
16\end{array}$ & $\begin{array}{l}22.7 \\
22.5 \\
17.1\end{array}$ & $\begin{array}{l}6.9 \\
5.4 \\
2.4\end{array}$ \\
\hline Peak II $-\alpha-, \beta-$, and $\gamma-$ Globl & ulins & & \\
\hline $\begin{array}{l}\text { Ante } \\
\text { Maximum } \\
\text { Post }\end{array}$ & $\begin{array}{l}17 \\
16 \\
15\end{array}$ & $\begin{array}{l}14.7 \\
14.3 \\
13.0\end{array}$ & $\begin{array}{l}1.8 \\
1.2 \\
1.9\end{array}$ \\
\hline Peak III - Albumin and some & $\alpha-, \beta-G l o b u l i n$ & & \\
\hline $\begin{array}{l}\text { Ante } \\
\text { Maximum } \\
\text { Post }\end{array}$ & $\begin{array}{l}13 \\
15 \\
16 \\
\end{array}$ & $\begin{array}{l}23.7 \\
23.5 \\
22.9 \\
\end{array}$ & $\begin{array}{l}2.3 \\
2.2 \\
2.4 \\
\end{array}$ \\
\hline
\end{tabular}

Peak I is the highest MW fraction and contains macroglobulins and lipoproteins. Peak II consists of $\alpha-, \beta$-, and $\gamma$-globulins, while Peak III contains the albumin plus some $\alpha$ - and $\beta$-globulins. In each peak the Ante-, Maximum, and Post-components had half-periods which did not differ significantly. Thus, within the limits of the measurements each peak was homogeneous with respect to turn-over times. Peaks I and III had about the same half-periods, but both differed from that of II ( $I$ vs. II, $0.05>p>0.02$ and II vs. III, $p<0.01$ ). The halfperiod of II was close to those of the $\alpha$ - and $\beta$-globulins separated by electrophoresis, and the half-period of III agrees well with that of 


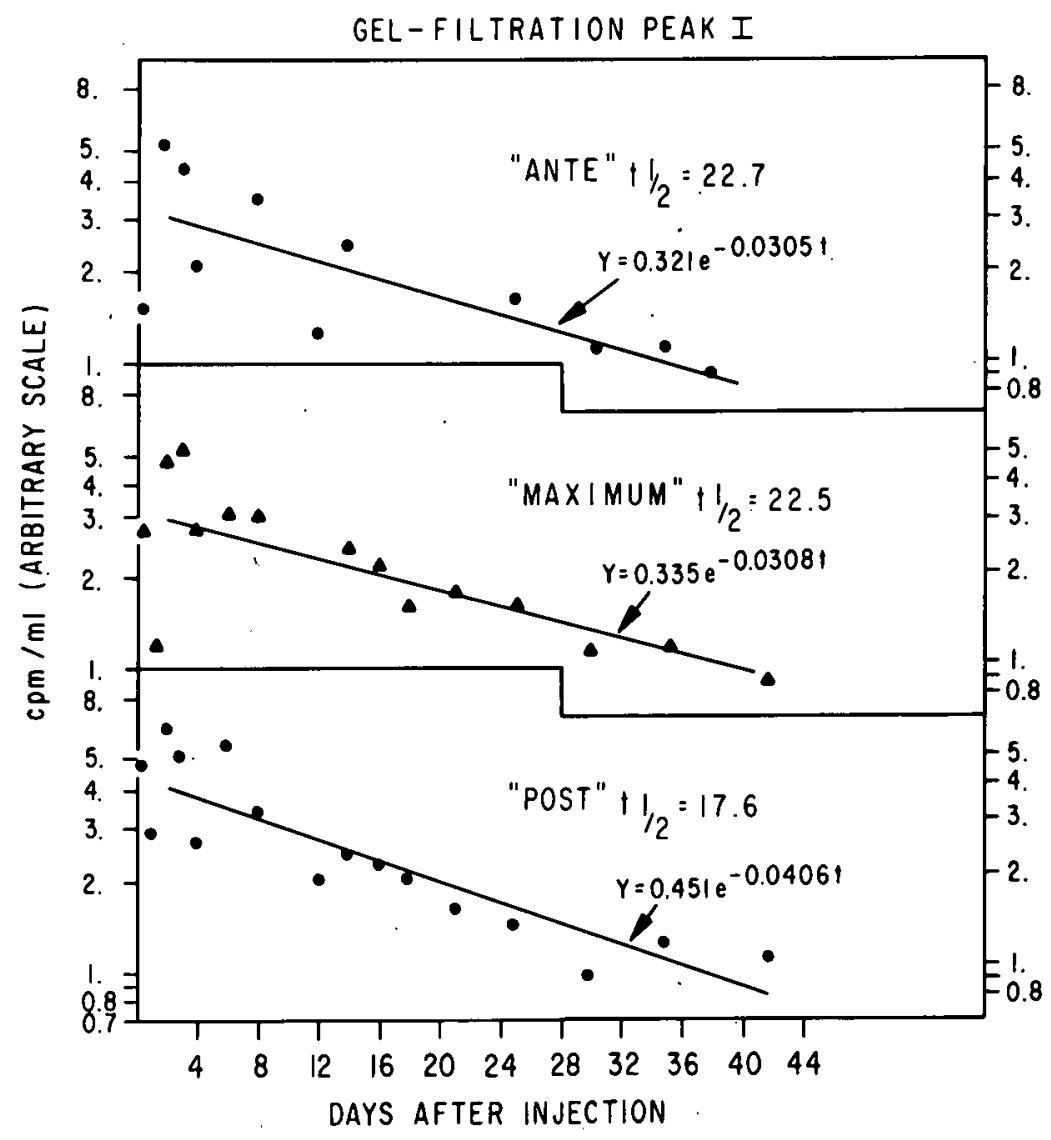

Fig. 3. Elimination of the $S^{35}$ label from serum proteins of high molecular weight as determined by gel-filtration. 


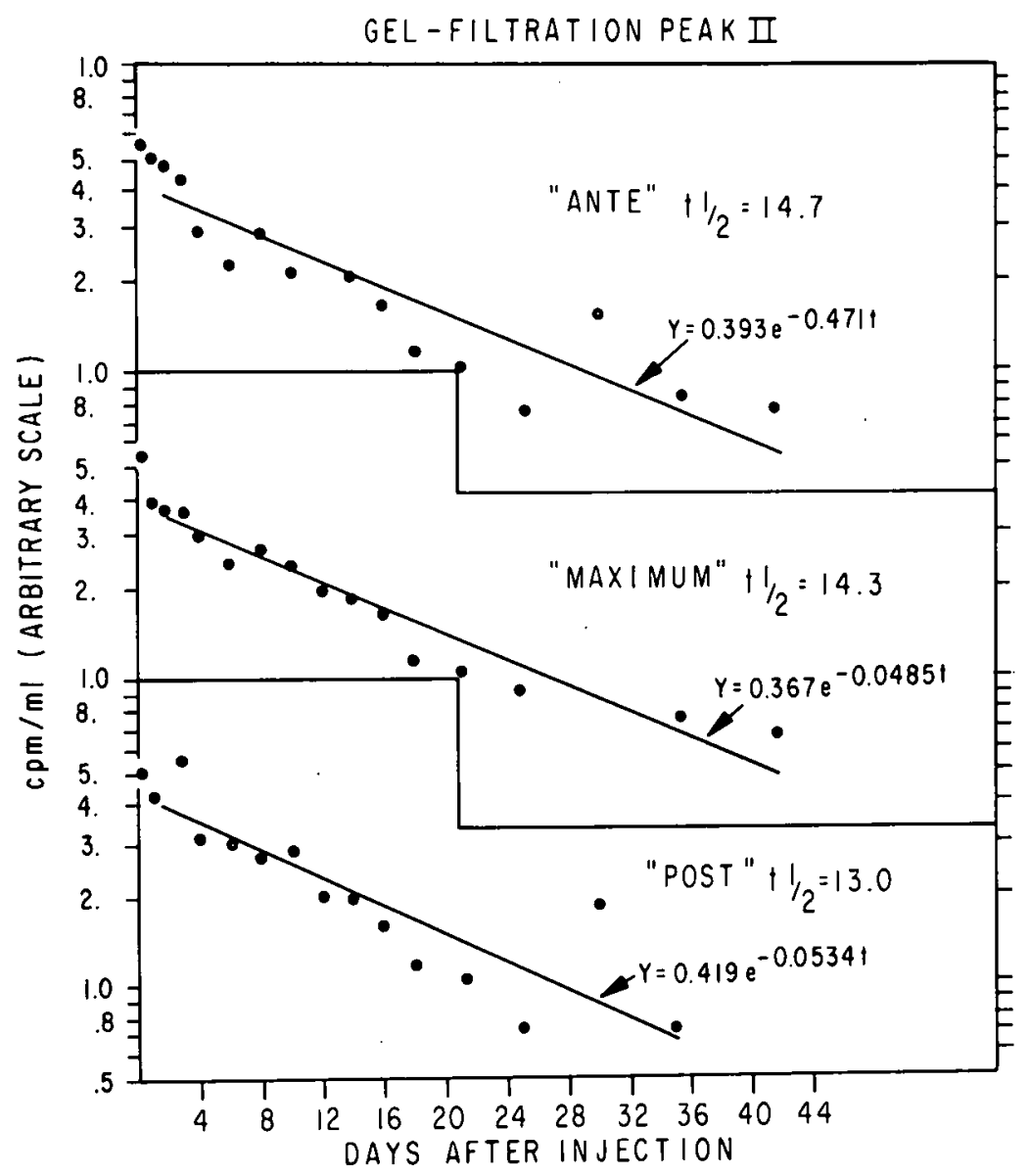

Fig. 4. Elimination of the $S^{35}$ label from serum proteins of medium molecular weight (globulins) as determined by gel-filtration. 


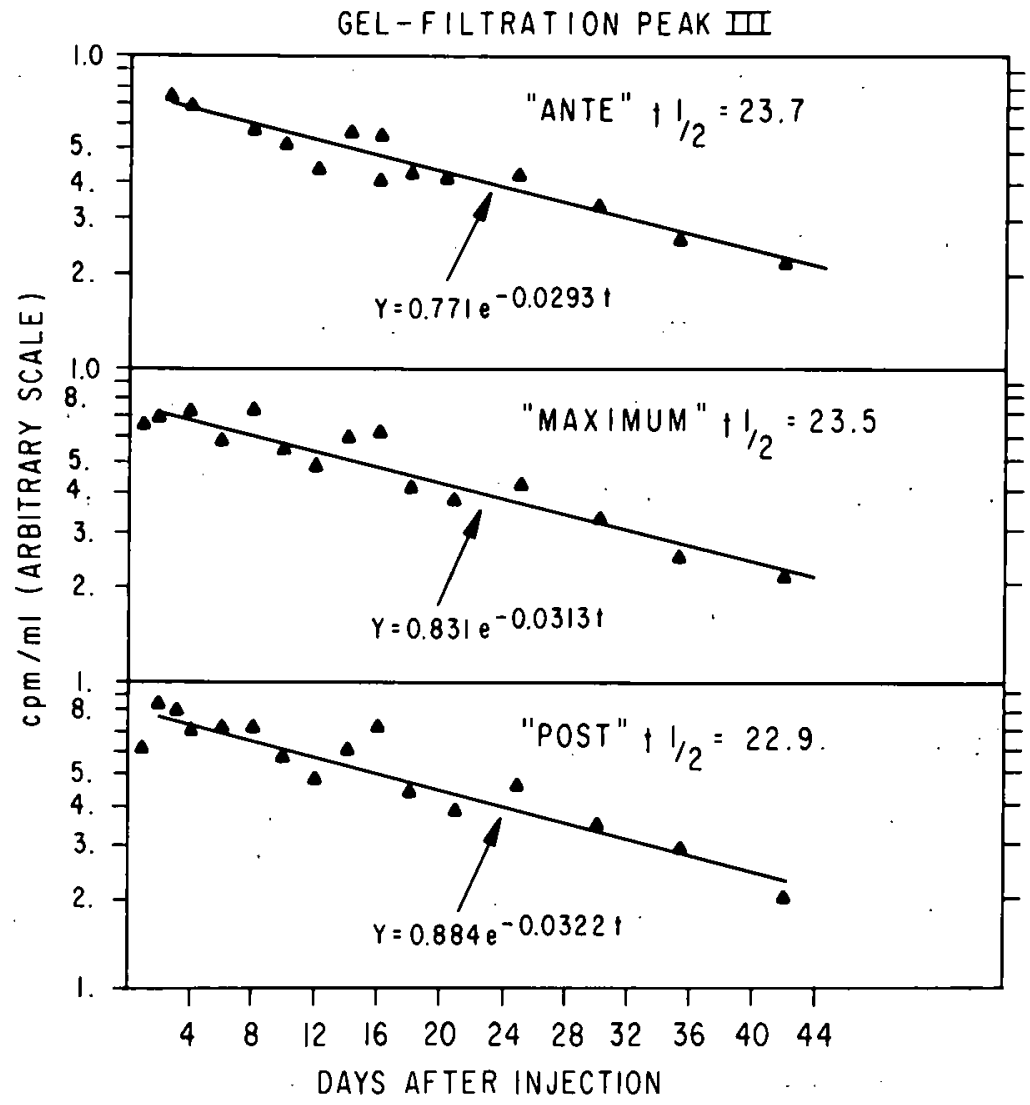

Eig. 5. Elimination of the $S^{35}$ lubel from the gel-tiltivejon fraction containing mostly albumin. 
albumin (see Table I). The curve for the Ante- component of III showed an early increase in $S^{35}$ activity. During the first few days the following equation holds:

$$
y=7707\left(e^{-0.0293 t}-e^{-2.65 t}\right)
$$

The half-period for the building-up of $\mathrm{S}^{35}$ in III Ante- was 6.3 hours. There were not sufficient data to calculate the growth in III Maximum and III Post, but early points available were consistent with a similar growth rate.

Early points for the components of I and II showed that the rate of incorporation of $S^{35}$ into these fractions was considerably more rapid than that of III. There were not enough early data for the fractions separated electrophoretically to permit observation of growth of $S^{35}$ activity in them.

\section{DISCUSSION}

It is difficult to evaluate results in terms of absolute halflives of the different protein constituents due to the possible reutilization of labeled amino acids. Recycling of $\mathrm{S}^{35}$ compounds is well established, but the extent of the recycling varies greatly $(1,2,5,8)$. A variety of data is available for humans, rats, rabbits, and some data are available for unspecified breeds of dogs ${ }^{(4)}$. They all differ by a. wide margin, but the general pattern of half-periods is consistent with our findings.

Reutilization of labeled amino acids depends on many factors. It has not yet been established whether the protein molecule has to break down to amino acids before its building blocks can be recycled. It is impossible to decrease reentry significantly by adding large 
quantities of unlabeled amino acids of the same kind as the.one: bearing the label (5). This would not provide material competing with the label in the synthesis of new protein since excess amino acids are cleared from the blood stream very rapidly. Also, Margen and Tarver point out that sites of degradation and synthesis may be close to the same pool and hence a high specific activity precurser pool might exist from degraded protein (2).

The 24 hour period of fasting apparently stimulated the incorporation of $S^{35}$-L-methionine into newly formed plasma proteins since approximately 5\% of the labeled amino acid circulated in protein bound form in the serum two hours after administration. The "faster than exponential drop-off" ${ }^{*}$ reported by others ${ }^{(6)}$ during the first day after introduction of labeled proteins did not show up in either the curve representing the $S^{35}$ content of the whole serum or the curve representing the protein bound $\mathrm{S}^{35}$. The first three data points were slightly higher. but this was not significant. If a quasi. steady state is produced by balancing losses of $S^{35}$ into the interstitial protein pool against synthesis of new labeled proteins, the $S^{35}$ concentration of whole serum will be slightly higher than that of the total serum proteins but both concentrations should decrease at the same rate.. This, in fact, was the case. This difference then is the maximum amount of $\mathrm{S}^{35}$-amino acids, i.e., L-methionine and L-cystine (since methionine may be converted to cystine, as shown by du Vigneaud (14) and also by Tarver (15) for rats), that would be available for reentry.

\footnotetext{
*i.e., this type of data is more adequately represented by a sum of two or more exponential terms whose slopes are greatly different.
} 
Since the $\alpha$ - and $\beta$-globulins attained their maximum activity faster than albumin did, the degree of labeling of $\alpha$ - and $\beta$-globulins was significantly greater than the one for albumin (see Table.I). This means also that the globulins were probably more uniformly labeled than albumin because the albumin activity was still increasing at the time when the $S^{35}$-L-methionine supply was already greatly diminished. The $\gamma$-globulin showed a different behavior which is consistent with the observed half-values because shorter half-lives require higher rates of formation. The $\gamma$-globulins, however, exhibited a considerably longer half-life than other globulins.

The analysis of gel-filtration data was more complex than the interpretation of electrophoretic data. The gel-filtration method, however, was included to correlate the data presented here with the work on the plasma protein binding of PuIV which is currently underway at this laboratory. Gel-filtration separated serum constituents accordingly to their molecular size and not to their electrophoretic mobilities. This caused a considerable degree of overlapping of constituents which were clearly separated by electrophoresis and sometimes a distinct separation resulted where electrophoretic mobilities were equal.

Peak I contained a variety of high molecular weight proteins (12) as $\alpha_{z_{m}}-, \beta_{z_{m}}$-globulins, $19 \mathrm{~S} \gamma$-globulin, anti-A $\gamma$-globulins, $19 . \mathrm{S}$ cold agglutinin and $\alpha-, \beta$-lipoprotein. This peak exhibited an unexpectedly long half-life for $S^{35}$.

Half-lives for Peak II were those expected in a mixture of all globulins. The low value in the "Post" fraction was again consistent with the fact that electrophoretic patterns show an increasing quaritity of $\alpha$-globulin and transferrin ( $\beta$-globulin) in this area. 
Peak III activities. were dominated by the high quantities of albumin present: Aithough some fast moving $\alpha$-globulins and some transferrin were present in this peak, $S^{35}$ half-lives were identical with those obtained by microzone electrophoreșis.

\section{ACKNOWLEDGEMENT}

The authors would like to thank Dr. D. L. Berliner for his help and encouragement.

\section{REFERENCES}

1. McFarlane, A.S., Use of labeled plasma proteins in the study of nutritional problems, Progress in Biophys. 7, 115 (1957).

2. Margen, S. H. and Tarver, H., The preparation of labeled albumin for turnover studies, Atomlight, No. 39, July 1964.

3. Choen, S., Holloway, R. C., Mathews, C., and McFarlane, A. S., Distribution and elimination of $\mathrm{I}^{131}$ and $\mathrm{C}^{14}$-labeled plasma proteins in the rabbit. Biochem. J. 62, 145-154 (1956)..

4. McFarlane, A. S., Labeling of plasma proteins with radioactive iodine, Biochem. J. $\underline{62}, 135-43$ (1956).

5.: Bronsky, D., Hyman, S., and Armstrong, H., The persistence in the blood of the radioactive label of albumins, gamma globulins and globulins of intermediate mobility. J. Lab. and Clin. Med., Sept. $1957(348-357)$.

6. Penn, N. W., Mandeles, S., and Anker, H. S., On the kinetics of turnover serum albumin. Biochim. et Biophys. Acta 26:349-360 (1957).

7. Fink, R. M., Enns, Plasma protein metabolism, Normal and Associated with Shock, J. Exp. Med. 므, $455-475$ (1944).

8. Margen, Sh., and Tarver, Comparative studies on the turnover of serum albumin in normal human subjects, J. Clin. Invest. 35, 1161 (1956) . 
9. Niklas, A. and Maurer, W., Neubildung von Serum-Eiweiss-Fraktionen Nach Gabe von $S^{35}-$ L-Methionin. Biochem 323; 89-103 (1952).

10. Sorm, F., Comparative studies in the field of protein microstructure. Symp. on Protein Structure 79 (1957), Publ. by G. Wiley \& Sons, Inc.

11. Allerton, S. E.; Elwyn, D., Edsall, G. T. and Spahr, P. F:, Isolation and amino acid composition of dog plasma albumin. J. Biol. Chem. 237, No. 1, 85-88 (1962).

12. Flodin, P., and Willander, G., Fractionation of human serum proteins by gel-filtration, Biochim. Bioph: Acta 63, 403-410 (1962) .

13. Stevens, W., Bruenger, F. W., and Stover, B. J., In vitro studies of the interactions of PuIV with blood proteins. Radiation Research (In press).

14. du Vigneaud, V., Audrieth, L. F., and Loring; H. S., The reduction of cystine in liquid ammonia by metallic sodium, J. Am. Chem. Soc. $\underline{52}, 4500$ (1930).

15. Tarver, H., and Schmidt, C. L. A., The conversion of methionine to cystine: Experiments with radioactive sulfur, J. Biol. Chem. 130, 67 (1939). 
Books

$$
\begin{aligned}
& \text { ADDITIONS TO BIBLIOGRAPHY } \\
& \text { (April:1, } 1964 \text { to March 31, 1965) }
\end{aligned}
$$

1. Henry Eyring, Douglas Henderson, Betsy Jones Stover and Edward.M. Eyring: Statistical Mechanics and Dynamics, John Wiley \& Sons Inc., New York (1964).

Publications

1. Jean H. Dougherty and Leon S. Rosenblatt: Changes in the hemogram of the Beagle with age, J. of Gerontology 20:131-138 (1965).

2. David R. Atherton, Betsy J. Stover and Charles W. Mays: Soft tissue retention of ${ }^{226} \mathrm{Ra}$ in the Beagle, Health Physics J... $11,101-108$ (1965).

3. G. N. Taylor, W. R. Christensen, W. S. S. Jee, C. E. Rehfeld and P. Petermann, Intercomparison of pathological fractures in Beagles injected with $\mathrm{Ra}^{226}$, $\mathrm{Ra}^{228}, \mathrm{Pu}^{239}$ and $\mathrm{Sr}^{90}$, Health Physics J. (in press) 1965.

4. Gottlieb L. Schneebeli and Thomas F. Dougherty: A time-lapse cinemicrography procedure for the study of steroid hormone effects on murine megakaryocytes in vitro. The Microscope and Crystal Front 14:8, 319-331, (1965).

5. N. L. Dockum: Autoradiographic localization of Zn-65, The Microscope and Crystal Front 14:4, 137-141 (1964).

6. W. S. S. Jee: The influence of reduced local vascularity on the rate of internal reconstructionoof adult long bone cortex, In Bone Biodynamics, Ed. by H. M. Frost, Little Brown and Co., Boston, 259-277 (1964).

7. W. S. S. Jee: A critical survey of the analysis of the microscopic distribution of some bone-seeking radionuclides and assessment of absorbed dose, In Assessment of Radioactivity in Man, Vol. I, International Atomic Energy Agency, Vienna, 369-393 (1964).

8. L. C. Ellis and D. L. Berliner: Alteration of steroid biotransformation by murine testicular tissue $x$-irradiation, $5^{a}$ Reunion Anual. Soc. Mex. Nutricion y.Endocrinologia, 99, (1964) .

9. W. S. S. Jee, E. L. Blackwood, N. L. Dockum, D. L. Berliner and F. A. Kincl: Bio assay of cortisol in growing bones, Proceedings of $5^{a}$ Reunion Anual. Sociedad Mexicana de Nutricion y Endocrinologia, 157-168, (1964). 
10. A. J. Gallegos, D. H. Hill, R. J. Williams and D. L. Berlinex: Formacion de fibroblastos resistentes a esteroides, $5^{\text {a }}$ Reunion Anual. Soc. Mex. Nutricion y Endocrinologia, 169 (1964).

11. T. F. Dougherty, M. L. Berliner, G. L. Schneebeli and D. L. Berliner: Hormonal control of lymphatic structure and function. Leukopoiesis in Health and Disease, Ann. N. Y. Acad. Sci. 113:825, (1964) .

12. D. L. Berliner: Biotransformation of corticosteroids as related to inflammation, Ann. N. Y. Acad. Sci. 116:1078 (1964)。

13. D. L. Berliner: The microchemical identification of steroids from biological media, in Advances in Tracer Methodology, Vol. II, Plenum Press, New York (1964).

14. D. L. Berliner, G. Taylor and L. C. Ellis: The effects of ionizing. radiation on endocrine cells. II. Restoration of androgen production with a reduced nicotinamide adenine dinucleotide phosphate-generating system of irradiation of rat testes, Rad. Res. 22:345, (1964).

15. L. C. Ellis and D. L. Berliner: The effects of ionizing radiation on endocrine cells. III. Restoration of androgen production with a reduced nicotinamide adenine dinucleotide phosphategenerating system after localized irradiation to heads of rats, Rad. Res. 23:156, (1964).

16. D. L. Berliner and L. C. Ellis, The effects of irradiation on endocrine cells IV. Increased production of 17 $\alpha, 20 \alpha$-Dihydroxyprogesterone in rat testes after irradiation, Rad. Res. 24, 368373 (1965).

17. D. L. Berliner and L. C. Ellis: The effects of irradiation on endocrine cells. V. A comparison between the effects of inanition and irradiation on androgen production by murine testicular tissue, Rad. Res. 24:572-578 (1965).

18. W. Stevens and D. L. Berliner: Serum transaminase levels in Beagle dogs burdened with $\mathrm{Pu}^{239}$, Rad. Res. 23:420 (1964).

19. A. G. Ruhmann and D. L. Berliner: Effect of steroids on growth of mouse fibroblasts in vitro, Endocrinology (In press).

20. Walter Stevens, Carolyn Collesides and Thomas F. Dougherty: Effects of cortisol on the incorporation of thymidine-2-14 $\mathrm{C}$ into nucleic acids of lymphatic tissue from adrenalectomized CBA mice. Endocrinology (In press).

21. Truls Brinck-Johnsen and Thomas F. Dougherty: Studies on the effect of cortisol and ACTH on incorporation of adenine- $8-^{14} \mathrm{C}$ into the lymphatic tissue nucleic acids. Acta Endocrinologia (In press). 
22. Martha L. Berliner and T: F. Dougherty: Interconvérsion of cortisol and cortisone by normal and leukemic murine lymphocytes. -Extrait de Acta Union Internationale Contre Le Cancer, XX:4-5, $1133-1136$ (1964).

23. G. F. Leong, D. M. Cazes, M. L: Berliner and D. L. Berliner: Biliery excretion of dihydro-ll-keto progesterone-4- $\mathrm{C}^{14}$ by isolated perfused liver, Am. J. Physiol. 207:1030 (1964).

24. D. L. Berliner: Studies of the mechanisms by which cells become resistant to corticosteroids, in Hormone Related Tumors, American Cancer Society (In press).

25. Robert C. Pendleton, Charles W. Mays, Ray D. Lloyd and Norman V. Hancock: Fallout plutonium-239 and zirconium-95 in the lungs of deer, Nature 202:4933, 715-716 (1964).

26. R. C. Pendleton, R. D. Lloyd, C. W. Mays and B. W. Church: Trophïc level effect on the accumulation of caesium-137 in cougars feeding on mule deer, Nature 204:4959, 708-709 (1964).

27. R. J. Della Rosa, M. Goldman, A. C. Andersen, C. W. Mays and B. J. Stover: Absorption and retention of ingested strontium and calcium in beagles as a function of age, Nature 205:4967, 197198 (1965).

28. Robert C. Pendleton, R. D. Lloyd, C. W. Mays, D. R. Atherton and N. V. Chamberlain: Radium contamination at the Jordan River Delta of the Great Salt Lake, Journal water pollution control federation, 36:7, 925-927 (1964).

\section{Abstracts}

1. Walter Stevens, Jr. and Thomas F. Dougherty: The effect of cortisol on the incorporation of thymidine $-\mathrm{C}^{14}$ into nucleic acids of lymphatic tissue. Fed. Proc。23:2, (March-April 1964).

2. R. K. Haslam, W. S. S. Jee, N. Dockum and K. A. Sears: Microdensitometric analysis of the quantitative microscopic distribution of radium-226 in dental tissues and bone of adult beagles. J. Dental Res. $43: 763$ (1964).

3. E. L. Blackwood, W. S. S. Jee, R. K. Haslam and F. Kincl: Bioassay of cortisol activity in growing bones. Anat。Rec. 151:325 (1965).

4. N. L. Dockum, R. G. Bromley, M. Lowe, R. Mical and J. S. Arnold: Quantitative studies on trabecular bones of dogs and humans. Anat. Rec. 151:344 (1965).

5. R. D. Kingston, D. H. Taysum and K. Dedekind: Frequency distribution of recently formed haversian systems in mandibular bone of the beagle. Anat. Rec. 151:372 (1965). 
6. $\mathrm{D}, \mathrm{L}$, Berliner and $\mathrm{W}$. Stevens: A comparison of serum transaminase levels in dogs.burdened with $\mathrm{Pu}^{239}, \mathrm{Ra}^{228}, \mathrm{Ra}^{226}, \mathrm{Ra}^{224}, \mathrm{Th}^{2213}$, and $\mathrm{Sr}^{90}$, Rad. Res. 25:1, 175 (1965):

7. Ray D. Lloyd and Charles W. Mays: Knothole I: a new well-type $\gamma$-ray detector, Rad. Res, 25:1, 212 (1965). 